
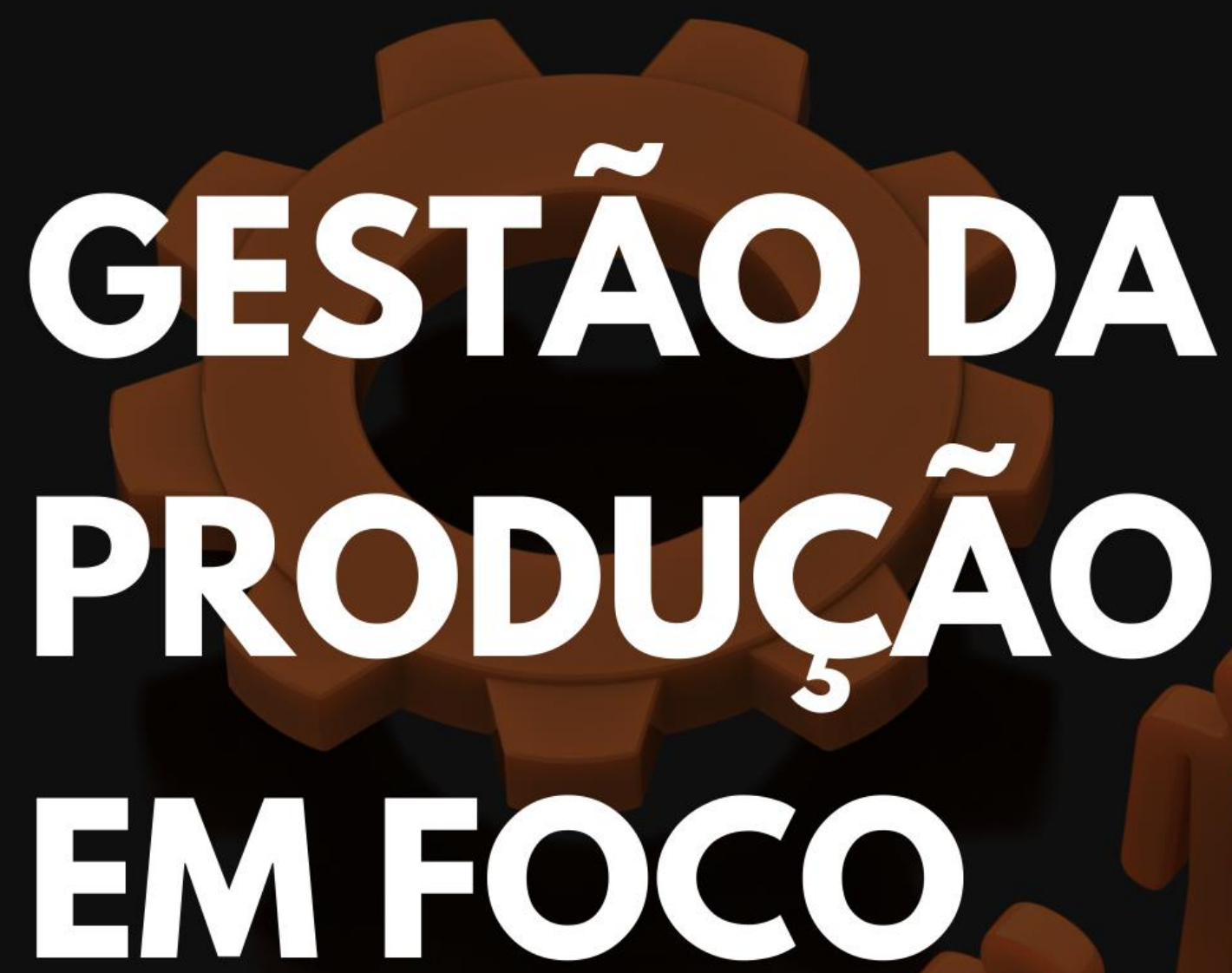

\title{
VOLUME 49
}

\section{Organizador \\ Rafael Alves Pedrosa}

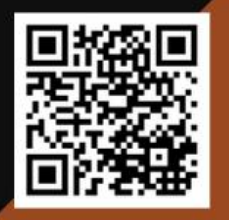

Editora Poisson 
Rafael Alves Pedrosa

(Organizador)

\section{Gestão da Produção em Foco Volume 49}

1a Edição

Belo Horizonte

Poisson

2021 
Editor Chefe: Dr. Darly Fernando Andrade

\section{Conselho Editorial}

Dr. Antônio Artur de Souza - Universidade Federal de Minas Gerais

Ms. Davilson Eduardo Andrade

Dra. Elizângela de Jesus Oliveira - Universidade Federal do Amazonas

MS. Fabiane dos Santos

Dr. José Eduardo Ferreira Lopes - Universidade Federal de Uberlândia

Dr. Otaviano Francisco Neves - Pontifícia Universidade Católica de Minas Gerais

Dr. Luiz Cláudio de Lima - Universidade FUMEC

Dr. Nelson Ferreira Filho - Faculdades Kennedy

Ms. Valdiney Alves de Oliveira - Universidade Federal de Uberlândia

Dados Internacionais de Catalogação na Publicação (CIP)

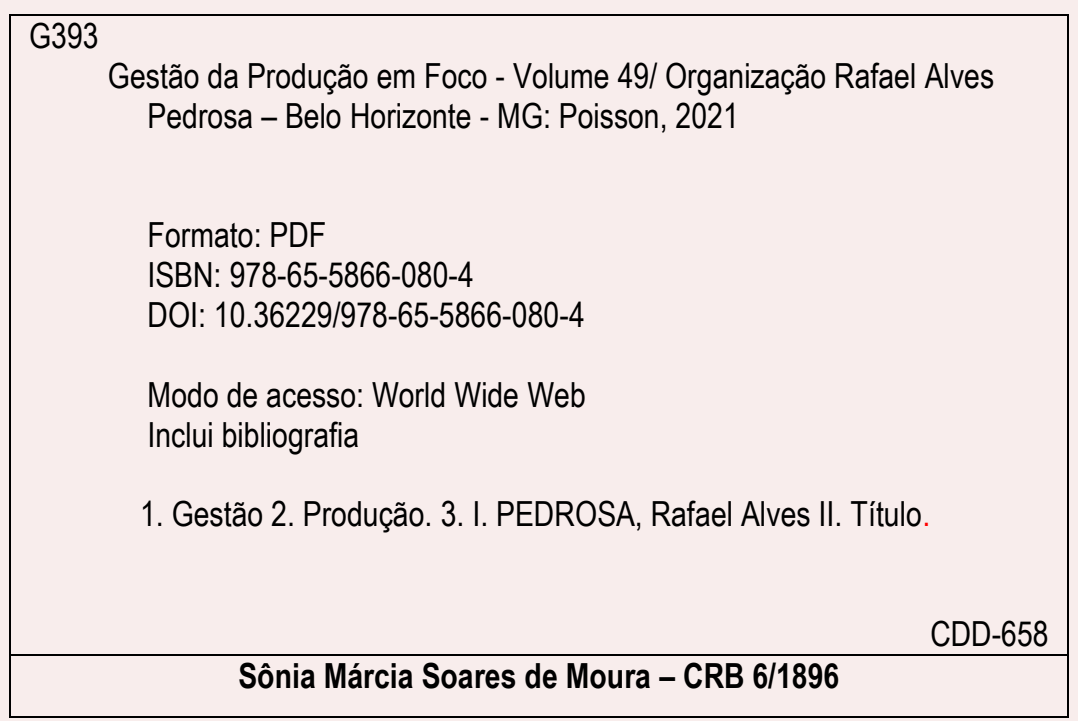

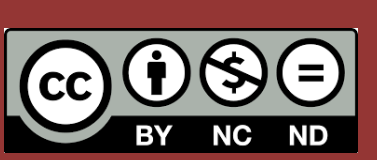

O conteúdo deste livro está licenciado sob a Licença de Atribuição Creative Commons 4.0.

Com ela é permitido compartilhar o livro, devendo ser dado o devido crédito, não podendo ser utilizado para fins comerciais e nem ser alterada.

O conteúdo dos artigos e seus dados em sua forma, correção e confiabilidade são de responsabilidade exclusiva dos seus respectivos autores.

Baixe outros títulos gratuitamente em www.poisson.com.br 


\section{SUMÁRIO}

Capítulo 1: Um estudo teórico sobre o grau de importância do monitor como um agente responsável por um papel de mediador para o compartilhamento do saber. 07

Marcos Antônio Pacífico da Silva, Stella Regina Reis da Costa

DOI: 10.36229/978-65-5866-080-4.CAP.01

Capítulo 2: A inovação através da colaboração e do compartilhamento 13

Marcio de Freitas Santa Ana, Roseli da Conceição Silva de Freitas Santa Ana, Bruna Soares Silva de Carvalho

DOI: $10.36229 / 978-65-5866-080-4 . C A P .02$

Capítulo 3: Percepção dos alunos do curso de logística quanto às competências necessárias ao seu exercício profissional

Luciano da Silva Ferreira, Roberto Kanaane

DOI: $10.36229 / 978-65-5866-080-4 . C A P .03$

Capítulo 4: Utilização do Sistema de Informação Gerencial pelos gestores de uma empresa prestadora de serviços de limpeza e conservação 26

Grayce Fontão, Adriano Dinomar Barp

DOI: $10.36229 / 978-65-5866-080-4 . C A P .04$

Capítulo 5: Avaliação da atividade de coleta seletiva à luz da PNRS: Um estudo na cidade de Belém - PA 42

Juliana Ribeiro Ranieri, Vívian Tereza de Souza Ferreira, André Cristiano Silva Melo, Rodrigo Rangel Ribeiro Bezerra, Denilson Ricardo de Lucena Nunes

DOI: $10.36229 / 978-65-5866-080-4 . C A P .05$

Capítulo 6: Simulação de processos para aplicação de balanceamento de linha na indústria

Fabyane Dias da Silva, Maylane Neres Costa Santos, André de Mendonça Santos, Djoille Denner Damm, Kalil Figueiredo Almeida

DOI: $10.36229 / 978-65-5866-080-4 . C A P .06$

Capítulo 7: Melhoria contínua: Implementando um método e reduzindo custos 62

Marcelo Paranzini, Roberto Kanaane, Jadir Perpétuo dos Santos

DOI: $10.36229 / 978-65-5866-080-4 . C A P .07$ 


\section{SUMÁRIO}

Capítulo 8: Previsão dos custos de produção de suínos por meio dos Modelos de HoltWinters. 68

Bruno Matos Porto, Daniela Althoff Philippi

DOI: $10.36229 / 978-65-5866-080-4 . C A P .08$

Capítulo 9: Análise de viabilidade econômica em sistema de pastejo irrigado rotacionado silvipastoril aplicado a produção de leite.

Lucas Carvalho Martins, Lydia Cheibub de Matos, Gleyzer Martins

DOI: 10.36229/978-65-5866-080-4.CAP.09

Capítulo 10: A elasticidade - Renda da demanda do Setor Privado do Ensino Superior Presencial no Brasil

Alexandre Barreto de Oliveira, Cristiane Heleodoro Cardoso, Daiane Rodrigues dos Santos, Ludmila Santana de Azevedo Matos, Waldemar Antônio das Chagas Bezerra

DOI: $10.36229 / 978-65-5866-080-4 . C A P .10$

Capítulo 11: Impactos da terceirização na contratação de mão de obra sob a ótica da saúde e segurança do trabalho 102

Anderson Alves de Alcântara, Emerson Nóbrega de Medeiros, Letícia Dantas Muniz Alves, Eduardo Braga Costa Santos, Denise Dantas Muniz

DOI: 10.36229/978-65-5866-080-4.CAP.11

Capítulo 12: Identificação de riscos na estruturação do sistema de trabalho em uma metalúrgica através da análise ergonômica do trabalho: Um estudo de caso 111

Ana Maria Moura Gouveia, Juliana Machion Gonçalves

DOI: $10.36229 / 978-65-5866-080-4 . C A P .12$

Capítulo 13: Desenvolvimento de equipamentos para automação de um processo de fabricação de corantes 118

Carolina de Padua Fernandes, José Tomadon Júnior, Thiago Pereira Paiva

DOI: $10.36229 / 978-65-5866-080-4 . C A P .13$

Capítulo 14: Soldas do aço inoxidável lean duplex grau 2101: Avaliação do grau de passivação e resistência à corrosão por polarização potenciodinâmica on-site e SKPFM

Luís Henrique Guilherme, José Guilherme Cossetti, Fernando Santos da Silva, Cecílio Sadao Fugivara, Dirk Engelberg, Assis Vicente Benedetti

DOI: $10.36229 / 978-65-5866-080-4 . C A P .14$ 


\section{SUMÁRIO}

Capítulo 15: Modelo de regressão múltipla para previsão da série temporal de um piezômetro usando regressão múltipla.

Emerson Lazzarotto

DOI: $10.36229 / 978-65-5866-080-4 . C A P .15$

Capítulo 16: Verificação da precisão nas medições realizadas por um medidor de distância a laser.

Lucas Carvalho Martins, Lucas Pereira Silveira, Hamma Carolina de Lima Nogueira, Bárbara Carolina Martins Teodoro

DOI: $10.36229 / 978-65-5866-080-4 . C A P .16$

Autores: 


\section{Capítulo 1}

Um estudo teórico sobre o grau de importância do monitor como um agente responsável por um papel de mediador para o compartilhamento do saber

\section{Marcos Antônio Pacífico da Silva}

Stella Regina Reis da Costa

Resumo: As ações, conhecidas como monitoria, são desenvolvidas em várias realidades específicas dentro dos ambientes escolares, cada qual com suas particularidades. Servem de auxílio ao aprendizado dos estudantes e é reconhecida como uma importante ferramenta de apoio pedagógico. Nesta pesquisa foi realizada uma revisão sistemática da literatura sobre o tema monitoria. A pesquisa bibliográfica utilizou artigos científicos publicados nos últimos 5 anos, obtidos nas bases de dados: SciELO.ORG; SciELO Citation Index; Scopus e Web of Science. Os artigos selecionados pertencem as categoras JBR (Journal of Citation Reports) ou QUALIS até B3 (parâmetro vigente em 2019). Buscou-se apresentar os vários entendimentos sobre a monitoria, dentro e fora do Brasil. Os achados apresentados demonstram que os programas de monitoria são instrumentos facilitadores do aprendizado e fortalecem as relações entre os alunos e entre alunos e professores.

Palavras-Chave: Monitoria. Programa de monitoria. Gestão. Educação. 


\section{INTRODUÇÃO}

Dentro das instituições de ensino, a monitoria faz parte das estratégias de apoio pedagógico. A gestão do programa de monitoria é vinculada à diretoria de ensino. Na monitoria, os alunos participam através da troca de informações sobre conteúdos específicos, estabelecidos pelos cursos nos quais os mesmos estão matriculados. Essa ferramenta de auxílio ao processo de ensino-aprendizagem vem sendo discutida, em pesquisas científicas, por teóricos preocupados com o ensino e com o sucesso dos estudantes, os futuros profissionais.

As atividades desenvolvidas na monitoria demonstram o grau de importância do monitor, como um agente responsável por um papel de mediador para o compartilhamento do saber, vivenciado entre um grupo de alunos destinado a discussões sobre determinados temas de estudo. Segundo Frison (2016), o trabalho realizado em parceria, na modalidade de monitoria, ganha força como uma atividade realizada entre os próprios alunos.

O objetivo desta pesquisa é apontar algumas experiências e concepções sobre monitoria, envolvendo estudantes, para que possam servir de incentivo para ampliar a perspectiva de discussões, a respeito da prática da monitoria dentro e fora do ambiente escolar.

\section{METODOLOGIA}

Cauchick-Miguel et. al. (2017) apontam como um aspecto muito importante, na metodologia das pesquisas científicas, a contribuição que essa traz para seus stakeholders mais diretos, para a comunidade na qual se insere e ainda, para um refinamento teórico e novas proposições.

Para Gray (2012), não há como se fazer pesquisa científica isoladamente, longe da literatura que aborda o tema anteriormente pesquisado. Ou seja, para que haja sustentação científica é primordial que se faça uma pesquisa bibliográfica, para que se possa conhecer com profundidade o campo a ser estudado pelo pesquisador.

Sendo assim, com o objetivo de se estabelecer uma fundamentação teórica para sustentação dessa pesquisa, realizou-se uma revisão da bibliográfica sobre os temas: A monitoria como modalidade do estudo compartilhado; As ações de mentoring; Espaços de aprendizagem na prática de monitoria; Impactos da relação entre professor e monitor. Utilizou-se literatura científica, acessível no Portal de Periódicos da Coordenação de Aperfeiçoamento de Pessoas de Nível Superior (CAPES). Essa busca foi realizada na área restrita onde foi necessário a utilização da ID UFF, que é o CPF do aluno, e da senha de acesso individual do aluno do Mestrado em Sistemas de Gestão (MSG).

A pesquisa bibliográfica utilizou artigos científicos publicados nos últimos 5 anos, obtidos nas bases de dados: SciELO.ORG; SciELO Citation Index; Scopus e Web of Science. Os artigos selecionados pertencem as categorias JBR (Journal of Citation Reports) ou QUALIS até B3 (parâmetro vigente em 2019). Também foram utilizadas dissertações que versassem sobre o tema.

As palavras-chave usadas na busca foram: SciELO.ORG - monitor, monitores, monitoria, tutor, tutores, tutoria, aprendizagem compartilhada e ensino compartilhado; SciELO Citation Index - monitors, monitoring, tutors, tutoring, shared learning, shared teaching; e nas bases Scopus e Web of Science somente foram utilizados os referidos termos em inglês.

\section{A MONITORIA COMO MODALIDADE DO ESTUDO COMPARTILHADO}

Para Andrade (2018, p. 1696), a atividade do monitor é importante, pois, devido a sua posição de alunomonitor, o mesmo contribui para o processo de ensino-aprendizagem e de melhoria social, uma vez que "compreende os anseios de seus pares" facilitando a troca de informações e o desenvolvimento de relações que facilitam o êxito na formação dos estudantes.

Essa fase caracterizada pelo estudo compartilhado é apontada por Balensiefer Vicenzi (2016), como uma etapa do curso onde o aluno-monitor desenvolve um sentimento de reconhecimento sobre o seu grau de conhecimento, sobre o conteúdo abordado na monitoria. Outro sentimento apontado pela autora é a gratidão que o monitor passa a ter com o seu professor orientador, na medida em que ambos se reúnem para que possam, juntos ou separados, tomar ações que possibilitem resultados positivos no aspecto do ensino-aprendizagem. 
Resultados positivos, no processo de ensino-aprendizagem, são observados quando o monitor busca envolvimento mais profundo e coletivo no que diz respeito às suas tarefas, isto é, a socialização, a convivência mútua em busca de resultados comuns. Flores (2017, p. 52) aponta que "a busca pela dimensão coletiva" leva ao êxito, do processo de desenvolvimento dos conteúdos na monitoria, seja por parte dos alunos, dos professores e dos próprios monitores. Para o autor, a monitoria é uma "possibilidade de fomento à autonomia". Ele também alerta sobre a importância de se desenvolver as atividades de monitoria, em um local específico, para facilitar a relação entre os estudantes, possibilitando um efetivo enriquecimento na formação desses, seja pessoal ou profissional.

Em uma pesquisa exploratória sobre habilidades e competências, realizada pela pesquisadora da Universidade de Ruprecht-Karls Heidelberg, na Alamanha, Alvarez (2019) verificou que a monitoria, como espaço de ensino-aprendizagem, abrange além do aprofundamento do conteúdo buscado pelo aluno que inicia os seus estudos em uma determinada disciplina. Para Alvarez (2019), a monitoria é uma atividade onde o monitor, designado pela autora como tutor, compartilha o seu conhecimento e é também uma oportunidade que possibilita ao monitor motivar-se como pessoa e engajar-se para a aprendizagem de novos conteúdos. Isso faz com que o monitor acrescente, em sua experiência pessoal, novos olhares para conteúdos já conhecidos, ou mesmo novos conteúdos.

Em um estudo realizado no Rio Grande do Sul, no Brasil (BR), a respeito do trabalho de mediação pedagógica realizada pelos tutores, a monitoria é apontada por pesquisadores como sendo uma modalidade do estudo compartilhado ainda em desenvolvimento, com poucas práticas de campo e com poucos estudos científicos sobre o assunto. Algo apontado como um campo que necessita, ainda, ser explorado com maior profundidade. Enfocam a importância da monitoria, mas relatam que a atividade de monitoria é uma prática não muito observada nas escolas. "Não estamos acostumados com alguém que nos ajude a mediar pedagogicamente um conteúdo específico.” (BROD, 2016, p. 18).

\section{AS AÇÕES DE MENTORING}

Em uma pesquisa realizada, com estudantes de uma universidade no norte da Inglaterra, Shields e Murray (2017) explicam que os mentoring, que são padrões que não constam do estatuto das escolas, foram criados para promover a coerência na qualidade de orientação, para professores estagiários, que quando são nacionais (Inglaterra), são citados como "Padrões de Tutoria". Esses padrões são relevantes, quando se discutem as descobertas pela natureza indutiva do projeto, e aplicados ao desenvolvimento das aprendizagens individualizadas. Outra observação realizada pelas autoras, diz respeito à postura dos monitores. No seu artigo elas destacam a necessidade dos monitores demonstrarem postura e comportamento compatíveis com as atitudes de professores iniciantes. Apontam que essa postura facilita no êxito do apoio pedagógico solicitado, pelos alunos, em direção ao aprofundamento do conhecimento buscado pelos estudantes, principalmente no inicio dos seus estudos em determinada disciplina.

Aravena (2018), em seu artigo, proveniente de evidências empíricas obtidas através de uma pesquisa realizada com oito monitores em uma escola chilena, aponta o mentoring como um processo de aprendizagem com oportunidades e limitações. Tal processo tem o seu enfoque estruturado e coordenado, no momento em que um aprendiz e um monitor estão dispostos a se envolverem em um relacionamento próximo, dentro de um contexto social e confidencial, no intuito de promover o desenvolvimento profissional, crescimento, e graus variados de apoio pessoal.

O mentoring consiste na conjugação dos processos de profissionalização do aprendiz e sua socialização em práticas diárias, onde a orientação para a aprendizagem parte da relação lógica entre esses sujeitos (SCHECHTER; FIRUZ, 2015; ARAVENA, 2018).

Além disso, pode servir para alicerçar e melhorar os resultados de uma empresa, isto é, vai além das instituições de ensino. Uma vez que essa melhoria depende da atuação dos agentes envolvidos. Sendo esses os responsáveis pelas ações de monitoria, assim possibilitando, de forma mutua, o aperfeiçoamento das funções demandadas pela empresa e a socialização dentro da organização profissional (TAHIR et al., 2015).

Daly e Milton (2017) identificaram em sua pesquisa, que no País de Gales a monitoria é uma estratégia utilizada para obter-se a melhoria dos padrões educacionais, naquele país. A melhoria, nesses padrões, é apontada como sendo um dos principais fatores para a também melhoria da qualidade dos alunos. Embora as autoras tenham utilizado como objeto da sua pesquisa a monitoria na modalidade externa, ou seja, realizada fora da escola, mas com o objetivo de melhoria nos estudos escolares, elas reforçam que a 
importância da estratégia de monitoria educativa, independentemente do fato de ser desenvolvida dentro ou fora do ambiente escolar, é de vital importância para o êxito do desempenho satisfatório dos estudantes.

\section{ESPAÇOS DE APRENDIZAGEM NA PRÁTICA DE MONITORIA}

Existem várias técnicas para o monitor desempenhar o seu papel. Uma delas é a do tipo colaborativa entre monitores, com a finalidade de incrementar as melhores práticas pedagógicas, através de um consenso, produzindo um ensino eficaz. Também entendido como Mentoring Shared (monitoria compartilhada) em Ambientes de Aprendizagem, é um método japonês de estudo da lição, ou ainda, uma atividade de ensino dentro de uma Comunidade de Aprendizagem Profissional (CHIZHIK et al., 2017).

Chizhik et al. (2017), da Universidade de San Diego, nos EUA, acreditam que a capacidade dos programas para monitores, com o objetivo de cultivar a mentalidade de crescimento em futuros professores, pode ter um efeito positivo sobre a educação.

Os espaços PLCs (Professional Learning Community - Comunidade de Aprendizagem Profissional) são espaços profissionais em que os professores trabalham em colaboração, para melhorar a aprendizagem dos alunos, transformando o ensino e a cultura profissional de uma instituição escolar, por meio de pedagogias autênticas, direcionadas a seu determinado grupo de aprendizagem (CHIZHIK et al., 2017).

Ações colaborativas dentro dos espaços PLCs também trazem benefícios que ampliam o espaço inclusivo, através de ações de melhoria, pela diferenciação e pela gestão comportamental dos praticantes.

A metodologia de investigação pode empregar os dados dos alunos para projetar lições, implementar esses ensinos, e conjecturar de maneira crítica sobre a eficácia dessas lições, gerando seu próprio desenvolvimento profissional (CHIZHIK et al., 2017).

Chizhik et al. (2017) enumeram seis características dos PLCs produtivos: missão compartilhada, cultura colaborativa, investigação coletiva em melhores práticas, orientação de ação, compromisso com a melhoria contínua e orientação para resultados. Chizhik et al. (2017), inclusive relatam três fases de foco aplicadas ao "SMILE" (Shared Mentoring in Learning Environments - Monitoria Compartilhada em Ambientes de Aprendizagem). Essa divisão trifásica foi ordenada como sendo: classroom management (gestão de sala de aula); design (projeto) instrucional e implementação; e utilização de dados de avaliação, para informar as decisões de instrução. 0 processo "SMILE" é baseado em competências pedagógicas exclusivas, referentes às proposições de melhoria que os monitores escolheram e que precisavam de suporte adicional, tais como: planejamento de aulas, gravações de vídeo e os resultados da avaliação.

\section{IMPACTOS DA RELAÇÃO ENTRE PROFESSOR E MONITOR}

A técnica é conhecida como Peer-to-Peer (P2P - ponto a ponto) e é utilizada como um instrumento facilitador da formação de identidade entre os grupos de estudo. Consiste em unir os participantes de programas, ou sistemas de orientação, com o objetivo de diminuir os níveis de stress relacionais de ensino dos envolvidos (membros do corpo docente de ensino e de pesquisa e alunos). O P2P é desenvolvido para ampliar e criar fundamentos solidários, a partir de conclusões exploradas, através de um estudo qualitativo e de natureza descritiva. A função do P2P consiste em abrir uma visão de prosperidade, em períodos de mudança das estruturas organizacionais e ambientes de trabalho, que pode ser incorporada a um Centro de Apoio ao Ensino e Inovação. Education and Innovation Support Center (EISC) - Centro de Apoio ao Ensino e Inovação - é o nome utilizado pelos autores, durante a sua pesquisa, na Universidade de Toronto, no Canadá, para se referir ao local de desenvolvimento e observação da prática P2P (SIMMONDS; DICKS, 2018).

Hamilton et al. (2019) defendem que a expansão dos programas de orientação, surtem efeito progressivo, em relação a quantidade de alunos que podem se beneficiar destes e que, para se chegar a essa finalidade é preciso fortalecer os laços que os unem. Esses laços entre alunos, monitores, professores e programas de monitoria também tem como objetivo, incentivar a continuidade destas relações entre os pares, mesmo entre aqueles que estão trabalhando em sua profissão, dentro das escolas e/ou universidades e na indústria. Os autores, da Universidade de Calgary, no Canadá, defendem o fortalecimento desses laços, através de programas de tutoria (monitoria) estruturantes. 
Um estudo exploratório realizado por pesquisadores da Universidade de Columbus, na Georgia (EUA), mostrou que efeitos de orientação positiva foram obtidos em um programa de preparação a estágios para monitores e/ou professores iniciantes. O programa prevê a colocação de campo, durante um ano, fundamentados na presença em sala de aula com "confiança, conhecimento e habilidades para servir a seus estudantes", utilizando "feedback construtivo e de colaboração (Mentoring-downthe-hall ou ambiente colaborativo)” (BENTLEY; WORKMAN; OVERBY, 2017, p. 228).

Os autores consideraram, também, os erros como "oportunidades de aprendizagem" e aplicaram "testes padronizados determinados pelo estado", como high-stakes (alto risco) ou avaliações anuais, além de testarem "novas estratégias" e serem "inovadores", para que "pudessem desenvolver suas próprias práticas pedagógicas" com seus alunos. Entretanto, existem desafios ligados com este modelo dentro de pares de tutoria (BENTLEY; WORKMAN; OVERBY, 2017, p. 235 e 238).

House, Spencer e Pfund (2018) em um estudo exploratório, onde foram levados em consideração os fatores culturais no que diz respeito à diversidade nas escolas de Winconsin, EUA, constataram que pouco se sabe, no meio escolar, como os envolvidos percebem a diversidade, e que no treinamento dos monitores há a necessidade de incluir esse tema, ou seja, preparar os monitores a respeito do tema diversidade. Recomendam o incremento de ferramentas expressivas, com a finalidade de impactar o desempenho, de modo a amparar, inclusivamente e diversificadamente, a força de trabalho dos alunos monitores.

Em um estudo, com amostras por conveniência, realizado em escolas localizadas no sudoeste dos EUA, Barnett, Shoho, Okilwa (2017) defendem a avaliação formal anual de diretores, que representam um importante papel na orientação de diretores adjuntos, auxiliando-os em seus desempenhos, crescimento e desenvolvimento de programas de monitoria estudantil. Além disso, devem ser "vistos como os principais membros de uma equipe, servindo para fazer avançar a escola com sucesso, como uma organização de aprendizagem para alunos e educadores" (PETRIDES; JIMES; KARAGLANI, 2014, p. 174).

Além disso, um diretor qualificado é capaz de exercer a supervisão de atividades como estágios com monitores ingressantes, acrescentando experiências na aprendizagem de forma prática, inclusive no que tange à liderança (BARNETT; SHOHO; OKILWA, 2017).

\section{CONSIDERAÇÕES FINAIS}

O estudo apresentado, mediante revisão bibliográfica, mostrou algumas experiências e concepções sobre monitoria, envolvendo estudantes. Foram relatados os achados dentro e fora do Brasil, publicados em artigos de periódicos. As pesquisas demonstram a importância da prática de monitoria, como eficaz apoio pedagógico às ações formais no processo ensino-aprendizagem e que pode ser efetivamente e amplamente implantada em toda a cadeia de ensino nacional. 0 atual artigo também serve de incentivo para ampliar a perspectiva de discussões a respeito da prática da monitoria dentro e fora do ambiente escolar.

\section{REFERÊNCIAS}

[1] ALVAREZ, S., \& Schultz, J. Professional and personal competency development in near-peer tutors of gross anatomy: A longitudinal mixed-methods study. Anatomical Sciences Education, Rockville (USA), v. 12, n. 2, p. 129-137, 2019. DOI: 10.1002/ase.1798. Disponível em: https://onlinelibrary.wiley.com/doi/full/10.1002/ase.1798. Acesso em 07 mar. 2019.

[2] ANDRADE, Erlon Gabriel Rego de et al. Contribuição da monitoria acadêmica para o processo ensinoaprendizagem na graduação em enfermagem. Revista Brasileira de Enfermagem, Brasília, v. 71, supl. 4, p. 15961603, 2018. DOI: http://dx.doi.org/10.1590/0034-7167-2017-0736. Disponível em: http://www.scielo.br/scielo.php?script=sci_arttext\&pid=S0034-71672018001001596\&lng=pt\&nrm=iso. Acesso em: 20 jan. 2020.

[3] ARAVENA, Felipe. Mentoring novice school principals in Chile: what do mentors learn? International Journal of Mentoring e Coaching in Education, England, v. 7, n. 3, p. 219-230, maio 2018. DOI 10.1108 / IJMCE-01-2018-0002. Disponível em: https://www.emeraldinsight.com/2046-6854.htm. Acesso em: 19 mar. 2019.

[4] BALENSIEFER VICENZI, Cristina et al. A monitoria e seu papel no desenvolvimento da formação acadêmica. Revista Ciência em Extensão, São Paulo, v. 12, n. 3, p. 88-94, jun. 2016. ISSN 16794605. Disponível em: http://ojs.unesp.br/index.php/revista_proex/article/view/1257/1254. Acesso em: 26 jan. 2019.

[5] BARNETT, Bruce; SHOHO, Alan R.; OKILWA, Nathern AS. Assistant principals1' perceptions of meaningful mentoring and professional development opportunities. International Journal of Mentoring e Coaching in Education, 
England, v. 6, n. 4, p. 285-301, jun. 2017. DOI 10.1108 / IJMCE-02-2017-0013. Disponível em: http://www.emeraldinsight.com/2046-6854.htm. Acesso em: 19 mar. 2019.

[6] BENTLEY, Erinn; Workman, Madison; Overby, Alex. Exploring mentoring relationships in a yearlong field placement. International Journal of Mentoring e Coaching in Education, England,v. 6, n. 3, p. 228-241, 2018. DOI 10.1108 / IJMCE-03-2017-0016. Disponível em: www.emeraldinsight.com/2046-6854.htm. Acesso em: 19 mar. 2019.

[7] BROD, FERNANDO AUGUSTO TREPTOW; RODRIGUES, SHEYLA COSTA. O conversar como estratégia de formação contínua na tutoria da educação profissional a distância. Rev. Bras. Educ., Rio de Janeiro, v. 21, n. 66, p. 631652, Sept. 2016. DOI: http://dx.doi.org/10.1590/S1413-24782016216633. Disponível em: http://www.scielo.br/scielo.php?script=sci_arttext\&pid=S1413-24782016000300631\&lng=en\&nrm=iso. Acesso em: 07 Jan. 2020.

[8] CAUCHICK-MIGUEL, Paulo et. Al.. Elaboração de artigos acadêmicos: estrutura, métodos e técnicas. Rio de Janeiro: Elsevier, 2017.

[9] CHIZHIK, E.W. et al.; CHIZHIK, A.W.; CLOSE, C.; GALLEGO, M. Developing student teachers' teaching selfefficacy through Shared Mentoring in Learning Environments (SMILE). International Journal of Mentoring e Coaching in Education, England, v. 7 n. 1, p. 35-53, 2018. DOI 10.1108 / IJMCE-02-2017-0014. Disponível em: https:// www.emeraldinsight.com/2046-6854.htm. Acesso em: 19 mar. 2019.

[10] DALY, C.; MILTON, E. External mentoring for new teachers: mentor learning for a change agenda. International Journal of Mentoring e Coaching in Education, England, v. 6, n. 3, p. 178-195, 2017. DOI 10.1108 / IJMCE03-2017-0021. Disponível em: http:// www.emeraldinsight.com/2046-6854.htm. Acesso em: 26 set. 2019.

[11] FLORES, Jeronimo Becker; LIMA, Valderez Marina do Rosário; FONTELLA, Caren Rejane de Freitas. Análise das monitorias de Cálculo e de Física: um estudo de caso em cursos de Engenharia. Caderno Brasileiro de Ensino de Física, Florianópolis, v. 34, n. 1, p.47-63, abr. 2017. DOI: http://dx.doi.org/10.5007/2175-7941.2017v34n1p47. Disponível em: https://dialnet.unirioja.es/servlet/articulo?codigo=5976854. Acesso em: 19 mar. 2019.

[12] FRISON, Lourdes Maria Bragagnolo. Monitora: uma modalidade de ensino que aprimora a aprendizagem colaborativa e autorregulada. Pro-Posições, Campinas, v. 27, n. 1, pp.133-153, abr. 2016. D0I: 10.1590/01037307201607908. Disponível em: http://dx.doi.org/10.1590/0103-7307201607908. Acesso em 26 jan. 2019.

[13] GRAY, David E, 2012. Pesquisa no mundo real. 2 ed. Porto Alegre: Penso, 2012.

[14] HAMILTON, Leah K. et al. Examining the impact of a university mentorship program on student outcomes. International Journal of Mentoring e Coaching in Education, England, v. 8, n. 1, p. 19-36, 2019. DOI 10.1108 / IJMCE02-2018-0013. Disponível em: https://www.emeraldinsight.com/2046-6854.htm. Acesso em: 07 set. 2019.

[15] HOUSE, S.C.; SPENCER, K. C.; PFUND, C. Understanding how diversity training impacts faculty mentors' awarensess and behavior. International Journal of Mentoring e Coaching in Education, England, v. 7, n. 1, p. 72-86, 2018. DOI 10.1108 / IJMCE-03-2017-0020. Disponível em: https://www.emeraldinsight.com/2046-6854.htm. Acesso em: 07 set. 2019.

[16] PETRIDES, L.; JIMES, C.; KARAGLANI, A. Lead Assistant Leadership Development: A Capture Study Narrative. Journal of Educational Administration, United Kingdom, v. 52, n. 2, p. 173-192, abr. 2014. ISSN: 0957-8234. Disponível em: https://www.emerald.com/insight/content/doi/10.1108/JEA-01-2012-0017/full/html. Acesso em: 07 set. 2019.

[17] SCHECHTER, Chen; FIRUZ, Florit. How Mentor Principals Interpret the Mentoring Process Using Metaphors. School Leadership \& Management: Formely School Organisation, United Kingdom, v. 35, n 4, p. 1-23, 2015. DOI 10.1080/13632434.2015.1010500. Disponível

em: https://www.tandfonline.com/doi/full/10.1080/13632434.2015.1010500. Acesso em: 07 set. 2019.

[18] SHIELDS, Samantha; MURRAY, Megan. Beginning Teachers' perceptions of mentors and access to communities of practice. International Journal of Mentoring and Coaching in Education, England, v. 6, n. 4, p. 317-331, jul. 2017. DOI: 10.1108 / IJMCE-01-2017-0004. Disponível em: https://www.emeraldinsight.com/2046-6854.htm. Acesso em: 07 set. 2019.

[19] SIMMONDS, Anne H.; DICKS, Andrew P. Mentoring and professional identity formation for teaching stream faculty: A case study of a university Peer-to-Peer mentorship program. International Journal of Mentoring e Coaching in Education, England, v. 7, n. 4, p. 282-295, 2018. DOI 10,1108 / IJMCE-02-2018-0012. Disponível em: https://www.emeraldinsight.com/2046-6854.htm. Acesso em: 07 set. 2019.

[20] TAHIR, Lokman. et al. The Benefits of Headship Mentoring: An Analysis of Malaysian Novice Headteachers' Perceptions, MOHD, S; KHADIJAH, D.; SHAFEEQ, V.; AQEEL, K. Educational Management Administration \& Leadership, United Kingdom, v. 44 n. 18, p. 420-450; 2015. DOI: 10.1177/1741143214549973. Disponível em: https://journals.sagepub.com/doi/abs/10.1177/1741143214549973. Acesso em 07 set. 2019. 


\section{Capitulo 2}

\section{A inovação através da colaboração e do compartilhamento}

\section{Marcio de Freitas Santa Ana}

\section{Roseli da Conceição Silva de Freitas Santa Ana}

Bruna Soares Silva de Carvalho

Resumo: 0 presente artigo apresenta o empreendedorismo e a Inovação como tendências colaborativas e de compartilhamento das economias, seus objetivos gerais e específicos, a importância da Inovação de uma maneira geral, principalmente em tempos de crise, o movimento do crescimento das economias em todos os países e suas fundamentações para este desenvolvimento. As inovações nas suas formas incrementais e radicais e suas contribuições com os avanços tecnológicos e sociais e o surgimento de grupos cada vez mais alternativos na busca de uma distribuição compartilhada. Mostrar a visão do mundo globalizado e de uma aliada que já faz parte do cotidiano das sociedades ," a Internet ", onde novas comunidades estão se formando no mundo compartilhado e colaborativo física e virtualmente, os novos modelos de gestão empreendedora crody economy analisados dentro de uma fundamentação teórica e o exemplo do Uber como forma radical de inovação das relação de prestação de serviços de transporte.

Palavras-chave: coworking, crowdsourcing, cocriação, crowdfunding. 


\section{INTRODUÇÃO}

As inovações Tecnológicas aliadas ao empreendedorismo têm sido fator de grande importância para manutenção e criação de alternativas para as economias em todos os países. Investimentos em pesquisa e desenvolvimento, criação de novos serviços e produtos tem reinventado e até mesmo criado novas perspectivas de modelos de negócios. A forma colaborativa e de compartilhamento entre grupos sociais ganha força nas economias globais, ese tornam necessárias para manter ou mesmo acelerar o ritmo de crescimento dessas economias. As Inovações buscam se adequar aos processos de compartilhamento colaborativo, nas quais atividades econômicas estão descobrindo uma forma de coexistirem em busca de soluções conjuntas nos mais diversos segmentos sociais.

A mudança de paradigma econômico da sociedade industrial para a sociedade do conhecimento científico, empregado para gerar inovações tecnológicas, tornou-se um dos principais propulsores do desenvolvimento socioeconômico, contribuindo para o aumento da competitividade de empresas e países. Nesse cenário a inovação é definida como resultado dos processos de pesquisas, descobertas, experimentação, desenvolvimento, imitação e adoção de novos produtos, novos processos de produção e novas formas de organizações e de vital importância para a sociedade contemporânea. Passaram então a surgir empresas que nasceram em laboratórios universitários, a partir de atividades de pesquisa que permitiram a introdução de inovações no mercado e atraíram atenção de agentes governamentais a ser essenciais para as universidades como geradores de conhecimento (ANPROTEC).

A colaboração é baseada na comunicação de informações que, na era da informação, cada vezmais ocorre através de redes em vários níveis, do local ao internacional. Algumas redes de informação são elaboradas para anunciar políticas de governo e fontes de financiamento, resultados de pesquisa de ponta de universidades e suas implicações para novas tecnologias e indústria, assim como as necessidades de colaboração da indústria. (ETZKOWITZ, 2009, p.31).

\subsection{PERGUNTA PROBLEMA}

Quais são as atuações empreendedoras através da colaboração e compartilhamento, na gestão de novos negócios que atendem as necessidades do mercado em níveis globais nos papéis das empresas e pessoas para criarem novas expectativas de trabalhos e renda, aliadas na busca pelas inovações e soluções de problemas sociais e econômicos?

\section{OBJETIVO}

\subsection{OBJETIVO GERAL}

Mostrar que a inovação Tecnológica tem fortalecido o surgimento em níveis globais de formas alternativas de empreender de maneira colaborativa e compartilhada de novos modelosde negócios sejam eles em grupos físicos ou virtuais.

\subsection{OBJETIVO ESPECÍFICO}

- Analisar o entendimento da Inovação Tecnológica empreendendo modos de colaboração através do compartilhamento;

- Identificar suas formas de compartilhamento;

- $\quad$ Análises Estatísticas e geográficas do Uber.

\section{JUSTIFICATIVA}

A importância da Inovação de uma maneira geral está ligada direta ou indiretamente asobrevivência das empresas num mundo cada vez mais global, contudo as empresas sendoelas de diferentes estruturas, sejam aquelas formadas por indivíduos em situações de subsistência ou mesmo aquelas com aporte administrativo organizacional estruturado precisam se adequar a nova visão do mercado e as novas ferramentas que ajudam a colocar as inovações em prática.

Desde então, a Internet 2.0 vem permitindo que a população global assuma um -poder social|| como 
jamais havia acontecido antes. Graças à força da colaboração, transformações importantes ocorreram e vêm ocorrendo: novas empresas nasceram outras grandes deixaram de existir e até ditadores foram removidos do poder (SEBRAE).

A economia colaborativa (compartilhada ou em rede, como também é conhecida) é um movimento de concretização de uma nova percepção de mundo. Ela representa oentendimento de que, diante de problemas sociais e ambientais que se agravam cada vez mais, a divisão deve necessariamente substituir o acúmulo. Trata-se, assim, de uma força que impacta a forma como vivemos e, principalmente, fazemos negócio (SEBRAE).

\section{FUNDAMENTAÇÃO TEÓRICA}

\subsection{INOVAÇÃO TECNOLÓGICA E EMPREENDEDORA}

O desenvolvimento empreendedor e inovador é resultante da realização de novas combinações de materiais e forças - sejam elas relacionadas a coisas novas ou métodos novos de geração das mesmas coisas sendo essas ocorrências espontâneas e descontínuas. Observa se que novas combinações resultantes de combinações antigas, por ajuste contínuo mediante pequenas etapas, caracterizam mudanças, mas não constituem um fenômeno novo, e tampouco desenvolvimento. A essas novas combinações, que refletem as atividades de inovação, foram associadas o termo -empreendimento\|, e aos indivíduos que o promovem, o termo -empresários|| (SCHUMPETER, 1982, p. 59).

\subsection{INOVAÇõES TECNOLÓGICAS DAS ATUAIS GERAÇÕES}

A geração atual está incorporada a uma nova era de Tecnologias, logo cedo surgem crianças expostas à Smartphones e Tabletes. Hoje é comum vermos jovens com facilidades no uso de aplicativos diversos como maneira de integrar as relações sociais.

A inovação pode ser conceituada como sendo: -um processo contínuo de busca, descoberta, experimentação, desenvolvimento, imitação e adoção de novos produtos, novos processos e nova organização|| (DOSI, 19881 apud LEMOS, 1999, p. 126).

\subsection{UBER - EMPREENDEDORISMO DE COLABORAÇÃO E COMPARTILHAMENTO}

Em um mercado competitivo, as empresas estão constantemente concorrendo umas com as outras, em busca de diminuição de seus custos e aumento de lucro, de duas formas: (i) caminhos inovativos e econômicos e (ii) competição por diferenciação de produtos e serviços dos demais. Esta maneira dinâmica e competitiva de negócios encoraja as empresas a descobrir novas formas de comércio e de gerar valor para seus clientes (KOOPMAN, Christopher. MITCHELL, Matthew. THIERE, Adam).

O aplicativo oferece aos passageiros um melhor serviço, com economia de capital e tempo de acesso a locais, sem acréscimos adicionais e taxas de licença pela atividade, como no sistema tradicional de transporte de passageiros (WATANABE, Chihiro. NAVEED, Kashif.NEITTAANMÄKI, Pekka).

\subsection{O SURGIMENTO DAS ECONOMIAS COMPARTILHADAS}

As economias compartilhadas surgem da busca e construção por novas modelagens. Os maiores movimentos que observamos hoje são:

\subsubsection{COWORKING}

O conceito de coworking poderia se dizer que está bem acima da idéia de consumo colaborativo ou economia compartilhada, pois parte de um princípio de ambiente inovador, fomentando o empreendedorismo para quem busca algo sustentável em um estilo de trabalho diferente (BOTSMAN; ROGERS, 2010). É também conhecido como escritório compartilhado, vem sendo um forte aliado dos trabalhadores autônomos. Esse novo segmento colaborativo, possibilita que estes sete profissionais tenham um escritório físico para administrar suas atividades, mas que não precisa ficar aberto a todo o momento, pois seu atendimento central é em casas ou então em empresas (MURAYAMA, 2014). 


\subsubsection{CROWDSOURCING}

O termo apareceu num artigo escrito pelo jornalista Jeff Howe para a revista americana Wired. É uma junção das palavras crowd (multidão) e outsourcing (terceirização). Significa

- usar a inteligência coletiva para resolver problemas|| (REVISTA EXAME).

- empreendedor que precisa resolver demandas pontuais ou criar produtos e serviços pode recorrer a uma imensa comunidade online de profissionais dispostos a vender sua força de trabalho\|, diz Alexandre Alves, da Inseed Investimentos (REVISTA EXAME).

\subsubsection{COCRIAÇÃO}

É a iniciativa de envolver clientes, fornecedores e até concorrentes no processo de criação de um produto ou serviço. 0 princípio é que muitas cabeças pensam melhor do que uma (REVISTA EXAME).

A contrapartida das empresas que optam pela cocriação é que, ao desenvolver projetos em grupo, elas abdicam da posse da propriedade intelectual. 0 conceito é mais fácil de ser compreendido no caso dos softwares livres, que podem ser usados de graça, copiados, modificados e redistribuídos de acordo com as necessidades de cada pessoa ou empresa (REVISTA EXAME).

\subsubsection{CROWDFUNDING}

É a palavra em inglês que define financiamento coletivo - várias pessoas e empresas contribuem com pequenas quantias em dinheiro para realizar uma idéia. 0 capital é obtido por meio de sites que fazem a intermediação entre o dono do projeto e os interessados em financiá-lo (REVISTA EXAME).

A vantagem sobre os métodos tradicionais é que não existe cobrança de juros nem necessidade de abrir mão de uma parte do negócio em troca do dinheiro.

\section{METODOLOGIA}

O artigo assume uma construção exploratória e um levantamento bibliográfico sobre inovação e colaboração através do compartilhamento, buscando mostrar a crescente demanda global por novas estratégias de economias compartilhadas através de grupos físicos e principalmente virtuais. A Inovação através da Colaboração e o Compartilhamento permitiu enquanto aluno articular muitos dos conhecimentos adquiridos ao longo do curso e formular a pergunta problema do tema em questão.

Nos objetivos do artigo procurou-se mostrar que a inovação Tecnológica tem fortalecido o surgimento de uma economia em níveis globais de grupos e na fundamentação teórica,explorar as principais tendências da economia compartilhada onde foram mostradas tabelas e localizações geográficas de formas de compartilhamento do Uber.

\section{DISCUSSÃO}

O caminho para a economia compartilhada e de colaboração depende fortemente do comportamento e valores que dirigem os agentes econômicos os consumidores e empresas.

Sabe-se, ainda, que a evolução para a economia nesses moldes é cada vez mais rápida, ou seja, há uma necessidade quase que obrigatória de enquadramento nesses grupos. Nessas condições toma-se, então, como oportuna a prática de negócios que possuam concepções institucionais próprias ou de subsistência.

As contribuições deste artigo destacam-se em seus objetivos, a fim de mostrar, identificar e analisar de forma geral e específica as relações dos sistemas de compartilhamento dentro das economias. 


\section{CONSIDERAÇÕES FINAIS}

O artigo apresentou o empreendedorismo e a Inovação como tendências colaborativas de compartilhamento dentro das economias dos países, o empreendedorismo e Inovação Tecnológica, principalmente em tempos de crise, movimentam o crescimento das economias e se fundamentam para este desenvolvimento. As inovações nas suas formas incrementais e radicais têm contribuído com os avanços tecnológicos e sociais e feito surgir grupos cada vez mais alternativos na busca de uma economia compartilhada. Foram apresentados objetivos e fundamentações teóricas que buscaram apresentar a economia compartilhada no mundo globalizado, novos modelos de Gestão Empreendedora, novas comunidades que estão se formando no mundo compartilhado física e virtualmente: os coworking, crowdsourcing, cocriação, crowdfunding.

0 grande desafio da proposta foi verificar as mudanças de antigas práticas de trabalho, no entanto, qualquer reforma organizacional está sujeita a desconfianças, resistências e é quase sempre conflitiva, exigindo uma estratégia para sua implantação na busca da colaboração e compartilhamento.

\section{REFERÊNCIAS}

[1]. ANPROTEC. A importância dos relacionamentos compartilhados para statups. Disponível em < https://document.onl/documents/a-importancia-dos-relacionamentos-compartilhados-para-startups-.html > Acesso em: 7 de março de 2020.

[2]. Botsman, R., \& Rogers, R. What's mine is yours. The rise of collaborative consumption, 2010.

[3]. DOSI, G. The nature of the innovative process. In: DOSI, G. et al. (Org.). Technical change and economictheory. Londres: Printer Publishers, 1988. p. 221-238.

[4]. ETZKOWITZ, H. Hélice tríplice: Universidade-Indústria-Governo: inovação em movimento. Porto Alegre: EDIPUCRS, 2009.

[5]. FANTONI, Margarida. Inovação em empresas de bases tecnológicas: o caso da Katal MG. Disponível em: < https://fpl.edu.br/2018/media/pdfs/mestrado/dissertacoes_2007/dissertacao_margarida_maria_souto_fantoni_200 7.pdf>. Acesso em: 6 de maio de 2020.

[6]. GINESI, Camila. FEIJÓ, Bruno. A economia colaborativa molda os negócios. Aceite ou morra. Revista EXAME. Disponível em: <https://exame.abril.com.br/pme/todo-mundo-junto/>. Acesso em 10 de abril de 2020.

[7]. KOOPMAN, Christopher. MITCHELL, Matthew. THIERE, Adam. The Sharing Economy and Consumer Protection Regulation: The Case for Policy Change. The Journal of Business, Entrepreneurship \& the Law. Vol. 08, Issue 2, 2015MURAYAMA, Anna. Coworking e a evolução dos espaços de escritórios até hoje. São Paulo, 2015. Disponível em: < https://meuartigo.brasilescola.uol.com.br/atualidades/coworking-evolucao-dos-espacos- escritorio-atehoje.htm>. Acesso em: 8 de março de 2020.

[8]. PRIEBE, Anna. ROVARIS, Nicole. VOLTARELLI, Francielle. ROJO, Claudio. Coworking como estratégia para empreender: uma nova forma de economia compartilhada. UNIOESTE - II CINGEM CONFERENCIA INTERGNAICONAL EM GESTAO DE NEGOCIOS, ago/2017.

[9]. SCHUMPETER, J. Alois. Teoria do desenvolvimento econômico: uma investigação sobre lucros, capital,crédito, juro e o ciclo econômico. São Paulo: Abril Cultural, 1982. 169p.

[10]. SCHUMPETER, Joseph. Empreendedorismo e inovação por Schumpeter. Empresas de Base. Disponível em

[11]. <https://ebtbrasil.wordpress.com/2010/06/19/empreendedorismo-e-inovacao-por-schumpeter/> Acesso em: 6 demaio de 2020.

[12]. SEBRAE. Economia colaborativa: a tendência que está mudando o mundo. Disponível em:

[13]. <https://m.sebrae.com.br/sites/PortalSebrae/artigos/economia-colaborativa-a-tendencia-que-esta-mudando-omercado,49115f4cc443b510VgnVCM1000004c00210aRCRD> . Acesso em 6 de maio de 2020.

[14]. TELÉSFORO, Rachel. Uber: inovação disruptiva e ciclos de intervenção regulatória. RLT -DISSERTACAO MESTRADO, 2017.

[15]. WATANABE, Chihiro. NAVEED, Kashif. NEITTAANMÄKI, Pekka. Co-evolution of three mega-trends nurtures un-captured GDP- Uber's ride-sharing revolution. Technology in Society, Vol. 46, Rio de Janeiro:Elsevier, 2016, p. 166. 


\section{Capítulo 3}

Percepção dos alunos do curso de logística quanto às competências necessárias ao seu exercício profissional

\section{Luciano da Silva Ferreira}

\section{Roberto Kanaane}

Resumo: 0 artigo apresenta uma análise da percepção dos discentes do curso de Tecnologia em Logística da Faculdade de Tecnologia (FATEC) Guarulhos, tendo em vista a relevância das competências relacionadas ao exercício profissional em Logística. A metodologia assumiu caráter descritivo, sob o enfoque da pesquisa de campo, originando-se em uma amostra não probabilística e fazendo o uso da aplicação de um questionário e sua respectiva análise. Como resultado identificou-se as dez principais competências, na opinião dos alunos, destacando-se entre elas o relacionamento com os clientes.

Palavras-chave: Logística, Competências e Recursos Humanos. 


\section{INTRODUÇÃO}

A apreensão das competências que os estudantes do curso de logística julgam necessárias ao seu exercício profissional é relevante para a compreensão de suas expectativas, além de contribuir para o aprimoramento contínuo do curso e, por conseguinte, a melhoria na formação do profissional de logística.

As empresas necessitam encontrar diferenciais competitivos frente aos seus concorrentes, uma das formas de se conseguir esse diferencial é a partir de seus funcionários. As organizações buscam contratar pessoas que possuem as competências adequadas ao ambiente organizacional em que atuam, e consequentemente, aqueles indivíduos que possuem essas competências desenvolvidas são valorizados em detrimento dos que ainda necessitam fortalecê-las.

As áreas e empresas de logística, como prestadoras de serviços, dependem do potencial humano para se distinguir no mercado e oferecer um serviço diferenciado aos clientes. Nesse contexto, identificar as competências necessárias para que o profissional de logística exerça suas atividades torna-se, então, um fator crítico para as empresas.

0 artigo buscou responder às seguintes questões: Quais são as competências relevantes para o profissional de logística, segundo os alunos do primeiro e sexto semestres do curso de logística da FATEC Guarulhos? Até que ponto o curso de tecnologia em Logística influencia a percepção dos alunos quanto às competências necessárias para a prática profissional?

Tem-se como objetivo, deste trabalho, identificar a percepção dos alunos do curso de tecnologia em Logística da Faculdade de Tecnologia (FATEC) localizada na cidade de Guarulhos, no estado de São Paulo, quanto a relevância às competências relacionadas ao exercício profissional em Logística. Para responder às questões formuladas e alcançar o objetivo proposto, foram aplicados questionários aos alunos do primeiro e sexto semestres do curso de logística da faculdade referenciada, analisando as posições dos envolvidos segundo a escala Likert.

\section{REFERENCIAL TEÓRICO}

\subsection{COMPETÊNCIAS}

Devido a sua importância para o desenvolvimento das pessoas e das organizações, o conceito de competências vem sendo estudado e analisado por diversos pesquisadores, segundo Carbone et al (2009), esse termo foi inserido ao vocabulário organizacional no início do século passado, mas apenas a partir da década de 1970 iniciou-se a discussão teórica e a produção científica sobre o assunto.

No Brasil uma das principais definições usadas é a que caracteriza competências como sendo: “[...] um saber agir responsável e reconhecido, que implica mobilizar, integrar, transferir conhecimentos, recursos e habilidades, que agreguem valor econômico à organização e valor social ao indivíduo" (Fleury e Fleury, 2001, p. 187), ressaltando a possibilidade da competência agregar valor econômico para a empresa e também para o indivíduo, através de reconhecimento pelo empregador, das vantagens comerciais obtidas pela organização a partir das competências do funcionário.

O entendimento atual de competência é descrito por Ruas (2015), como uma mobilização de conhecimentos, habilidades e atitudes pessoais e profissionais com a finalidade de realizar tarefas ou deveres em uma situação estabelecida no ambiente empresarial ou pessoal.

Toner (2011) defende que a utilização de métodos organizacionais eficientes em indústrias e prestadores de serviços condiz como um argumento para demandar mão de obra com maior amplitude de competências profissionais.

De acordo com Stank et al (2015), as empresas reconhecem que é mais apropriado adquirir o talento (recursos humanos) adequado aos perfis de habilidades e competências necessárias.

\subsection{LOGÍSTICA}

O conceito de logística é amplo e diretamente conectado ao atendimento das necessidades dos clientes. 0 Council of Supply Chain Management Professionals (Conselho dos Profissionais de Gerenciamento da Cadeia de Suprimentos) CSCMP (2012) define logística como processo de planejamento, implementação e procedimentos para a armazenagem e transporte eficientes e eficazes de produtos, desde a origem até o local de consumo, incluindo ainda os serviços e informações para satisfazer as necessidades do cliente. 
Para cumprir com todas essas atividades as áreas e empresas de logística dependem de profissionais especializados e com competências desenvolvidas adequadamente frente a necessidade organizacional.

O World Economic Forum - WEF (Fórum Econômico Mundial), defende a importância da logística ao declarar que "[...] o setor de logística é uma das principais áreas de crescimento da economia global e é absolutamente crítico para a melhoria dos padrões de vida em todo o mundo" (WEF, 2012, p. 5).

Conforme Closs e Bolumole (2015), há um progressivo incremento da importância dos transportes, logística e da cadeia de suprimentos para apoiar as atividades industriais, chegando a apoiar o desenvolvimento econômico de regiões com a consolidação de competências dessas operações.

Stank et al (2015) sustenta que os gerentes de Logística e Cadeia de Suprimentos necessitam olhar para fora das empresas e aprender com as melhorias alcançadas por seus parceiros, cada vez mais se integrando com os fornecedores e clientes e assim criando valor através desses relacionamentos.

\subsection{COMPETÊNCIA EM LOGÍSTICA}

Pesquisas realizadas pela Fundação Getúlio Vargas (FGV) em 2012 e 2014, relatam que "há uma carência expressiva de informações confiáveis sobre profissionais de logística e supply chain no mercado brasileiro[...]". (REIS et al, 2012, p. 2) e (REIS et al, 2014, p. 3).

De acordo com Wong (2014) é necessário um equilíbrio entre conhecimento e competências de modo que os profissionais em Logística sejam capazes de gerenciar atividades, independentemente da função que exerçam ou de sua especialidade. Foi identificado ainda por Wong (2014), a necessidade para os profissionais de Logística de competências práticas e profissionais, foco no cliente e qualificação profissional ou certificado de competência profissional.

Pesquisa realizada pelo WEF (2012) junto a 300 executivos de empresas identificou que 64\% dos mesmos tiveram dificuldade em contratar funcionários na área de logística no ano de 2011. Essa dificuldade estava relacionada às competências desejadas pelas empresas e não encontradas nos candidatos.

Toner (2011) identifica a necessidade da adoção de métodos organizacionais mais eficientes em indústrias e prestadores de serviços e que tal situação se sustenta como argumento para selecionar recursos humanos com amplitude de competências. As áreas e empresas de Logística por serem dependentes intensivos de pessoas, para a prestação de serviços, são exemplos dessa exigência.

Wu et al (2013), nos resultados de sua pesquisa, identifica algumas das competências esperadas para um profissional de logística, tais como habilidades de comunicação e negociação, responsabilidade social, experiência no campo de logística, aplicações de informações integradas, comércio internacional, gerenciamento de riscos e financeiros, gerenciamento de armazéns e planejamento de materiais. Ele também argumenta que o profissional de Logística deve ser capaz de manter uma boa relação com fornecedores e clientes, exibir habilidades com pessoas e compreender leis e regulamentos relevantes, aprender outras línguas e exibir sensibilidade transcultural.

Reis et al (2014), destacou as seguintes competências como sendo as esperadas pelas empresas para o profissional de Logística: Relacionamento com público interno; conhecimento sobre distribuição; conhecimento sobre armazenagem; conhecimento sobre transportes; relacionamento com público externo; serviço ao cliente; logística Integrada; gerenciamento de estoques em múltiplas instalações; conhecimento sobre restrições dos centros urbanos; planejamento Integrado; sustentabilidade ambiental; organização e métodos e gestão de custos.

\section{MÉTODO}

Quanto aos fins, a presente pesquisa se caracteriza como descritiva, ao identificar quais competências os alunos, do curso de Logística do primeiro e sexto semestres da FATEC Guarulhos, consideram relevantes para a sua atuação profissional na área. Conforme Vergara (2016) a pesquisa descritiva apresenta as características de uma população específica, apesar de não ter a obrigação de esclarecer esses fenômenos.

Quanto aos meios de investigação, tipifica-se como uma pesquisa de campo, pois foi realizada no local onde os alunos estudam, ou seja, nas instalações da faculdade. 
Essa pesquisa se configura, quanto a natureza, como uma pesquisa mista com características dos tipos quantitativa e qualitativa. Para mensurar a relevância das competências na opinião dos alunos, adotou-se de uma pesquisa de avalição, também chamada de Survey, agregando características de natureza quantitativa ao estudo. Miguel (2012) explana que a característica mais marcante desse tipo de abordagem é a mensuração. A análise sobre as influências do curso de Tecnologia em Logística sobre a visão dos indivíduos pesquisados incorpora características qualitativas à investigação. Conforme Miguel (2012), nas pesquisas qualitativas existe uma preocupação com a obtenção de informações com relação aos indivíduos e também em interpretar o ambiente onde ocorrem.

O universo da amostra correspondeu ao corpo discente da FATEC Guarulhos, especificamente os alunos do primeiro e sexto semestres do curso de Logística.

Optou-se por uma amostra não probabilística acidental, definida pela acessibilidade do pesquisador, composta por um total de 155 alunos que cursam os semestres selecionados, dos quais 93 alunos responderam aos questionários (60\%).

A escolha das competências analisadas baseou-se em pesquisa realizada por Reis et al (2012), pela Fundação Getúlio Vargas (FGV) no Centro de Excelência em Logística e Supply Chain (GVcelog), pesquisa com o objetivo de obter informações e identificar as competências necessárias e as que faltam aos profissionais no mercado de operações logísticas e cadeia de suprimentos.

A coleta de dados deu-se pela aplicação de um questionário semiestruturado e por pesquisa documental. 0 questionário foi precedido por um termo de consentimento livre e esclarecido, elaborado com uma pergunta fechada sobre a faixa etária do respondente, uma pergunta fechada para identificação do semestre e turno que o aluno estuda, 26 competências a serem analisadas por uma escala Likert com seis dimensões, sendo a primeira "não é importante" e a última "extremamente importante" e foi elaborada também uma pergunta aberta sobre quais competências o respondente acrescentaria. Foram desconsiderados cinco questionários respondidos, três deles por terem selecionado o mesmo nível de importância para todas as competências e outros dois questionários em que os respondentes não assinaram o termo de consentimento livre e esclarecido. Os dados foram coletados entre os dias 19 e 26 de junho do ano de 2017, nas dependências da FATEC Guarulhos.

\section{RESULTADOS E DISCUSSÃO}

Adotou-se como premissa, a apresentação das 10 competências consideradas relevantes pelos respondentes dos questionários. Foram consideradas as notas médias e o desvio padrão das respostas para a apresentação dos resultados.

Pelos resultados obtidos nas coletas de dados, constatou-se que a competência mais relevante na opinião geral dos indivíduos estudados foi o Relacionamento com clientes, com uma média de 5,523 pontos em uma escala de um a seis. Na Tabela 1, apresentam-se as 10 competências mais relevantes na opinião geral dos alunos da faculdade estudada. 
Tabela 1 - Competências mais relevantes na opinião geral dos alunos.

\begin{tabular}{|lrr|}
\hline \multicolumn{1}{|c}{ Competências } & Média & Desvio Padrão \\
\hline Relacionamento com clientes & 5,523 & 0,711 \\
\hline Tomada de decisões & 5,500 & 0,715 \\
\hline Gestão de Transportes & 5,425 & 0,658 \\
\hline Gestão de estoques & 5,352 & 0,774 \\
\hline $\begin{array}{l}\text { Uso de ferramentas de informática: } \\
\text { Excel, PowerPoint, Word, Etc }\end{array}$ & 5,310 & 0,840 \\
\hline Negociação & 5,307 & 0,778 \\
\hline $\begin{array}{l}\text { Uso de ferramentas de informática } \\
\text { aplicadas (ERP - TMS - MRP - } \\
\text { Rastreadores - Roteirizadores) }\end{array}$ & 5,307 & \\
\hline Previsão de demanda & 5,307 & 0,939 \\
\hline Distribuição & 5,250 & 0,764 \\
\hline Negociação de fretes & 5,207 & 0,806 \\
\hline
\end{tabular}

Fonte: Os autores

Nota-se ainda que todas as competências listadas entre as 10 mais relevantes possuem avaliação acima de cinco pontos na média dos respondentes, apontando uma escolha acertada pelas 26 competências analisadas na pesquisa.

Observa-se também na Tabela 1, que duas competências listadas possuem desvio padrão acima de 0,9, o que significa uma alta variação de percepção quanto às mesmas, reduzindo a possibilidade de generalização dessas para o grupo em geral, são elas a Negociação de fretes e o Uso de ferramentas de informática aplicadas.

Na Tabela 2, apresentam-se as competências mais relevantes na opinião dos alunos do primeiro semestre da faculdade referenciada. Nota-se que a competência nomeada como Relacionamento com Clientes ainda é a melhor posicionada entre as listadas.

Destaca-se a uniformidade entre os respondentes do primeiro semestre, onde verifica-se que apenas uma competência possui um desvio padrão acima 0,9 , sendo ela o Uso de ferramentas de informática aplicadas.

Pode-se observar, ainda, que a competência Negociação de fretes, que foi a décima na Tabela 1, foi substituída pela competência Relacionamento com fornecedores, em oitavo lugar na Tabela 2, demonstrando uma diferenciação na opinião do primeiro semestre em relação ao grupo total de alunos. 
Tabela 2 - Competências mais relevantes na opinião dos alunos do primeiro semestre.

\begin{tabular}{|lrr|}
\hline \multicolumn{1}{|c}{ Competências } & Média & Desvio Padrão \\
\hline Relacionamento com clientes & 5,625 & 0,590 \\
\hline Tomada de decisões & 5,482 & 0,713 \\
\hline Gestão de estoques & 5,411 & 0,733 \\
\hline Gestão de Transportes & 5,400 & 0,683 \\
\hline Negociação & 5,339 & 0,769 \\
\hline Previsão de demanda & 5,286 & 0,731 \\
\hline $\begin{array}{l}\text { Uso de ferramentas de informática: } \\
\text { Excel, PowerPoint, Word, Etc }\end{array}$ & 5,268 & 0,798 \\
\hline Distribuição & 5,232 & 0,809 \\
\hline Relacionamento com fornecedores & 5,214 & 0,847 \\
\hline $\begin{array}{l}\text { Uso de ferramentas de informática } \\
\text { aplicadas (ERP - TMS - MRP - }\end{array}$ & & \\
Rastreadores - Roteirizadores) & 5,196 & 1,017 \\
\hline
\end{tabular}

Fonte: Os autores

Na tabela 3, encontram-se os dados referentes às respostas dos alunos do sexto semestre, que se distinguem dos demais quanto às competências Tomada de decisões, Relacionamento com clientes e Negociação de fretes. Quanto a Tomada de decisões os respondentes do sexto semestre a consideram como a principal competência, diferentemente do primeiro semestre e da opinião geral dos alunos na qual ela é a segunda mais importante. Para a competência Relacionamento com clientes, que para o primeiro semestre e na opinião geral dos alunos foi a mais relevante, para o sexto semestre ela é a quinta em importância.

A competência Negociação de fretes que não estava entre as dez mais relevantes na Tabela 2, que se apresentava como a décima na Tabela 1, revelou-se como a sétima colocada para os respondentes do sexto semestre.

Tabela 3 - Competências mais relevantes na opinião dos alunos do sexto semestre.

\begin{tabular}{|lrr|}
\hline \multicolumn{1}{|c}{ Competências } & Média & Desvio Padrão \\
\hline Tomada de decisões & 5,533 & 0,730 \\
\hline $\begin{array}{l}\text { Uso de ferramentas de informática } \\
\text { aplicadas (ERP - TMS - MRP - }\end{array}$ & & \\
Rastreadores - Roteirizadores) & 5,500 & 0,762 \\
\hline Gestão de Transportes & 5,469 & 0,621 \\
\hline $\begin{array}{l}\text { Uso de ferramentas de informática: } \\
\text { Excel, PowerPoint, Word, Etc }\end{array}$ & 5,387 & 0,919 \\
\hline Relacionamento com clientes & 5,344 & 0,865 \\
\hline Previsão de demanda & 5,344 & 0,827 \\
\hline Negociação de fretes & 5,313 & 0,931 \\
\hline Distribuição & 5,281 & 0,813 \\
\hline Gestão de estoques & 5,250 & 0,842 \\
\hline \hline
\end{tabular}

Fonte: Os autores

$\mathrm{Na}$ análise do desvio padrão, entre os respondentes representados na Tabela 3, observa-se que duas competências alcançaram desvios acima de 0,9 , a Negociação de fretes, a qual também teve um desvio acima de 0,9 nas Tabelas 1 e 2, e o Uso de ferramentas de informática: Excel, Power Point, Word e outros.

Na Tabela 4, não distinguem-se diferenças significativas nas opiniões das turmas do sexto e primeiro semestre pesquisadas, demonstrando uniformidade na opinião dos respondentes quanto à relevância das 10 competências relacionadas como mais relevantes pelo grupo em geral. 
Tabela 4 - Diferença entre as médias das turmas

\begin{tabular}{|lrrr|}
\hline \multicolumn{1}{|c}{ Competências } & Primeiro & Sexto & Diferença \\
\hline Relacionamento com clientes & 5,625 & 5,344 & 0,281 \\
\hline Tomada de decisões & 5,482 & 5,533 & 0,051 \\
\hline Gestão de Transportes & 5,400 & 5,469 & 0,069 \\
\hline Gestão de estoques & 5,411 & 5,250 & 0,161 \\
\hline $\begin{array}{l}\text { Uso de ferramentas de informática: } \\
\text { Excel, PowerPoint, Word, Etc }\end{array}$ & 5,268 & 5,387 & 0,119 \\
\hline Negociação & 5,339 & 5,250 & 0,089 \\
\hline $\begin{array}{l}\text { Uso de ferramentas de informática } \\
\text { aplicadas (ERP - TMS - MRP - }\end{array}$ & & & \\
Rastreadores - Roteirizadores) & 5,196 & 5,500 & 0,304 \\
\hline Previsão de demanda & 5,286 & 5,344 & 0,058 \\
\hline Distribuição & 5,232 & 5,281 & 0,049 \\
\hline Negociação de fretes & 5,145 & 5,313 & 0,167 \\
\hline
\end{tabular}

Fonte: Os autores

Destaca-se ainda, que 28 respondentes, dos 88 com questionários válidos, acharam importante acrescentar outras competências à pesquisa, sendo a competência Uso de línguas estrangeiras a que mais se repetiu com oito ocorrências, estando em consonância com Wu (2013), que em sua pesquisa identificou que os profissionais de logística necessitam aprender outro idioma devido à internacionalização das empresas.

Demonstra-se consonância entre o conceito de Logística e os resultados apresentados. A competência Relacionamento com clientes, que foi considerada pelos respondentes em geral como a mais relevante, está vinculada à satisfação dos clientes e presente no conceito de Logística do CSCMP (2012), também com os resultados da pesquisa de Wu (2013) que identificou que os profissionais de logística devem manter boas relações com os seus clientes, para Wong (2014), que cita o foco no cliente como necessidade ao profissional de logística e Stank et al (2015), que sustenta a criação de valor a partir desse relacionamento.

\section{CONSIDERAÇÕES FINAIS}

Como resposta à questão: Quais são as competências relevantes para o profissional de logística, segundo os alunos do primeiro e sexto semestre do curso de logística da FATEC Guarulhos? 0 presente artigo identificou, como mais relevantes, as competências a seguir: Relacionamento com clientes; tomada de decisões, gestão de transportes; gestão de estoques, uso de ferramentas de informática (Excel, PowerPoint, Word, etc...); negociação; uso de ferramentas de informática aplicadas: (ERP, TMS, MRP, Rastreadores e Roteirizadores); previsão de demanda; distribuição e Negociação de fretes.

Em resposta à questão: Até que ponto o curso de tecnologia em Logística influência a percepção dos alunos quanto às competências necessárias para a prática profissional? Identificou-se que há diferença entre a opinião dos alunos do sexto e primeiro semestre quanto à relevância das competências para o seu exercício profissional, pois foram elencadas de forma diferente as 10 competências mais relevantes. Diferenciando-se principalmente quanto ao Relacionamento com clientes, primeira competência para o primeiro semestre e quinta para o sexto semestre, quanto ao Uso de ferramentas de informáticas aplicadas, segunda mais relevante para o sexto semestre e décima para o primeiro semestre e Negociação de fretes, que é a sétima mais importante para o sexto semestre e apenas décima segunda para o primeiro semestre.

Ainda é importante ressaltar que apesar de haver diferenças entre os semestres quanto a relevância das competências, essas diferenças não são significativas pois na maior discrepância, que é o Uso de ferramentas de informática aplicadas, com pontuação de 5,550 para o sexto semestre e 5,196 para o primeiro semestre, apresentam apenas 0,304 pontos de diferença entre elas, ou seja, 5,52\% de discordância entre as avaliações. 
Esperava-se uma maior discrepância entre os resultados; a pesquisa documental identificou alguns motivos que podem ter contribuído para essa pequena discordância, entre eles destacam-se: A pesquisa foi realizada em junho e o início das aulas foi em fevereiro, nesse período os alunos tiveram contato com os professores e matérias específicas de logística, trazendo conhecimento sobre as competências necessárias ao profissional; aproximadamente $10 \%$ dos alunos são oriundos de cursos técnicos em logística e, portanto, já tiveram relação anterior com professores e matérias específicas da área; em torno de $11 \%$ já são profissionais da área de logística e já têm conhecimento empírico das competências necessárias ao exercício profissional; ao realizar a pesquisa, aproximadamente $5 \%$ dos alunos não responderam por não estarem frequentando as aulas, ou seja, houve evasão.

A pesquisa limitou-se ao universo do curso de Logística na FATEC Guarulhos, não se generalizando para outras faculdades e universidades.

Recomenda-se a realização de pesquisas abrangendo um universo maior de respondentes e também trabalhos científicos que comparem o resultado da investigação atual com resultados de estudos em empresas do ramo de logística.

\section{REFERÊNCIAS}

[1] CARBONE, P. P. et al. Gestão por Competências e gestão do Conhecimento. 3. Ed. Rio de Janeiro: Editora FGV 2009.

[2] CLOSS, D.J., Bolumole, Y.A.. Transportation's Role in Economic Development and Regional Supply Chain Hubs. Transportation Journal, Vol. 54, No. 1, Special Issue Transportation \& Supply Chain; 2015), pp. 33-54; Published by: Penn State University Press Stable URL: http://www.jstor.org/stable/10.5325/transportationj.54.1.0033; acessado em 22/05/2017

[3] CSCMP; Supply Chain Management Terms and Glossary; Illinois-US; $2013 . \quad$ Disponível em: http://cscmp.org/CSCMP/Educate/SCM_Definitions_and_Glossary_of_

Terms/CSCMP/Educate/SCM_Definitions_and_Glossary_of_Terms.aspx?hkey=60879588-f65f-4ab5-8c4b-6878815ef921. Acesso em $20 / 05 / 2017$

[4] FLEURY, M. T. L.; FLEURY, A. Construindo o Conceito de Competência. Rio de Janeiro: RAC. REVISTA DE ADMINISTRAÇÃO CONTEMPORÂNEA, 2001. 188 p. Disponível em: <http://www.scielo.br/pdf/rac/v5nspe/v5nspea10.pdf>. Acesso em: 01 jun. 2017.

[5] Miguel, P.A.C.; et al. Metodologia de pesquisa em engenharia de produção e gestão de operações. Rio de Janeiro: Elsevier, 2012

[6] REIS, M.A.S. et al; Profissionais de logística e supply chain - Entendendo o mercado. EAESP - Escola de Administração de Empresas de São Paulo; GVcelog - Centro de Excelência em Logística e Supply Chain - Relatórios Técnicos - São Paulo, 2012. Disponível em http://bibliotecadigital.fgv.br/dspace/handle/10438/16400 acessado em: 04/06/2017

[7] REIS, M.A.S. et al; Profissionais de logística e supply chain no Brasil - 2a fase. EAESP - Escola de Administração de Empresas de São Paulo; GVcelog - Centro de Excelência em Logística e Supply Chain - Relatórios Técnicos - São Paulo, 2014. Disponível em: http://bibliotecadigital.fgv.br/dspace/handle/10438/16398 acessado em: 04/06/2017

[8] RUAS, R.L.; ANTONELLO, C.; Boff, L.H.: Aprendizagem Organizacional e Competências: novos horizontes da Gestão; São Paulo; 2005; disponível em: https://www.researchgate.net/publication/286444477_Aprendizagem_Organizacional_e_Competencias_novos_horizontes_da_Gesta o, acessado em 04/06/2017

[9] STANK, T. et al: Reimagining the 10 Megatrends That Will Revolutionize Supply Chain Logistics. Transportation Journal, Vol. 54, No. 1, Special Issue Transportation \& Supply Chain; 2015), pp. 33-54; Published by: Penn State University Press Stable URL: http://www.jstor.org/stable/10.5325/transportationj.54.1.0007; acessado em 22/05/2017

[10] TONER, P.: Workforce skills and innovation: An overview of major themes in the literature. OECD Publications, ParisFrance, 2011

[11] VERGARA, S.C: Projetos e relatórios de pesquisa em administração.16 ed. São Paulo. Atlas, 2016

[12] WONG, C.Y. et al: Logistics and supply chain education and jobs: a study of UK markets. The International Journal of Logistics Management, Vol. 25 Iss3 pp. 537 - 552 - 2014.

[13] WORLD ECONOMIC FORUM: Outlook on the logistics \& supply Chain industry 2012: Global agenda Council on Logistics \& Supply Chains 2011-2012. Geneva - Switzerland. Disponível em: http://www3.weforum.org/docs/WEF_SCT_GAC _Outlook LogisticsSupplyChainIndustry_IndustryAgenda_2012.pdf . Acessado em 12/06/2012

[14] WU, Y.F. et al: Global logistics management curriculum: perspective from practitioners in Taiwan. Supply Chain Management: An International Journal, 376 - 388 - Vol 18 - Number 4 - 2013 


\section{Capítulo 4}

Utilização do Sistema de Informação Gerencial pelos gestores de uma empresa prestadora de serviços de limpeza e conservação

\section{Grayce Fontão}

Adriano Dinomar Barp

Resumo: 0 presente estudo tem por objetivo compreender como gestores utilizam-se do Sistema de Informações Gerenciais - SIG, além do exposto visa também: identificar qual é o sistema utilizado por cada gestor, verificar a eficácia da tomada de decisões e por fim avaliar como os gestores se utilizam das informações para tomada de decisões. A pesquisa no que tange aos objetivos se classifica como descritiva, com abordagem qualitativa, o estudo de caso foi o procedimento utilizado através da aplicação de entrevista semiestruturada junto aos gestores de uma empresa prestadora de serviços na área de limpeza e conservação. 0 estudo possibilitou a compreensão de como os gestores entendem e de utilizam o SIG de diversos departamentos da empresa pesquisada. Logo, compreende-se como a empresa pode melhorar cada vez mais seu modelo de gestão para que garanta estabilidade organizacional, proporcionando crescimento constante.

Palavras-chave: Tecnologia da Informação. Sistema de Informação Gerencial. Controladoria. Tomadas de decisões. 


\section{INTRODUÇ̃̃OO}

O ambiente interno das empresas é cada vez mais composto de segmentos sendo que cada um deles prestam informações para a contabilidade, assim necessitando da tecnologia da informação para o levantamento de dados, que após passarem por tratamento, transformam-se em informações, esta é gerada para atender gestores e demais usuários que necessitam delas para tomada de decisões.

As empresas precisam, portanto, de uma estrutura de apoio que apresente relatórios gerados a partir da realização de uma contabilidade gerencial, através de gestores e de sua equipe, para assim obter vantagem competitiva, diante de um mercado cada vez mais exigente.

Para a empresa Liderança Serviços onde parte de seus valores é 'Satisfazer plenamente os clientes internos e externos', estas podem ter preocupações em comum como a rentabilidade da empresa e a continuidade de seus negócios.

Outro fator importante para a maioria das organizações é a utilização sistemas de informação para automatizar seus processos de trabalho, para armazenar e recuperar dados e para compartilhar informações (MORESI; RAMOS; PRADO, 2010).

De acordo com Oliveira e Perez Júnior (2012, p. 113), os administradores necessitam de informações confiáveis e rápidas, que possibilitem ter tomadas de decisão corretas, no intuito de alcançar as metas traçadas e superar a expectativa dos resultados delimitados de um negócio.

Tendo como um problema comum ouvir que na prática, o profissional da área contábil direciona $95 \%$ de seu tempo de trabalho e de seu esforço para o preenchimento de formulários, ou lançamentos contábeis, porem a informação para tais lançamentos dependem em geral de outros departamentos e usuários que utilizam da tecnologia da informação.

Deve ser compreendido como sendo muito mais amplo do que apenas processamento de dados, informática ou o conjunto de hardware e software, devendo ser considerados aspectos humanos, administrativos e da organização.

A empresa Liderança Serviços, com sua matriz localizada em São José, SC, possui mais de 20 mil funcionários a nível Brasil, utiliza a Tecnologia da informação em vários departamentos, como por exemplo: Diretoria, Assessoria Jurídica, Departamento Pessoal, TI\&I, Controladoria, Contingenciamento, Faturamento entre outros.

Neste contexto tem-se a seguinte questão problema: Como os gestores utilizam-se do sistema de informações gerenciais na organização?

O objetivo deste trabalho é compreender como gestores utilizam-se do sistema de informações gerenciais na organização, assim como: identificar qual sistema utilizado por cada gestor, avaliar como os gestores se utilizam das informações para tomada de decisões e verificar a eficácia da tomada de decisões.

Teoricamente o presente estudo é justificado pelas pesquisas correlatas ao tema, que foram realizadas por Löbler et al (2015) que investigaram como os gestores das organizações gaúchas percebem o impacto da Tecnologia de Informação (TI) no desempenho organizacional; Junqueira et al (2016) investigaram o efeito das escolhas estratégicas genéricas e dos sistemas de controle gerencial - SCG no desempenho organizacional de empresas de médio e grande porte localizadas no Espírito Santo. Silva et al (2017) identificaram a influência do Sistema de Informação Contábil - SIC como instrumento de apoio à geração de informações fidedignas pela Controladoria; e Eberle, Milan e Persch (2014) investigaram e compreenderam o método de gerenciamento das operações e processos, as ferramentas estratégicas utilizadas para controle dos mesmos, a influência das pessoas na execução, os métodos de gestão da produtividade e dos gargalos nos processos.

Justifica-se empiricamente a realização do presente estudo no sentido de evitar que os gestores deixem de utilizar os sistemas como ferramenta de gestão, em função da evidência que muitos deles, em sua maioria de empresas de pequeno porte são os próprios empresários, os quais tem o entendimento técnico do serviço ou produto que comercializam, mas não possuem conhecimentos gerenciais, tomando decisões com base em seu feeling e expertise, o que acarreta na maioria das vezes em lentidão no desenvolvimento do seu departamento ou da empresa como um todo. 
Os instrumentos gerenciais mais presentes na empresa objeto do estudo estão relacionados à controles financeiros, dentre os quais destacam-se: a) Diretoria: tomada de decisões com base em relatórios gerados ; b) Assessoria Jurídica: análise minutas contratuais e demandas judiciais de clientes c) Departamento Pessoal: benefícios para os funcionários, próprios e os alocados nos postos de serviços contratados d) TI\&I: suporte e desenvolvimento de sistemas e)departamento de controladoria: análise de margem de contribuição dos serviços prestados a terceiros, bem como, criticidade de contratos e valor orçado versus valor realizado f) Contingenciamento: reajustes contratuais e equilíbrio em contratos onde a margem de contribuição está fora do esperado pela empresa. Estes podem ser entendidos como os mais utilizados pelos gestores na maioria das organizações, o presente estudo visa apresentar de forma detalhada o entendimento dos gestores acerca desses instrumentos gerenciais.

Neste contexto a pesquisa pretende entender como cada um dos controles supracitados é entendido pelos gestores, além da sua percepção acerca da sua utilização e da importância no auxílio nas tomadas de decisões.

A pesquisa está estruturada: i) da presente introdução; ii) do referencial teórico que busca dar embasamento utilizando-se de outras pesquisas; iii) da metodologia onde são apresentados os instrumentos utilizados para respostas tanto da questão problema, quanto dos objetivos geral e específicos; iv) da analise das informações obtidas junto aos gestores que serão entrevistados e comporão portanto a amostra da pesquisa; por fim v) as considerações finais, onde são apresentados os principais achados, bem como as limitações e sugestões de futuras pesquisas.

\section{REFERENCIAL TEÓRICO}

O referencial teórico tem por objetivo apresentar além do conhecimento que a pesquisadora tem do tema pesquisado, estudos e percepções de outros autores em torno do referido tema, norteando-se por artigos, teses, dissertações, monografias e livros.

\subsection{TECNOLOGIA DA INFORMAÇÃO - TI}

Os estudos que avaliam o impacto da Tecnologia de Informação - TI no desempenho das organizações têm recebido grande destaque por parte dos pesquisadores. Entretanto, quase que na sua totalidade os mesmos têm observado apenas empresas de grande porte, que vai ao encontro do presente estudo. Dentre os benefícios do uso da TI tem-se: a confiabilidade, e a segurança e eficiência nas informações por ele disponibilizadas.

Neste contexto, Pinto (2016, p. 14) apregoa que "com a concorrência, as organizações vêm sendo obrigadas a investir em $\mathrm{TI}$, entretanto muitos executivos têm investido em tecnologias sem nenhum planejamento e sem mensurar o impacto organizacional, apenas reproduzindo a concorrência com medo de ficar para trás". A melhoria dos controles organizacionais, a manutenção ou aumento de sua participação no mercado, a redução de custos, são alguns dos fatores que podem motivar os executivos a investirem em diferentes tecnologias.

Segundo Pereira (2016, p. 1) “As organizações estão cada vez mais exigentes no que tange a qualidade de serviços a serem prestados. Com o avanço contínuo da TI, se faz necessário ter a mesma alinhada aos objetivos da atividade fim, sendo que a TI como atividade meio deve suportar o negócio, mas não de qualquer modo".

Tem-se, portanto que o uso efetivo da TI pode proporcionar uma série de ganhos às empresas, como o aumento da produtividade, maiores vendas, redução dos custos operacionais, aumento da base de clientes, decisões com maior qualidade. É notório que muitos são os benefícios que as boas práticas proporcionam às organizações, dentre eles destacam-se: satisfação do cliente; melhoria dos serviços prestados pela TI etc. Agregando com isso, ainda mais valor aos serviços prestados (PEREIRA, 2016).

A qualidade do serviço prestado pela área de TI segundo Löbler et al (2015, p. 483) é a variável que mais influência o desempenho das organizações na visão dos gestores, seguida pela qualidade da informação e da qualidade do sistema. Já Silva, Araújo e Primo (2015, p. 62) entendem que "o valor estratégico da TI está exigindo, por parte dos administradores, um maior conhecimento de suas peculiaridades e melhores práticas". 
Löbler et al (2015, p. 493) corroboram a afirmação acima: "A TI está cada vez mais agregando valor aos serviços prestados (agilidade na execução de tarefas, diminuindo assim o tempo de espera do cliente) e na criação de novos produtos e serviços". Em suma a TI possui uma importância crucial para a empresa. Na área de produção, por exemplo, a utilização das ferramentas de gestão de projetos, desenvolvimento e comunicação da equipe são fundamentais ao andamento dos trabalhos. Igualmente para a operação de todas as atividades terceirizadas pela empresa (SILVA, 2010).

Na maioria das empresas a adoção da TI surge em função de uma necessidade derivada dos objetivos organizacionais preestabelecidos - seja para solucionar algum problema organizacional ou até mesmo manter a empresa operando bem, levando então a necessidade de operacionalização de um Sistema de Informação Gerencial - SIG. Isso acontece de maneira particular, quando o processo está voltado para a geração de informações que são necessárias e utilizadas nas tomadas de decisões da empresa.

\subsection{SISTEMA DE INFORMAÇÃO GERENCIAL - SIG}

Na percepção de Borges e Fernandes (2016, p. 29) “A competição entre empresas faz com que haja uma melhoria de processos e produtos entre os competidores. Para que isto ocorra, muitos gestores trabalham objetivando a diferenciação e a inovação, visto que contribuem para o desempenho e, a até mesmo, para a obtenção de vantagem competitiva, e isso tende a ocorrer de uma melhor forma se houver um SIG". Os SIG propiciam evidências técnicas que permitem ao gestor conhecer melhor uma realidade que lhe oportuniza a correção de fatos desagradáveis, tais como a proteção aos colaboradores (MONACO; REDMON, 2012)

De forma geral, o SIG pode ser visto como uma importante rotina no âmbito das organizações ou, ainda, pode ser enfocado como um conjunto fortemente estruturado de rotinas. Aprofundar o nível de entendimento sobre as causas do gap que existe entre a teoria e a prática da Informação Gerencial estabelece uma estrutura fundamental para que os eventos econômicos sejam apresentados e representados para os membros da organização.

Segundo Guerreiro, Frezatti e Casado (2006, p. 71 e 72) SIG são como um conjunto de recursos e procedimentos interdependentes que interagem para produzir e comunicar informações para gestão.

Os SIG's suprem os gerentes com relatórios sobre o desempenho passado e presente da empresa. Na percepção de Junqueira et al (2016, p. 334). “As escolhas estratégicas e o SIGs possuem impacto positivo no desempenho organizacional. Além disso, empresas que combinam estratégia de diferenciação com práticas gerenciais possuem desempenho superior às demais."

Esses sistemas atendem prioritariamente ao nível hierárquico intermediário de uma organização, entretanto são bastante úteis na gestão de informações para os níveis operacionais, bem como no fornecimento de análises para o nível estratégico.

Segundo Ferreira et al (2015, p. 45) “As organizações produzem informações que interferem nas decisões e nos resultados decorrentes. Consequentemente, há necessidade de compreender os recursos disponíveis e os principais atributos da informação para tomada de decisão, aperfeiçoando o SIG".

Além de prover os meios para representar o desempenho, as regras e os procedimentos da contabilidade, também, definem os direitos dos grupos de indivíduos (donos, financiadores, gestores, trabalhadores etc.) e estabelecem as diretrizes para a implementação de ações (alocação de recursos, decisões operacionais, decisões de preços etc.).

Nesse contexto, mais do que adotar na Informação Gerencial como geradora de informações para a tomada de decisões, mas também para a maximização do lucro nas instituições.

Na percepção de Guerreiro, Frezatti e Casado (2006, p.54) “Um SIG consiste em captar e identificar os eventos econômicos, interpretar, analisar, registrar e acumular os dados relativos aos eventos e processar os dados transformando-os em informações que possam ser, de fato, utilizadas nas decisões dos gestores, dando sustentação à administração, para que atinja seus objetivos e otimize os resultados esperados".

De modo geral, existe um consenso de que um sistema de informação gerencial deve ser estratégico e contribuir para que uma organização possa alcançar os seus objetivos. 
O processo de tomada de decisão é de grande importância nas atividades a serem executadas pelas empresas e beneficia o seu sistema de operações com um melhor atendimento e desenvolvimento empresarial. É com isso que se pode ter uma maior facilidade, rapidez e cuidado durante cada processo de atividade a ser executada, (MAEHLER et al, 2016). Em um ambiente onde se aplica um SIG, definido como o conjunto de processos para transformar dados em informações que auxiliem na tomada de decisão, a importância da informação cresce na medida em que o grau de complexidade das organizações aumenta, impactando os níveis operacionais e estratégicos (FERREIRA et al, 2015).

Para entender como se dá o processo de um SIG, apresenta-se a figura1.

Figura 1: Modelo de SIG

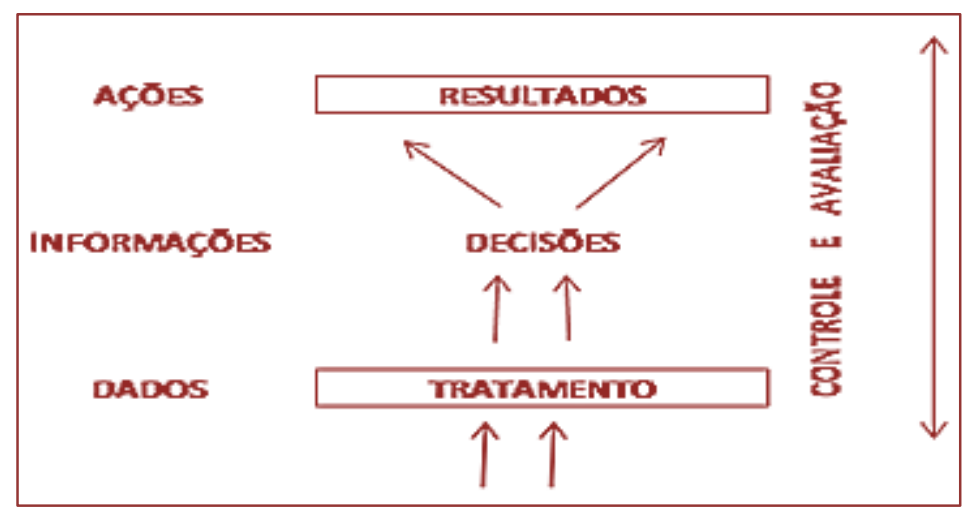

Tem-se portanto que a partir de um levantamento de dados os mesmos sofrem tratamento, tornando-se informações que auxiliam nas tomadas de decisões, onde a partir destas ações são colocadas em prática, visando o atingimento de determinados resultados, todos esses passos são controlados e avaliados, visto que, em havendo necessidade os mesmos podem ser revistos e colocados novamente em prática.

Com o atual estágio evolutivo da contabilidade, surge a necessidade de analisar, interpretar e divulgar informações econômico-financeiras para todas as partes interessadas, onde há um cuidado maior com o patrimônio empresarial por meio da identificação, mensuração, comunicação e decisão sobre os eventos econômicos. A controladoria, portanto, pode ser entendida como a ciência contábil evoluída.

\subsection{CONTROLADORIA}

O aumento da complexidade no gerenciamento das empresas tem ocasionado maior demanda por controles de gestão eficientes. Assim, o objetivo da controladoria é auxiliar no controle das atividades da empresa, monitorando permanentemente todas as etapas do processo de gerenciamento. Na percepção de Lay, Santos e Silva (2017, p. 23) "O processo de globalização e a evolução tecnológica têm gerado um cenário cada vez mais competitivo para as organizações, como também tem exigido que os profissionais de contabilidade adotem posturas cada vez mais ágeis e responsáveis na busca da eficiência e eficácia do processo de tomada de decisão".

A concorrência acirrada pode trazer riscos e incertezas, sendo necessária a utilização de ferramentas que aperfeiçoem o processo decisório, o que influencia diretamente no desempenho da empresa. A controladoria é responsável por acompanhar informações operacionais, financeiras e contábeis de uma organização, sendo os indicadores de controle ferramentas que auxiliam neste propósito (OLIVEIRA, PEREZ JUNIOR E SILVA, 2013). Neste sentido Silva et al (2017, p. 126) entendem que "É papel da controladoria, auxiliar a gestão da empresa na busca desse resultado pelo acompanhamento e controle das informações necessárias para tomada de decisão".

Analisar indicadores de controle pode contribuir para tomada de decisões mais seguras por isso se baseiam em fatos e dados que possibilitam planejar ações preventivas conseguindo minimizar as incertezas, assim, é função da controladoria o acompanhamento de todas as informações, objetivando elaborar um sistema de planejamento e controle para projetar e simular resultados operacionais, econômicos e financeiros da organização. Albuquerque et al (2013, p. 125) entendem que "a Controladoria 
representa uma evolução da Contabilidade no que diz respeito ao acesso e demanda por informações úteis ao processo decisório e a avaliação dos resultados das empresas". Ainda neste contexto de conceituação Lay, Santos e Silva (2017, p. 23) entendem a controladoria como "um ramo do conhecimento que contempla a unidade gestora das organizações".

O profissional responsável pela controladoria nas organizações é denominado controller, neste sentido, Albuquerque et al (2013, p. 124) asseveram que "Os profissionais que atuam exercendo atividades de Controladoria precisam deter diversas habilidades, no sentido de se alcançar os resultados desejados pelos gestores".

Neste viés tem-se que, as medidas financeiras indicam se as estratégias implementadas pela empresa estão contribuindo para a otimização dos resultados (OLIVEIRA, PEREZ JUNIOR E SILVA, 2013), visto que a tomada de decisão nas empresas, independentemente do seu porte, implica diretamente em custos, perdas, gastos e ganhos, portanto toda decisão pode ser considerada uma decisão financeira.

Portanto, a controladoria utilizada como estratégia pode estar voltada, por exemplo, para o departamento de compras, setor considerado crucial na grande maioria das organizações. Neste sentido Sousa et al (2016, p. 43) apontam que "A controladoria e atividade de compras, conforme sua própria denominação, deve ser respondida com exclusividade pelo gestor da área de compras, que também deverá buscar com eficiência a otimização do resultado econômico de sua área de responsabilidade".

\subsection{PESQUISAS ANTERIORES}

Para melhor entender as situações relacionadas ao estudo, buscou-se outros pesquisadores, entendo quais foram os objetivos buscados, os resultados obtidos e o instrumento utilizado pelos mesmos em seus experimentos, a busca pela referida literatura se deu na plataforma de pesquisa "Google acadêmico" que disponibiliza de forma aberta, qual seja domínio público, as pesquisas já realizadas e em sua maioria já publicadas em periódicos ou eventos das áreas, fator esse que reforça o teor científico das mesmas. Os principais estudos relacionados ao tema, estão apresentados resumidamente no quadro 1.

Quadro1: Pesquisas anteriores

\begin{tabular}{|c|c|c|c|}
\hline Autor (ano) & Objetivo & Resultado & Instrumento de Pesquisa \\
\hline $\begin{array}{c}\text { Biancolino et al } \\
\text { (2013) }\end{array}$ & $\begin{array}{l}\text { Avaliar qual é o papel das } \\
\text { competências organizacionais que } \\
\text { estão vinculadas ao universo de } \\
\text { gestão da tecnologia } S O A \text { e dos } \\
\text { sistemas ERPs no processo de } \\
\text { sustentação do valor de uso destes } \\
\text { aplicativos no cenário } \\
\text { macroeconômico brasileiro, em } \\
\text { sua perspectiva de pós- } \\
\text { implementação. }\end{array}$ & $\begin{array}{l}\text { O tema não só é um item } \\
\text { primordial na formação do } \\
\text { planejamento estratégico de TI } \\
\text { como sua aplicação tem sido } \\
\text { reconhecida como relevante } \\
\text { para os resultados das } \\
\text { empresas que adotaram esta } \\
\text { tecnologia. }\end{array}$ & $\begin{array}{l}\text { Estudo de casos múltiplos, } \\
\text { através do qual as } \\
\text { informações colhidas nas } \\
\text { empresas foram analisadas } \\
\text { em conjunto e de forma } \\
\text { cruzada, possibilitando a } \\
\text { identificação mais robusta } \\
\text { das competências } \\
\text { organizacionais e de suas } \\
\text { respectivas aderências ao } \\
\text { problema da pesquisa. }\end{array}$ \\
\hline $\begin{array}{l}\text { Eberle, Milan e } \\
\text { Persch (2014) }\end{array}$ & $\begin{array}{l}\text { Investigar e compreender o } \\
\text { método de gerenciamento das } \\
\text { operações e processos, as } \\
\text { ferramentas estratégicas } \\
\text { utilizadas para controle dos } \\
\text { mesmos, a influência das pessoas } \\
\text { na execução, os métodos de gestão } \\
\text { da produtividade e dos gargalos } \\
\text { nos processos. }\end{array}$ & $\begin{array}{l}\text { Os resultados obtidos } \\
\text { evidenciaram a importância do } \\
\text { desenvolvimento de melhorias } \\
\text { nas operações dos serviços } \\
\text { objetivando maior } \\
\text { produtividade e qualidade no } \\
\text { serviço prestado. }\end{array}$ & $\begin{array}{l}\text { Foi realizado um estudo de } \\
\text { caso numa franquia } \\
\text { prestadora de serviços de } \\
\text { limpeza e conservação. }\end{array}$ \\
\hline
\end{tabular}


(Continuação) Quadro1: Pesquisas anteriores

\begin{tabular}{|c|c|c|c|}
\hline Autor (ano) & Objetivo & Resultado & Instrumento de Pesquisa \\
\hline Löbler et al (2015) & $\begin{array}{l}\text { Investigar como os gestores das } \\
\text { organizações gaúchas percebem o } \\
\text { impacto da Tecnologia de } \\
\text { Informação (TI) no desempenho } \\
\text { organizacional }\end{array}$ & $\begin{array}{l}\text { Os resultados indicaram que a } \\
\text { TI impacta no desempenho } \\
\text { organizacional na visão dos } \\
\text { gestores das empresas } \\
\text { investigadas, sendo maior a } \\
\text { influência pela qualidade do } \\
\text { serviço prestado pela área de } \\
\text { TI, o que destaca a importância } \\
\text { do suporte técnico. }\end{array}$ & $\begin{array}{l}\text { O estudo, do tipo descritivo, } \\
\text { foi desenvolvido em duas } \\
\text { etapas. Primeiramente, } \\
\text { procedeu-se uma pesquisa } \\
\text { quantitativa, contando com } \\
\text { uma amostra de } 212 \text { gestores } \\
\text { de diferentes empresas, a } \\
\text { maioria ocupando cargos de } \\
\text { gerência. }\end{array}$ \\
\hline $\begin{array}{l}\text { Hollveg, Fores, da } \\
\text { Rosa - (2015) }\end{array}$ & $\begin{array}{l}\text { Analisar a atuação dos Sistemas de } \\
\text { Informação Integrado no } \\
\text { gerenciamento dos processos das } \\
\text { organizações e sua integração com } \\
\text { a Contabilidade. }\end{array}$ & $\begin{array}{l}\text { Verificou-se as funções que } \\
\text { mais afetam a contabilidade de } \\
\text { acordo com o nível de } \\
\text { integração de seus sistemas de } \\
\text { informação, identificou-se } \\
\text { também os estágios de } \\
\text { integração em cada módulo da } \\
\text { empresa, assim como a } \\
\text { avaliação destes módulos. }\end{array}$ & $\begin{array}{l}\text { Pesquisa combinada, } \\
\text { qualitativa e quantitativa. }\end{array}$ \\
\hline Junqueira et al (2016) & $\begin{array}{l}\text { Investigar o efeito das escolhas } \\
\text { estratégicas genéricas e dos } \\
\text { sistemas de controle gerencial } \\
\text { (SCG) no desempenho } \\
\text { organizacional de empresas de } \\
\text { médio e grande porte localizadas no } \\
\text { Espírito Santo, tendo a teoria da } \\
\text { contingência como plataforma } \\
\text { teórica. }\end{array}$ & $\begin{array}{l}\text { Empresas que combinam } \\
\text { estratégia de diferenciação com } \\
\text { práticas gerenciais } \\
\text { contemporâneas possuem } \\
\text { desempenho superior às } \\
\text { demais empresas analisadas. }\end{array}$ & $\begin{array}{l}\text { Trata-se de uma pesquisa } \\
\text { quantitativa, com a utilização } \\
\text { de um survey como técnica de } \\
\text { coleta de dados. Foram } \\
\text { validados } 73 \text { questionários, } \\
\text { respondidos pelos } \\
\text { responsáveis pela } \\
\text { controladoria ou área afim } \\
\text { dessas empresas, no período } \\
\text { de fevereiro a abril de } 2014 \text {. }\end{array}$ \\
\hline Maehler et al (2016) & $\begin{array}{l}\text { Avaliar a necessidade do uso de } \\
\text { informações contábeis gerenciais e } \\
\text { sua contribuição no gerenciamento } \\
\text { das empresas. }\end{array}$ & $\begin{array}{l}\text { A maioria das empresas deste } \\
\text { segmento pesquisada não faz } \\
\text { uso de informações contábeis } \\
\text { gerenciais no processo de } \\
\text { tomada de decisão. }\end{array}$ & $\begin{array}{l}\text { Descritiva e qualitativa, } \\
\text { embasada na pesquisa } \\
\text { bibliográfica e também um } \\
\text { estudo de multicasos, sendo } \\
\text { aplicado um questionário em } \\
\text { treze empresas do ramo de } \\
\text { transportes de cargas } \\
\text { perigosas. }\end{array}$ \\
\hline Galvão et al (2017) & $\begin{array}{l}\text { Verificar a percepção de discentes } \\
\text { da graduação em Ciências } \\
\text { Contábeis quanto aos benefícios e } \\
\text { malefícios proporcionados pela } \\
\text { inserção dos SIGS em classe e nas } \\
\text { atividades acadêmicas. }\end{array}$ & $\begin{array}{l}\text { Os resultados apontaram que os } \\
\text { discentes concordam, em maior } \\
\text { proporção, com os benefícios } \\
\text { que o uso da ferramenta pode } \\
\text { proporcionar em sala de aula. }\end{array}$ & $\begin{array}{l}\text { Descritiva, Levantamento ou } \\
\text { Survey. Quantitativa }\end{array}$ \\
\hline Silva et al (2017) & $\begin{array}{l}\text { Identificar a influência do SIC como } \\
\text { instrumento de apoio à geração de } \\
\text { informações fidedignas pela } \\
\text { Controladoria. }\end{array}$ & $\begin{array}{l}\text { Concluiu-se que o SIC possui } \\
\text { aspectos que o diferenciam dos } \\
\text { demais sistemas de informação, } \\
\text { por gerar informações em } \\
\text { formatos compativeis com as } \\
\text { diretrizes contábeis, o que } \\
\text { contribui para o aspecto da } \\
\text { qualidade operacional da } \\
\text { empresa, facilitando a tomada } \\
\text { de decisão e o levantamento de } \\
\text { informações pela Controladoria } \\
\text { com maior agilidade, } \\
\text { veracidade e segurança. }\end{array}$ & $\begin{array}{l}\text { Trata-se de um estudo } \\
\text { qualitativo cuja metodologia } \\
\text { aplicada foi a pesquisa } \\
\text { bibliográfica e documental, } \\
\text { por meio também de um } \\
\text { estudo de caso em uma } \\
\text { empresa de construção civil, } \\
\text { buscando captar a percepção } \\
\text { dos colaboradores acerca da } \\
\text { utilização do SIC como } \\
\text { ferramenta de suporte e seu } \\
\text { papel no processamento da } \\
\text { informação contábil na } \\
\text { organização. }\end{array}$ \\
\hline
\end{tabular}




\section{METODOLOGIA}

Neste tópico da pesquisa abordaremos sobre as ferramentas utilizadas na busca das respostas tanto da questão problema, quanto dos objetivos, tanto o geral quanto os específicos. Tem-se, portanto que no tange aos objetivos a presente pesquisa se classifica como descritiva qual sejam, as mesmas se referem à obtenção de informações sobre um fenômeno ou sobre determinada população e à descrição de suas características.

A pesquisa descritiva configura-se como um estudo intermediário entre a pesquisa exploratória e a explicativa, ou seja, não é tão preliminar como a primeira e nem tão aprofundada como a segunda. Nesse contexto, descrever significa identificar, relatar, comparar, entre outros aspectos (BEUREN et al, 2008).

0 estudo descritivo tem como característica exigir que o pesquisador delimite de forma precisa as técnicas, modelos, metodologia, bem como, quais as teorias que irão orientar a coleta e a interpretação dos dados, objetivando a validação científica da pesquisa. Cabe ressaltar que além do exposto se faz necessário também a delimitação da população e da amostra (BEUREN et al 2008).

Os mesmos autores continuam afirmando que a pesquisa descritiva pode ser utilizada para Beuren et al (2008 p. 81) "analise e descrição de problemas de pesquisa na área contábil. Podem ser questões, por exemplo, relacionadas as características próprias da profissão contábil em instrumentos contábeis utilizados na gestão das organizações".

Quanto à abordagem a pesquisa utiliza-se do método qualitativo, onde, a utilização da expressão investigação qualitativa, segundo Silva, (2010 p.29), nos remonta ao entendimento de estratégias de investigação que partilham determinadas características tais como: as questões a investigar não se estabelecem mediante a operacionalização de variáveis, porem se estudam os fenômenos em toda sua complexidade; a investigação, não é feita com objetivo de responder as questões previas ou testar hipóteses; privilegia, essencialmente, a compreensão dos comportamentos a partir da perspectiva dos sujeitos da investigação.

Sobre o objetivo da pesquisa qualitativa Amaral (2017, p. 295) aponta que "A pesquisa qualitativa parece identificar um caminho natural para a compreensão de fenômenos comportamentais que abrangem a gestão dos serviços informativos, tendo em vista os aspectos comportamentais do usuário da informação em relação às suas ações e práticas para se informar, destacando o seu papel como influenciador na definição da oferta de informação para atender a sua demanda".

0 procedimento utilizado foi o estudo de caso, esse procedimento tem o objetivo de mostrar sua aplicação, indica as vantagens e as limitações mais comuns encontradas e destaca o papel relevante do investigador que deverá ter cuidado com as generalizações e buscar sempre o rigor científico no tratamento da questão (VENTURA, 2007).

Para Meirinhos e Osório (2010, p.53) que apesar de diferenciadas "as características dos estudos de caso não sejam completamente coincidentes e podem sofrer alguma variação conforme as abordagens, o desenho metodológico e os aspectos a que cada autor atribui mais importância".

Percebe-se que esse tipo de pesquisa é realizado de maneira mais intensiva, em decorrência de os esforços dos pesquisadores concentrarem-se em determinado objeto de estudo. No entanto o fato de relacionar-se a um único objeto ou fenômeno constitui-se em uma limitação, uma vez que seus resultados não podem ser generalizáveis a outros objetos ou fenômenos e quando relacionado à Contabilidade, concentra maior numero de pesquisas em organizações, visando à configuração, à analise e/ou à aplicação de instrumentos ou teorias contábeis (BEUREN et al 2008).

Para coletar os dados utilizou-se como técnica de investigação a entrevista semiestruturada. Para Silva et al (2017, p. 158) a entrevista pode ser entendida como "uma comunicação verbal entre duas ou mais pessoas, com um grau de estruturação previamente definido. Excelente instrumento de pesquisa e é largamente usada no mundo das organizações, com diversas finalidades".

Como técnica de análise dos dados será utilizada a análise de discurso que na percepção de Gondim e Fischer (2009, p. 12) propõem que "Em síntese, se a análise de discurso é a análise da fala em contexto, ela ajuda a compreender como as pessoas pensam e agem no mundo concreto". Neste sentido temos o entendimento de Silva e Araújo $(2015$, p. 20) "os estudos nessa linha de pesquisa possuem sempre um caráter qualitativo interpretativista, que estuda o objeto de investigação em seu contexto natural na tentativa de dar sentido aos fenômenos levando em conta os significados que as pessoas the atribuem". 
Em um primeiro momento, cada um dos gestores, dos departamentos que comporão a amostra, foram inquiridos sobre o tema da pesquisa, as entrevistas foram gravadas e posteriormente transcritas, cujos resultados serão apresentados no próximo tópico do estudo.

Há mais de 20 anos atuando como prestadora de serviços na área de limpeza e conservação, seus recursos humanos somam mais de 23.000 colaboradores.

A empresa Liderança Serviços tem sua Matriz situada na cidade de São José/SC porem com filiais distribuídas em todo território Brasileiro. Valores como: Comprometimento, Aprendizagem, Disciplina, Eficiência e Presteza, fizeram com que a empresa Liderança esteja entre as maiores 1.000 empresas do Brasil (REVISTA EXAME, 2017).

Para que este reconhecimento nacional fosse possível, os departamentos internos da instituição que mais se destacaram e que seus gerente serão entrevistado e comporão a amostra da presente pesquisa são: i) Diretoria; ii) Assessoria jurídica; iii) Departamento pessoal; iv) TI\&I; v) Controladoria; e vi) Contingenciamento.

Além de colaboradores treinados e capacitados para a realização de suas rotinas, a empresa Liderança Serviços investe continuamente em tecnologia visando a facilitar os trabalhos da corporação.

Para estar mais presente junto a seus clientes, a instituição conta com a matriz na cidade de São José (SC), na Grande Florianópolis, e escritórios em outros 16 Estados do país, buscando assim atender todas as necessidades e facilitando a atuação da empresa em todo o Brasil.

No campo tecnológico, a empresa possui equipamentos de última geração e sistemas de informação que integram e atendem de forma ágil toda a organização. A área de TI e busca sempre por novas soluções que facilitem o trabalho de toda a equipe, mantendo assim uma maior otimização dos processos e agilidade no atendimento às solicitações.

\section{ANÁLISE DOS DADOS}

Nesta etapa da pesquisa, serão apresentados os resultados obtidos por intermédio das entrevistas, realizadas junto aos diretores dos departamentos supracitados, com o intuito de verificar quais são os SIGs utilizados, bem como, identificar qual o nível de entendimento apresentado pelos gestores sobre os citados SIGs.

Cabe ressaltar que todos os questionamentos foram feitos com igual teor para todos os departamentos, onde primeira questão apresentada foi a seguinte: Seu departamento utiliza algum sistema de informação gerencial? Em caso afirmativo: qual? Qual a sua finalidade? As respostas estão representadas no quadro 1.

Quadro1: Utilização do SIG

\begin{tabular}{|c|c|}
\hline Departamento & Resposta \\
\hline Diretoria & $\begin{array}{l}\text { Sim. O sistemas da Senior (Sapiens e Rubi) e o próprio sistema interno da empresa (Lidera } \\
\text { ERP). A finalidade é gerar relatórios para acompanhar os processos da empresa. }\end{array}$ \\
\hline Assessoria Jurídica & $\begin{array}{l}\text { Sim. Liderajurisadm. Os departamentos da empresa cadastram as demandas para a } \\
\text { Assessoria Jurídica dar andamento. Neste mesmo sistema incluímos informações do que } \\
\text { fizemos e os seus resultados obtidos (todos têm acesso). }\end{array}$ \\
\hline $\begin{array}{l}\text { Departamento } \\
\text { pessoal }\end{array}$ & $\begin{array}{l}\text { Sim. Rubi® é um sistema de administração de pessoal completo, que permite o controle } \\
\text { dos colaboradores em todos os níveis legais e gerenciais incluindo todo o departamento de } \\
\text { pessoal e tratando desde a admissão, transporte, férias e folha de pagamento, até a rescisão } \\
\text { contratual. }\end{array}$ \\
\hline TI\&I & Sim, ERP para controle e gestão. \\
\hline Controladoria & Sim, QlikView BI Dashboard. Informações Econômicas e Financeiras \\
\hline Contingenciamento & $\begin{array}{l}\text { Sim. ERP's (Lidera, ERP, Sapiens e Rubi), através desses sistemas observamos os } \\
\text { resultados gerencias no Indicadores utilizando como base o Balcend Scorecard. }\end{array}$ \\
\hline
\end{tabular}


O contexto das respostas dos gestores acerca do SIG utilizado apresenta-se de maneira específica para cada departamento, bem como, que a utilização dos mesmos se dá de forma diferenciada e que não menos diferentes as finalidades também se distinguem. Comparado ao estudo de Hollveg, Flores, Rosa (2015. p.13), onde os autores afirmam que os resultados apontam para "melhora do fluxo de informações das empresas se dá pelo aumento de integração dos subsistemas com a contabilidade".

Corroborando com os achados do estudo de Hollveg, Flores, Rosa (2015. p.13), que entendem que "Os Sistemas de Informação surgem como um importante aliado no gerenciamento dos processos e busca por informações apuradas, onde o empresário procura por ferramentas que estão ao seu alcance de modo a obter vantagens competitivas para impulsionar seu negócio".

Entendida a utilização e finalidade do SIG, passou-se para a segunda questão, onde os respondentes foram assim inquiridos: Foi necessário alterar a estrutura do departamento para a implantação do SIG? As respostas estão representadas no quadro 2.

Quadro2: Implantação do SIG

\begin{tabular}{|c|l|}
\hline \multicolumn{2}{|c|}{ Departamento } \\
Diretoria & $\begin{array}{l}\text { Não. Pois os sistemas foram implantados quase junto com a fundação da empresa, } \\
\text { portanto já existiam quando o departamento da assessoria da direção foi criado. }\end{array}$ \\
\hline Assessoria Jurídica & Não. \\
\hline Departamento pessoal & Não. \\
\hline TI\&I & $\begin{array}{l}\text { Não, no entanto fizemos algumas customizações em nosso SIG para se adequar às } \\
\text { nossas necessidades. }\end{array}$ \\
\hline Controladoria & $\begin{array}{l}\text { Sim, atualmente existe um recurso que cuida exclusivamente da manutenção deste } \\
\text { sistema. }\end{array}$ \\
\hline Contingenciamento & Não. \\
\hline
\end{tabular}

Diferente do estudo feito por Caldas e Wood Jr (1999. p.2) que "argumentam que algumas estratégias de implantação são em muitos casos, inadequadas e que os resultados sejam decepcionantes". Percebe-se que na empresa pesquisada a estrutura em sua maioria foi definida previamente, adequando-se a necessidade da companhia, integrando os departamentos da empresa com a obtenção de informações em tempo real e agilizando com isso o processo de tomada de decisão.

Outra questão importante dentro das organização é a manutenção do SIG atualizado, dentro deste contexto perguntou-se: Como é feita a retroalimentação dos dados no sistema? As respostas estão representadas no quadro 3.

Quadro3: Retroalimentação do SIG

\begin{tabular}{|c|l|}
\hline \multicolumn{2}{|c|}{ Departamento } \\
\hline Diretoria & $\begin{array}{l}\text { Não é feita a alimentação dos dados por este departamento (assessoria da direção), apenas } \\
\text { é analisado as informações geradas por outros departamentos. }\end{array}$ \\
\hline Assessoria Jurídica & $\begin{array}{l}\text { Sempre que o setor toma alguma ação ou recebemos resposta das nossas ações o sistema é } \\
\text { alimentado, portanto, diariamente movimentamos o sistema. }\end{array}$ \\
\hline $\begin{array}{c}\text { Departamento } \\
\text { pessoal }\end{array}$ & $\begin{array}{l}\text { É feito pelo Depto Tecnologia da Informação da Empresa, que atualiza as versões assim que } \\
\text { a Sênior (Sênior Sistemas é a desenvolvedora do software.) disponibiliza, que no caso não } \\
\text { tem uma periodicidade. }\end{array}$ \\
\hline TI\&I & $\begin{array}{l}\text { Diário, Departamento de TI é que mantem o SIG e os demais 400 usuários fazem a } \\
\text { alimentação no SIG. }\end{array}$ \\
\hline Controladoria & Em cargas noturnas diárias. \\
\hline Contingenciamento & $\begin{array}{l}\text { A alimentação das informações é diária. Para o Contingenciamento as informações são } \\
\text { alimentadas pelo Operacional e Dpto pessoal, porém para o Contingenciamento consegue } \\
\text { verificar os dados somente após o fechamento do mês. }\end{array}$ \\
\hline
\end{tabular}
Fonte: Dados primários da pesquisa

É possível entender que os resultados encontrados apontam para um entendimento de não haver um regramento na alimentação de dados nos sistemas de cada departamento, mas que ao mesmo tempo 
apresenta-se certa integração entre eles no que tange a utilização das informações. Vindo ao encontro do estudo de Hollveg, Flores, Rosa (2015. p.02), onde os resultados apontam para "Utilização de sistemas de informações integrados entre os departamentos da empresa, cada departamento será um subsistema abastecido de informações".

Neste contexto é necessário que as empresas devessem estar atentas ao treinamento dos usuários, pois eles serão os responsáveis pela alimentação do sistema com os dados, sendo fundamentais para o sucesso e boa utilização do sistema, visto que os mesmos resultarão em informações que auxiliarão nas tomadas de decisões. Tem-se, portanto, que o usuário do sistema precisa estar consciente da importância de alimentar os dados corretamente e de forma tempestiva além, de estar ciente das consequências que podem advir de seu erro.

Seguindo a entrevista o próximo questionamento foi: Na sua percepção quais são as principais vantagens de se manter um SIG regularmente? As respostas estão representadas no quadro 4.

Quadro 4: Manter um SIG regularmente

\begin{tabular}{|c|c|}
\hline Departamento & Resposta \\
\hline Diretoria & A facilidade de obter as informações e de gerenciar os processos da empresa. \\
\hline Assessoria Jurídica & $\begin{array}{l}\text { Agilidade nos processos em geral. Facilidade para os envolvidos tomarem ciência quanto } \\
\text { ao que está ou não sendo feito pelo setor (AJ). }\end{array}$ \\
\hline Departamento pessoal & $\begin{array}{l}\text { Ganhamos eficiência e agilidade nos processos, integração de todas as informações em } \\
\text { um único lugar. Oferece soluções que maximizam os resultados das principais tarefas do } \\
\text { setor, entre elas a Administração de Pessoal, Avaliação por Competências, Cargos e } \\
\text { Salários, Controle de Benefícios, Controle de Frequência, Medicina do Trabalho, Controle } \\
\text { de Custos, Processos Trabalhistas, Folha de Pagamento, Recrutamento e Seleção, } \\
\text { Convênios e Treinamento. }\end{array}$ \\
\hline TI\&I & Agilidade e precisão nas informações gerenciais. Alertas em anomalias no \\
\hline Controladoria & $\begin{array}{l}\text { Agilidade na obtenção de informações padronizadas, automação de relatórios, geração de } \\
\text { histórico de dados, etc. }\end{array}$ \\
\hline Contingenciamento & $\begin{array}{l}\text { Acesso rápido as informações para tomada de decisão; Acompanhamento semanal } \\
\text { (manual) dos indicadores mensais; }\end{array}$ \\
\hline
\end{tabular}

Fonte: Dados primários da pesquisa

Para ser possível um melhor entendimento da manutenção de um SIG dentro da organização, se faz necessário o entendimento do conceito de controladoria, que na percepção de Morante e Jorge (2009, p. 1): "Para ser exercida em toda sua plenitude, a controladoria precisa ser conduzida por profissional experiente, com larga vivência em finanças empresariais e uma particular habilidade no relacionamento com os responsáveis pela gestão das diversas áreas funcionais da organização".

Agilidade e precisão nas informações é um consenso no que tange tomada de decisões e que as informações são geradas através da utilização de processos para os usuários dos SIG.

Os processos e SIGs utilizados para apoio aos gestores na manutenção de suas atividades se tornam responsáveis pelo controle econômico da entidade para que a mesma tenha condições de exercer sua missão. Corroborando com o estudo de Junqueira et al (2016, p.337) "para a obtenção de vantagem competitiva é necessário um ajuste entre o SIG e a estratégia organizacional”. Os autores argumentam ainda que "o SIG possui um papel proativo no processo de mudança estratégica".

O próximo questionamento feito aos gestores após observar que todos eles utilizam SIG para tomada de decisões, foi: Ao adotar o SIG regular, houve melhorias no seu setor? Em caso afirmativo qual(is)? As respostas estão representadas no quadro 5. 
Quadro 5: Melhorias no setor através do SIG

\begin{tabular}{|c|c|}
\hline Departamento & Resposta \\
\hline Diretoria & $\begin{array}{l}\text { Sim. Hoje conseguimos gerenciar melhor os processos, detectar os problemas de forma } \\
\text { mais rápida, e corrigi-los. Como a empresa é de grande porte, nem iríamos conseguir } \\
\text { fazer um gerenciamento dos processos se não tivéssemos um SIG. }\end{array}$ \\
\hline Assessoria Jurídica & $\begin{array}{l}\text { Sim. Controle de processos para não cair no esquecimento. Controle dos processos para } \\
\text { obter informações sempre que necessário. }\end{array}$ \\
\hline Departamento pessoal & $\begin{array}{l}\text { Para a Empresa o reflexo da utilização do sistema Rubi® vem no aumento da } \\
\text { competitividade através da economia de tempo, redução de custos e qualidade nos } \\
\text { resultados. }\end{array}$ \\
\hline TI\&I & $\begin{array}{l}\text { Sim, os indicadores são atualizados de forma instantânea e com isto podemos } \\
\text { identificar de imediato as anomalias. }\end{array}$ \\
\hline Controladoria & $\begin{array}{l}\text { A agilidade na obtenção de informações complexas, padronização da informação, } \\
\text { automação de relatórios, e a disponibilidade de informação histórica. }\end{array}$ \\
\hline Contingenciamento & $\begin{array}{l}\text { Sim. É perceptível a melhora nas entrega e nos processos do setor, também } \\
\text { identificamos gargalos e rupturas, onde atuamos para melhorar as atividades (em } \\
\text { alguns casos automatizando) com isso conseguimos reduzir alguns prazos (envio dos } \\
\text { pedidos ao cliente e recebimento do mesmo). }\end{array}$ \\
\hline
\end{tabular}

Fonte: Dados primários da pesquisa

Para o sucesso de um sistema, é necessária a participação de todos os envolvidos na esquematização das informações. É imprescindível que as pessoas estejam comprometidas e isso é conseguido com a participação de técnicos e usuários para a elaboração e discussão dos procedimentos. Ao participar do processo, o funcionário fica comprometido com sua implantação, uso e sucesso. É necessário motivar através da sua participação na definição dos serviços.

O estudo feito por Maehler et al $(2016$, p. 2) apontam que "Os relatórios gerenciais são documentos que reúnem informações, dados e análises sobre uma determinada situação da empresa. Podem ser relatórios financeiros, de produtividade ou mesmo de controle para melhoria e qualidade contínua".

Neste sentido Carteri e Rodrigues (2011, p. 4), em seu estudo apontam para "a retroalimentação ou feedback do sistema que pode ser analisado como a reintrodução de uma saída que foi fornecida sob a formato de informação. 0 feedback tem como finalidade ajustar as informações que foram realimentadas, resultantes dos desacordos observados entre os objetivos que foram definidos e as saídas que serão produzidas".

Dentro deste contexto As informações geradas refletem a realidade da empresa? As respostas estão representadas no quadro 6.

Quadro 6: Realidade da empresa

\begin{tabular}{|c|c|}
\hline Departamento & Resposta \\
\hline Diretoria & Sim. O SIG, são informações sempre atualizadas, confiáveis e precisas. \\
\hline Assessoria Jurídica & Sim. \\
\hline Departamento pessoal & Sim. \\
\hline TI\&I & $\begin{array}{l}\text { Sim, os dados são gerados conforme alimentação dos dados e validados de } \\
\text { forma automática pelas regras pré-configuradas pelas gestões. }\end{array}$ \\
\hline Controladoria & $\begin{array}{l}\text { Totalmente, os dados carregados no BI são extraídos dos sistemas oficiais da } \\
\text { organização, sem manipulações. }\end{array}$ \\
\hline Contingenciamento & Sim. \\
\hline
\end{tabular}


A Utilização de SIGS otimiza o fluxo de informações e facilita o acesso aos dados operacionais, favorecendo a adoção de estruturas organizacionais mais achatadas e flexíveis. Além disso, as informações tornam-se mais consistentes, possibilitando a tomada de decisão com base em dados que refletem a realidade da empresa.

Ao encontro do estudo feito por Silva et al (2017, p.63) constata-se a importância do SIG em relação à facilidade no planejamento, controle, avaliação de desempenho e tomada de decisão, facilidade de acesso às informações financeiras e econômicas da empresa e segurança, confiabilidade e exatidão nos relatórios oferecidos e extraídos pelos SIGS.

As informações geradas são utilizadas nas decisões diárias? Em caso afirmativo, exemplifique. As respostas estão representadas no quadro 7.

Quadro 7: Tomada de decisões

\begin{tabular}{|c|c|}
\hline Departamento & Resposta \\
\hline Diretoria & $\begin{array}{l}\text { Sim. Utilizamos diversos relatórios para o controle e definições da diretoria. } \\
\text { Como por exemplo, geramos diariamente o relatório de Volantes (Reservas } \\
\text { Técnicas) para saber quanto gastamos com reserva técnica e através dessa } \\
\text { informação percebemos se precisamos diminuir o número de volantes, ou não. }\end{array}$ \\
\hline Assessoria Jurídica & $\begin{array}{l}\text { As informações inseridas no sistema decorrem de decisões diárias. Não o } \\
\text { contrário. }\end{array}$ \\
\hline Departamento pessoal & $\begin{array}{l}\text { Sim. No gerenciamento dos custos administrativos e operacionais, } \\
\text { principalmente nas tomadas de decisões efetuadas pelas Gerencias e } \\
\text { Presidência. }\end{array}$ \\
\hline TI\&I & $\begin{array}{l}\text { Sim, nossa empresa conta com um sistema avançado de indicadores e alertas } \\
\text { diários através de e-mails RMS (Report Manager System) }\end{array}$ \\
\hline Controladoria & $\begin{array}{l}\text { Todas as informações relacionadas ao resultado gerado pelos contratos são } \\
\text { disponibilizadas a partir do BI, com isso são utilizadas na tomada de decisão do } \\
\text { rumo do negócio diariamente. }\end{array}$ \\
\hline Contingenciamento & $\begin{array}{l}\text { Sim. O setor de Contingenciamento controla todas as atividades de forma a } \\
\text { atender o esperado pela empresa. Também trabalhamos com vários RMS que } \\
\text { nos apontam as demandas que devemos atender, tudo amarrado aos } \\
\text { Indicadores do setor e da empresa. }\end{array}$ \\
\hline
\end{tabular}

Fonte: Dados primários da pesquisa

É notório que as empresas mais do que nunca precisam estruturar e transformar os dados em informações úteis para as tomadas de decisões. Neste sentido Armelin, Silva e Colucci (2016, p. 24) "A organização de dados é uma das atividades mais importantes de uma organização. 0 bom gerenciamento de um banco de dados é determinante para melhorar a eficiência dos processos - incluindo o de tomada de decisão - pelo fato de tornar mais ágil o acesso à informação".

Assim a informação correta e no momento certo vem auxiliando sobremaneira aos gestores, Assim, Armelin, Silva e Colucci (2016, p. 27) entendem que as organizações visualizaram a aquisição de conhecimento: "A partir do momento em que as empresas perceberam a importância estratégica da boa administração do conhecimento gerado dentro delas, apareceram os sistemas de gestão de conhecimento, desenvolvidos para dar suporte à criação, coleta, organização e disseminação desses conhecimentos".

Os relatórios gerenciais são documentos que reúnem informações, dados e análises sobre uma determinada situação da empresa. Podem ser relatórios financeiros, de produtividade ou mesmo de controle para melhoria e qualidade contínua. Esses documentos são grandes auxiliares na tomada de decisões sobre a empresa e servem como base para o aprimoramento constante do negócio, mais uma vez comparado ao estudo de (MAEHLER et al, 2016). 


\section{CONSIDERAÇÕES FINAIS}

0 estudo teve como objetivo compreender como gestores utilizam-se do sistema de informações gerenciais na organização, assim como: identificar qual sistema utilizado por cada gestor, verificar a eficácia da tomada de decisões e avaliar como os gestores se utilizam das mesmas. Partindo-se dos relatos dos gestores dos principais departamentos da organização.

Tem-se, portanto como principais resultados que o SIG utilizado pela organização atende as demandas dos gestores, visto que na percepção dos mesmos o referido SIG é utilizado de forma diferenciada para as mais diversas finalidades, onde os gestores apontaram ainda para os sistemas propriamente ditos que são utilizados, quais sejam: Sapiens, Rubi. Lidera ERP, Liderajurisadm, QlikView e BI Dashboard.

De maneira unânime os gestores afirmam que não se fizeram necessárias alterações estruturais para implantação do sistema, o que facilita a sua utilização.

No que tange a retroalimentação o destaque a ser apresentado reside no fato de que a mesma se dá diariamente, para tanto os responsáveis são treinados para entender a importância do trabalho por eles realizada.

Os respondentes entendem que a manutenção do sistema se apresenta como de suma importância para a geração de informações tempestivas e fidedignas, com isso as melhorias são visíveis, visto que as decisões são tomadas com maior precisão, mitigando o risco de erro.

Novamente de forma unânime os gestores afirmam que as informações geradas pelo SIG refletem a verdadeira situação que a empresa se encontra em um determinado momento.

Reiterando também que o acesso rápido às informações facilitam as tomadas de decisões, onde todos os respondentes asseveram que as informações geradas são utilizadas nas tomadas de decisões de maneiras diferentes, mas com o mesmo intuito, qual seja, entende quanto se gasta com reserva técnica, possibilitando o aumento ou a diminuição dos custos associados à essa ação; no gerenciamento dos custos administrativos e operacionais; avaliação dos resultados para dar direcionamento às próximas providencias de manutenção do que está dando certo e ajustes necessários ao que não está dando tão certo e controlando as atividades desenvolvidas, analisando se a mesmas estão atendendo o que foi estabelecido previamente.

Neste contexto, o estudo proporcionou compreensão das formas com que os gestores dos diversos departamentos de uma empresa prestadora de serviços, entendem e se utilizam de um SIG. Logo, compreende-se como a empresa pode melhorar cada vez mais seu modelo de gestão para que garanta estabilidade organizacional, proporcionando crescimento constante.

Como limitação da presente pesquisa tem-se que nem todos os departamentos da empresa participaram da amostra, fato esse que faz com que não se possam generalizar os achados do presente estudo.

Neste viés apresenta-se como sugestão para estudos futuros que a presente pesquisa possa ser desenvolvida, sob a forma de estudo de caso, buscando relacionar o SIG das empresas com as práticas de gestão como forma de aprendizagem organizacional em outras organizações de outras regiões do país, bem como, de outros ramos de atividade, proporcionando assim a possibilidade de se traçar um comparativo.

\section{REFERÊNCIAS}

[1] ALBUQUERQUE, Lúcia Silva, LIMA, Aline Pereira de; RÊGO, Thaiseany de Freitas, CARVALHO, José Ribamar Marques de. Análise Bibliométrica dos Artigos Sobre Controladoria Publicados no Congresso USP de Controladoria e Contabilidade no Período de 2004 a 2010. Revista Evidenciação Contábil \& Finanças, ISSN 2318-1001, João Pessoa, v.1, n. 2, p. 123-138, jul./dez. 2013.

[2] AMARAL, Sueli Angélica do. Abordagem metodológica qualitativa e a pesquisa brasileira sobre marketing na Ciência da Informação. Investigação Qualitativa em Ciências Sociais. Investigación Cualitativa en Ciencias Sociales. Volume 3. 2017.

[3] ARMELIN, Danylo Agusto, SILVA, Simone Cecília Pelegrini da, COLUCCI, Claudio. Sistemas de informação gerencial. Londrina : Editora e Distribuidora Educacional S.A., 2016.236 p.

[4] BEUREN, Ilse Maria; LONGARAI, André Andrade, RAUPP, Fabiano Maury, SOUZA, Marco Aurélio Batista de, COLAUTO, Romualdo Douglas, PORTON, Rosimeri Alves de Bona. Como elaborar trabalhos monográficos em contabilidade: Teoria e prática. 1. ed. São Paulo: Atlas, 2008. 
[5] BIANCOLINO, Cesar Augusto; SAKATA, Marici Cristine Gramacho; RICCIO, Edson Luiz; MACCARI, Emerson Antônio. Gerenciamento por Competências Como Base da Flexibilização dos Sistemas ERP no Cenário Macro Econômico Brasileiro: Estudo de Casos Múltiplos. Revista de Sistemas e Computação, Salvador, v. 3, n. 1, p. 78-90, jan./jun. 2013.

[6] BORGES, Gustavo da Rosa; FERNANDES, Francisco Carlos. A Contribuição do Sistema de Informação Gerencial para a Obtenção de Vantagem Competitiva. SINERGIA, Rio Grande, 20 (1): 29-40, 2016.

[7] CALDAS, Miguel P.; WOOD JÚNIOR, Thomas. Modas e modismos em gestão: pesquisa exploratória sobre adoção e implantação de ERP. Foz do Iguaçu. Anais do Enanpad 1999, 1999.

[8] CARTERI, Gláucia Maria; RODRIGUES, Pabblo Abadia Miranda. SIG: Sistema de Informação Gerencial Como Ferramenta De Apoio As Empresas. Interdisciplinar - Revista Eletrônica da Univar. 2011. n.5 p.1-9.

[9] EBERLE, Luciene; MILAN, Gabriel Sperandio; PERSCH, Leonice Link. Gerenciamento de Processos, Pessoas e Produtividade: Um Estudo de Caso Ambientado em uma Empresa de Prestadora de Serviços de Limpeza e Conservação. Revista Global Manager v. 14, n. 1, p. 60-73, 2014.

[10] FERREIRA, Deosio Cabral; SILVA, Roni Braz da; SILVA, Wallace Alves da; MELO, Daniel Reis Armond de; SOUZA, Waldemar Antonio da Rocha de. Avaliação do Sistema de Informações Gerenciais da Assembleia Legislativa do Amazonas. Contabilidade, Gestão e Governança - Brasília • v. 18 •n. 2 · p. 45-68 · mai./ago. 2015.

[11] GALVÃO, Nadielli Maria dos Santos; SANTOS, Luana leite Pereira dos; LIMA, Andreza Cristiane Silva de; SILVA, Magda Vanessa Souza da; FERREIRA, Paulecy Nunes. Percepção dos Discentes quanto ao Uso de Sistemas de Informações Gerenciais nas Atividades Acadêmicas: um Estudo no Curso de Ciências Contábeis. Pensar Contábil, Rio de Janeiro, v. 19, n. 69, p. 18-29, maio/ago. 2017.

[12] GONDIM, Sônia Maria Guedes; FISCHER, Tânia. O Discurso, a Análise de Discurso e a Metodologia do Discurso do Sujeito Coletivo na Gestão Intercultural. Cadernos Gestão Social, Salvador, v.2, n.1, p.09-26, set.-dez. 2009.

[13] GUERREIRO, Reinaldo; FREZATTI, Fábio, CASADO, Tânia. Em Busca de um Melhor Entendimento da Contabilidade Gerencial Através da Integração de Conceitos da Psicologia, Cultura Organizacional e Teoria Institucional. Revista Contabilidade \& Finanças - USP, vol. 17, Setembro, 2006, pp. 7-21.

[14] HOLLVEG, Scheila Daiana Severo; FLORES, Jeferson de Souza; ROSA, Leandro Cantorski da. A Produção de Informações Gerenciais a Partir de Sistemas Integrados a Contabilidade. Revista ESPACIOS, Vol. 36, n12, 2015.

[15] JUNQUEIRA, Emanuel; DUTRA, Eduardo Viera; ZANQUETTO FILHO, Helio; GONZAGA, Rosimeire Pimentel. Efeito das Escolhas Estratégicas e dos Sistemas de Controle Gerencial no Desempenho Organizacional. Revista Contabilidade \& Finanças - USP, vol. 27, núm. 72, setembro/dezembro, 2016, pp. 334-348.

[16] LAY, Luís Antônio; SANTOS, Cleston Alexandre dos; SILVA, Márcia Zanievicz da. Estrutura Conceitual Básica de Controladoria nos Artigos Sobre Controladoria em Periódicos Nacionais de Contabilidade. Revista Perspectivas Contemporâneas, v. 12, n. 1, p. 22-45, jan./abr. 2017.

[17] LÖBLER, Mauri Leodir; VISENTINI, Monize Sâmara; BASSO, Lara Denise; TAGLIAPIETRA, Rafaela. Investigando o Impacto da Tecnologia da Informação no Desempenho Organizacional. Revista Eletrônica Sistemas \& Gestão. Volume 10, Número 3, 2015, pp. 482-495

[18] MAEHLER, Carine; SILVA, Luciana Kulau da; COVARY, Alessandra; VIEIRA, Franciele; BRASIL, Mariana Moura; VIEIRA, Euselia Paveglio. A Relevância de Informações Contábeis Gerenciais na Tomada de Decisões em Transportadoras de Cargas Perigosas da Região Noroeste do Estado do Rio Grande do Sul - XXIV Seminário de Iniciação Científica - 2016.

[19] MEIRINHOS, Manuel; OSÓRIO, Antônio. O estudo de caso como estratégia de investigação em educação. EDUSER: revista de educação, Vol 2(2), 2010.

[20] MONACO, Kristen; REDMON, Brydey. Does contracting with owner operators lead to worse safety outcomes for US motor carriers? Evidence from the Motor Carrier Management Information System. Accident Analysis \& Prevention, v. 45, p. 654-659, 2012.

[21] MORANTE, Antonio Salvador; JORGE, Fauzi Timaco. Controladoria: análise financeira, planejamento e controle orçamentário. São Paulo: Atlas, 2009.

[22] MORESI, Eduardo Amadeu Dutra; RAMOS, Rosana Guedes Cordeiro; PRADO, Hércules Antônio do. Mapeamento de informações organizacionais: um estudo na Embrapa. TransInformação, v. 22, n. 2, p. 101-110, 2010.

[23] OLIVEIRA, Luis Martins de; PEREZ JÚNIOR, Jose Hernandes. Contabilidade de Custos para não contadores. 5. ed. São Paulo: Atlas, 2012.

[24] OLIVEIRA, Luís Martins de; PEREZ JUNIOR, José Hernandez; SILVA, Carlos Alberto dos Santos. Controladoria estratégica. 9. ed. São Paulo: Atlas, 2013. 
[25] PEREIRA, Fábio Tibúrcio Bonifácio. Governança de TI: Gerenciamento dos Serviços de TI nas Organizações. Universidade Tecnológica Federal do Paraná - UTFPR Curitiba - Paraná - Brasil - n.16, p. 1-10, 2016.

[26] PINTO, Alinde de Vargas. O Impacto da Adoção de Tecnologias da Informação no Desempenho Organizacional das Micro e Pequenas Empresas. Monografia. Departamento de Ciências Administrativas da Universidade Federal do Rio Grande do Sul. Porto Alegre. 2016.

[27] REVISTA EXAME, São Paulo, edição 1147, ano 50. 11 out. de 2017.

[28] SILVA, Antonio Carlos Ribeiro da. Metodologia da Pesquisa aplicada à contabilidade: orientações de estudos, projetos, artigos, relatórios, monografias, dissertações, teses. 3. ed. São Paulo: Atlas, 2010.

[29] SILVA, Cristiano Moreira; SILVA, José Ronaldo da; PEREIRA, Victor Hugo; SILVA, Davson Mansur Irffi. A Influência do Sistema de Informação Contábil como Instrumento de Apoio à Geração de Informações Fidedignas pela Controladoria: Um Estudo de Caso. SINERGIA, Rio Grande, 21 (1): 53-66, 2017.

[30] SILVA, Jonathan Chasko da; ARAÚJO, Alcemar Dionet de. A Metodologia de Pesquisa em Análise do Discurso. Grau Zero - Revista de Crítica Cultural, v. 5, n. 1, 2017.

[31] SILVA, Humberto Caetano Cardoso da; ARAÚJO, Marcus Augusto Vasconcelos; PRIMO, Marcos André Mendes. Antecedentes da Retenção de Clientes Pós-Falha e Recuperação de Serviços de Tecnologia da Informação em Ambientes Business-to-Business. Revista de Gestão e Projetos - GeP Vol. 6, N. 3. Setembro/Dezembro. 2015.

[32] SOUSA, Adail José de; NOBRE, Fábio Chaves; PADOVEZE, Clóvis Luís; CALIL, José Francisco. Controladoria na Gestão de Compras como Estratégia na Busca da Eficiência e Otimização do Resultado Econômico. Management Control Review, v. 1, n. 1, 2016.

[33] VENTURA, Magda Maria. O Estudo de Caso como Modalidade de Pesquisa. Rev SOCERJ. 2007;20(5):383-386 setembro/outubro 


\section{Capítulo 5}

Avaliação da atividade de coleta seletiva à luz da PNRS: Um estudo na cidade de Belém - PA

\section{Juliana Ribeiro Ranieri}

Vivian Tereza de Souza Ferreira

André Cristiano Silva Melo

Rodrigo Rangel Ribeiro Bezerra

Denilson Ricardo de Lucena Nunes

Resumo: No Brasil, apesar de alguma evolução decorrente da sanção e aplicação de instrumentos regulatórios, na prática, os resultados de ações de coleta seletiva (CS) ainda são pouco expressivos. em Belém (PA), a CS acontece por meio de cooperativas e associações de profissionais catadores que realizam um roteiro de coleta nos bairros. 0 presente artigo teve por objetivo analisar a CS atualmente desenvolvida em Belém e verificar se está em conformidade com a atual legislação, já que tal atividade é bastante complexa do ponto de vista logístico e que Belém está localizada em uma região de $1.059,46 \mathrm{~km}^{2}$, com população de 1.393 .399 habitantes. Como método, foi realizada uma pesquisa bibliográfica, seguida de levantamento de dados de fontes primárias, por meio de entrevistas com agentes ligados ao serviço, e observações de operações in loco. A partir disso, foi mapeado o atual processo de CS, sendo este analisado de acordo com a legislação. Foi constatado que a CS realizada atualmente tem sido pouco efetiva e, assim, para as não conformidades identificadas, foram propostas mudanças no atual processo, com vistas a melhoria do serviço prestado.

Palavras-chave: Gerenciamento de Resíduos Sólidos; Política Nacional de Resíduos Sólidos; Logística Reversa; Coleta Seletiva. 


\section{INTRODUÇÃO}

Com o crescimento da população, cresce também a produção de Resíduos Sólidos (RS) que hoje chega a níveis alarmantes. Para piorar, grande parte dos RS é lançada a céu aberto o que é degradação ambiental e um enorme desperdício de matéria-prima e energia (SILVA, 2011), constituindo uma séria ameaça ao planeta.

De acordo com MMA (2016), RS constituem qualquer tipo de material ou substância no estado sólido ou semissólido, além de gases contidos em recipientes e líquidos com características que tornam inviável seu lançamento em rede pública de esgotos ou em corpos d'água, resultante de atividades humanas em sociedade.

Segundo Fonseca et al. (2015), a crescente geração de RS demanda ações, como manipulação, tratamento e descarte adequados, para redução de impactos ambientais. Para tal, foi sancionada no Brasil a Lei 12.305/10, que instituiu a Política Nacional de Resíduos Sólidos (PNRS), a qual orienta a destinação ambientalmente adequada de RS, conferindo grande destaque a reciclagem; responsabilidade compartilhada pelo ciclo de produto; fomento, criação e manutenção de cooperativas e associações de catadores de materiais recicláveis e prática da Logística Reversa (LR).

o Gerenciamento de Resíduos Sólidos (GRS) é definido como ações exercidas para a destinação (resíduos) e disposição (rejeitos) finais ambientalmente adequadas, de acordo com planos municipais de gestão integrada ou planos de gerenciamento de resíduos, nas etapas de coleta, transporte, transbordo e tratamento. Assim, um dos principais objetivos da PNRS é a ordem de prioridades para o GRS, que são: não geração; redução; reutilização e tratamento aos resíduos; e disposição final ambientalmente adequada aos rejeitos (BRASIL, 2010a).

Já a LR é definida pela PNRS como instrumento de desenvolvimento socioeconômico, identificado por ações e meios direcionados a viabilizar a coleta e restituição de RS, para reaproveitar, em seu ciclo ou outros ciclos produtivos, ou outra destinação final ambientalmente adequada (BRASIL, 2010a; MMA, 2016). Em linhas gerais, a LR visa a recuperação de produtos, para reincorporá-los aos ciclos produtivos e de negócios, relacionando-a à Coleta Seletiva (CS), já que ambos objetivam reuso de resíduos (MARCHI, 2011). Assim, CS e LR são atividades, indicadas pela PNRS que, se exercidas de forma integrada e coordenada, contribuirão à preservação do meio ambiente, aumento da qualidade de vida e redução de custos.

A CS, foco desta pesquisa, constitui a coleta de RS previamente segregados conforme a sua constituição ou composição (MMA, 2016), tendo como premissa a implementação de estratégias de EA, com vistas a mobilização, participação e conscientização da sociedade sobre os impactos gerados pela poluição e desperdício de recursos naturais.

Esta pesquisa buscou uma base teórica que relacionou GRS, PNRS, LR e CS, considerando o atual processo de CS desenvolvido pela Secretaria Municipal de Saneamento (SESAN) de Belém-PA, em parceria com cooperativas e associações de catadores credenciadas na Prefeitura desta cidade. Após a revisão da literatura, foi descrito o método de pesquisa, destacando-se etapas, ferramentas e estratégias utilizados. Para alcançar o objetivo proposto, que foi analisar e avaliar o atual processo de CS desenvolvido, considerando sua execução em conformidade com o Decreto 7.404/2010, propondo as melhorias cabíveis. Neste artigo, foram apresentados o contexto atual da CS, a proposta de melhorias e as considerações finais, ressaltando as restrições encontradas, que poderão ser discutidas e analisadas de maneira mais específica em trabalhos futuros.

\section{REVISÃO DA LITERATURA}

\subsection{GERENCIAMENTO DE RESÍDUOS SÓLIDOS - GRS}

Segundo Lima (2014), um dos princípios instituídos pela PNRS foi a visão sistêmica no GRS, devendo-se abordar aspectos ambientais, sociais, culturais, econômicos, tecnológicos e de saúde pública. 0 estudo mostrou ainda que o reconhecimento de RS passíveis de reuso e reciclagem é um bem de valor econômico e social, e de desenvolvimento sustentável.

O GRS envolve todos os resíduos e deve ser abordado de modo completo, por ser uma atividade de tamanha complexidade. Assim, o correto GRS deve obedecer a leis nacionais, estaduais e municipais, além de estar alinhado com as tecnologias mais modernas do mundo (PORTAL RESÍDUOS SÓLIDOS, 2017). 
A maioria das prefeituras ainda não dispõem de recursos técnicos e financeiros para solucionar os problemas ligados ao GRS. Ignora-se, muitas vezes, possibilidades de parcerias com segmentos a serem envolvidos na gestão e busca de alternativas à implementação de soluções. Raramente utiliza-se possibilidades e vantagens de cooperação por meio do estabelecimento de consórcios públicos nos moldes previstos pelas Leis no 11.445/2007 (Saneamento Básico) e no 11.107/2005 (Consórcios Públicos). Além disso, ainda são frequentes as ações de GRS sem adequado planejamento técnico-econômico, sendo esse quadro agravado pela falta de fiscalização e controle social no setor (MMA, 2017).

\subsection{POLÍTICA NACIONAL DE RESÍDUOS SÓLIDOS - PNRS}

Em 2 de agosto de 2010, após várias discussões na Câmara dos Deputados, o Projeto de Lei 203/1991 foi transformado na Lei 12.305/2010 (PNRS) e em 23 de dezembro de 2010 foi sancionado o Decreto 7.404, que regulamentou a PNRS, criando o Comitê Interministerial da PNRS e o Comitê Orientador para a Implantação dos Sistemas de LR.

Segundo MMA (2016), a PNRS é bastante atual e contém instrumentos importantes para permitir que o país enfrente os principais problemas decorrentes do manejo inadequado dos RS. Esta Lei prevê prevenção e redução na geração de RS; institui a responsabilidade compartilhada dos geradores de RS; cria metas importantes que contribuem à eliminação dos lixões e institui instrumentos de planejamento nos níveis nacional, estadual e municipal.

Com essa Lei foi oficializado o princípio da Responsabilidade Compartilhada sobre Ciclo de Vida dos Produtos que implica em "responsabilidade comum" entre os segmentos da sociedade sobre o GRS, para reduzir a geração e o desperdício de materiais, diminuir impactos causados à saúde humana e à qualidade ambiental, e estimular produção e consumo de produtos derivados de materiais reciclados e recicláveis (MMA, 2016; GOUVEIA, 2012).

\subsection{LOGÍSTICA REVERSA (LR)}

Cada vez mais rapidamente os produtos têm se tornado obsoletos, com ciclos de vida útil menores e inseridos no comércio eletrônico. Com leis mais severas sobre responsabilidade pela destinação de bens ou resíduos e o aumento da consciência ambiental, intensificaram-se os retornos, aumentando a importância da LR (HERNANDEZ, MARINS e CASTRO, 2012).

Segundo Fonseca et al. (2017), há várias definições para LR já propostas desde os anos 1990, por autores como: FLEICHMANN, TIBBEN-LEMBKE, BRITO, FLAPPER, DEKKER e VEIGA. Assim, a LR pode ser caracterizada pelo planejamento, controle e decisões voltadas ao fluxo de bens, materiais, componentes, peças ou resíduos, a montante nas redes de suprimentos, ou seja, do consumidor ao produtor, com objetivos de revalorização, para ampliação de ciclos de vida e redução de descartes, ou definição de locais adequados, para disposição final destes materiais.

A LR em seu sentido mais amplo, refere-se às operações relacionadas à "captura" para reutilização de produtos e materiais, referindo-se às atividades de coleta, desmonte e processamento de bens e/ou materiais e peças usados, a fim de assegurar uma recuperação sustentável, relacionando várias atividades como parte da administração logística, dentre estas o reaproveitamento e remoção de refugos e a administração de devoluções (SANTOS, 2012).

Além do refugo gerado em seu próprio processo produtivo, o fabricante está sendo responsabilizado pelo bem até o final de sua vida útil. Neste sentido, a LR constitui um importante processo de suporte para sistematizar os fluxos de resíduos, partes de bens ou bens descartados, pelo fim de vida útil ou por obsolescência tecnológica, voltados à sua destinação ou disposição final adequada (MAHAJAN e VAKHARIA, 2016).

\subsection{COLETA SELETIVA (CS)}

No relatório preliminar da PNRS no Capítulo I, Art. 2o (BRASIL, 2010a), define-se a CS como ato de recolher RS previamente selecionados nas fontes geradoras, para destiná-los para reciclagem, compostagem, reuso, tratamentos, além de alternativas (ambientalmente adequadas), a exemplo de aterros e coprocessamento e incineração. 
Nesse sentido, a prática da separação dos resíduos orgânicos e inorgânicos facilita a reciclagem, porque os materiais, estando mais limpos, têm maior potencial de reaproveitamento e comercialização (IBGE, 2000). Dessa forma, a CS, por meio da separação de resíduos recicláveis, representa uma atividade relevante à redução da quantidade de RS da coleta convencional, e apresenta-se basicamente sob duas modalidades: os Postos de Entrega Voluntária (PEV) e a coleta porta a porta (CAMPOS, 2012; GRIMBERG e BLAUTH, 1998).

Ribeiro e Besen (2007) afirmam que a prática da CS cumpre um papel estratégico na Gestão Integrada de Resíduos Sólidos (GIRS), pois estimula o hábito da separação de RS na fonte geradora, para o seu aproveitamento; promove a educação ambiental voltada à redução de consumo e desperdício; gera trabalho e renda; e ainda melhora a qualidade da matéria orgânica para a compostagem. Assim, sociedade e meio ambiente são beneficiados com a CS, visto que promove a redução de extração de insumos do sistema natural, e a economia dos recursos renováveis e não renováveis, bem como a economia de energia no reprocessamento de materiais, quando comparada a extração e produção a partir destes insumos. Reduz-se também a disposição de RS nos aterros, prolongando a vida útil destas instalações, além de diminuir a poluição e o desperdício de recursos (SOUZA, RAMOS e BAHIA, 2014).

\section{MÉTODO DE PESQUISA}

Este estudo caracterizou a Coleta Seletiva (CS) realizada na cidade de Belém-PA e avaliou, segundo a legislação vigente, os atuais procedimentos de CS, caracterizando-se como pesquisa exploratória, qualitativa e estudo de caso. Por meio de fontes primárias, foram obtidas informações acerca dos procedimentos de CS atuais, sendo realizadas entrevistas não estruturadas com funcionários da Secretaria Municipal de Saneamento (SESAN); e líderes e encarregados das cooperativas e associações de catadores cadastradas na prefeitura de Belém. Foram ainda consultadas fontes secundárias (legislação e normativas acerca do assunto, documentos da SESAN, livros e trabalhos científicos), com o objetivo de mapear, de modo mais aderente com a realidade, os procedimentos e técnicas de LR, atualmente realizados na atividade de CS em Belém, de modo a compará-los ao que é proposto na legislação vigente.

A legislação, apesar de não definir claramente os procedimentos de LR para a CS, delega responsabilidades. Aliás, não poderia haver um procedimento padrão, visto que o Brasil é um país de grandes dimensões e cada contexto deve ter suas especificidades consideradas, sendo necessário que os responsáveis por tais atividades proponham seus próprios métodos de execução às leis atuais. Nesse sentido, verificou-se se a CS está sendo desenvolvida de forma efetiva, identificando se há inconsistências legais no processo de CS atualmente realizado pela SESAN, apontando possíveis melhorias sob tal contexto. Nesta pesquisa, foi caracterizada a LR associada à atual CS e verificado se as responsabilidades legais estão sendo desenvolvidas de forma efetiva pelos partícipes. Às inconsistências constatadas foram propostas melhorias.

\section{RESULTADOS E DISCUSSÕES}

Foram realizadas entrevistas com representantes de 4 cooperativas ou associações de catadores de materiais reutilizáveis e recicláveis, que definiram os procedimentos de CS de forma semelhante, como descrito na Seção 4.1 .

Em Belém-PA, a CS é realizada pela SESAN em parceria com cooperativas e associações de profissionais catadores cadastradas na Prefeitura, atuando como "centrais de triagem" de materiais reutilizáveis e recicláveis, localizadas em bairros da cidade. Como já mencionado, tais cooperativas e associações desenvolvem a CS de forma bastante semelhante.

Basicamente, a SESAN é responsável pela conscientização (Educação ambiental) da população (etapa anterior à CS) e pela fiscalização e controle do serviço (etapa posterior à CS); e as cooperativas e associações responsáveis pela LR associada à CS propriamente dita. Por ser um serviço público, há interesses políticos que dificultam o trabalho, pois, segundo dados de entrevistas, a divisão de responsabilidades tem gerado alguns conflitos.

Segundo entrevistas com funcionários da SESAN, Belém produz, em média, 1.800 toneladas de RS/dia e coleta somente 700 toneladas/dia. Isso significa que apenas 38,88\% de todo o RS gerado na cidade são, de fato, coletados. Em relação à CS, o número é ainda menor, já que, segundo funcionários da Associação de Catadores da Coleta Seletiva de Belém (ACCSB), são coletadas, aproximadamente, 2,15 toneladas de RS 
recicláveis/dia, ou seja, apenas $0,3 \%$ do montante de RS coletados. Tendo em vista esses dados, torna-se imperativa a necessidade de propor melhorias a gestão e operacionalização da CS realizada em Belém, a fim de apurar estatísticas mais favoráveis no futuro e gerar ganhos ambientais, econômicos e sociais às cooperativas e associações, além de conscientização da sociedade.

\subsection{MAPEAMENTO DO PROCESSO ATUAL}

De posse dos dados apurados, foi possível mapear o processo de CS atualmente desenvolvido em Belém (PA), a saber:

a) Educação Ambiental/Conscientização, promovida pela SESAN que visita residências e grandes geradores de RS (hospitais, shoppings, empresas etc.), informando a importância de promover a separação prévia dos RS e os dias que será realizada a coleta in loco dos materiais que já devem estar previamente separados (modalidade porta a porta);

b) Orientação e motivação, efetuadas também pela SESAN, junto às famílias que residem próximo às cooperativas e associações credenciadas, quanto a prévia separação e depósito dos RS já separados nos PEV dessas cooperativas e associações (modalidade PEV);

c) Coleta dos RS já separados, efetuada pelas cooperativas e associações credenciadas que visitam residências e grandes geradores de RS, em dias previamente agendados pela SESAN, para coletar os materiais. Para a coleta nas residências, são usados veículos pequenos "carrinhos de metalom" e para os grandes geradores, caminhões caçamba;

d) Processamento dos RS coletados, refere-se a descarga, separação, limpeza, moagem/ compactação, embalagem etc., realizadas nas cooperativas e associações credenciadas;

e) Armazenagem dos RS já processados, voltada a guarda e manutenção das condições de consumo e comercialização destes resíduos, também realizada nas cooperativas e associações credenciadas que constituem estruturas de grande porte, cobertas na parte superior e descobertas nas laterais;

f) Monitoramento dos processos nas cooperativas e associações credenciadas, realizado pela SESAN, dentro das instalações dessas organizações, registrando dias e horários que os veículos saem e retornam ao galpão, e as quantidades e tipos de materiais coletados.

As atividades identificadas foram organizadas no macroprocesso de CS, apresentado na Figura 1.

FIGURA 1: Macroprocesso de coleta seletiva atualmente desenvolvido em Belém-PA.

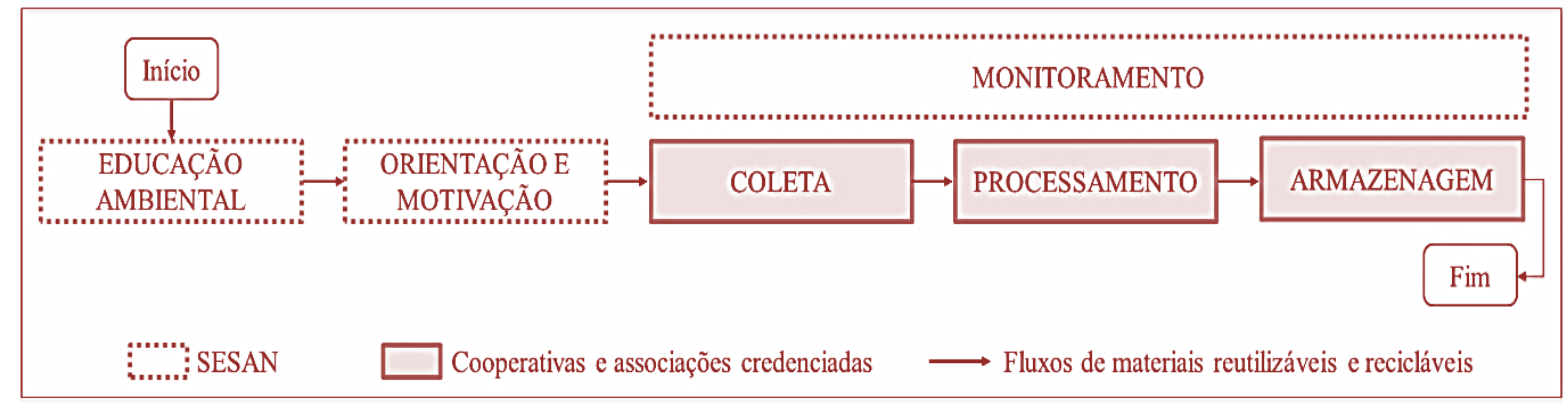

Fonte: Autores $(2020$

Definido o processo de CS atualmente realizado, tornou-se viável sua avaliação considerando-se os aspectos legais em vigência.

\subsection{AVALIAÇÃO DA OPERAÇÃO DE CS QUANTO ÀS DIRETRIZES LEGAIS}

O Decreto 7.404/2010 estabelece as diretrizes da CS. No Quadro 1, entre as ações de CS previstas em lei, foi possível constatar quais destas a SESAN e as associações e cooperativas credenciadas têm efetivamente realizado em Belém. 
Como é possível observar no Quadro 1, pelo que foi avaliado em entrevistas, em relação à conformidade legal, concluiu-se que a CS é até realizada, porém aquém do que está previsto em Lei. Foi constatado que há, de fato, a participação prioritária de cooperativas e associações credenciadas na execução da CS. Entretanto, o poder público falha em relação ao incentivo a atividades de caráter educativo, pois notou-se que há limitações nas informações sobre CS veiculadas, além de poucas ações e campanhas levadas às escolas e aos bairros, pois muitas pessoas ainda desconhecem o programa de CS e sua importância para a sociedade.

QUADRO 1 - Resultado do check list de cumprimento de diretrizes da legislação.

\begin{tabular}{|l|c|}
\hline \multicolumn{1}{|c|}{ Diretriz da legislação } & Realização pela SESAN \\
\hline $\begin{array}{l}\text { O sistema de CS deve ser implantado pelo titular do serviço público de limpeza } \\
\text { urbana e manejo de RS e deverá estabelecer, no mínimo, a separação de RS secos } \\
\text { e úmidos e, progressivamente, ser estendido à separação dos RS secos em suas } \\
\text { parcelas específicas, segundo metas estabelecidas nos respectivos planos. }\end{array}$ & Realiza \\
\hline $\begin{array}{l}\text { O sistema de CS de RS deve priorizar a participação de cooperativas e } \\
\text { associações ou de outras formas de associação de catadores de materiais } \\
\text { reutilizáveis e recicláveis constituídas por pessoas físicas de baixa renda. }\end{array}$ & Realiza \\
\hline $\begin{array}{l}\text { O poder público deve incentivar atividades de caráter educativo e pedagógico, } \\
\text { em colaboração com entidades do setor empresarial e da sociedade civil } \\
\text { organizada. }\end{array}$ & Não realiza \\
\hline $\begin{array}{l}\text { O poder público deve realizar ações educativas voltadas a fabricantes, } \\
\text { importadores, comerciantes e distribuidores, com enfoque diferenciado aos } \\
\text { agentes envolvidos direta e indiretamente com sistemas de CS e LR. }\end{array}$ & Não realiza \\
\hline
\end{tabular}

Fonte: Autores (2020).

Quanto aos procedimentos realizados pelas cooperativas e associações credenciadas, de acordo com as etapas da CS definidas na Seção 4.1, foram analisadas as atividades realizadas, tendo como base as respostas das entrevistas, conforme demonstrado no Quadro 2.

QUADRO 2 - Análise dos procedimentos de CS desenvolvidos pelas cooperativas e associações de catadores credenciadas pela prefeitura de Belém-PA.

\begin{tabular}{|c|c|}
\hline $\begin{array}{c}\text { Etapas da atividade } \\
\text { de CS }\end{array}$ & Análise \\
\hline $\begin{array}{l}\text { Coleta de pequenos } \\
\text { geradores }\end{array}$ & $\begin{array}{l}\text { A rotatividade de funcionários nas cooperativas e associações credenciadas prejudica o } \\
\text { trabalho. Não há estratégias para retenção de conhecimento (como procedimentos } \\
\text { operacionais padrão - POP). Assim, a cada novo integrante que ingressa, todo o trabalho } \\
\text { precisa ser repassado, o que gera perda de tempo e capacidade que poderiam ser usados na } \\
\text { atividade de CS. Segundo entrevistas, a falta de autonomia e gestão das cooperativas e } \\
\text { associações sobre recursos usados também dificulta a efetividade do trabalho. }\end{array}$ \\
\hline $\begin{array}{l}\text { Coleta de grandes } \\
\text { geradores }\end{array}$ & $\begin{array}{l}\text { Os caminhões e caçambas, disponibilizados pela SESAN, não são suficientes para a coleta da } \\
\text { demanda real (reprimida). A maior parte da coleta é feita por carrinhos de metalom, ou } \\
\text { seja, ainda apenas nos pequenos geradores. Assim, atualmente não há estrutura capaz de } \\
\text { promover a capacidade adequada, sobretudo aos geradores mais distantes ou de grande } \\
\text { porte, ou monitorar o desempenho de processos (coleta e TLC), como POP, pessoal } \\
\text { capacitado (definição de rotas), equipamentos (ecoconteineres, caminhões-guinchos), ou TI } \\
\text { (planilhas para previsão de veículos). }\end{array}$ \\
\hline $\begin{array}{l}\text { Processamento e } \\
\text { Armazenamento }\end{array}$ & $\begin{array}{l}\text { Os galpões são suficientes para o RS que é coletado atualmente, porém, se fosse para } \\
\text { atender a real demanda, já não seriam suficientes. Em caso de aumento da demanda, } \\
\text { atualmente não há estrutura adequada que promova mais agregação de valor ou mantenha } \\
\text { por mais tempo as condições de consumo dos materiais processados, bem como agilize os } \\
\text { trabalhos, como POP, pessoal capacitado; equipamentos, como paleteiras, empilhadeiras, } \\
\text { prensas, elevadores (carga/descarga); ou qualquer tipo de automação ou TI voltada ao } \\
\text { monitoramento e desempenho dos processos. } \\
\text { Em relação aos estoques de RS processados, a rotina das cooperativas e associações de } \\
\text { catadores é vender semanalmente o material coletado. Com isso, as grandes quantidades de } \\
\text { RS ficam pouco tempo no galpão, havendo grande rotatividade nos estoques. No entanto, } \\
\text { no caso de aumento da demanda, não há estrutura adequada, como POP, pessoal capacitado } \\
\text { ou qualquer tipo de TI para melhor gestão dos estoques. }\end{array}$ \\
\hline
\end{tabular}


Pelas informações levantadas, percebeu-se que não há suporte necessário ao atendimento à real demanda de CS na cidade. A prefeitura, por meio da SESAN, é o órgão gestor do programa de CS, mas há outras responsabilidades que deveriam estar sob a gestão do município, como atividades de drenagem, pavimentação e educação ambiental.

As cooperativas e associações credenciadas desenvolvem a CS, processamento e armazenamento dos RS gerados, porém não influenciam nas decisões do programa. A falta de integração e autonomia, e o baixo emprego de tecnologias de informação (TI) nos processos, tornam a capacidade logística e o nível de serviço dessas cooperativas e associações muito baixos, refletindo nos números pouco representativos, obtidos no processo de CS.

De acordo com a revisão bibliográfica realizada, também foi possível constatar, após a instituição da PNRS, a existência de leis municipais relacionadas à CS, desde a coleta até a destinação final, além de não prever ações voltadas aos grandes geradores de RS, a saber: Lei no 8.899 e o Decreto no 83.021-PMB (BELÉM, 2015).

\section{CONSIDERAÇÕES FINAIS}

Esta pesquisa avaliou sob o ponto de vista legal e propôs melhorias ao atual processo de Coleta Seletiva (CS), desenvolvido pela Secretaria Municipal de Saneamento (SESAN) da cidade de Belém-PA, em parceria com cooperativas e associações de catadores credenciadas na Prefeitura. Para tal, a partir de consultas a fontes primárias e secundárias, e entrevistas com funcionários, líderes e encarregados das instituições responsáveis, foi caracterizado o atual processo de CS, viabilizando sua comparação ao proposto na legislação vigente.

Constatou-se que a SESAN desenvolve a CS, priorizando a participação de cooperativas e associações de profissionais catadores, conforme o estabelecido na PNRS, porém as atividades educativas estão aquém do indicado na Lei.

Percebeu-se que alguns componentes legais só são cumpridos porque a demanda atendida é inferior à real. Se a demanda real tivesse que ser totalmente atendida, a infraestrutura (logística) atual instalada para CS não apresentaria capacidade suficiente, sendo necessário investimentos na frota de caminhões e em roteirização mais eficiente, além de ampliação ou aquisição de novas instalações de processamento e armazenamento, de modo a também atender às demandas dos grandes geradores de RS presentes no município.

A falta de integração entre os atuais elos envolvidos (SESAN, outras secretarias da administração municipal e Associações e cooperativas de profissionais catadores) na CS também prejudica esta operação. Para reverter esse quadro, propõe-se estabelecer Procedimentos Operacionais Padrões (POP), desenvolvidos em conjunto entre a SESAN e as cooperativas e associações credenciadas.

Ainda sob o aspecto institucional, indica-se que a SESAN busque estratégias para tanto integrar outros entes da gestão municipal potencialmente envolvidos (Secretaria Municipal de Meio Ambiente, Secretaria Municipal de Finanças, Secretaria Municipal de Urbanismo, entre outros) e organizações (públicas ou privadas) como ampliar as capacidades das cooperativas e associações credenciadas, de modo a fornecer as infraestrutura (logística e de processamento) adequada ao atendimento à real demanda.

Além disso, é fundamental promover o monitoramento eficiente das operações de CS, a fim de viabilizar a mensuração do real desempenho e possibilitar intervenções para avaliação quantitativa e proposição de melhorias efetivas para essas operações.

Pela necessidade de conformidade da CS com a legislação atual, outra proposta é que a SESAN realize engajamento da sociedade civil e setor empresarial, para promover campanhas de Educação Ambiental, pois grande parte da população ainda desconhece o programa de CS e sua importância para a sociedade. Recomenda-se ainda que a SESAN faça ampla divulgação de materiais candidatos para CS e formalize, via Decreto n 7.404/2010, responsabilidades e ações de agentes envolvidos na CS desenvolvida em BelémPA. 


\section{REFERÊNCIAS}

[1] ABRELPE. Associação Brasileira de Empresas de Limpeza Pública e Resíduos Especiais. Panorama de Resíduos Sólidos no Brasil, 2016.

[2] ABRELPE. Associação Brasileira de Empresas de Limpeza Pública e Resíduos Especiais. Panoramas de Resíduos Sólidos no Brasil. Edições 2011, 2012, 2013, 2014, 2015 e 2016. Disponível em: http://www.abrelpe.org.br/panorama_edicoes.cfm. Acesso em: 08 set. 2017.

[3] BELÉM. Lei no 8899, de 26 de dezembro de 2011. Plano de Gerenciamento Integrado de Resíduos Sólidos do Município de Belém. Disponível em: http://www.belem.pa.gov.br/semaj/app/Sistema/view_lei.php?lei=8899\&ano=2011\&tipo=1. Acesso em: 08 set. 2017.

[4] ___ Decreto no 83.021 - PMB, 19 de junho de 2015. Normas e prazo para o cadastramento dos Grandes Geradores de Resíduos Sólidos. Disponível em: https://www.legisweb.com.br/legislacao/?id=286078. Acesso em: 08 set. 2017.

[5] BRASIL. 2010 a. Lei no 12.305, de 02 de agosto de 2010. Política Nacional dos Resíduos Sólidos. Disponível em: http://www.planalto.gov.br/ccivil_03/_ato2007-2010/2010/lei/112305.htm. Acesso em: 08 set. 2017.

[6] _ 2010 b. Decreto no 7.404, de 23 de dezembro de 2010. Disponível em: http://www2.camara.leg.br/legin/fed/decret/2010/decreto-7404-23-dezembro-2010-609830-publicacaooriginal131134-pe.html. Acesso em: 08 set. 2017.

[7] CAMPOS, H. K. T. Renda e evolução da geração per capita de resíduos sólidos no Brasil. Engenharia Sanitária e Ambiental, v. 17, n. 2, p. 171-180, 2012.

[8] FONSECA, E. C. C.; BARREIROS, E. C. M.; MELO, A. C. S.; NUNES, D. R. L.; CARNEIRO, M. P. Evolução dos estudos de logística reversa realizados no contexto nacional: Uma análise bibliométrica. Produção Online, v. 15, n. 4, p. 1457 1480, 2015.

[9] FONSECA, E. C. C.; BARREIROS, E. C. M.; GONÇALVES, P. V. S.; MELO, A. C. S.; NUNES, D. R. L. Proposta de mapa de processos de logística reversa de pós-consumo sob a ótica da política nacional de resíduos sólidos. GEPROS - Gestão da Produção, Operações e Sistemas, Bauru, Ano 12, no 1, jan-mar/2017, p. 83-99. DOI: 10.15675/gepros.v12i1.1601.

[10] GOUVEIA, N. Resíduos sólidos urbanos: impactos socioambientais e perspectiva de manejo sustentável com inclusão social. Revista Ciência \& Saúde Coletiva, Vol. 17, N.6, abril, p.1503-1510, 2012.

[11] GRIMBERG, E., BLAUTH, P. Coleta Seletiva - Reciclando Materiais, Reciclando Valores. Revista Pólis, no 31, p. 103, $1998 . \quad$ Disponível em: http://www.lixoecidadania.org.br/lixoecidadania/Files/m_coletaSeletiva/Coleta\%20Seletiva.doc. Acesso em 15 de setembro de 2016.

[12] HERNÁNDEZ, C. T.; MARINS, F. A. S.; CASTRO, R. C. Modelo de gerenciamento da logística reversa. Gestão \& Produção, p. 445-456, 2012.

[13] IBGE. INSTITUTO BRASILEIRO DE GEOGRAFIA E ESTATÍSTICA. Censo Demográfico 2000. Disponível em: ttp://www.ibge.gov.br/home/estatistica/populacao/censo2000/migracao/ Brasil_mig_Censo2000.pdf. Acesso em 15 de setembro de 2016.

[14] JACOBI, P. R.; BESEN, G. R. Gestão de resíduos sólidos em São Paulo: desafios da sustentabilidade. Estudos avançados, v. 25, n. 71, p. 135-158, 2011.

[15] LIMA, A. K. T. Principais Pontos da política Nacional de Resíduos Sólidos para a Gestão de Resíduos Municipais. En: EL-DEIR, SG (Org.). Resíduos Sólidos: Perspectiva e Desafios para a Gestão Integrada, v. 1, 2014.

[16] MACHADO, P. A. L. Princípios da política nacional de resíduos sólidos. Revista do Tribunal Regional Federal da 1를 Região, 2012.

[17] MAHAJAN, J.; VAKHARIA, A. J. Waste Management: A Reverse Supply Chain Perspective. The Journal for Decision Makers, v. 41, n. 3, p. 197- 208, julho-setembro. 2016.

[18] MMA. MINISTÉRIO DO MEIO AMBIENTE. Política Nacional dos Resíduos Sólidos. Disponível em: http://www.mma.gov.br/politica-de-residuos-solidos. Acesso em 15 de setembro de 2016.

[19] MMA. MINISTÉRIO DO MEIO AMBIENTE. Gestão de Resíduos. Disponível em: http://www.mma.gov.br/responsabilidade-socioambiental/a3p/eixos-tematicos/gest\%C3\%A3o-adequada-dosres\%C3\%ADduos. Acesso em 22 de março de 2017.

[20] MARCHI, C. M. D. F. Cenário mundial dos resíduos sólidos e o comportamento corporativo brasileiro frente à logística reversa. Perspectivas em Gestão \& Conhecimento, Vol. 1, N. 2, julho/dezembro, p. 118-135, 2011.

[21] NAIME, R.; RAMALHO, A. H. P.; NAIME, I. S. Diagnóstico do sistema de gestão dos resíduos sólidos do hospital de clínicas de Porto Alegre. Uniciências, v. 10, n. 1, 2015. 
[22] PORTAL RESÍDUOS SÓLIDOS. 2017. Disponível em: http://www.portalresiduossolidos.com/gestao-egerenciamento/ . Acesso em: 10 abr. 2017.

[23] RIBEIRO, H.; BESEN, G. R. Panorama da coleta seletiva no Brasil: desafios e perspectivas a partir de três estudos de caso. InterfacEHS - Revista de Gestão Integrada em Saúde do Trabalho e Meio Ambiente, v. 2, n. 4, Ago., 2007.

[24] SANTOS, J. G. A Logística Reversa como Ferramenta para a Sustentabilidade: Um estudo sobre a importância das cooperativas de reciclagem na gestão dos resíduos sólidos urbanos. Revista Reuna, v. 17, n. 2, p. p. 81-96, 2012.

[25] SILVA, V. B. Um Breve Relato sobre a Gestão Ambiental. Revista de Geografia, Meio Ambiente e Ensino, v. 2, n. 1, p. p. 163-175, 2011.

[26] SOUZA, A. S. O.; RAMOS, M. A.; BAHIA, P. Q. Estudo de Caso da Coleta Seletiva de Resíduos Sólidos Recicláveis no Bairro da Pedreira-Belém/PA. Revista Caribeña de Ciencias Sociales, Vol. 11, 2014. 


\section{Capítulo 6}

Simulação de processos para aplicação de balanceamento de linha na indústria

\section{Fabyane Dias da Silva}

Maylane Neres Costa Santos

André de Mendonça Santos

\section{Djoille Denner Damm \\ Kalil Figueiredo Almeida}

Resumo: A competitividade do mercado tornou-se inevitável, o que permitiu a indústria fazer uso de ferramentas para redução de custos, desperdícios de tempo, mão-de-obra, matéria-prima, e com o foco no valor agregado do produto para aumentar a produtividade. Nesse contexto, o presente estudo visa aplicar uma metodologia que associe os conceitos da modelagem e simulação de eventos discretos com o balanceamento de linha para produção de repetidores wi-fi. 0 método envolveu coleta de tempos de trabalho, análise estatística de dados com o Stat: Fit, simulação computacional com software Simul8 e proposta de balanceamento da linha de uma linha de montagem. Os resultados mostraram que a empresa não opera de maneira satisfatória, sendo que a melhoria atingida contempla: redução da ociosidade e mão-deobra, evolução dos postos de trabalho e aumento da produtividade em atendimento às necessidades da empresa.

Palavras-chave: Modelagem e Simulação, Balanceamento de Linha, Melhoria de Processos. 


\section{INTRODUÇÃO}

$\mathrm{Na}$ indústria, processos submetidos à diferentes variáveis são tratados cotidianamente pelo setor de engenharia de processos, e para melhor aproveitamento dos recursos disponíveis, o balanceamento de linha de montagem é utilizado como método de dimensionamento de capacidade de produção. 0 mercado tornou-se mais competitivo, o que conduziu a indústria a fazer uso de ferramentas para redução de custos, desperdícios de tempo, mão-de-obra, matéria-prima, com o foco no valor agregado do produto para aumentar a produtividade. Neste contexto, é fundamental que as empresas norteiem suas ações levando em consideração temas como mapeamento de processos, balanceamento de linha, capacidade produtiva, dentre outros.

A linha de montagem determina o fluxo de operações no sistema produtivo com características de produção contínua, subdividida em número de tarefas e definidas em postos de trabalho (MOREIRA, 2014). Concomitantemente, o balanceamento de linha promove estabilidade e melhoria ao processo, em função da busca por equidade entre as tarefas, na redução de filas e, principalmente, em manter a qualidade do produto da empresa.

Ademais, a influência de vários fatores, tais como os econômicos elevou o interesse em técnicas de modelagem e simulação (SECCHI, 1995). A simulação computacional assumiu uma posição de destaque relacionado a técnicas para análise de problemas complexos em ambientes de manufatura. Segundo afirmações de Montevechi et al. (2009), sistemas reais são complexos principalmente devido às suas características dinâmicas e aleatórias. Quanto mais complexo um processo, maior a necessidade de técnicas de análise. Sendo assim, a simulação permite visualizar determinada mudança, em forma de elementos gráficos e computacionais, com aproximação da realidade fabril, que permite diminuir a margem de erro em alterações processuais.

0 presente estudo busca a aplicação de uma metodologia que associe as ferramentas e conceitos da engenharia de produção - mapeamento de processos, cronoanálise, capacidade produtiva, etc. - com a modelagem de eventos discretos, possibilitando atingir assim o balanceamento de uma linha produtiva de repetidores wi-fi, e consequentemente, uma produção mais equilibrada, com menos ociosidade e com maior produtividade.

\section{REFERENCIAL TEÓRICO}

\subsection{SISTEMAS DE PRODUÇÃO}

Para Santos Filho (2000), os sistemas produtivos cabem a uma classe de sistemas cujo intuito é a prestação de serviços e/ou a produção de materiais e/ou informações. Ou seja, sistemas desenvolvidos "pelo homem e para o homem" possui evolução dinâmica dos estados e é resultante da ocorrência de eventos que são considerados instantâneos. Estes sistemas são caracterizados como sistemas a eventos discretos.

Para Moreira (2014), os sistemas de produção quanto à classificação tradicional permeiam-se em função do fluxo do produto e agrupa os sistemas de produção em três grandes categorias:

- Sistemas de produção contínua ou de fluxo em linha - apresentam sequência linear de fluxo e trabalham com produtos padronizados. Dessa forma, pode se distinguir dois tipos, a produção contínua propriamente dita, aquela que é o caso das indústrias de processo, sendo este tipo tendencioso a ter um alto grau de automatização e a produzir produtos altamente padronizados, e a produção em massa, aquela onde as linhas de montagem possuem larga escala de poucos produtos com grau de diferenciação relativamente pequeno;

- Sistemas de produção intermitente (fluxo intermitente) - aquela que pode ser atendida por lotes, onde ao término da fabricação de um produto, outros tomam seu lugar nas máquinas, de maneira que o primeiro produto só voltará a ser fabricado depois de algum tempo, e a aquela por encomenda, onde o cliente apresenta seu próprio projeto do produto, devendo ser seguidas essas especificações na fabricação;

- Sistemas de produção de grandes projetos sem repetição - aquela que possui produto único, não há rigorosamente um fluxo do produto, existe uma sequência predeterminada de atividades que deve ser seguida e com pouca/nenhuma repetitividade. 


\subsection{BALANCEAMENTO DE LINHA}

Balanceamento de linha é o processo de distribuir tarefas em postos de trabalho de uma linha produção, visando a obtenção de equivalência processual (BETTS \& MAHMOUD, 1989). Para Moreira (2014) as atividades devem ser equilibradas entre os postos visando atingir uma estabilidade entre os tempos de processo e, consequentemente, atingir uma melhor eficiência produtiva.

Segundo Monden (1998), a obtenção de alta produtividade através da eliminação dos desperdícios, estoque mínimo de material em processo e com a aplicação do balanceamento da linha de montagem determina o sucesso da ferramenta. E, conforme Festugatto (2006), o balanceamento de linha de produção é alcançado quando há equivalência entre os tempos das operações, permitindo o aumento da capacidade produtiva e a redução da ociosidade entre as operações industriais.

De acordo com Freitas (2019), o desbalanceamento da linha de produção é causado pelos tempos de ciclo desiguais das várias operações e também pela elevada variabilidade do tempo de produção. 0 desbalanceamento é a razão entre a descontinuidade do fluxo unitário da linha de produção e a acumulação de WIP (Work in Progress) entre estações de trabalho. Inevitavelmente, o número de unidades em curso aumenta fazendo o Lead Time, tempo necessário para percorrer todo ciclo de produção, aumentar.

Por conseguinte, umas das ferramentas que auxilia o balanceamento de linha é o gráfico de balanceamento de operadores (GBO) que é uma ferramenta gráfica que auxilia a criação de um fluxo contínuo em processos de múltiplas etapas e operadores, de forma a distribuir as atividades entre os operadores em relação ao takt time (LEAN INSTITUTE BRASIL, 2003).

Para Pyzdek e Keller (2011) o quê e quando o cliente necessita é o que norteia o fluxo de processo, atribuído a seus tempos de processamento. Alvarez \& Júnior (2001) definiram takt time como o ritmo de produção necessário para atender a demanda.

0 takt time é obtido pelo tempo de produção efetivo por turno dividido pela demanda do cliente por turno e podem ser obtidos pela Equação 1 (ALVAREZ e ANTUNES, 2001).

$$
\text { Tempo takt }=\frac{\text { Tempo disponível de Produção por dia }(T P)}{\text { Demanda de Produção Diária }(D)}
$$

A obtenção dos tempos de ciclo durante a operação da linha de montagem "piloto" fora obtida pelo somatório dos tempos das tarefas dos postos de trabalho (ROTHER \& SHOOK, 1998).

O número mínimo de operadores por linha de montagem foi obtido pela Equação 2, proposto por Tubino (2007).

$$
N_{\text {Mínimo de Operadores }}=\frac{\text { Somatório dos tempos das oeprações }\left(\sum t\right)}{\text { Tempo takt }} \quad \text { Equação } 2
$$

A eficiência do balanceamento de linha foi obtida pelo parâmetro (LOB - Line of Balance). 0 cálculo é baseado através da ociosidade entre os tempos das operações, que pode ser obtido pela Equação 3, definido por Tubino (2007).

$$
\begin{array}{ll}
I_{\text {Eficiência }}=1-\frac{\sum \text { Ociosidade }}{N^{\circ} \text { de postos de trabalho } \times T C_{\text {Processo }}} & \text { Equação } 3
\end{array}
$$

\subsection{SIMULAÇÃO DE PROCESSOS}

A simulação de processos possibilita desenvolver em ambiente computacional, diferentes cenários que aproxima a realidade dos processos industriais. A análise dos dados desse estudo minimiza o risco na tomada de decisão, pois origina-se de resultados confiáveis estatisticamente (CHWIF \& MEDINA, 2010). 
Conceitua-se a simulação como um processo de experimentação, compreendendo o sistema real em ambiente computacional, e possibilitando o estudo de correlação de cenários entre a realidade e o ambiente virtual (BATEMAN et al., 2013).

Segundo Simas (2018) a simulação é uma representação simplificada da realidade, podendo ser utilizada para explorar situações fictícias, perigosas e identificar possíveis falhas, além disso, também permite a oportunidade de desenvolver hipóteses, testá-las e analisar resultados. Os modelos virtuais apresentam uma estrutura lógica que auxilia à tomada de decisão.

O software Simul8 oferece em seu pacote de simulação, medidas de desempenho em postos de trabalho sobre a ociosidade, ocupação, paradas, mudanças e turnos de trabalho, fornecidas através de dados representados em gráficos (ALMEIDA, 2012). 0 software Stat: Fit é responsável por realizar o tratamento estatístico dos dados, permitindo realizar uma inferência estatística para atribuição da melhor distribuição que se adéqua ao processo real. As distribuições que podem ser utilizadas, individualmente ou combinadas, pelo software Stat: Fit são: Fixa, Beta, Gama, Normal, Lognormal, Uniforme, Triangular, Pearson 5 ou Chi-Quadrado e a Weibull.

\section{METODOLOGIA}

O método é do tipo quantitativo, devido o emprego de um estudo de caso para explanação de dados coletados e trabalhados estatisticamente. Neste sentido, trata-se de um estudo de caso simples, pois, segundo Marconi e Lakatos (2005) ele permite entender o como e o porquê, ou entender a complexidade e a natureza dos processos que estão ocorrendo.

0 método adotado seguiu as etapas abaixo:

- Mapeamento de processos da empresa em estudo;

- Escolha da linha de montagem piloto;

- Coleta, análise e tratamento estatístico dos tempos de processo para cada elemento de trabalho;

- Remoção das paradas de produção com a implementação do trabalho padronizado;

- Elaboração de modelos de simulação utilizando os softwares SIMUL8 e Stat: Fit para captura da realidade do processo;

- Análise e teste do modelo desenvolvido;

- Aplicação de balanceamento de linha para novas propostas de processo para as linhas de montagem.

O estudo utilizou o software Simul8 para a modelagem e simulação de eventos discretos quanto às suas análises acerca dos parâmetros descritos no objetivo desse trabalho. Embora esse software apresente uma facilidade sobre análises, existem outros disponíveis no mercado como Arena, FlexSim, ProModel, dentre outros.

Para Barnes (1977) “o estudo de tempos é um processo por amostragem, para tal quanto maior o número de tempos cronometrados maior será a representatividade dos resultados obtidos com o estudo". Sendo assim, os elementos de trabalho foram coletados com base na fórmula de Barnes (1977), representada pela Equação 4:

$$
N^{\prime}=\left[\frac{40 \sqrt{N \sum X^{2}-\left(\sum X\right)^{2}}}{\sum X}\right]^{2}
$$

Onde:

N' = o número necessário de observações para prever o tempo verdadeiro com erro relativo de $95 \%$ de confiança;

$\mathrm{X}=$ a leitura do cronômetro ou observação individual;

$\mathrm{N}$ = ao número efetivo de observações do elemento. 


\section{ESTUDO DE CASO}

O presente trabalho apresenta um estudo de caso em uma empresa do polo de informática da cidade de Ilhéus-BA. A empresa é considerada de pequeno porte, com aproximadamente 100 colaboradores, produzindo repetidores wi-fi de longo alcance.

A empresa disponibilizou uma linha de montagem "piloto" para o estudo de melhoria de processo de seu produto mais vendido, definidos por produtos A, através da simulação da produção, contemplando o tratamento estatístico dos dados.

Definido o produto do estudo para linha de montagem "piloto", produtos A, foram coletadas as atividades executadas em cada posto e as atividades executadas no período de preparação da linha, em seguida as atividades foram cronometradas individualmente. A empresa opera com a montagem em lotes (10 unidades por prancha), logo, os tempos foram multiplicados por 10 para adequação aos modelos de simulação.

\section{RESULTADOS E DISCUSSÕES}

Os modelos de simulação foram elaborados inicialmente considerando os tempos coletados para a realidade atual da empresa, dividindo-se em: modelo com paradas para setup de preparação dos kits de montagem e outro modelo sem paradas para setup de preparação dos kits de montagem. Após a captura da realidade, os dados demonstram a implementação aplicada à linha piloto na prática.

As características utilizadas para os modelos foram:

- 06 postos de produção;

- Lotes de produção de 10 peças;

- 08 horas e 18 minutos de produção por dia;

- 02 paradas de 15 minutos por dia;

- Paradas para separação das Ordens de Produção e Kits de montagem.

O modelo para esta situação atual está representado abaixo. Para a proposta, não haverá mudanças de layout, e sim uma alteração no número de postos de trabalho mediante a uma redistribuição das atividades do processo.

Figura 1 - Modelo da Situação Atual.

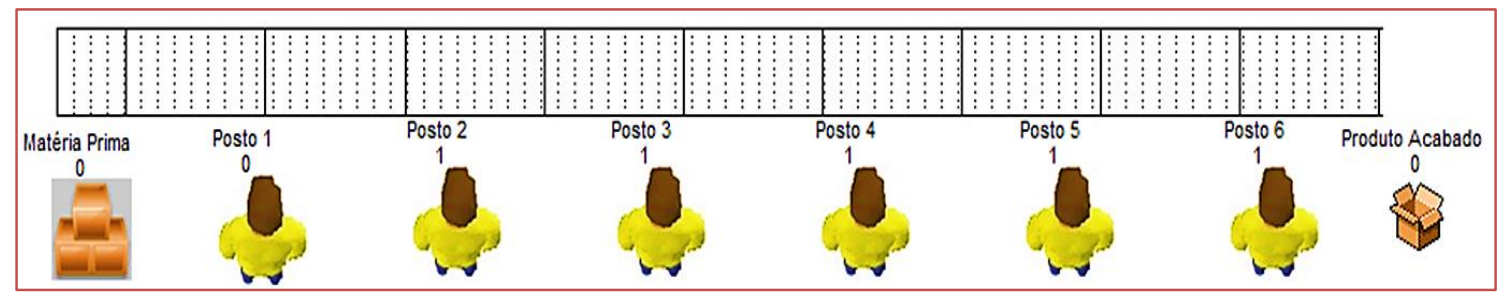

Fonte: Adaptado pelo próprio autor.

A Tabela 1 abaixo demonstra os dados obtidos na cronoanálise do processo real, o qual permitiu o balanceamento das atividades. As atividades "colocar e passar prancha" foram atribuídas distribuições triangulares com os tempos mínimos, máximos e moda de 1, 5 e 3 segundos, respectivamente. 
Tabela 1 - Dados da cronoanálise e do software de ajuste (Stat: Fit).

\begin{tabular}{|c|c|c|c|c|c|c|}
\hline Posto & Etapa / Elemento & $\begin{array}{l}\text { Tempos } \\
\text { Coletados }\end{array}$ & Out $<$ & Out $>$ & Moda & Distribuições - Stat: Fit \\
\hline \multirow[t]{5}{*}{1} & Colocar prancha & - & - & - & 3 & Triangular \\
\hline & Pegar caixa e abrir com estilete & 24 & 2 & 4 & 2 & Normal \\
\hline & Posicionar manual & 23 & 2 & 3 & 2 & Normal \\
\hline & $\begin{array}{llll}\begin{array}{l}\text { Desencaixar } \\
\text { etiqueta }\end{array} & \text { suporte } & \text { e } & \text { retirar } \\
\end{array}$ & 11 & 6 & 9 & 7 & Fixa + Pearson 5 \\
\hline & Passar prancha & - & - & - & 3 & Triangular \\
\hline \multirow[t]{4}{*}{2} & Colar etiqueta de resolução & 16 & 8 & 16 & 11 & Fixa + Uniforme \\
\hline & Colar etiqueta da WDC & 46 & 3 & 11 & 6 & Beta \\
\hline & Pegar e colar etiqueta Anatel & 13 & 6 & 10 & 9 & Fixa + Weibull \\
\hline & Passar prancha & - & - & - & 3 & Triangular \\
\hline \multirow[t]{4}{*}{3} & Colar etiqueta de lacre na fonte PoE & 41 & 4 & 10 & 6 & Fixa + Pearson 5 \\
\hline & Colar etiqueta da empresa & 26 & 3 & 8 & 5 & Triangular \\
\hline & Colar etiqueta & 39 & 4 & 10 & 7 & Beta \\
\hline & Passar prancha & - & - & - & 3 & Triangular \\
\hline \multirow[t]{4}{*}{4} & $\begin{array}{l}\text { Coletar código EAN e conferir a } \\
\text { impressão }\end{array}$ & 22 & 4 & 7 & 5 & Fixa + Pearson 5 \\
\hline & $\begin{array}{l}\text { Destacar a etiqueta impressa e } \\
\text { separar por kit }\end{array}$ & 16 & 8 & 13 & 10 & Triangular \\
\hline & Colar a etiqueta LV no PoE & 27 & 4 & 8 & 6 & Fixa + Weibull \\
\hline & Passar prancha & - & - & - & 3 & Triangular \\
\hline \multirow[t]{6}{*}{5} & Encaixar suporte e colar etiqueta LV & 21 & 5 & 9 & 7 & Fixa + Weibull \\
\hline & Montar caixa individual & 25 & 8 & 13 & 8 & Fixa + Weibull \\
\hline & Organizar kit & 4 & 14 & 19 & 14 & Fixa + Weibull \\
\hline & Colocar kit na caixa & 31 & 3 & 7 & 4 & Triangular \\
\hline & $\begin{array}{l}\text { Desmontar e descartar caixa do } \\
\text { fornecedor }\end{array}$ & 11 & 4 & 5 & 4 & Triangular \\
\hline & Passar prancha & - & - & - & 3 & Triangular \\
\hline \multirow[t]{5}{*}{6} & $\begin{array}{l}\text { Carimbar caixas de identificação da } \\
\text { linha }\end{array}$ & 42 & 1 & 2 & 2 & Fixa + Lognormal \\
\hline & Colar etiqueta NSE & 28 & 3 & 6 & 4 & Fixa + Gama \\
\hline & Fechar caixa individual & 32 & 2 & 5 & 4 & Fixa + Weibull \\
\hline & Armazenar na caixa coletiva & 32 & 1 & 2 & 2 & Fixa + Gama \\
\hline & $\begin{array}{l}\text { Alocar as caixas coletivas completas } \\
\text { no palete }\end{array}$ & 28 & 14 & 17 & 15 & Triangular \\
\hline
\end{tabular}

Fonte: Adaptada pelo próprio autor.

É importante salientar sobre os gráficos que serão apresentados nas análises posteriores em relação ao tempo takt - o qual será referenciado através do atendimento da capacidade produtiva diária da empresa, a demanda diária da empresa, e ao tempo de ciclo - o qual será referenciado ao tempo em cada posto de trabalho. Sendo que, pode-se observar que quando o tempo de ciclo superar o tempo takt representará ineficiência no processo de montagem. 
A eficiência de linha não foi medida durante os "setups" de produção porque o tempo diário disponível é reduzido devido ao processo de preparação das peças de montagem e a produtividade/hora fica superestimada com as paradas de produção.

\subsection{PROCESSO REAL}

A Tabela 2 abaixo demonstra os dados utilizados para análise com setup.

Tabela 2 - Dados de análise com setup.

\begin{tabular}{|cccc|}
\hline \multicolumn{4}{c|}{ Processo Real com Setup } \\
\hline Posto & Tempo de Ciclo & Necessidade & 800 \\
Posto 1 & 170 & Horas & 8,3 \\
Posto 2 & 290 & Horas de setup & 3,7 \\
Posto 3 & 210 & Horas efetivas & 4,6 \\
Posto 4 & 240 & Produtividade/hora & 174,0 \\
Posto 5 & 400 & Takt & 20,7 \\
Posto 6 & 270 & Takt - Lote 10 & 207,0 \\
\hline
\end{tabular}

Fonte: Adaptado pelo próprio autor.

A Tabela 3 abaixo demonstra os dados utilizados para análise sem setup.

Tabela 3 - Dados de análise sem setup.

\begin{tabular}{|cccc|}
\hline \multicolumn{4}{c|}{ Processo Real sem Setup } \\
\hline Posto & Tempo de Ciclo & Necessidade & 800 \\
Posto 1 & 170 & Horas & 8,3 \\
Posto 2 & 290 & Produtividade/hora & 96,4 \\
Posto 3 & 210 & Takt & 37,3 \\
Posto 4 & 240 & Takt - Lote 10 & 373,0 \\
Posto 5 & 400 & LOB & $65,8 \%$ \\
Posto 6 & 270 & & \\
\hline
\end{tabular}

Fonte: Adaptado pelo próprio autor.

A Tabela 4 abaixo demonstra os dados dos processos.

Tabela 4 - Dados dos processos.

\begin{tabular}{|ccc|}
\hline Indicadores & Com paradas de produção & Sem paradas de produção \\
\hline Produção Média Diária & 760 & 931 \\
Produção por Homem.Hora & 15 & 19 \\
\hline
\end{tabular}

Fonte: Adaptado pelo próprio autor.

Logo, o balanceamento atual deste produto está representado abaixo, evidenciando através de gráficos com paradas e sem paradas de produção. 
Figura 2 - Balanceamento atual com setup.

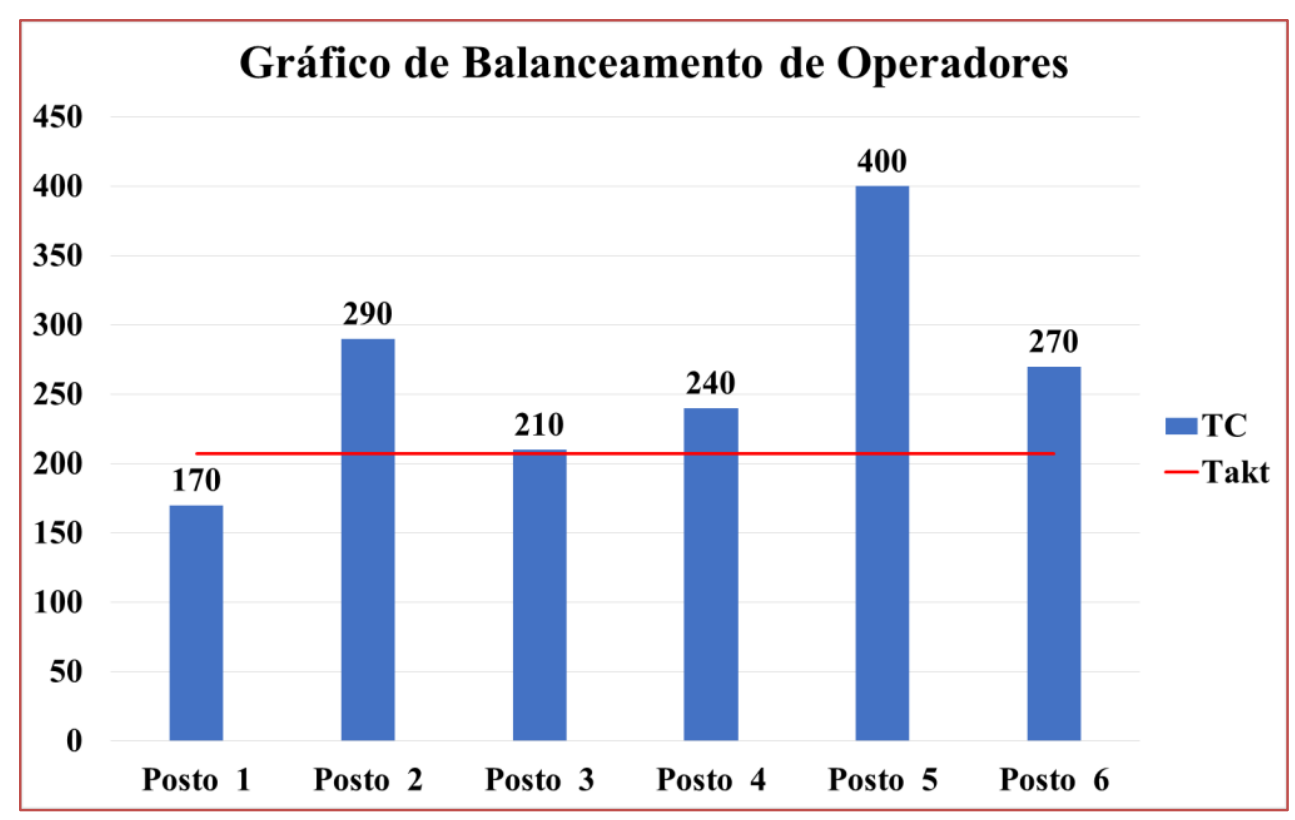

Fonte: Adaptado pelo próprio autor.

Figura 3 - Balanceamento atual sem setup.

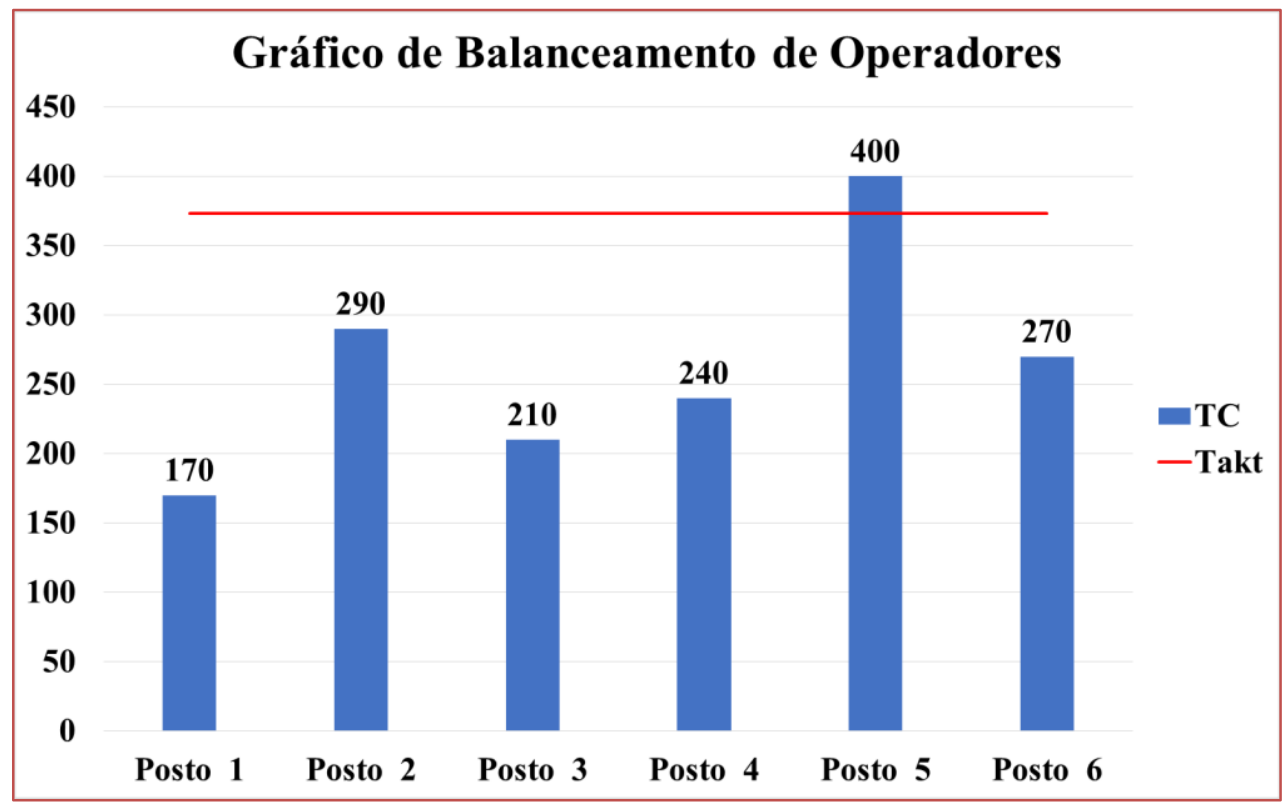

Fonte: Adaptado pelo próprio autor.

Embora a implementação do balanceamento de linha para o produto tenha sido efetiva, os gráficos representados ainda demonstram a necessidade equilíbrio entre as estações de trabalho, justificado pelo baixo line of balance (LOB) mostrado na tabela 3. O que evidencia a necessidade de um novo balanceamento de linha com um menor número de operadores. 


\subsection{PROPOSTA}

O cálculo do número mínimo de operadores da linha "piloto", com 6 postos de trabalho, proposto por Tubino (2007) sugere o número de operadores a seguir, respectivamente, determinado pela Equação 2:

$$
\begin{gathered}
N_{\text {Mínimo de Operadores }}=\frac{\text { Somatório dos tempos das operações }\left(\sum \mathrm{t}\right)}{\text { Takt Time }} \\
N_{\text {Mínimo de Operadores }}=\frac{170+290+210+240+400+270}{373,0} \\
N_{\text {Mínimo de Operadores }}=\frac{1580,0}{373,0} \cong 4 \text { Operadores com o Produto A. }
\end{gathered}
$$

O cálculo do número de operadores resultou em 4 operadores para a linha de montagem, o que demonstra a necessidade de adequação do fluxo produtivo para atingir melhoria processual. Com o novo balanceamento, as atividades do primeiro posto e outras que permitem a montagem do kit fora da linha, em novo setor da empresa, foram eliminadas para evitar o antigo "gargalo", o que favoreceu maior estabilidade ao manuseio e montagem do produto em estudo.

A Tabela 5 abaixo demonstra os dados utilizados para análise.

Tabela 5 - Dados de análise da proposta.

\begin{tabular}{|cccc|}
\hline \multicolumn{4}{c|}{ Proposta } \\
\hline Posto & Tempo de Ciclo & Necessidade & 800 \\
Posto 1 & 252 & Horas & 8,3 \\
Posto 2 & 257 & Produtividade/hora & 96,4 \\
Posto 3 & 275 & Takt & 37,3 \\
Posto 4 & 250 & Takt - Lote 10 & 373,0 \\
& & LOB & $95,6 \%$ \\
\hline
\end{tabular}

Fonte: Adaptado pelo próprio autor.

A Tabela 6 abaixo demonstra os dados dos indicadores.

Tabela 7 - Dados do processo da proposta.

\begin{tabular}{|cc|}
\hline Indicadores & Lotes de 10 \\
\hline Produção Média Diária & 1009 \\
Produção por Homem.Hora & 30 \\
\hline
\end{tabular}

Fonte: Adaptado pelo próprio autor.

Logo, o novo balanceamento com 4 operadores na linha de montagem demonstra uma melhoria nos resultados quando comparado ao processo real. 
Figura 4 - Balanceamento da proposta.

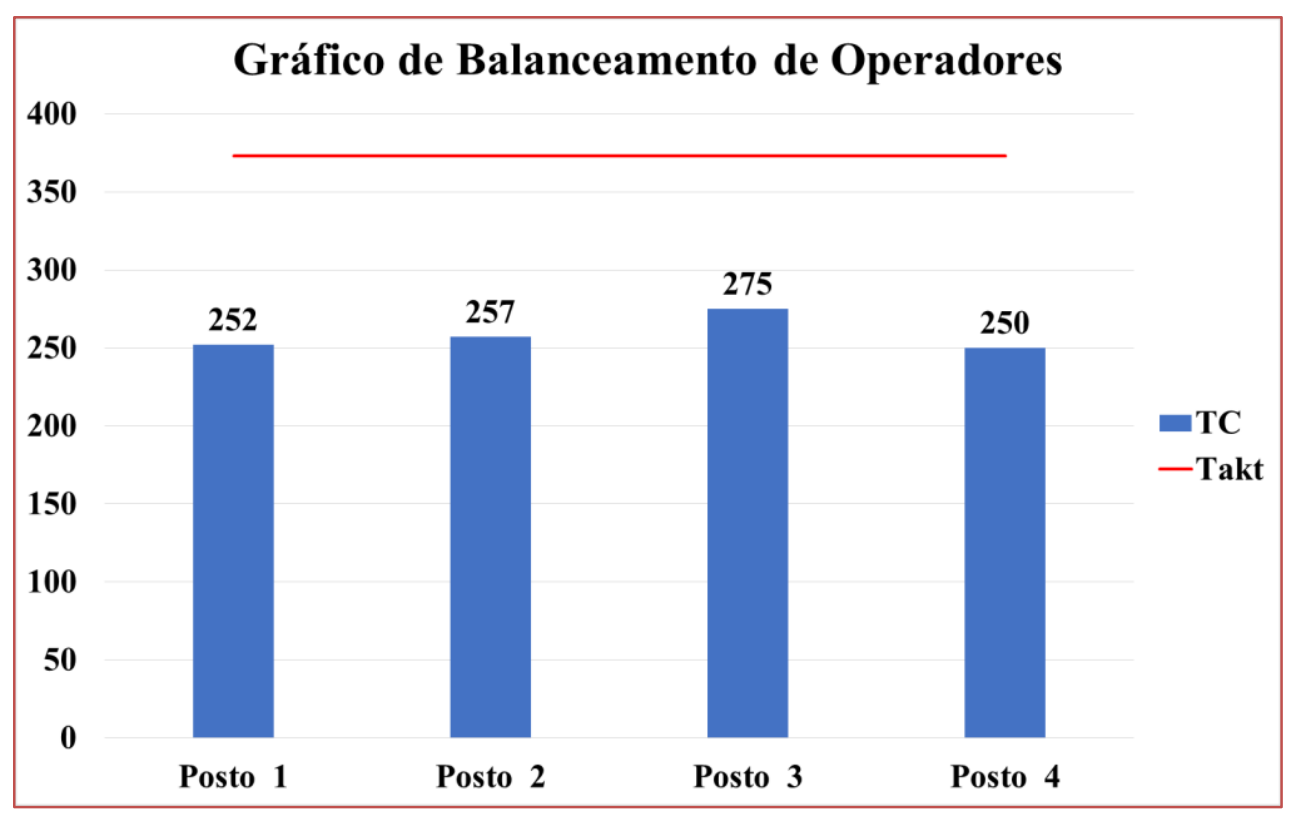

Fonte: Adaptado pelo próprio autor.

A análise de dados realizada demonstra o melhor desempenho em termos de atendimento à necessidade da demanda da empresa, produtividade homem.hora e fluxo produtivo. A folga ainda existente entre os tempos das estações de trabalho e o tempo takt indica que com o tempo e treinamento, os operadores poderão atingir maiores números de produtividade. A Figura 5 demonstra a eficiência analisada no estudo.

Figura 5 - Comparativo de Produção.

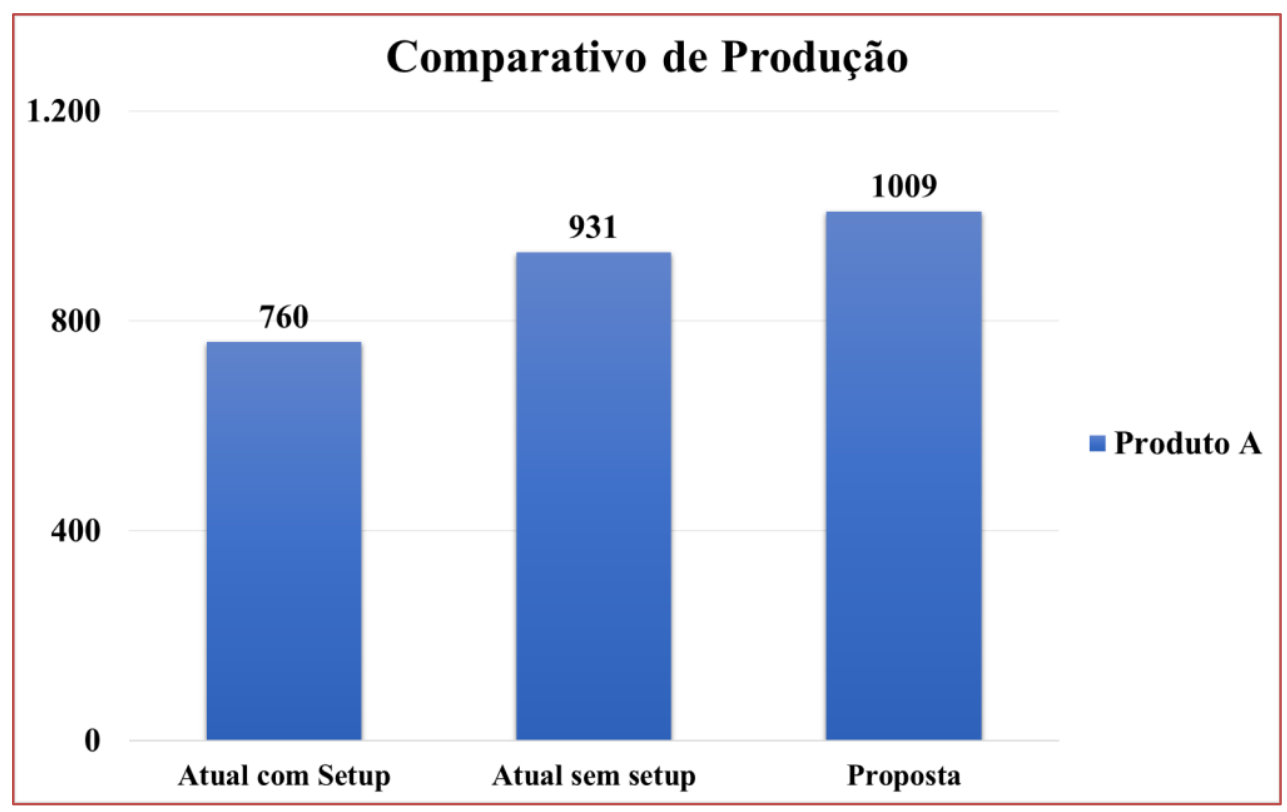

Fonte: Adaptado pelo próprio autor.

\section{CONCLUSÃO}

0 estudo permitiu concluir que a empresa não opera de maneira satisfatória, utilizando parte do tempo de produção em setups. Após o balanceamento, e melhor distribuição das atividades, a empresa terá condição de replicar o processo para as outras linhas de montagem em todo o seu mix produtivo. 
O balanceamento de linha associado à simulação para prever o comportamento da realidade de alterações processuais, garantiram maior estabilidade e eficiência ao processo produtivo com a distribuição de atividades equivalentes entre os postos de trabalho.

No cenário atual, haviam 6 colaboradores e na proposta, 4 operadores, com a produção de 1009 unidades e com maior produtividade de 30 unidades por homem.hora, o que denota um aumento de desempenho e melhor eficiência do processo produtivo com a equivalência das atividades.

A associação das ferramentas da Engenharia de Produção evidenciou as vantagens na utilização da modelagem e simulação de eventos discretos, o que permitiu analisar o cenário atual, realização de testes e alterações de variáveis em ambiente computacional, reduzindo os riscos e viabilizando o balanceamento de linha. A proposta permitiu a redução da ociosidade, redução de mão-de-obra, evolução dos postos de trabalho, aumento da produção homem.hora e da capacidade produtiva da empresa, de maneira estável e equilibrada.

\section{REFERÊNCIAS}

[1] ALMEIDA, K.F. Aplicação de modelagem e simulação de eventos discretos como ferramenta de análise em processos produtivos: um estudo de caso. Trabalho de Conclusão de Curso (Engenharia de Produção), Universidade Estadual de Santa Cruz, Ilhéus, 2012.

[2] ALVAREZ, R. R.; ANTUNES Jr., J. A. V. Takt time: contexto e contextualização dentro do Sistema Toyota de Produção. Revista Gestão \& Produção, v. 8, n. 1, p. 01-18, 2001.

[3] BARNES, R. M. Estudo de Movimento e de Tempo: Projeto e Medida do Trabalho. São Paulo: Edgard Blucher, 1977.

[4] BATEMAN, R.; BOWDEN, R.; GOGG, T.; HARREL, C.; MOTT, J.; MONTEVECHI, J. A. B. Sistemas de simulação: aprimorando processos de logística, serviços e manufatura. Rio de Janeiro: Elsevier, 2013.

[5] BETTS, J.; MAHMOUD, K. I. A method for assembly line balancing. Engineering Costs and Production Economics. v. 18, p. 55-64, 1989.

[6] CHWIF, L.; MEDINA, A.C. Modelagem e simulação de eventos discretos: teoria e aplicações. São Paulo: Editora dos Autores, 2010.

[7] FestugATTO, J. R.; BRAMBilla, N.; FOLLMANN, A. F.; OLIVEIRA, G. A. Aplicação da metodologia de balanceamento de linhas na empresa Atlas Eletrodomésticos Ltda. In: ENCONTRO NACIONAL DE ENGENHARIA DE PRODUÇÃO, 26, 2006, Fortaleza. Anais do XXVI ENEGEP 2006. p. 1-9.

[8] FREITAS, J. Criação de Fluxo numa Indústria de Acrílicos. Mestrado, Faculdade de Engenharia Universidade do Porto, Portugal, 2019.

[9] LEAN INSTITUTE BRASIL. Léxico Lean: Glossário Ilustrado para praticantes do pensamento Lean. São Paulo. 2003.

[10] MARCONI, M.A.; LAKATOS, E.V. Fundamentos de metodologia científica. 6.ed. São Paulo: Atlas, 2005.

[11] MONDEN, Y. Produção sem estoque: uma prática do sistema de produção Toyota. São Paulo: IMAM, 1998.

[12] MONTEVECHI, J. A. B.; COSTA, R. F. S.; LEAL, F.; PINHO, A. F.; JESUS, J. T. Economic evaluation of the increase in production capacity of a high technology products manufacturing cell using discrete event simulation. In: Proceedings of the Winter Simulation Conference, Austin, USA, 2009.

[13] MOREIRA, D. A. Administração da Produção e Operações. 2 Ed. São Paulo: Editora Cengage Learning, 2014.

[14] PYZDEK, T.; KELLER, P. Seis Sigma - guia do profissional. 3. ed. São Paulo: Alta Books, 2011.

[15] ROTHER, M. \& SHOOK, J. Learning to See: Value Stream Mapping to Add Value and Eliminate MUDA. Brookline: The Lean Enterprise Institute, 1998.

[16] SANTOS FILHO, D. J. Aspectos do projeto do controle de sistemas produtivos. Tese (Livre Docência), Escola Politécnica, Universidade de São Paulo, São Paulo, 2000.

[17] SIMAS, M. E. L. Simulação e modelagem como estratégia para a melhoria do processo de ensino aprendizagem de física. Orientador: Dr. Antonio Xavier Gill. 2018. 217 f. Dissertação (Mestrado em Ensino de Ciências e Matemática) - Universidade Federal do Amazonas, Manaus, 2018.

[18] TUBINO, D. F. Planejamento e Controle da Produção: teoria e prática. 1aㅡ Edição, Editora Atlas, 2007. 


\section{Capítulo 7}

\section{Melhoria contínua: Implementando um método e reduzindo custos}

\section{Marcelo Paranzini \\ Roberto Kanaane \\ Jadir Perpétuo dos Santos}

Resumo: Este artigo tem como objetivo apresentar um método de melhoria continua o qual traz a redução de custos nas negociações com fornecedores estratégicos. Trata-se de um relato de caso em uma empresa de telecomunicações multinacional, em sua regional no Brasil. Implementando-se esta metodologia obtém-se redução de custos com a redução de matérias-primas utilizadas, de retrabalhos por defeitos, bem como a melhoria de produtividade com a redução de tempos durante os processos e melhor disposição do layout.

Palavras-chave: Teoria das Restrições (TOC), Melhoria contínua, Gargalo. 


\section{INTRODUÇÃO}

A busca de uma maior competitividade caracteriza-se como uma alternativa para que as empresas se diferenciem em seus mercados, sendo a adoção da otimização de seus recursos um caminho para gerar um resultado que traga a perenidade.

A simples prática de ferramentas e técnicas de Gestão já consagradas não levam a obtenção das vantagens competitivas necessárias.

Percebe-se empresas que incessantemente tentam sobreviver em seu mercado, muitas vezes abrindo mão de recursos significativos, sejam de pessoas ou de equipamentos, esquecendo-se que existem possibilidades a serem exploradas internamente em seus processos antes de chegar a tais medidas.

A implementação de um método de melhoria contínua simples, sem a necessidade de grandes investimentos financeiros e de capacitação de pessoal, pode ser uma destas possibilidades.

Assim sendo, como a empresa pode melhorar seus processos internos, identificando e atuando nos pontos que levarão aos resultados de eficiência operacional reduzindo seus custos?

Este artigo tem como objetivo principal, apresentar um método que possibilite atuar sobre uma ou mais etapas do processo, identificando e definindo ações de baixo investimento focada nos processos gargalos.

\section{REFERENCIAL TEÓRICO}

\subsection{MELHORIA CONTÍNUA}

Tanaka et. al (2012) define melhoria contínua como um grupo de pessoas em busca das melhores práticas nas atividades de trabalho, de forma organizada, com eficiência dos recursos.

A melhora nas práticas de processos obtém-se com estratégias para obtenção de inovações em processos, com ferramentas de melhoria contínua, que tenham como foco eliminar desperdícios, melhorar produtos, aumentar a produtividade, implementando soluções que motivem e aguce a criatividade dos colaboradores (Guimarães et al. 2013).

Kennedy (2012) conceitua melhoria contínua como um processo onde as corporações buscam a melhoraria de seus serviços, processos e produtos. Ainda segundo o autor, os processos de melhoria contínua de sucesso incorporam mecanismos de medição, avaliação e monitoramento, que levam em consideração as necessidades dos clientes. Essa visão do autor nos remete a ligação do processo de melhoria contínua com os sistemas de qualidade das organizações.

Por meio da avaliação dos processos busca-se a melhoria contínua, analisando a capacidade do estado atual para atingir os objetivos, após a identificação os processos críticos e a prioridade de melhoria (Fernandes, 2012).

Segundo Mesquita e Alliprandini (2003), as competências existentes nas organizações quando utilizadas na prática da melhoria contínua, podem levar ao aperfeiçoamento continuado dos processos. A visão dos autores demonstra que as competências existentes nas organizações através de seu corpo de colaboradores, devem ser canalizadas para os processos de melhoria continua. Ainda segundo os autores é possível verificar em várias organizações, atividades e processos de melhoria que são denominados processos de "melhoria contínua".

Oprime et al. (2011) cita que a melhoria contínua pode ser considerada como um fundamento dos modelos de gestão da produção baseados na gestão da qualidade total e produção enxuta.

A melhoria contínua pode ser implementada em quaisquer organizações por meio de um programa independente, que produz avanços cumulativos nos indicadores de resultados de uma organização (Oprime et al. 2011).

\subsection{TEORIA DAS RESTRIÇÕES (THEORY OF CONSTRAINTS - TOC)}

A Teoria das Restrições (Theory of Constraints - TOC) originou-se de um Sistema de Informação denominado Optimized Production Technology (OPT), englobando planejamento da produção, administração de gargalo e sincronização da manufatura, desenvolveu-se para obtenção de ganho, por meio da gestão eficiente dos recursos e restrições de cada empresa (Ferreira 2008). 
De acordo com Reis (2007), buscando-se a diferenciar os temas restrição e gargalo dentro da TOC, tem-se que uma restrição pode ocorrer em qualquer parte da empresa, ou mesmo fora dela, como no caso das restrições de mercado e a existência de um gargalo dependerá da relação entre capacidade e volume de demanda dos recursos fabris.

A base da TOC está em que qualquer sistema tem ao menos uma restrição, caso contrário o mesmo poderia produzir uma quantidade infinita do seu produto (Zattar 2004).

Segundo Goldratt e Cox (2014), a TOC leva a uma melhoria que abrange não só os custos (despesas operacionais), mas principalmente o aumento dos ganhos atuando sobre os gargalos existentes.

Neste sentido, Alves et al. (2011) apontam que a TOC, coloca em primeiro lugar o ganho; o inventário em segundo; e em terceiro, o custo (despesas operacionais).

Evidencia-se que com a aplicação da TOC, obtém-se melhoria nos resultados, que por sua vez impactam positivamente no desempenho organizacional (Pacheco 2014).

Segundo Zattar (2004) com a TOC propõe-se 9 princípios de otimização: balanceamento do fluxo e não da capacidade do sistema; não é o potencial do recurso que determina seu nível, e sim outra restrição do sistema; utilização e ativação de um recurso não são sinônimos; uma hora perdida no gargalo é uma hora perdida em todo sistema; uma hora economizada em recurso que não é gargalo não gerará resultado no sistema; os gargalos ditam o ganho e o inventário; lotes de transferência e de processamento não podem, e muitas vezes, não deve ser iguais; o lote de processo deve ser variável e não fixo e os programas devem ser estabelecidos considerando todas as restrições simultaneamente.

A aplicação da TOC consiste basicamente em: identificação do gargalo do sistema; tomada de decisão de como explorar os gargalos; subordinação de todos os recursos a decisão anterior; elevação dos gargalos do sistema e atuação contínua nos recursos que terão a migração do gargalo (Goldratt e Cox 2014).

\section{MÉTODO}

Utilizou-se como método de pesquisa o relato de caso, como investigação exploratória e escolheu-se como amostra uma empresa, objeto deste estudo, por conveniência, a partir da experiência prática de um dos autores que trabalhou na empresa entre abril de 2000 a março de 2008, na unidade brasileira de uma multinacional do Segmento de Telecomunicações, posicionada entre as maiores do mundo. Sendo um dos responsáveis por monitorar os resultados obtidos pelas empresas fornecedoras que integravam a cadeia de suprimentos e tendo acesso a documentação do método de melhoria contínua aplicado, possibilitou-se o acompanhamento em mais de 10 (dez) empresas fornecedoras. Por questões de sigilo e confidencialidade contratual, o nome da empresa e dos processos serão preservados, pois por serem específicos, possibilitaria a identificação da mesma.

Para fundamentação teórica, executou-se pesquisa bibliográfica de materiais já publicados tais como: livros, revistas, publicações em periódicos, artigos científicos, monografias, internet, entre outros.

Também foram pesquisadas bases de dados (Google Acadêmico; Portal de Periódicos CAPES e EBSCO), as seguintes palavras-chave: Teoria das Restrições, Gargalos, Melhoria Contínua.

Os estudos exploratórios são aplicáveis para descrever completamente determinado fenômeno, tanto descrições quantitativas e qualitativas quanto acumulação de informações detalhadas como as obtidas por intermédio da observação do participante (Marconi e Lakatos 2003).

Implementou-se o seguinte método de melhoria contínua na empresa fornecedora:

- Formação de 02 (dois) grupos de trabalho;

- Reunião de sensibilização com os grupos de trabalho, envolvendo também dois executivos da empresa;

- Esclarecimento do método e esclarecimentos de dúvidas;

- Mobilização dos grupos de trabalho, a princípio os gestores da empresa;

- Medição de parâmetros iniciais antes das melhorias;

- Identificação dos processos gargalos a serem explorados;

- Descrição detalhada dos processos gargalos; 
- Levantamento dos pontos potenciais de melhoria dos processos descritos, identificando suas causas;

- Propostas de soluções para os pontos potenciais levantados, de modo a solucionar todas causas identificadas;

- Simulação das soluções propostas visando sua aplicabilidade;

- Cálculo do retorno sobre o investimento para as soluções que contemplavam investimento financeiro;

- Medição dos resultados obtidos pós-melhorias implementadas;

- Preenchimento dos relatórios do trabalho realizado;

- Preparação do trabalho realizado para apresentação;

- Apresentação dos resultados aos executivos.

Aplicando-se a metodologia descrita, trabalhou-se para verificar qual o resultado obtido nos processos da empresa fornecedora.

\section{RESULTADOS E DISCUSSÃO}

Inicialmente a empresa compradora objeto do estudo foi procurada pelo fornecedor para obtenção de um reajuste no contrato de fornecimento na ordem de $\mathrm{R} \$ 5.000 .000,00$ anuais. Neste momento foi apresentado e proposto para o fornecedor a implementação de um método de melhoria contínua com potencial resultado para a redução dos custos, para que posteriormente ao trabalho fossem retomadas as negociações.

Tendo sido aceito pelo fornecedor, implementou-se o método de melhoria contínua conforme descrito no item anterior deste artigo, tendo sido identificados dois processos gargalos a serem trabalhados, com a respectiva formação de dois grupos de trabalhos, sendo dois integrantes da empresa contratante e 07 integrantes da empresa fornecedora, tendo sido o segundo processo gargalo trabalhado após a conclusão dos trabalhos sobre o primeiro processo gargalo.

Mediu-se os parâmetros iniciais antes da melhoria, conforme coluna "Inicial" da tabela 1, e em seguida após a descrição detalhada dos processos gargalos, procedeu-se a identificação de 45 pontos de melhorias nos gargalos e foram propostas e implementadas 19 soluções para aliviar os gargalos, Grupo A. Quanto ao Grupo B, procedeu-se a identificação de 47 pontos de melhorias nos gargalos e foram propostas e implementadas 11 soluções para aliviar os gargalos.

Testou-se por simulação as soluções propostas, e após evidenciar-se a viabilidade das mesmas, procedeuse ao cálculo do resultado do trabalho, conforme colunas "Final", "Diferença" e "Melhoria(\%)" da tabela 1.

Tabela 1: Parâmetro antes e pós melhoria

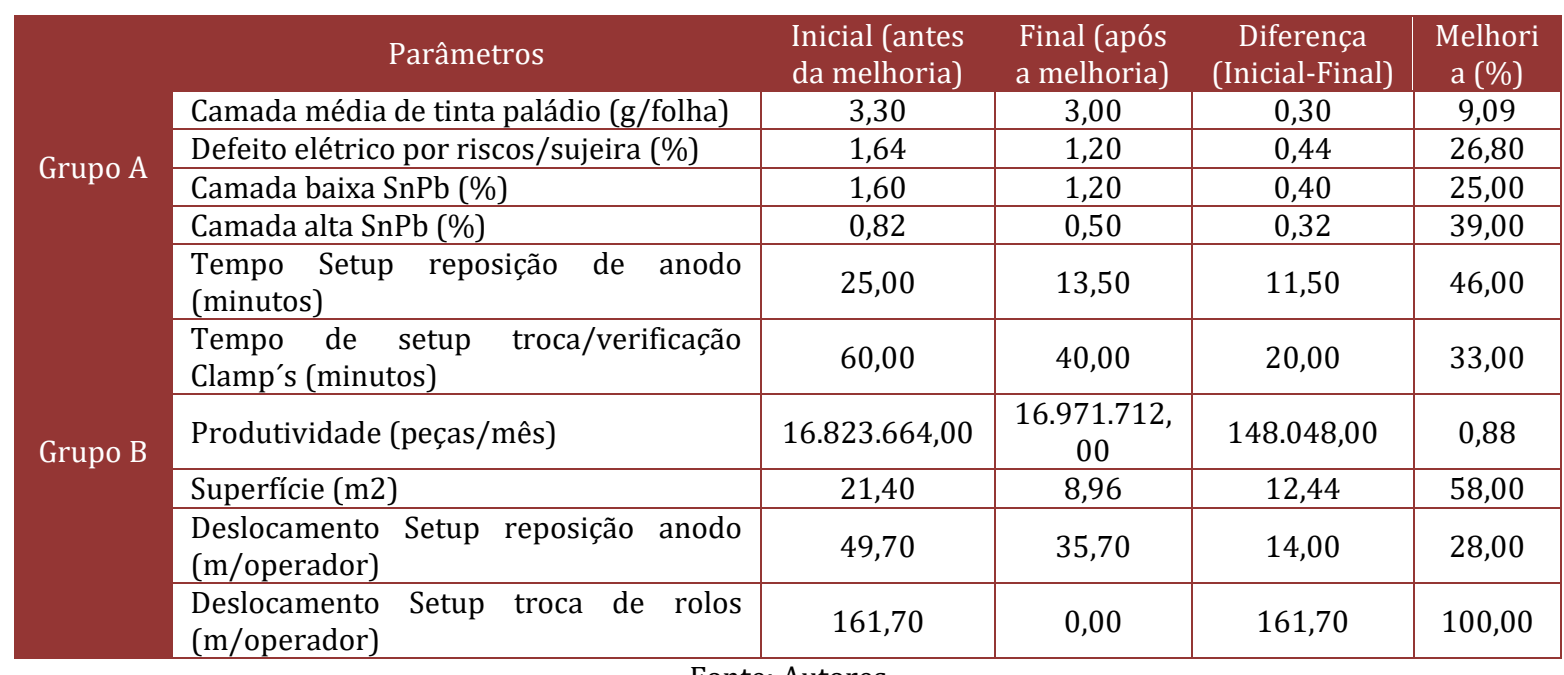


Após implementação do método de melhoria, obteve-se como resultado final os seguintes valores de melhoria: 9,09\% na camada média de tinta paládio; $26,80 \%$ de redução no defeito elétrico por riscos/sujeira; $25,00 \%$ na camada baixa de estanho-chumbo(SnPb); 39,00\% na camada alta de estanhochumbo(SnPb); 46,00\% no tempo de setup para reposição de anodo; 33,00\% no tempo de setup para troca/verificação de Clamp's; 0,88\% na produtividade; 58,00\% em área utilizada no processo (superfície); $28,00 \%$ no deslocamento no setup para reposição do anodo e $100,00 \%$ no deslocamento no setup para troca de rolos.

Em valores, estes resultados obtidos propiciaram que quando retornou-se a negociação do reajuste contratual, a empresa fornecedora que a princípio pedia um aumento de $\mathrm{R} \$ 5.000 .000,00$ no ano, acabou por conceder um desconto de R\$1.000.000,00 no ano.

Com estes resultados a empresa fornecedora identificou que sua estratégia para melhoria do resultado estava internamente em seus processos e não em buscar externamente um reajuste de valor junto a empresa contratante.

Evidencia-se ainda que a melhoria contínua é uma forma que a empresa obteve para repensar seus processos, seus fluxos, seus recursos, humanos, físicos, financeiros, entre outros, e assim possibilitar ainda inovações de processos, as quais são de baixo investimento e alto retorno.

Para empresa contratante, tal método apresentou-se totalmente rentável junto ao contrato de fornecimento do produto em questão. Obtém-se resultados financeiros positivo ao implementar um processo de manufatura enxuta, na liquidez, atividade e lucratividade (Silva, et al. 2016). Também neste sentido Schemes (2014), nos traz que a melhoria na eficiência operacional com processos mais aderentes proporciona segurança na performance, redução de tempos de espera e dos serviços e redução dos custos operacionais, tornando a operação mais rentável.

\section{CONSIDERACÕES FINAIS}

Este artigo buscou demonstrar que aplicando-se um método de melhoria contínua é possível a identificação de pontos internos de melhoria que se, identificadas, propostas e implementadas as soluções, levarão a empresa a obter eficiência operacional, e possibilitando assim a redução dos custos e consequentemente redefinição de suas estratégias e políticas de preços.

Apresentou-se um método que envolveu uma estratégia pelas partes cliente-fornecedor, possibilitando que prioridades de atuação fossem identificadas, e que o foco de atuação direcione-se para estas visando a redução dos custos, sem a necessidade da realização prévia de treinamento por parte dos integrantes das equipes da empresa fornecedora.

Percebeu-se que com a metodologia obteve-se maior valor agregado, pois ao melhoras os processos gargalos, possibilita-se que os fluxos das atividades sejam reduzidos, e assim, a empresa evolui em sua eficiência operacional.

Este método, após os resultados obtidos, foi aplicado para diversas outras empresas fornecedoras, que conseguiram também obter resultados de eficiência operacional, comprovando a viabilidade da adoção como uma metodologia para melhoria contínua, baseada na Teoria das Restrições.

Este relato apresenta um caminho para futuros estudos por empresas e instituições de qualquer outro segmento e porte em aplicar esta metodologia, adequando sua estrutura por meio da priorização de pontos de atuação inerentes a sua realidade, cultura e estratégias, uma vez que a Teoria das Restrições possibilita que cada empresa otimize seus processos, reduzindo os desperdícios de processo e consequentemente os custos, bem como proporciona que os resultados obtidos possa gerar condições das empresas expandirem-se e conquistar perenidade em seu mercado.

\section{REFERÊNCIAS}

[1] ALVES, A. P., SILVA, T. G., ALMEIDA, R. S., COGAN, S. Utilizando os Passos da Teoria das Restrições para a Melhoria Contínua da Produção: um Estudo Aplicado a uma Fábrica de Jeans. Revista ADM.MADE, Rio de Janeiro, ano 11, v.15, n.1, p.93-114. 2011.

[2] FERNANDES, Diogo Gouveia. Melhoria contínua na gestão de projetos: desenvolvimento e aplicação da ferramenta MAPEA. 104f. Dissertação (Mestrado em Engenharia e Gestão Industrial). Faculdade de Ciências e Tecnologia da Universidade Nova de Lisboa. Lisboa. 2012. 
[3] FERREIRA, Alessandra Henriques. Aspectos importantes na implantação da teoria das restrições na gestão da produção: um estudo multicaso. 167 f. Dissertação (Mestrado em Administração das Organizações), Departamento de Administração da faculdade de Economia, Administração e Contabilidade de Ribeirão Preto, Universidade de São Paulo, Ribeirão Preto. 2008.

[4] GOLDRATT, Eliyahu Moshe; COX, Jeff. A Meta: um processo de melhoria continua. São Paulo. Nobel. 2014. 366 p.

[5] GUIMARÃES, J.C.F.; SEVERO, E.A.; PEREIRA, A.A.; DORION, E. C. H.; OLEA, P.M. Inovação no processo e melhoria contínua em uma indústria de plásticos do pólo moveleiro da serra gaúcha, Revista Eletrônica Sistemas \& Gestão v. 8, n. 1, p. 34-43. 2013.

[6] KENNEDY, Barrack. Impact of continous improvement on costumer's satisfaction: A case study of Emirates Airline. Grin Verlag, Munich. 2012.34 p.

[7] MARCONI, Marina de Andrade; LAKATOS, Eva Maria. Fundamentos da metodologia científica. 5 Ed., Atlas, São Paulo. 2003.

[8] MESQUITA, M., ALLIPRANDINI, D. H. Competências essenciais para melhoria contínua da produção: estudo de caso em empresas do setor de autopeças. Gestão \& Produção, v. 10, n. 1, p. 17-33, São Carlos. 2003.

[9] OPRIME, P. C., MENDES, G. H. S, PIMENTA, M. L. Fatores críticos para a melhoria contínua em indústrias brasileiras. Revista Produção, v. 21, n. 1, p. 1-13. 2011.

[10] PACHECO, Diego Augusto de Jesus. Teoria das Restrições, Lean Manufacturing e Seis Sigma: limites e possibilidades de integração. Production, v. 24, n. 4, p. 940-956. 2012.

[11] REIS, Elias dos Santos. Teoria das restrições e gestão da demanda: uma análise conceitual. 170 f. Dissertação (Mestrado em Engenharia da Produção). Faculdade de Engenharia, Arquitetura e Urbanismo, da Universidade Metodista de Piracicaba, Piracicaba. 2007.

[12] SCHEMES, Gilcinei Souza Alinhamento dos processos de negócio aos objetivos estratégicos: método de estudo de caso no setor de concessionárias de veículos automotores. 109 f. Dissertação (Mestrado em Economia). Faculdade de Ciências Econômicas, da Universidade Federal do Rio Grande do Sul, Porto Alegre. 2014.

[13] SILVA, M.M.; LIMA, S.R.; IZABEL CRISTINA ZATTAR, I. C.; CLETO, M. G. O Impacto da implementação da Manufatura Enxuta nos indicadores financeiros de uma indústria Fordista: um estudo de caso. Produção em foco, v. 6 n. 1, p. 163-182. 2016.

[14] TANAKA, W. Y.; MUNIZ JR., J.; NETO, A.F. Fatores críticos para implantação de projetos de melhoria contínua segundo líderes e consultores industriais. Revista Eletrônica Sistemas \& Gestão, v. 7, n. 1, p. 103-121. 2012.

[15] ZATTAR, Izabel Cristina. Análise da aplicação dos sistemas baseados no conceito de capacidade finita nos diversos níveis da administração da manufatura através de estudos de caso. 136 f. Dissertação (Mestrado em Engenharia). Universidade Federal de Santa Catarina, Florianópolis. 2004. 


\section{Capítulo 8}

\section{Previsão dos custos de produção de suínos por meio dos Modelos de Holt-Winters}

\section{Bruno Matos Porto}

\section{Daniela Althoff Philippi}

Resumo: 0 objetivo da pesquisa descrita neste artigo foi gerar previsões e comparar a precisão no curto prazo do modelo Holt-Winters (HW), versões aditiva e multiplicativa nos custos de produção de suínos da região do estado de Goiás, por meio do R Studio. 0 modelo foi aplicado com o pacote forecast, baseando-se no histórico de dados da Empresa Brasileira de Pesquisa Agropecuária (Embrapa). Os dados referem-se a custos de produção de suínos do período entre janeiro de 2007 e julho de 2017. Constatou-se que a versão aditiva de HW obteve melhores resultados quando comparados aos da versão multiplicativa. As previsões dos custos geradas com o modelo de HW apresentaram, no conjunto dos dados analisados e no horizonte de previsão de três meses fora da amostra, plausível acuracidade. Contudo, como qualquer modelo de previsão que se baseia unilateralmente em dados históricos, deve-se, também, considerar variáveis extrínsecas no processo decisório.

Palavras-chave: Modelagem; Precisão da previsão; Previsão de séries temporais; Commodity; Modelos de previsão. 


\section{INTRODUÇ̃̃OO}

Tanto no meio acadêmico, quanto em corporações empresariais, destacam-se pesquisas relacionadas ao comportamento dos custos (Medeiros, Costa, \& Silva, 2005). A pesquisa sobre custos de produção de suínos para a gestão do ramo de suinocultura tem grande relevância, pois revela a eficiência da atividade (Girotto \& dos Santos Filho, 2000; Girotto \& Protas, 1989). No ramo empresarial da suinocultura, a adesão a ferramentas gerenciais, pode possibilitar ao produtor a conferência de resultados financeiros e, desta maneira, contribuir com a permanência no negócio (Toigo, Gollo, Leite, \& Klann, 2015).

(Maher, 2001) afirma que há três razões para o monitoramento dos custos pelos gestores: (1) usar o seu conhecimento para estimar custos de produção futuros, o que contribui para elaborar projetos semelhantes e participar de concorrências; (2) confrontar os custos reais dos trabalhos em relação aos orçados para controlar, objetivando evitar inesperados custos adicionais em andamento do projeto; e, por fim, (3) utilizar as informações sobre custos estimados na renegociação de contratos.

A tomada de decisão depende de previsões precisas para não incorrer em mau uso de recursos ou eliminação de oportunidades (Karchere, 1976). Neste enfoque, para Silver (2000), na seleção do método de previsão é necessário considerar: (a) o objetivo da previsão; (b) até quando será realizada a predição; (c) a relação quantidade/custo das predições desejadas; (d) a experiência dos desenvolvedores; (e) o período; (f) é compatível com o sistema de planejamento já utilizado; (g) as características estatísticas das séries temporais; e (h) os dados históricos.

Previsões são obtidas a partir dos conceitos de custo real e previsão de custo, que possibilitam a comparação entre ambos. 0 custo real é aquele que realmente ocorreu no período de produção dos itens; assim, a previsão de custo refere-se ao futuro, ou seja, ao que ocorrerá para os itens que serão produzidos (Colmanetti, 2001). A possibilidade de prever os dados futuros, por meio do histórico de dados, é uma ferramenta interessante para apoiar as decisões individuais e organizacionais (Tong, 2015). Entretanto, é necessário que os métodos de previsão sejam adotados por gestores, com precaução, pois, além das próprias observações, outras variáveis devem ser consideradas, como bem pontua (Stevenson, 1981), de que as variáveis extrínsecas podem influenciar as observações históricas.

A taxa de câmbio é uma variável econômica que afeta os custos de produção dos insumos importados para a produção de suínos (Talamini \& dos Santos Filho, 2015). Em 2014 e 2015, a desvalorização do real frente ao dólar influenciou, de forma negativa, a produção da suinocultura, pois acarretou uma inflação de custos nos insumos importados (Miele \& Sandi, 2015).

A versão multiplicativa de HW tem sido comumente estudada na previsão dos custos de produção em segmentos distintos, e a sua adoção tem produzido previsões confiáveis comparadas às de outros modelos. Neste contexto, (Brandon, Jarrett, \& Khumawala, 1987) evidenciaram que o método de previsão de HW é bastante útil para os decisores e planejadores estratégicos que visam a um modelo rentável e relativamente preciso, com predições de valores fora da amostra de uma grande variedade e um vasto número de séries cronológicas.

$\mathrm{Na}$ área da saúde, o método foi adotado nos custos da eletricidade de um hospital da rede pública do Reino Unido. Realizou-se uma comparação com os métodos de alisamento exponencial simples e duplo, com a média móvel simples e dupla e com HW versões aditiva e multiplicativa, aplicados aos dados reais. 0 método de HW, versão multiplicativa, apresentou os melhores resultados e, sendo validado por especialistas e com medição de erro estatístico, incidiu na conclusão de que o método pode ser utilizado na previsão de custos de eletricidade futuros (Kirkham, Boussabaine, \& Matthew P. Kirkham, 2002).

Na construção civil, o método foi utilizado com base no índice de custos de construção (CCI), a partir dos preços de atividades de construção de 20 cidades norteamericanas. Com a comparação da previsibilidade dos modelos média móvel simples, suavização exponencial de Holt, Holt-Winters, ARIMA e ARIMA sazonal para modelar o CCI, o modelo ARIMA sazonal foi identificado como o modelo de séries temporais mais preciso e aplicável para a previsão na amostra de CCI. Na sequência, o Holt-Winters revelou-se como a abordagem de séries temporais mais precisa para a previsão de CCI para fora da amostra (Ashuri \& Lu, 2010).

No Brasil, segundo (Massilon, 2013), no histórico do agronegócio, houve determinados períodos com aumento nos custos de produção e queda dos preços dos produtos da agropecuária, exigindo do produtor, ainda mais, a busca por menores custos para se manter competitivo e, até mesmo, para aumentar a sua competitividade. 
A indústria de suínos foi selecionada para este estudo, pois o setor tem grande importância na economia do país. Em termos de competitividade de custos de produção de suínos, o Brasil foi líder em 2014 e 2015, entre os países analisados pela rede InterPIG e Embrapa Suínos e Aves (Miele \& Sandi, 2015).

Ademais, o mercado da suinocultura brasileira, de acordo com a Associação Brasileira dos Criadores de Suínos (ABCS \& SEBRAE, 2016), somou, em 2015, R\$ 62,576 bilhões do Produto Interno Bruto (PIB) da suinocultura, e a sua cadeia produtiva movimentou R\$149,867 bilhões. Além disso, conforme dados da Associação Brasileira de Proteína Animal (ABPA, 2015, 2016), nos anos de 2014 e 2015, o Brasil foi o 4 o maior produtor mundial de suínos e o $4^{\circ}$ maior exportador.

A suinocultura foi selecionada: (1) por ter uma série temporal potencialmente candidata ao modelo por suas premissas particulares de tendência e sazonalidade; (2) há flutuações diárias de preços de insumos de produção (milho e farelo de soja) que são commodities agrícolas vendidas; e (3) a série temporal dos custos de produção mensais de suínos está disponível (Embrapa, 2017).

Diante disso, o objetivo da pesquisa descrita neste artigo foi realizar previsões de curto prazo, especificamente num único horizonte de três meses à frente e comparar as previsões, por meio dos critérios MAD, MAPE e MSE, em série temporal de custos de produção do quilograma vivo de suínos.

\section{BASE TEÓRICA}

A seguir, apresentam-se, com base na literatura consultada, séries temporais, o modelo de Holt-Winters (HW) e índices de desempenho.

\subsection{SÉRIES TEMPORAIS}

Os métodos mais utilizados na prática para prever custos são: estimativas de engenharia; análise de contas; diagrama e estimativas alto-baixo e métodos estatísticos como análise de regressão (Maher, 2001). Nessa linha e de forma geral, previsões são resultantes de métodos que: (1) comtemplam a coleta de informações importantes; e (2) analisam os dados para que, então, apliquem-se procedimentos quantitativos de séries temporais de informações do histórico, entre outros (Corrêa, 2012).

As séries cronológicas são formadas de valores observados em vários períodos ordenados e subsequentes (Kazmier, 1982; Porto, 2021; Stevenson, 1981). A compreensão das séries pretende verificar se há algum padrão não aleatório, com o objetivo de utilizar as séries para estimar os seus valores futuros com base nos valores passados (Stevenson, 1981). A decomposição de série temporal tem utilidade para o planejamento e previsão (Silver, 2000). Como exemplo para afirmação, o autor cita a relevância de se conhecer a amplitude da sazonalidade quando a demanda é sazonal.

(Stevenson, 1981) complementa que os modelos de séries temporais classificam-se em duas variantes: multiplicativo e aditivo. 0 primeiro considera a série como resultado do produto dos componentes individuais, enquanto que o segundo consiste na resultante da soma dos componentes individuais, sendo o multiplicativo o mais utilizado por trazer mais exatidão nas previsões.

\subsection{HOLT-WINTERS (HW)}

0 modelo de previsão Holt foi criado em 1957, e o método Holt-Winters foi proposto por Winters em 1960, sendo uma extensão do modelo Holt, pois apresenta adicionalmente um parâmetro de suavização e uma equação para a sazonalidade (Makridakis, 1976). As principais vantagens da aplicação do HW são: a sua simples utilização (Chatfield, 1978; Chatfield \& Yar, 1988; Silver, 2000); o seu bom desempenho, de modo geral e na prática (Chatfield \& Yar, 1988); o baixo custo de operação (Newbold \& Granger, 1974; Serra, Tavares, \& Santos, 2005) e a utilidade que apresenta para prever semelhante ao modelo complexo ARIMA de Box-Jenkins (Silver, 2000).

De acordo com (Chatfield, 1978), o método de HW é mais apropriado para planejamento de produção e controle de estoque quando as predições referem-se a um amplo número de observações. HW ainda possibilita que os dados sejam modelados pela média, tendência e sazonalidade locais, atualizadas pela suavização exponencial (Chatfield \& Yar, 1988). 
O método de HW baseia-se em equações apresentadas a seguir: a primeira, o componente nível (1), em seguida, o componente tendência (2) e, então, o componente sazonal (3) e, por fim, as previsões do tempo (4). Quanto à sazonalidade, pode-se adotar a versão sazonal aditiva que considera os efeitos sazonais de dimensionamento constante ou multiplicativo que supõem os efeitos sazonais simétricos em dimensão, em um nível médio dessazonalizado local (Chatfield, 1978). As equações das versões multiplicativa e aditiva são exibidas na sequência.

$$
\begin{aligned}
& L_{t}=\alpha\left(\frac{x_{t}}{s_{t}-\mathrm{m}}\right)+(1-\alpha)\left(L_{t-1}+T_{t-1}\right) \\
& T_{t}=\beta\left(L_{t}-L_{t-1}\right)+(1-\beta) T_{t-1} \\
& S_{t}=\gamma\left(\frac{x_{t}}{L_{t}}\right)+(1-\gamma) S_{t-m} \\
& F_{t+n}=\left(L_{t}+n T_{t}\right) S_{t-m+n}
\end{aligned}
$$

Fonte: Adaptado de (Chatfield, 1978).

Na versão aditiva, são as equações:

$$
\begin{aligned}
& L_{t}=\alpha\left(x_{t}-S_{t-m}\right)+(1-\alpha)\left(L_{t-1}+T_{t-1}\right) \\
& T_{t}=\beta\left(L_{t}-L_{t-1}\right)+(1-\beta) T_{t-1} \\
& S_{t}=\gamma\left(x_{t}-L_{t}\right)+(1-\gamma) S_{t-m} \\
& F_{t+n}=L_{t}+n T_{t}+S_{t-m+n}
\end{aligned}
$$

Fonte: Adaptado de (Chatfield, 1978).

Onde: $L_{t}$ - estimativa do grau médio dessazonalizada no período $\mathrm{t}$; $T_{t}$ - fator sazonal estimado para o tempo t; $S_{t}$ - prazo de tendência estimado para o tempo t; $\mathrm{m}$ - número de considerações em ciclo sazonal; $F_{t+n}$ - predições de período $\mathrm{n}$ em diante; $\mathrm{n}-1,2, \ldots ; x_{t}$ - número observado e $\alpha, \beta$ e $\gamma$ - constantes de ponderação de nível, tendência e sazonalidade, nesta ordem (Chatfield, 1978).

\section{3 ÍNDICES DE DESEMPENHO}

Medidas de precisão ou erros são maneiras de obter informações sobre a predisposição de certo método de previsão para valores futuros dos dados reais, tanto para medidas que são ajustadas aos dados quanto para períodos previstos, posteriores aos dados (Makridakis, 1993). O problema de identificar quais indicadores de acurácia devem ser utilizados para verificar o modelo de previsão mais exato é bastante enfatizado na literatura sobre o tema previsão, sendo que, dentre as classes de indicadores que se dedicam ao tema discrepância de previsão, estão Mean Absolute Deviation (MAD) equação (9) e Mean Squared Error (MSE) equação (10) (Fader, Hardie, \& Zeithammer, 2003).

O MSE é um indicador vastamente adotado para verificar o desempenho de um método de previsão a um histórico de dados e a exatidão das predições feitas pelo método de previsão e, por vezes, coerente indicador de predição para examinar uma única série temporal (Chatfield, 1988). Ainda sobre o MAD e o MSE, estes são medidas utilizadas para observar o desempenho de um método de previsão já selecionado (Moreira, 2011).

Outro indicador utilizado na intenção de comparar qual versão multiplicativa ou aditiva ajustou-se melhor aos dados foi Mea Absolute Percentage Error (MAPE) equação (11). Neste aspecto, o MAPE pode ser mais apropriado, pois gera os resultados em percentagem média, facilitando a compreensão da informação pelos tomadores de decisão por ser uma medida estatística em porcentagem (Makridakis, 1993). 
Em alguns estudos, foram adotadas as medidas de precisão MAD, MAPE e MSE para verificar a acuracidade de modelos, tais como a pesquisa de (Ashuri \& Lu, 2010), na previsão do índice de custo de construção (CCI); (Oliveira, Bortolotti, Minosso, \& Lazzarotto, 2013), na previsão de quantidade de leite vendida (Schrippe, Santos, Vincenzi, Junior, \& Iarczewski, 2015), na previsão do lucro líquido da Natura, (Porto \& Philippi, 2017), na previsão de custos de produção de suínos; (Porto \& Philippi, 2018), na previsão de custos de produção de suínos; (Porto, Philippi, \& Leite, 2018); (Porto, Philippi, \& Leite, 2019), na previsão da demanda turística; e (Porto, 2021), na previsão de preços da soja, respectivamente nos setores de indústria da construção nos Estados Unidos, na indústria de produção leiteira em um laticínio paranaense e na indústria Brasileira de produtos de higiene pessoal, perfumaria e cosméticos, suinocultura industrial, indústria do turismo e complexo da soja. Além disso, (Milnitz, Marchi, \& Samohyl, 2011; Porto, 2021; Porto et al., 2019) consideram que métodos de predição necessitam de avaliações, por meio das medidas de discrepância. As equações são:

$$
\begin{aligned}
M A D & =\frac{\sum|Y-D|}{n} \\
M S E & =\frac{\sum(Y-D)}{n-1} \\
M A P E & =\frac{\sum|Y-D / Y|}{n} \cdot 100,(Y \neq 0)
\end{aligned}
$$

Fonte: Adaptado de (Moreira, 2011).

Sendo, $\mathrm{Y}=$ valor real de custo; $\mathrm{D}=$ predição; $\mathrm{n}$ = número de observações.

A partir disso, as medidas de erro MAD, MSE e MAPE são importantes indicadores para avaliar o desempenho do modelo HW.

\section{PROCEDIMENTOS METODOLÓGICOS}

A pesquisa descreveu o comportamento da amostra referente a custos de produção de suínos de 2007 até julho 2017, por meio de variações percentuais. Para adoção do modelo, foram utilizados dados do estado de Goiás da Central de Inteligência de Aves e Suínos (CIAS), que pertence à empresa Brasileira de Pesquisa Agropecuária (Embrapa, 2017).

Os dados são referentes aos custos de produção de suínos nos períodos de janeiro de 2007 a julho de 2017, atingindo 127 períodos mensais de amostra.

Os dados utilizados encontram-se na Tabela 1 a seguir:

Tabela 1: Custo de produção de suínos, ciclo completo R $\$$ Kg vivo de janeiro de 2007 a julho de 2017

\begin{tabular}{|c|c|c|c|c|c|c|c|c|c|c|c|c|}
\hline Ano/Mês & Jan & Fev & Mar & Abr & Mai & Jun & \multicolumn{1}{c|}{ Jul } & Ago & \multicolumn{1}{c|}{ Set } & Out & Nov & Dez \\
\hline 2007 & 2,03 & 2,01 & 1,92 & 1,87 & 1,85 & 1,85 & 1,94 & 2,12 & 2,29 & 2,57 & 2,77 & 2,88 \\
\hline 2008 & 2,95 & 2,97 & 2,75 & 2,45 & 2,24 & 2,06 & 2,00 & 1,99 & 2,08 & 2,18 & 2,22 & 2,29 \\
\hline 2009 & 2,38 & 2,43 & 2,42 & 2,41 & 2,39 & 2,37 & 2,38 & 2,37 & 2,41 & 2,43 & 2,44 & 2,44 \\
\hline 2010 & 2,29 & 2,24 & 2,19 & 2,18 & 2,16 & 2,17 & 2,2 & 2,28 & 2,22 & 2,45 & 2,56 & 2,76 \\
\hline 2011 & 2,67 & 2,5 & 2,45 & 2,38 & 2,31 & 2,24 & 2,32 & 2,27 & 2,34 & 2,32 & 2,36 & 2,35 \\
\hline 2012 & 2,43 & 2,47 & 2,38 & 2,46 & 2,49 & 2,58 & 2,92 & 2,98 & 3,02 & 2,99 & 3,05 & 2,98 \\
\hline 2013 & 2,8 & 2,71 & 2,66 & 2,64 & 2,9 & 2,86 & 2,88 & 2,74 & 2,74 & 2,76 & 2,81 & 3,11 \\
\hline 2014 & 3,05 & 2,97 & 2,92 & 2,98 & 2,88 & 2,71 & 2,72 & 2,68 & 2,75 & 2,89 & 2,92 & 3,06 \\
\hline 2015 & 3,09 & 3,11 & 3,2 & 3,15 & 3,07 & 3,06 & 3,15 & 3,21 & 3,32 & 3,48 & 3,49 & 3,57 \\
\hline 2016 & 3,86 & 3,9 & 4,02 & 4,15 & 4,18 & 4,41 & 4,57 & 4,08 & 3,88 & 4,16 & 3,94 & 4,01 \\
\hline 2017 & 3,83 & 3,87 & 3,66 & 3,48 & 3,50 & 3,38 & 3,42 & - & - & - & - & - \\
\hline
\end{tabular}


A aplicação dos modelos de HW ocorreu por intermédio da linguagem de programação R. Procederam-se às previsões e à acuracidade no R Studio, mediante o pacote forecast (R. Hyndman et al., 2020; R. J. Hyndman \& Khandakar, 2008). A análise quantitativa dos dados seguiu o que ponderam (Bettis, Gambardella, Helfat, \& Mitchell, 2014) sobre o seu uso na pesquisa em administração, quanto à previsão de ocorrências futuras versus dados empíricos. Assim, contemplando o período entre janeiro de 2007 e julho de 2017, verificou-se o comportamento das previsões em relação aos dados reais, já disponibilizados em (Embrapa, 2017) e concernentes ao período de agosto a outubro de 2017.

\section{RESULTADOS E DISCUSSÕES}

Seguindo as orientações de (R. J. Hyndman \& Athanasopoulos, 2018), que recomendam inicialmente mostrar os dados em gráfico, por meio do qual se encontram padrões presentes de tendência e sazonalidade nos dados, plotou-se o gráfico de série temporal representado na Figura 1.

Figura 1. Custo de produção de suínos, ciclo completo, $\mathrm{R}$ /Kg vivo, no estado de Goiás

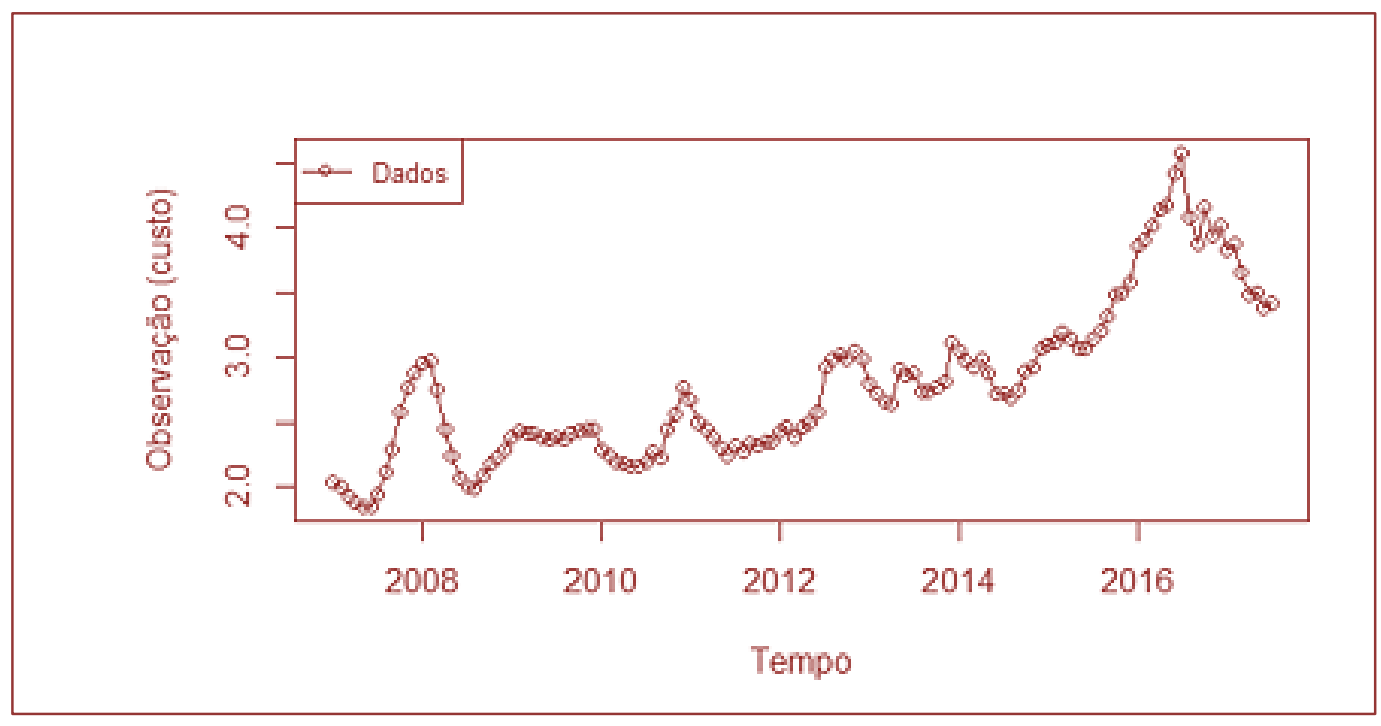

Fonte: Elaborada pelos autores, com base em dados da (Embrapa, 2017).

Pelos dados demonstrados de custo de produção, há uma clara tendência positiva que parece aumentar no final da série, exceto no primeiro semestre de 2008, quando ocorreram as maiores quedas percentuais $(7,40 \%, 10,90 \%, 8,57 \%, 8,03 \%)$, de março a junho, em comparação com o mês anterior, sendo os maiores aumentos mensais e consecutivos no segundo semestre de 2007 (4,86\%, 9,27\%, 8,01\%, 12,22\%, 7,78\%, 3,97\%), de julho a dezembro.

Na Figura 2, apresenta-se um gráfico elaborado a partir de análises de variação percentual mensal dos custos de produção de suínos com base nos dados secundários. Nota-se um padrão repetitivo nos dados dos meses de março quando comparados ao mês anterior (fevereiro) de quedas percentuais, caracterizando um comportamento sazonal anual que pode ser visto na Figura 2. Contudo, percebe-se que, com exceção nos meses de março de 2015 e 2016, nesses meses houve um baixo crescimento de 2,89\% e $3,07 \%$ em comparação aos respectivos meses anteriores de cada ano (fevereiro). No entanto, em março de 2017, retomou-se uma queda de (5,43\%), o que confirma o comportamento sazonal dos dados. 
Figura 2. Variação percentual mensal dos custos de produção de suínos de 02/2007 a 07/2017

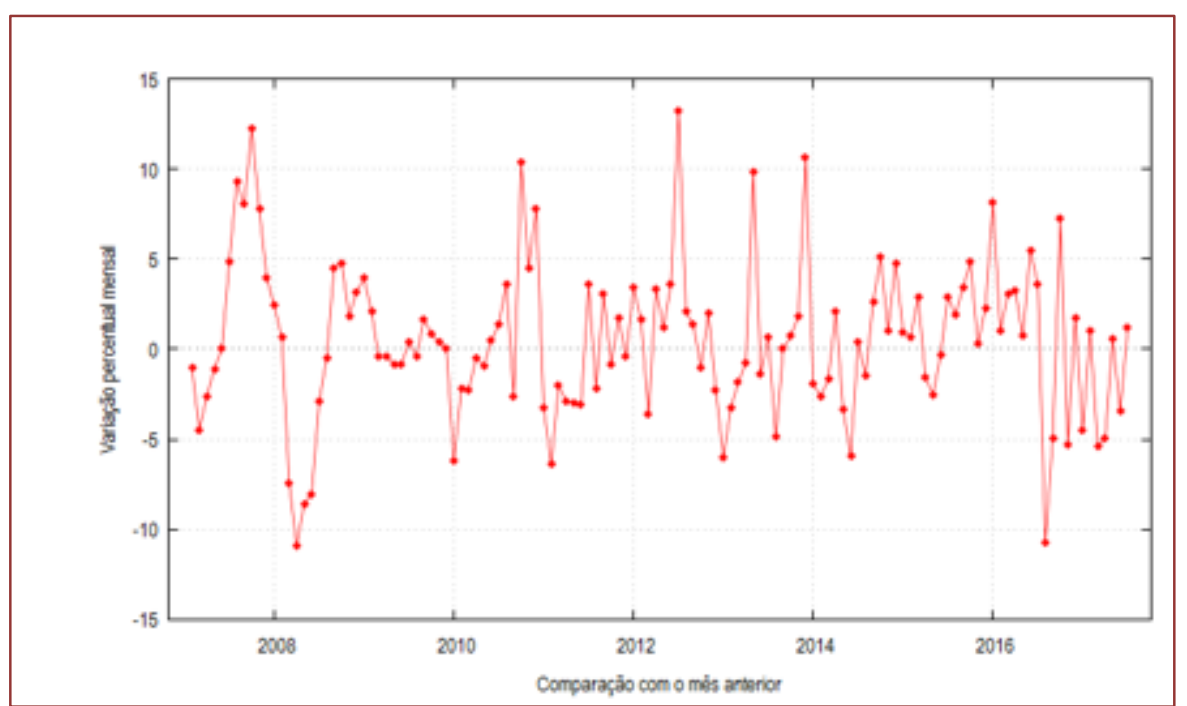

Fonte: Elaborada pelos autores, com base em (Embrapa, 2017).

(Silver, 2000) sugere que deve ser aplicado o método de HW para as séries temporais que apresentem padrão de sazonalidade. Diante das constatações, os dados têm duas características identificadas: por meio da variação percentual e decomposição da série temporal. Ambas são os componentes tendência e sazonalidade, características dos dados que demonstram que o modelo HW é adequado para a série temporal selecionada neste estudo.

Os parâmetros adotados pelo pacote forecast (R. Hyndman et al., 2020; R. J. Hyndman \& Khandakar, 2008), de suavização ou alisamento, são alpha $(\alpha)$, beta $(\beta)$ e gama $(\gamma)$, nesta sequência: da versão multiplicativa para as equações de nível (1), tendência (2) e sazonalidade (3) e a versão aditiva de nível (5), tendência (6) e sazonalidade (7) são demonstrados na Tabela 2.

Tabela 2: Parâmetros das previsões dos modelos

$$
\begin{array}{ll}
\text { HW multiplicativa }(\alpha, \beta, \gamma) & (0.6523389,0,1) \\
\text { HW aditiva }(\alpha, \beta, \gamma) & (0.9729007,0,1)
\end{array}
$$

Fonte: elaborada pelos autores.

A série temporal dos dados históricos de custo de produção de janeiro de 2007 a julho de 2017 foi decomposta para versão multiplicativa, em observações, nível, tendência e sazonalidade. A demonstração gráfica está na Figura 4. Observadas as Figuras 3 e 6, as séries temporais com observações e das versões multiplicativa e aditiva foram mostradas para visualizar o acompanhamento das versões com os dados reais antes das previsões. 
Figura 3. Série temporal da versão multiplicativa

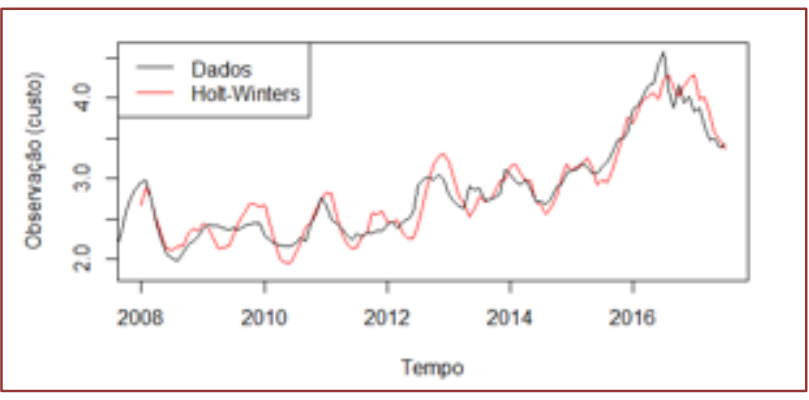

Fonte: Elaborada pelos autores, com base em dados da (Embrapa, 2017).
Figura 4. Decomposição da série multiplicativa em observação, nível, tendência e sazonalidade

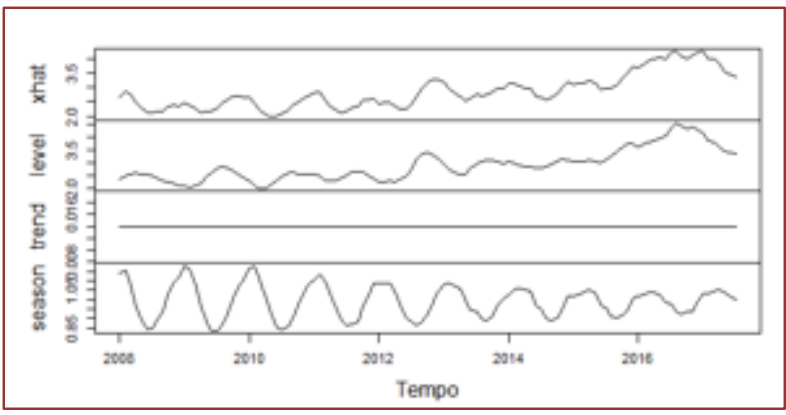

Fonte: Elaborada pelos autores, com base em dados da (Embrapa, 2017).

Figura 5. Previsão versão multiplicativa de agosto até outubro de 2017, com intervalo de confiança de $95 \%$

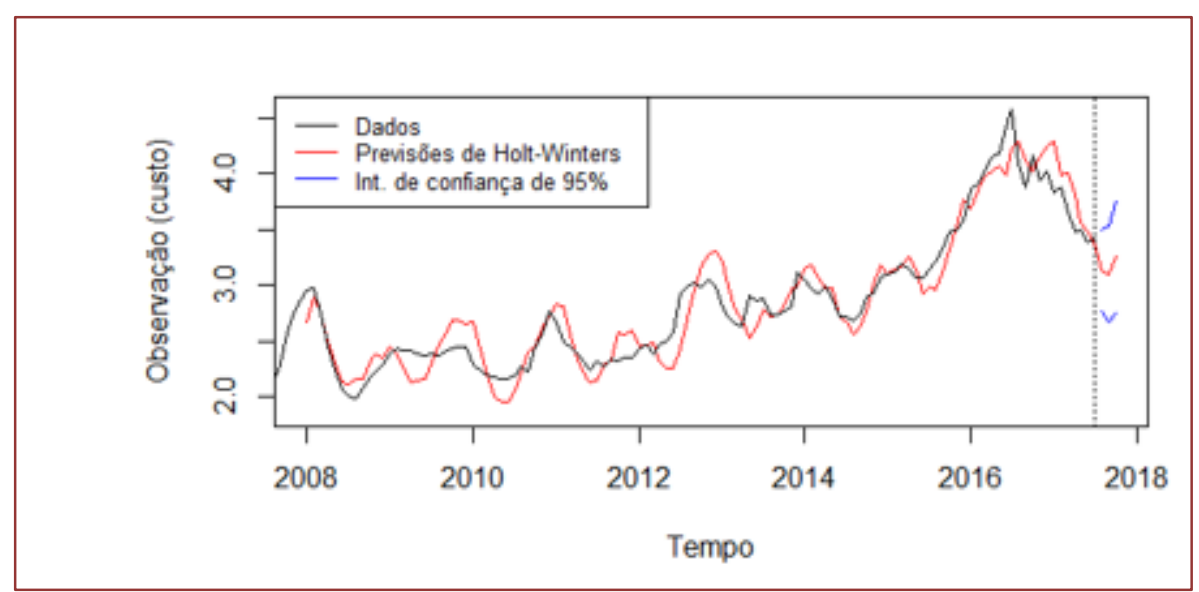

Fonte: Elaborada pelos autores, com base em (Embrapa, 2017).

Em seguida, como está apresentada na Figura 7, a série temporal foi decomposta em componentes: observações, nível, tendência e sazonalidade, nesta ordem.

Figura 6. Série temporal da versão aditiva

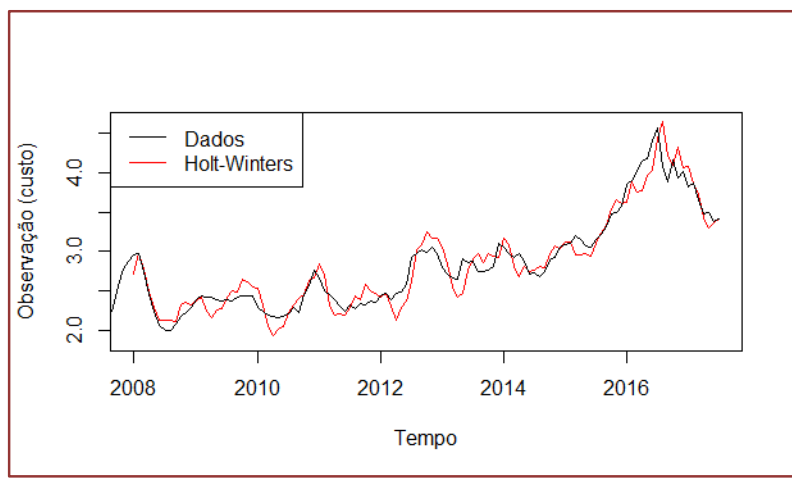

Fonte: Elaborada pelos autores, com base em dados da (Embrapa, 2017)
Figura 7. Decomposição da série aditiva em observação, nível, tendência e sazonalidade

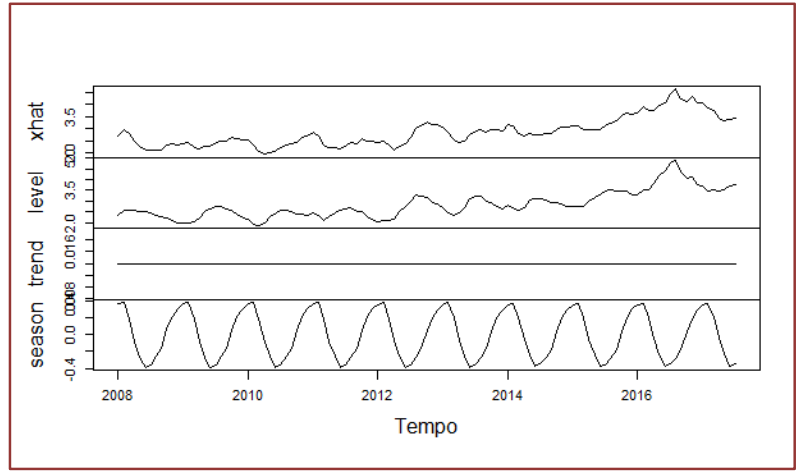

Fonte: Elaborada pelos autores, com base em dados da (Embrapa, 2017). 
Figura 8. Previsão versão aditiva de agosto até outubro de 2017, com intervalo de confiança de 95\%

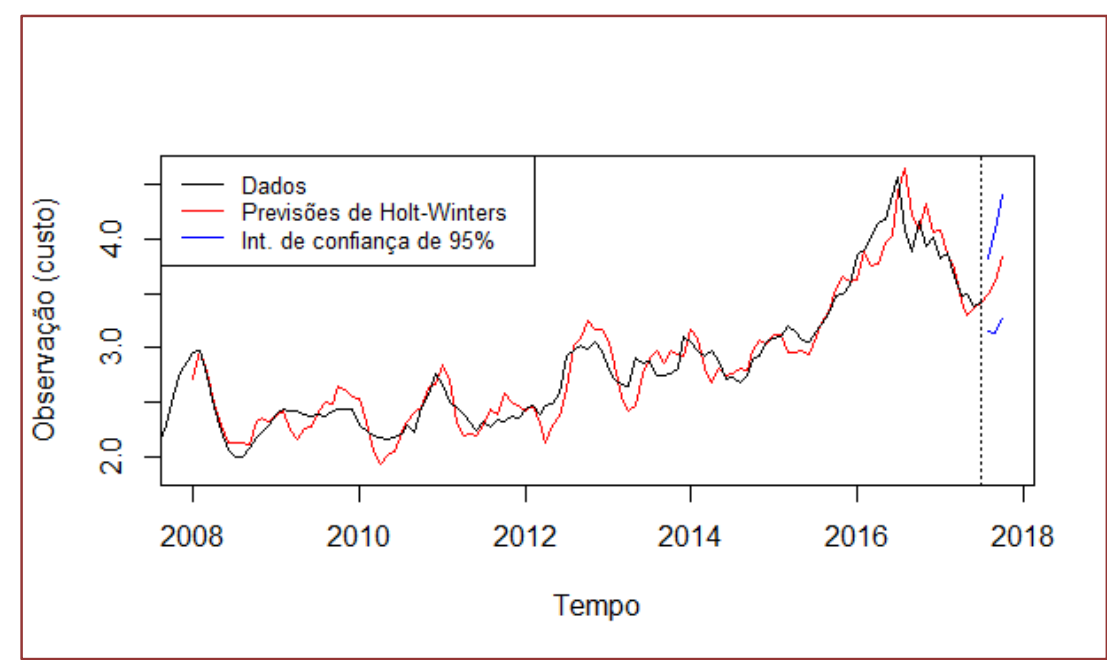

Fonte: Elaborada pelos autores, com base em (Embrapa, 2017).

As previsões em números, tanto da versão multiplicativa quanto da aditiva, para os meses de agosto até outubro de 2017, podem ser visualizadas na Tabela 3.

Tabela 3: Comparação dos valores previstos com dados reais

\begin{tabular}{|l|c|c|c|}
\multicolumn{4}{c}{ Ano-2017 } \\
\multicolumn{1}{|c|}{ Meses } & Dados reais & Previsões multiplicativa & Previsões aditiva \\
\hline Agosto & 3,48 & 3,14 & 3,49 \\
\hline Setembro & 3,46 & 3,10 & 3,61 \\
\hline Outubro & 3,57 & 3,25 & 3,84 \\
\hline
\end{tabular}

Fonte: elaborada pelos autores, com base em (Embrapa, 2017).

Os cálculos das medidas de erro MAD, MAPE e MSE também foram executados com o pacote forecast no $R$ studio (R. Hyndman et al., 2020; R. J. Hyndman \& Khandakar, 2008). Os resultados são demonstrados na Tabela 4. Na comparação dos modelos HW versões aditiva e multiplicativa, a aditiva obteve destaque na acurácia, com base nos valores de MAD, MAPE e MSE, por serem menores do que a versão multiplicativa, como pode ser observado na Tabela 4.

Tabela 4

\section{Medidas de erro}

\begin{tabular}{|c|c|c|c|}
\hline Modelo & MAPE & MAD & MSE \\
\hline Holt-Winters multiplicativa & $9,763821 \%$ & 0,3417754 & 0,115867 \\
\hline Holt-Winters aditiva & $4,070326 \%$ & 0,1436272 & 0,032018 \\
\hline
\end{tabular}

Fonte: Elaborada pelos autores, com base em dados da (Embrapa, 2017).

0 estudo reforça outros estudos realizados com o método de HW em setores distintos como o da construção civil (Ashuri \& Lu, 2010) e energia nos custos de eletricidade hospitalar (Kirkham et al., 2002) sobre a precisão do modelo HW na previsão de custos. 


\section{CONSIDERAÇÕES FINAIS}

A partir dos resultados da pesquisa, considerando os dados de custos de produção de suínos, do período de janeiro de 2007 a julho de 2017, em relação à previsibilidade do período de agosto a outubro de 2017, na comparação com os dados reais do período de previsão, constatou-se que a versão aditiva do modelo superou a versão multiplicativa em todas as medidas de erro.

As previsões do modelo HW, versões aditiva e multiplicativa, com os dados de custos de produção de suínos, demonstraram o comportamento das predições de três meses (Figuras 5 e 8). Compararam-se os dados reais de custo de produção de agosto a outubro de 2017, com as previsões do modelo (Tabela 3), sendo que a versão aditiva apresentou menores medidas de erro.

Verificou-se que as duas versões apresentaram baixo MAPE, como expresso na Tabela 4. No entanto, a versão aditiva ajustou-se melhor aos dados e, por isso, apresentou melhor acuracidade (Tabela 4). Portanto, a versão aditiva foi mais precisa na previsão do que a multiplicativa, tornando-se perceptível a capacidade que o método de previsão de HW proporciona para fazer previsões de custo de produção de suínos de curto prazo.

A constatação do estudo ora apresentada não assegura que, em outros estudos, adotando o mesmo método com dados distintos de custos de produção de suínos ou, até mesmo, de outro segmento da pecuária ou não, os mesmos resultados possam ser alcançados. Para pesquisas futuras, sugere-se realizar as previsões do método ARIMA no horizonte de previsão de curto, médio e longo prazos e comparar os resultados com o modelo Holt-Winters.

\section{REFERÊNCIAS}

[1] ABCS, A. B. dos C. de S., \& SEBRAE, S. B. de A. às M. e P. E. (2016). Mapeamento da suinocultura brasileira. Brasília, DF. Retrieved from https://goo.gl/QM1Tss

[2] ABPA. (2015). Relatório anual 2015. São Paulo: Associação Brasileira de Proteína Animal. Retrieved from https://goo.gl/vrW7aT

[3] ABPA. (2016). Relatório Anual 2016. São Paulo: Associação Brasileira de Proteína Animal. Retrieved from https://goo.gl/CSF3jE

[4] Ashuri, B., \& Lu, J. (2010). Time series analysis of ENR construction cost index. Journal of Construction Engineering and Management, 136(11), 1227-1237.

[5] Bettis, R., Gambardella, A., Helfat, C., \& Mitchell, W. (2014). Quantitative empirical analysis in strategic management. Strategic Management Journal, 35(7), 949-953.

[6] Brandon, C., Jarrett, J. E., \& Khumawala, S. B. (1987). A Comparative Study of the Forecasting Accuracy of Holt-Winters and Economic Indicator Models of Earnings Per Share For Financial Decision Making. Managerial Finance, 13(2), 10-15.

[7] Chatfield, C. (1978). The Holt-Winters Forecasting Procedure. Journal of the Royal Statistical Society, 27(3), 264-279.

[8] Chatfield, C. (1988). Apples, oranges and mean square error. International Journal of Forecasting, 4(4), 515518.

[9] Chatfield, C., \& Yar, M. (1988). Holt-Winters forecasting: some practical issues. Journal of the Royal Statistical Society. Series D (The Statistician), 37(2), 129-140.

[10] Colmanetti, M. S. (2001). Modelagem de sistemas de manufatura orientada pelo custeio das atividades $e$ processos (Escola de). São Carlos. Retrieved from https://goo.gl/4Dr85Q

[11] Corrêa, H. (2012). Administração de produção e operações: manufatura e serviços - uma abordagem estratégica. São Paulo: Atlas.

[12] Embrapa. (2017). Custo de produção de suínos ciclo completo. Concórdia, SC: Embrapa Suínos e Aves. Retrieved from https://goo.gl/Ac21eb

[13] Fader, P. S., Hardie, B. G. S., \& Zeithammer, R. (2003). Forecasting New Product Sales in a Controlled Test Market Environment. Journal of Forecasting, 22(215), 391-410.

[14] Girotto, A. F., \& dos Santos Filho, J. I. (2000). Custo de Produção de Suínos. Concórdia, SC: Embrapa Suínos e Aves. Retrieved from https://goo.gl/AuuXdk

[15] Girotto, A. F., \& Protas, J. F. da S. (1989). Custo de produção de suínos para abate: uma revisão. Concórdia, SC: 
EMBRAPA-CNPSA. Retrieved from https://goo.gl/zUmedx

[16] Hyndman, R., Athanasopoulos, G., Bergmeir, C., Caceres, G., Chhay, L., O’Hara-Wild, M., ... Zhou, Z. (2020). forecast: Forecasting functions for time series and linear models. CRAN. Retrieved from https://pkg.robjhyndman.com/forecast/

[17] Hyndman, R. J., \& Athanasopoulos, G. (2018). Time series graphics. In Forecasting: principles and practice. Melbourne, Australia: OTexts.

[18] Hyndman, R. J., \& Khandakar, Y. (2008). Automatic time series forecasting: The forecast package for R. Journal Of Statistical Software, 27(3), 2-22. https://doi.org/10.18637/jss.v027.i03

[19] Karchere, A. J. (1976). Forecast error and planning. Business Economics, 11(3), $70-73$. https://doi.org/www.jstor.org/stable/23481468

[20] Kazmier, L. J. (1982). Estatística aplicada à economia e administração. São Paulo: McGraw-Hill do Brasil.

[21] Kirkham, R. J., Boussabaine, A. H., \& Matthew P. Kirkham. (2002). Next Page A Risk Integrated Forecasting Model Of Electricity Cost In An Nhs Acute Care Hospital Building: An Application To Whole Life Cycle Costing. Engineering, Construction and Architectural Management, 9, 38-52.

[22] Maher, M. (2001). Contabilidade de custos: criando valor para a administração (1st ed.). São Paulo: Atlas.

[23] Makridakis, S. (1976). A Survey of Time Series. International Statistical Review / Revue Internationale de Statistique, 44(1), 29.

[24] Makridakis, S. (1993). Accuracy concerns measures: theoretical and practical concerns. International Journal of Forecasting, 9(4), 527-529. https://doi.org/10.1016/0169-2070(93)90079-3

[25] Massilon, J. A. (2013). Fundamentos de agronegócios. São Paulo: Atlas.

[26] Medeiros, O. R. de, Costa, P. de S., \& Silva, C. A. T. (2005). Testes empíricos sobre o comportamento assimétrico dos custos nas empresas brasileiras. Revista Contabilidade \& Finanças, 16(38), 47-56.

[27] Miele, M., \& Sandi, A. J. (2015). Custos de produção, câmbio e competitividade da suinocultura brasileira a partir dos dados da rede InterPIG. Suinocultura Industrial, 38(268), 10.

[28] Milnitz, D., Marchi, J. J., \& Samohyl, R. W. (2011). Previsão da demanda: uma aplicação do método HoltWinters em uma indústria têxtil de grande porte. XXXI Encontro Nacional de Engenharia de Produção (ENEGEP). Belo Horizonte, MG: ENEGEP.

[29] Moreira, D. A. (2011). Administração da produção e operações. São Paulo: Cengage Learning.

[30] Newbold, P., \& Granger, C. W. J. (1974). Experience with Forecasting Univariate Time Series and the Combination of Forecasts. Wiley for the Royal Statistical Society, 137(2), 131-165.

[31] Oliveira, K. de, Bortolotti, S. L. V., Minosso, A. M., \& Lazzarotto, T. C. (2013). Utilização do modelo holt-winters para previsão das vendas de leite em um laticínio no oeste paranaense. Revista Eletrônica de Tecnologia e Cultura, 13, 147-156.

[32] Porto, B. M. (2021). Revisão bibliométrica sobre modelagem e previsão do preço da soja: uma comparação entre os modelos ARIMAX, redes neurais e máquina de aprendizado extremo. Universidade Federal de Mato Grosso do Sul, Escola de Administração e Negócios, Programa de Pós Graduação em Administração (PPGAD). Retrieved from https://posgraduacao.ufms.br/portal/trabalhos/index/113

[33] Porto, B. M., \& Philippi, D. A. (2017). Previsão dos Custos de Produção de Suínos Por Meio do Modelo de HoltWinters. In EnANPAD 2017 (pp. 1-14). São Paulo-SP: XLI Encontro da ANPAD. Retrieved from http://www.anpad.org.br/eventos.php?cod_evento=1\&cod_edicao_subsecao=1453\&cod_evento_edicao=89\&cod_edic ao_trabalho $=23722$

[34] Porto, B. M., \& Philippi, D. A. (2018). Previsão dos Custos de Produção de Suínos por meio de Modelos de Holt-Winters. ABCustos, 13(1), 110-128. https://doi.org/10.47179/abcustos.v13i1.493

[35] Porto, B. M., Philippi, D. A., \& Leite, V. A. W. (2018). Aplicação de modelos univariados e rede neural FeedForward na demanda turística internacional do estado de Mato Grosso do Sul, Brasil. In Cooperação e Desenvolvimento (pp. 2-16). Sucre-Bolivia: Congresso Internacional de Administração. Retrieved from https://admpg2018.com.br/anais/2018/arquivos/04302018_220445_5ae7c3bde4f60.pdf

[36] Porto, B. M., Philippi, D. A., \& Leite, V. A. W. (2019). Previsão dos modelos univariados e rede neural da demanda turística do estado de Mato Grosso do Sul. Caderno Virtual de Turismo, 19(3). https://doi.org/10.18472/cvt.19n3.2019.1520

[37] Schrippe, P., Santos, S. R. dos, Vincenzi, S. L., Junior, F. de J. M., \& Iarczewski, A. M. W. (2015). Estratégia Empresarial Para a Natura: Análise De Correlação E Previsão Dos Lucros Por Meio Do Modelo Holt-Winters. Reuna, 20(4), 5-26. 
[38] Serra, C. M. V., Tavares, H. R., \& Santos, J. C. C. (2005). Aplicação de séries temporais na análise de demanda turística no estado do Pará usando os modelos de Holt-Winters. In XXV Encontro Nacional de Engenharia de Produção (pp. 3077-3083). Porto Alegre. Retrieved from https://goo.gl/xKkXCE

[39] Silver, M. (2000). Estatística para administração. São Paulo: Atlas.

[40] Stevenson, W. J. (1981). Estatística aplicada à administração. São Paulo: Harper \& Row do Brasil.

[41] Talamini, D. J. D., \& dos Santos Filho, J. I. (2015). Como vai a Suinocultura Brasileira. Anuário Da Suinocultura Industrial. Florianópolis, SC.

[42] Toigo, L. A., Gollo, V., Leite, M., \& Klann, R. C. (2015). Análise comparativa dos custos de produção de suínos sob a ótica da teoria contratual. ABCustos, $10(2)$.

[43] Tong, H. (2015). Threshold Models in Time Series Analysis - Some Reflections. Journal of Econometrics, 4(2), 485-491. https://doi.org/10.1016/j.jeconom.2015.03.039 


\section{Capítulo 9}

\section{Análise de viabilidade econômica em sistema de pastejo irrigado rotacionado silvipastoril aplicado a produção de leite}

\section{Lucas Carvalho Martins \\ Lydia Cheibub de Matos}

Gleyzer Martins

Resumo: A produção de leite no Brasil é uma atividade muito antiga, e envolve diversos produtores, cada qual com seu tamanho de propriedade e formas de se produzir. Esse setor tem se tornado cada vez mais competitivo e exigente em termos de organização, qualidade de produto, bem-estar animal e mão de obra envolvida. A irrigação de pastagem é uma metodologia eficaz para otimizar a produção leiteira, porque diminui os gastos com ensilagem ou alimentação no período de estiagem e garante uma alimentação saudável e de ótima qualidade aos animais diretamente ao pasto. 0 sistema de pastejo rotacionado silvipastoril integrado a irrigação, garante o bem-estar animal, maior produção por área, diferentes tipos de produção num mesmo espaço e sustentabilidade. 0 objetivo deste trabalho consiste em avaliar o investimento da utilização do sistema de irrigação de baixo custo consorciada com o pastejo rotacionado silvipastoril na produção de leite em pequenas propriedades rurais e verificar os principais indicadores de desempenho desse sistema. Os resultados obtidos mostram que é possível a implementação do projeto com o retorno sobre investimento a partir do sétimo ano e que o projeto é viável.

Palavras-chave: Tecnologia. Baixo custo, Produção leiteira, Área reduzida. 


\section{INTRODUÇÃO}

A agropecuária no Brasil representa grande participação na economia nacional, e a produção de leite é uma das mais importantes atividades nesse contexto. Dentro da atividade leiteira existem vários tipos de sistemas de produção adotados. Um sistema que pode ser adotado para esse tipo de produção é o sistema rotacionado irrigado e silvipastoril.

O sistema de irrigação de baixo custo é muito eficiente. Segundo Scaloppi (2014) a alteração aos sistemas convencionais se dá pelo uso de materiais diferentes em sua montagem o que é mais atrativo aos interesses dos produtores, principalmente de pequenas propriedades devido ao preço.

Outra tecnologia utilizada para melhoria da produtividade é a inseminação artificial. Ela difunde a evolução genética dentro do rebanho, aumentando a produção por animal, gerando rentabilidade ao produtor, que além de vender carne e leite, pode-se enquadrar como vendedor de genética (MARTINS et al., 2011).

O objetivo deste trabalho consiste em apresentar a viabilidade econômica e os principais indicadores de desempenho na produção de leite em um sistema de pastejo irrigado rotacionado e silvipastoril. Para tanto foi avaliando os custos de instalação, os custos operacionais e os investimentos. 0 trabalho tem como justificativa a implementação de estudos científicos no setor rural, formulando um modelo de análise de projeto em fazendas leiteiras, mostrando aos fazendeiros que as ferramentas de engenharia bem aplicadas nas atividades rurais podem ser o caminho de sucesso do produtor.

\section{REFERENCIAL TEÓRICO}

Será apresentado neste capítulo a engenharia de produção no campo, o que corresponde a engenharia econômica; a irrigação por aspersão de baixo custo; fertirrigação de baixo custo; sistema de pastejo rotacionado, irrigado e silvipastoril; a inseminação artificial e estudo do mercado do leite.

\subsection{ENGENHARIA DE PRODUÇÃO NO CAMPO}

A engenharia de produção visa a otimização e qualificação de sistemas produtivos, tornando-os mais lucrativos e eficientes para que o retrabalho seja mínimo e o sucesso da organização seja máximo. Segundo Miguel et al. (2007) com esta descrição é possível relacionar a engenharia de produção de forma diretamente proporcional as necessidades do setor agropecuário. As propriedades do sul do Brasil têm experimentado o uso dos princípios dessa engenharia como a otimização, a análise de custos, a tecnologia de informação, treinamentos e especialização das atividades produtivas e análise de investimento (EPAGRI, 2015).

\subsection{ENGENHARIA ECONÔMICA}

Um dos formatos para se verificar a viabilidade de um projeto. Segundo Peres (2006) é a análise de investimento, a qual pode ser realizada em um projeto rural através do valor presente líquido, uma ferramenta da engenharia econômica que mostra a viabilidade ou não do projeto.

A engenharia econômica fornece ferramentas para a análise de investimentos e é de suma importância que os empreendedores rurais tenham a visão da viabilidade do próprio negócio. Dois tipos de métodos de análise de investimentos que são muito importantes: Valor presente líquido e Payback Descontado.

\subsubsection{MÉTODO DETERMINÍSTICO DE ANÁLISE DE INVESTIMENTOS: VALOR PRESENTE LÍQUIDO (VPL)}

O VPL é um método que mede o valor atual dos fluxos de caixa oriundos do projeto e o compara com o investimento inicial. Para Brom e Balian (2007) a função do método do VPL é encontrar investimentos que rendam mais do que custam. A formulação proposta para o cálculo do valor presente líquido pode ser analisada na Figura 1. 
Figura 1 - Fórmula do VPL

$$
V P L=-I+\sum_{i=1}^{n} \frac{F C t}{(I+i a \cdot a)^{t}}\left\{\begin{array}{c}
\mathrm{FCt}=\text { fluxo de caixa no } \mathrm{t}-\text { ésimo período } \\
\mathrm{I}=\text { investimento inicial } \\
\text { ia. a }=\text { custo do capital anual } \\
\mathrm{n}=\text { horizonte de planejamento }
\end{array}\right.
$$

Fonte: Brom e Balian (2007)

Se o valor do VPL é positivo, significa projeto viável. Quanto maior o seu valor, economicamente melhor é o projeto.

Segundo Brom e Balian (2007), o VPL tem como intuito analisar, em valor atual, os resultados dos fluxos de caixa que estão associados a um projeto ou investimento. Ou seja, mostra ao investidor quais desembolsos precisa realizar e o retorno em formato de fluxos de caixas líquidos que ele terá, sendo todos trazidos a data atual através de uma específica taxa de desconto, conhecida como taxa de atratividade.

Segundo Brom e Balian (2007) a taxa de atratividade é uma taxa mínima de retorno agenciada pelo investidor. Isto significa que com uma remuneração inferior a essa taxa torna o investimento inaceitável. Para o VPL a taxa de atratividade é o parâmetro fundamental para avaliação.

\subsubsection{PAYBACK DESCONTADO}

Segundo Brom e Balian (2007) o método payback descontado calcula quando o investimento será retornado ao investidor, a valor presente, utilizando uma taxa de atratividade.

Essa ferramenta, através da formulação e taxa de atratividade, mostra em valor presente em que período o projeto se paga. É muito importante que produtores de leite tenham o conhecimento real da funcionalidade, viabilidade e comportamento financeiro de um projeto.

\subsection{INDICADORES DE DESEMPENHO}

Segundo Peres (2006) indicadores de desempenho são ferramentas que atuam como instrumento para planejar, gerenciar e mobilizar, e a partir deles é possível organizar ações ou mostrar novas medidas, além de ajudar na observação dos resultados alcançado. Os indicadores são ferramentas que atuam na medição de níveis de eficácia e eficiência de um processo ou uma organização, desta forma medem o desempenho do processo produtivo.

De acordo com Takashina e Flores (1996) os indicadores de desempenho são abordados como fundamentais para o planejamento do processo, pois eles definem metas quantificadas, e a partir disso é possível ver os resultados na organização. Os autores ainda ressaltam que os indicadores são importantes para o controle, pois os resultados encontrados a partir deles são essenciais para a análise crítica do desempenho, e direcionam as estratégias para a tomada de decisão.

\subsection{IRRIGAÇÃO POR ASPERSÃO DE BAIXO CUSTO}

A irrigação por aspersão é feita por meio de um jato de água fracionado que incide sobre o terreno. Sendo indicada para a maioria das plantações e podem se adaptar em diferentes tipos de solos irrigáveis (DE ANDRADE; BRITO, 2006).

Scaloppi (2014) mostra que a irrigação feita por aspersão de baixo custo é uma ferramenta viável para as propriedades, o sistema se torna mais econômico devido a substituição dos materiais convencionais por matérias mais acessíveis e baratos, e que-apresentam pouca diferença na durabilidade, como exemplos de materiais: canos de polietileno e aspersores de jardinagem.

\subsection{FERTIRRIGAÇÃO DE BAIXO CUSTO}

Segundo Scaloppi (2014) a fertirrigação é realizada com a inserção de fertilizantes orgânicos ou minerais na água. Esse procedimento de aplicação de fertilizantes é um modo eficiente e econômico. A fertirrigação 
não deve ser realizada exclusivamente com a experiência do produtor, deve-se utilizar de bases técnicas e científicas. O uso impróprio da fertirrigação pode acarretar em desequilíbrio ambiental e danos econômicos.

\subsection{SISTEMA DE PASTEJO IRRIGADO ROTACIONADO SILVIPASTORIL}

As características desse sistema são divididas em três partes pastagem irrigada, pastejo rotacionado e o sistema silvipastoril. Essas atividades conectadas formam um elo de otimização da atividade leiteira. É necessário uma boa capacitação e estudo para que a integração desses segmentos gere o sucesso da atividade.

\subsubsection{SISTEMA DE PASTEJO ROTACIONADO}

O sistema de pastejo rotacionado consiste na subdivisão de um pasto maior em pastos menores, o ideal é que o animal se alimente nesse espaço menor por apenas um dia.

Algumas vantagens e desvantagens do sistema de pastejo rotacionado podem ser vistas na Figura 2.

Figura 2 - Vantagens e desvantagens do pastejo rotacionado

\begin{tabular}{|c|c|}
\hline Vantagens & Desvantagens \\
\hline Baixa compactação do solo & Médio custo com equipamentos e instalações \\
\hline Baixa perda de alimento devido ao pisoteio & $\begin{array}{l}\text { Serviço mais complexo para o funcionário se } \\
\text { comparado ao pastoreio contínuo }\end{array}$ \\
\hline Maior concentração de nutrientes na pastagem & Maior custo com manutenção \\
\hline Alto descanso do pasto & Maior trabalho envolvido com relação ao manejo \\
\hline Pastagem mais forte e com raízes profundas & Maior estrutura e tecnologia \\
\hline Maior concentração de animais por área & Custo com adubação constante \\
\hline
\end{tabular}

Fonte: Adaptado de Santos e Corrêa (2009)

\subsubsection{SISTEMA SILVIPASTORIL}

Segundo Nicodemo (2005) o sistema silvipastoril consiste na integração de árvores e pastagem em um mesmo espaço, desse modo existe a geração de receita tanto pela venda de árvores quanto pela pecuária. Esta atividade é sustentável e garante qualidade de vida e melhora no meio ambiente das propriedades. Os benefícios do sistema silvipastoril podem ser observados na Figura 3.

Algumas qualidades e técnicas a mais dentro do sistema são: elevar o índice de fertilidade do solo, diminuir o nível de erosão e aumentar a viabilidade do sistema, gerando maior lucro, podendo investir em tecnologia. A indicação de plantio é que entre as faixas de plantio de árvores haja uma distância entre 25 e 30 metros, essas faixas de árvores devem conter no máximo 10 metros de largura, necessitando que as árvores sejam plantadas paralelas aos raios de sol e a forrageira deve ser plantada no restante do solo, não deve existir o contato durante o período entre 1 e 2 anos com os animais (CASTRO e PACIULLO, 2006). Exemplo da distância de plantio é apresentado na Figura 3.

Figura 3 - Distância para o plantio das mudas

$$
\begin{aligned}
& \hline \text { Árvores (3 metros) (1 fileira) } \\
& \text { Forrageira (20 a } 30 \text { metros) } \\
& \text { Árvores (3 metros) (1 fileira) } \\
& \hline
\end{aligned}
$$




\subsubsection{PASTAGEM IRRIGADA}

O manejo adequado da cultura da forrageira irrigada é essencial para a elevada produção de alimento com alto valor nutricional para o bovino (SCALOPPI, 2014). A alta produção depende de fatores como: clima, disponibilidade hídrica, fertilidade e o cuidado com o solo; o bom valor nutritivo da pastagem influência no ganho de peso do bovino e na produção de leite.

Segundo Drumond (2013), os métodos de irrigação mais utilizados em pastagens são os de pivô central e aspersão em malha. Métodos que geram grande elevação da produção de massa seca e verde das gramíneas ao se usar a irrigação, além disso, não existem sazonalidades de tempo seco e chuvoso. Portanto a pastagem irrigada oferece pasto verde e de qualidade o ano todo, diminuindo os custos com ensilagem, estes, que tanto pesam entre os demais custos da produção leiteira

As principais vantagens da irrigação em pastos podem ser vistas na Figura 4.

Figura 4 - Vantagens da irrigação de pastagens

\begin{tabular}{|c|}
\hline $\begin{array}{l}\text { Segundo DIAS-FILHO (2014), em pastejo } \\
\text { contínuo, a média de lotação no Brasil é de } 1 \\
\text { animal (adulto } 450 \mathrm{~kg} \text { ) por hectare. Com a } \\
\text { irrigação, rotação e adubação de pastagem é } \\
\text { aceitável } 15 \text { animais por hectare. }\end{array}$ \\
\hline $\begin{array}{l}\text { A irrigação conserva o pasto verde e com } \\
\text { crescimento durante todo o ano, podendo } \\
\text { extinguir o uso de silagem. }\end{array}$ \\
\hline $\begin{array}{l}\text { Aumento extraordinário da lotação de animais } \\
\text { por área. }\end{array}$ \\
\hline $\begin{array}{l}\text { Capim sempre alto, redução da proliferação de } \\
\text { pragas. }\end{array}$ \\
\hline $\begin{array}{l}\text { Diminui custos de aplicação de corretivos e } \\
\text { fertilizantes através do uso da fertirrigação; } \\
\text { aumentando a eficácia da aplicação dos } \\
\text { fertilizantes. }\end{array}$ \\
\hline $\begin{array}{l}\text { Potencializa e melhora para os produtores rurais } \\
\text { sua condição econômica. }\end{array}$ \\
\hline $\begin{array}{l}\text { Motiva os produtores rurais, jovens ou não, a } \\
\text { prosseguirem o serviço no campo, devido ao } \\
\text { aumento crescente da renda gerada pela } \\
\text { irrigação. }\end{array}$ \\
\hline $\begin{array}{l}\text { Diminui a procura por novas áreas para } \\
\text { produção, ajudando na conservação da } \\
\text { vegetação nativa, solos e nascentes dos cursos } \\
\text { de águas superficiais. }\end{array}$ \\
\hline
\end{tabular}

Fonte: Adaptado de Scaloppi (2014)

\subsection{INSEMINAÇÃO ARTIFICIAL}

Segundo Martins et al. (2011) a inseminação artificial em bovinos é um procedimento em que o sêmen de um touro é colhido, e posteriormente inserido no útero de uma fêmea, para futuramente ocorrer a fecundação, sem que aconteça o contato com o touro diretamente. A inseminação é realizada com instrumentos e procedimentos adequados.

As vantagens da inseminação artificial para os produtores rurais são (MARTINS et al., 2011):

- $\quad$ Permite o uso de sêmen de touros com ótimo valor genético;

- Diminui muito gastos desnecessários com a aquisição de touros;

- $\quad$ Evita a propagação de doenças pelo touro;

- $\quad$ Permite cruzamentos entre diferentes raças;

- Possibilita que o rebanho seja padronizado, com a utilização de muitas vacas e poucos reprodutores; 


\subsection{MERCADO DO LEITE}

De acordo com CEPEA (2016) é possível determinar uma linha de tendência do preço do leite brasileiro para o ano de 2017, a partir dos anos anteriores. Assim na Figura 5 (preço do leite versos meses do ano) é observado o comportamento do preço do leite e sua linha de tendência

Figura 5 - Linha de tendência do preço do leite

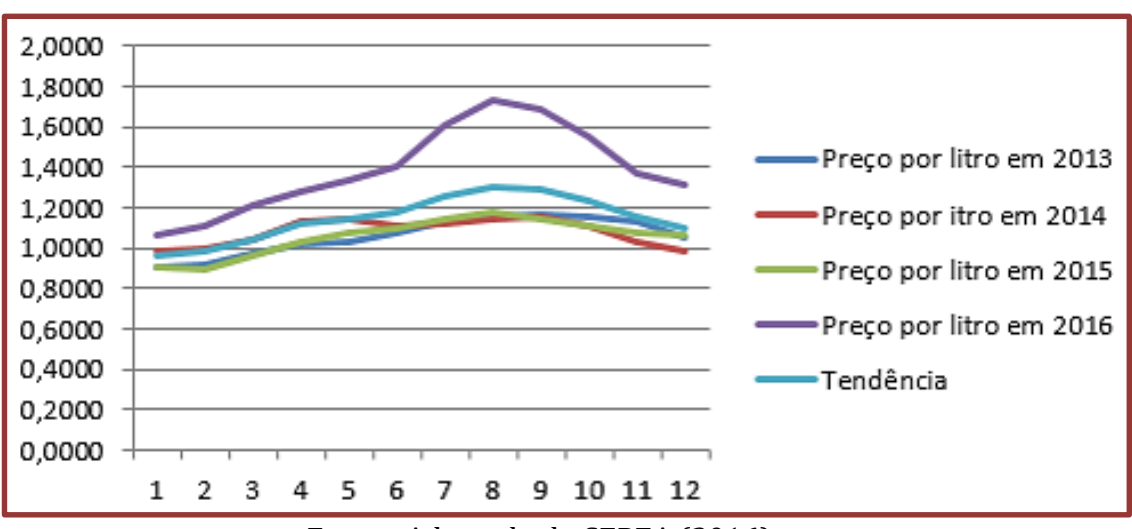

Fonte: Adaptado de CEPEA (2016)

Usando dados do CEPEA (2016) é possível traçar uma linha de tendência para o preço da ração no ano de 2017 através da Figura 6 (preço da ração versos os meses do ano).

Figura 6 - Linha de tendência do preço da ração

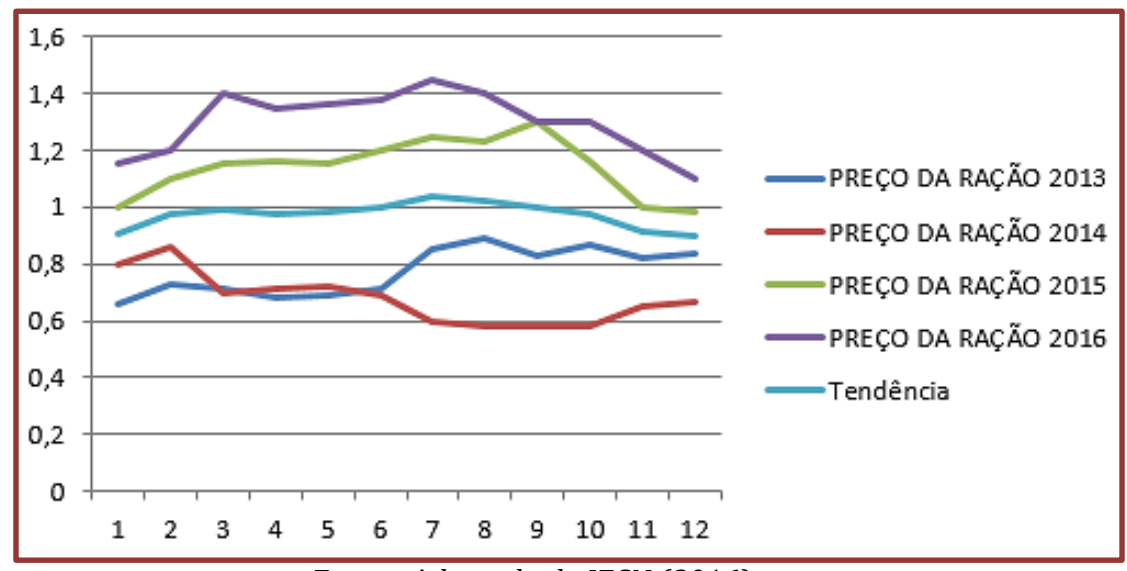

Fonte: Adaptado de IFCN (2016)

Esses dados estatísticos possuem segurança e confiabilidade, sendo assim, podem ser usados para futuras previsões do preço do leite, dos custos e insumos da atividade leiteira.

\section{METODOLOGIA}

A metodologia do trabalho consiste nas seguintes fases:

- Verificação das necessidades de um projeto de pastagem irrigada rotacionada e silvipastoril para produção de leite em uma Fazenda de 17,7 hectares na região de Ituiutaba-Mg;

- $\quad$ Estudo de caso na propriedade Rural;

- $\quad$ Cálculo dos custos de construção do projeto;

- $\quad$ Cálculo dos custos operacionais e receitas em 10 anos de projeto; 
- $\quad$ Análise de viabilidade através de ferramentas de engenharia econômica.

\section{ESTUDO DE CASO}

O estudo de caso traz a proposta de criar um sistema de pastejo rotacionado irrigado e silvipastoril para a produção de leite, sem a implementação real. Foram feitas analises em uma propriedade rural situada na região de Ituiutaba- $\mathrm{Mg}$.

\subsection{MENSURAÇÃO DA ÁREA}

A área total do projeto e sua distribuição podem ser vista na Figura 7.

Figura 7 - Área total destinada ao sistema

\begin{tabular}{|l|c|}
\multicolumn{1}{|c|}{ Área do Projeto } & Hectare \\
\hline Pasto das vacas secas e novilhas & 2 \\
\hline Currais, bezerreiro e cede & 4,2 \\
\hline Área de preservação permanente e reservatório de água & 3,5 \\
\hline Pasto Irrigado rotacionado e silvipastoril & 17,7 \\
\hline \multicolumn{1}{|c|}{ Total } & \\
\hline
\end{tabular}

Fonte: Autoria Própria (2017)

A Figura 8 apresenta a área destinada ao pastejo rotacionado, irrigado e silvipastoril com a distribuição das linhas de irrigação em cor azul e divisão dos piquetes na cor preta.

Figura 8 - Área irrigada rotacionada e silvipastoril

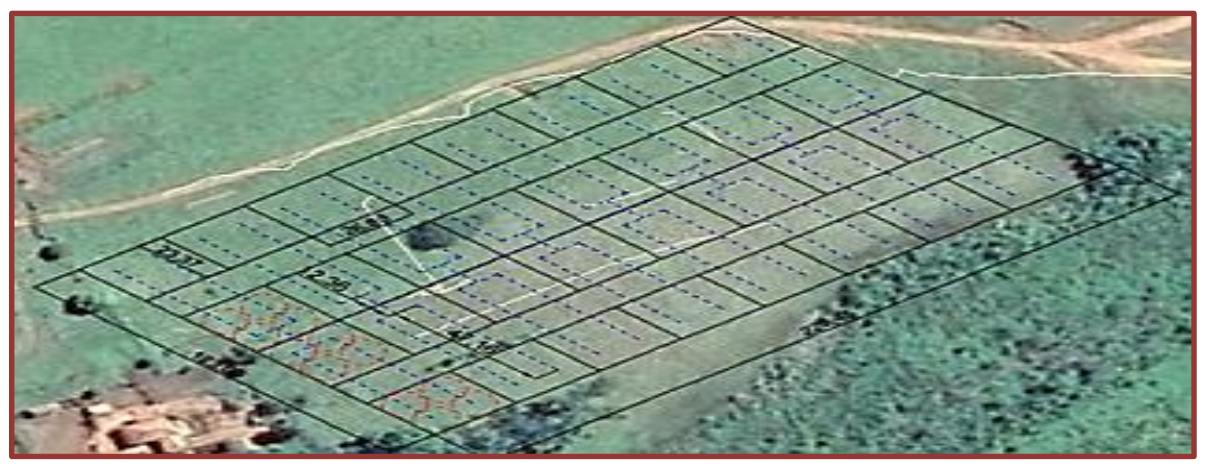

Fonte: Google Earth (2017)

\subsection{CÁlCULO DO CUSTO DE INSTALAÇÃO DO PROJETO}

Para a implementação do projeto foram considerados todos os fatores de custo. As partes de irrigação, pastejo rotacionado, sistema silvipastoril, bezerreiro para criação das bezerras, ordenhadeira, resfriador para estocar o leite, galpão de ordenha, galpão para resfriador e botijão de inseminação, estes envolveram quantificação e análise de preço do mercado. A aquisição das vacas leiteiras foi nitidamente o custo mais alto do projeto e nela estão o preço de animais de boa qualidade e o frete.

0 custo total para instalação do projeto, feito por capital próprio do produtor, pode ser visto na Figura 9. 
Figura 9 - Custos de instalação do projeto

\begin{tabular}{|l|r|}
\hline \multicolumn{2}{|c|}{ Custo total de instalação do projeto } \\
\hline Irrigação & $\mathrm{R} \$ 16.249,25$ \\
\hline Pastejo rotacionado & $\mathrm{R} \$ 9.788,31$ \\
\hline Aquisição das vacas & $\mathrm{R} \$ 120.000,00$ \\
\hline Aquisição da ordenhadeira & $\mathrm{R} \$ 5.000,00$ \\
\hline Instalação da ordenhadeira & $\mathrm{R} \$ 1.000,00$ \\
\hline Resfriador & $\mathrm{R} \$ 7.000,00$ \\
\hline Sistema silvipastoril & $\mathrm{R} \$ 1.312,08$ \\
\hline Adubação do pasto para bezerras e vacas secas & $\mathrm{R} \$ 1.500,00$ \\
\hline Botijão para inseminação & $\mathrm{R} \$ 2.500,00$ \\
\hline Galpão de ordenha e resfriador & $\mathrm{R} \$ 1.0000,000$ \\
\hline Bezerreiro & $\mathrm{R} \$ 180.349,64$ \\
\hline Total & \\
\hline
\end{tabular}

Fonte: Autoria Própria (2017)

\subsection{O FUNCIONAMENTO DO SISTEMA}

O conhecimento sobre o funcionamento do sistema é essencial para a compreensão dos custos e receitas envolvidas. Na Figura 10 é observado um fluxograma que representa o sistema de produção e as atividades que geram receita e também o detalhamento das atividades, nas quais se buscou a melhor representação das atividades em uma visão pessimista de análise, sempre considerando os fatores de risco. Na Figura 11 são observados os custos envolvidos na atividade leiteira e como esses custos se ramificam para gerar todo o cálculo de custos. A partir dos tópicos dos fluxogramas e as tendências de preços do leite e ração das Figuras 5 e 6, foram feitas análises de custo e receita muito bem estabelecidas durante o período de dez anos do projeto.

Figura 10 - Fluxograma da produção do sistema

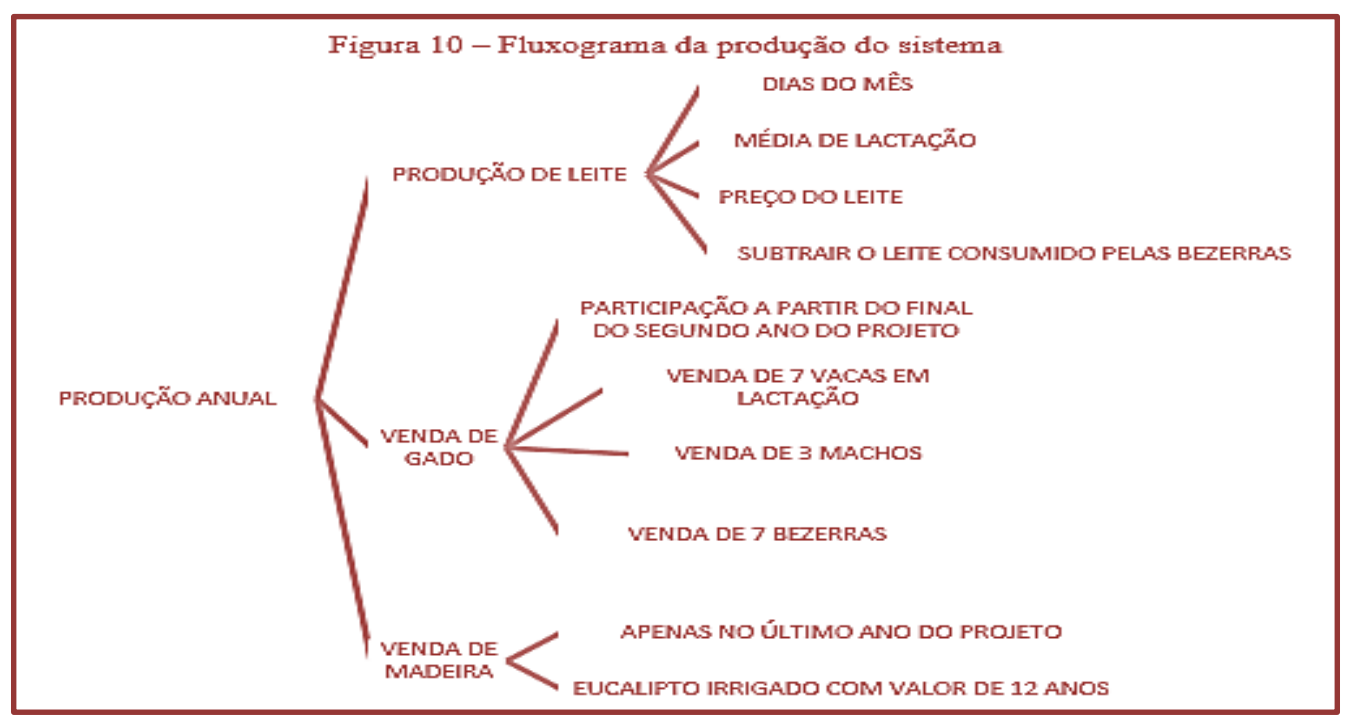


Figura 11 - Custos envolvidos na atividade

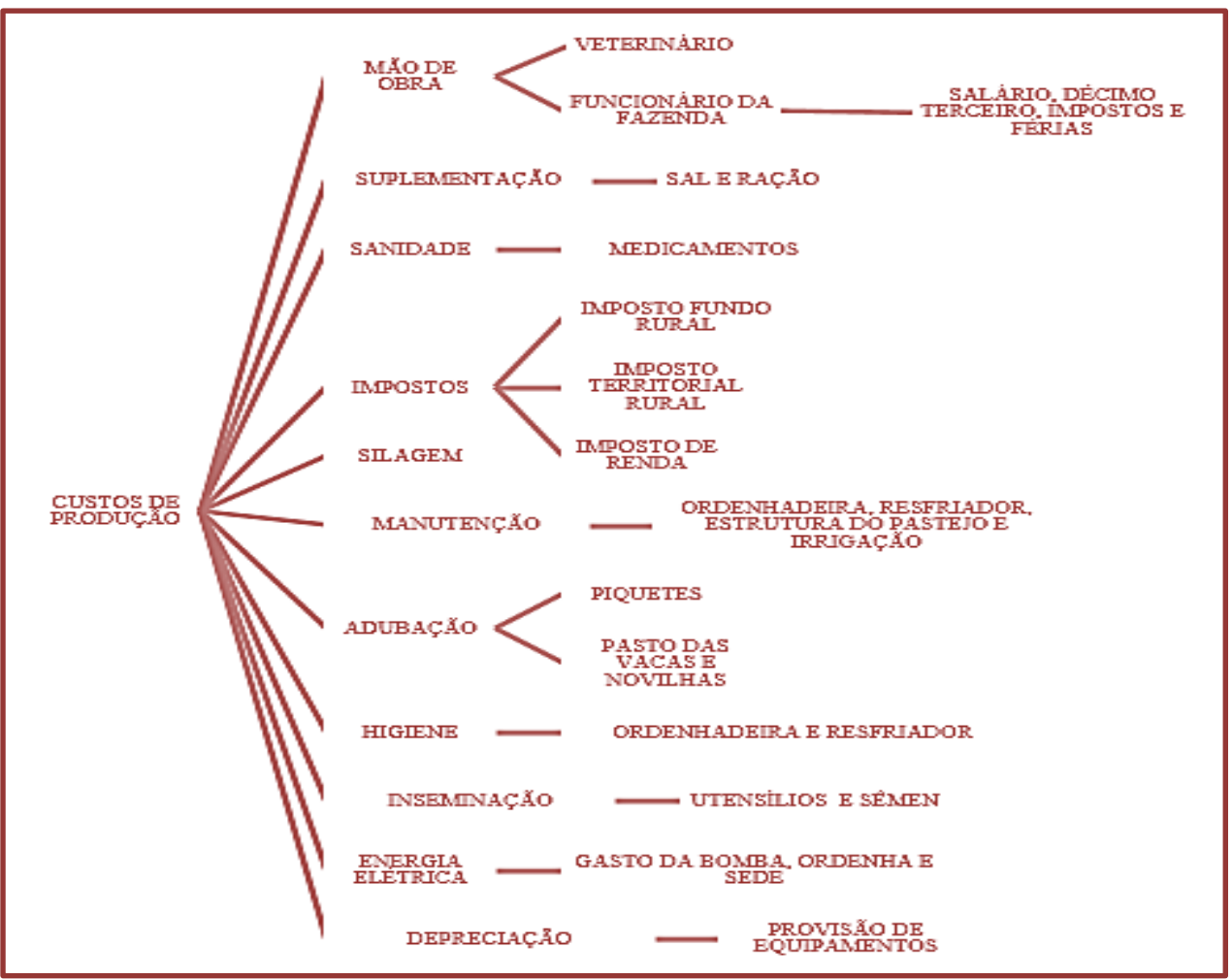

Fonte: Autoria própria (2017)

\subsection{ANÁLISE FINANCEIRA E ECONÔMICA}

Foi possível estabelecer as demonstrações dos resultados do exercício (DRE’S) que podem ser vistas na Figura 12.

Figura 12 - DRE's

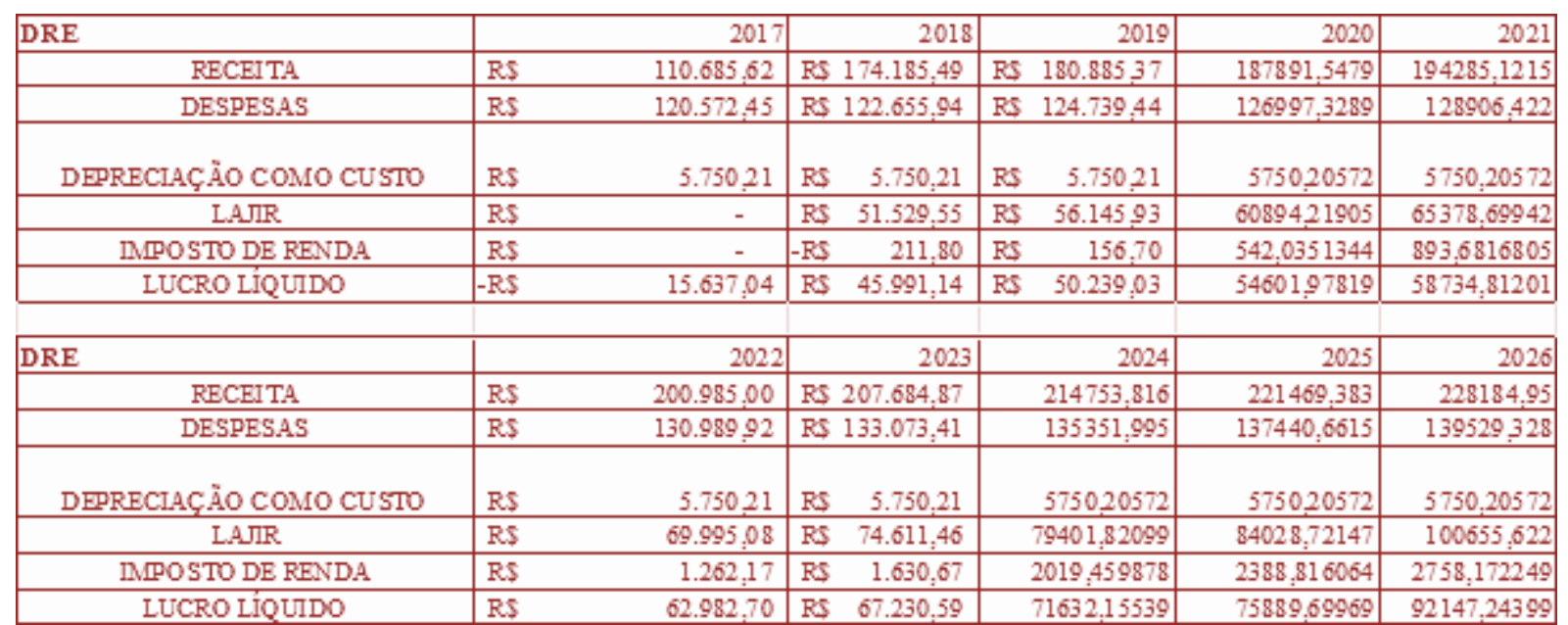


O gráfico que representa o fluxo de caixa pode ser visualizado na Figura 13.

Figura 13 - Fluxo de caixa no decorrer dos 10 anos do sistema

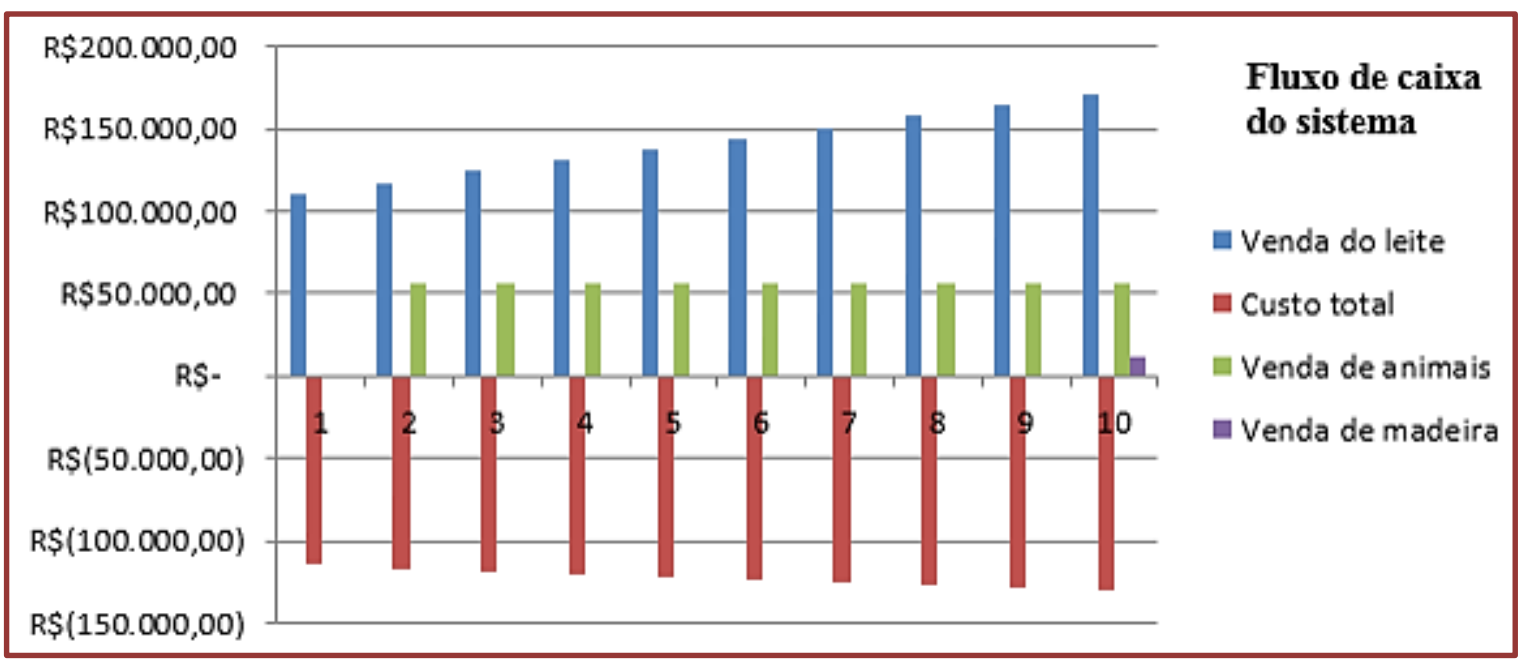

Fonte: Autoria Própria (2017)

A partir das Figura 12 e 13 do fluxo de caixa podem ser observados os seguintes fatores: a produção de leite obteve um aumento no decorrer dos anos devido ao aumento da lactação das vacas no decorrer do tempo. Os custos aumentaram em decorrência do acréscimo do consumo de ração devido ao aumento da produtividade das vacas. Pode-se observar que a produção de leite gerou pouco lucro, contudo foi responsável pelo pagamento dos custos operacionais do sistema. A venda de animais se manteve constante em número, sendo responsável pelo lucro adicional do projeto. Outro item adicional a renda foi apresentada pela venda da madeira, fato ocorrido no último ano do projeto.

\subsection{INDICADORES DE DESEMPENHO ANALISADOS NO SISTEMA}

Os indicadores de desempenho analisados a partir nas análises financeiras e econômicas podem ser vistos na Figura 14.

Figura 14 - Indicadores de desempenho analisados no sistema

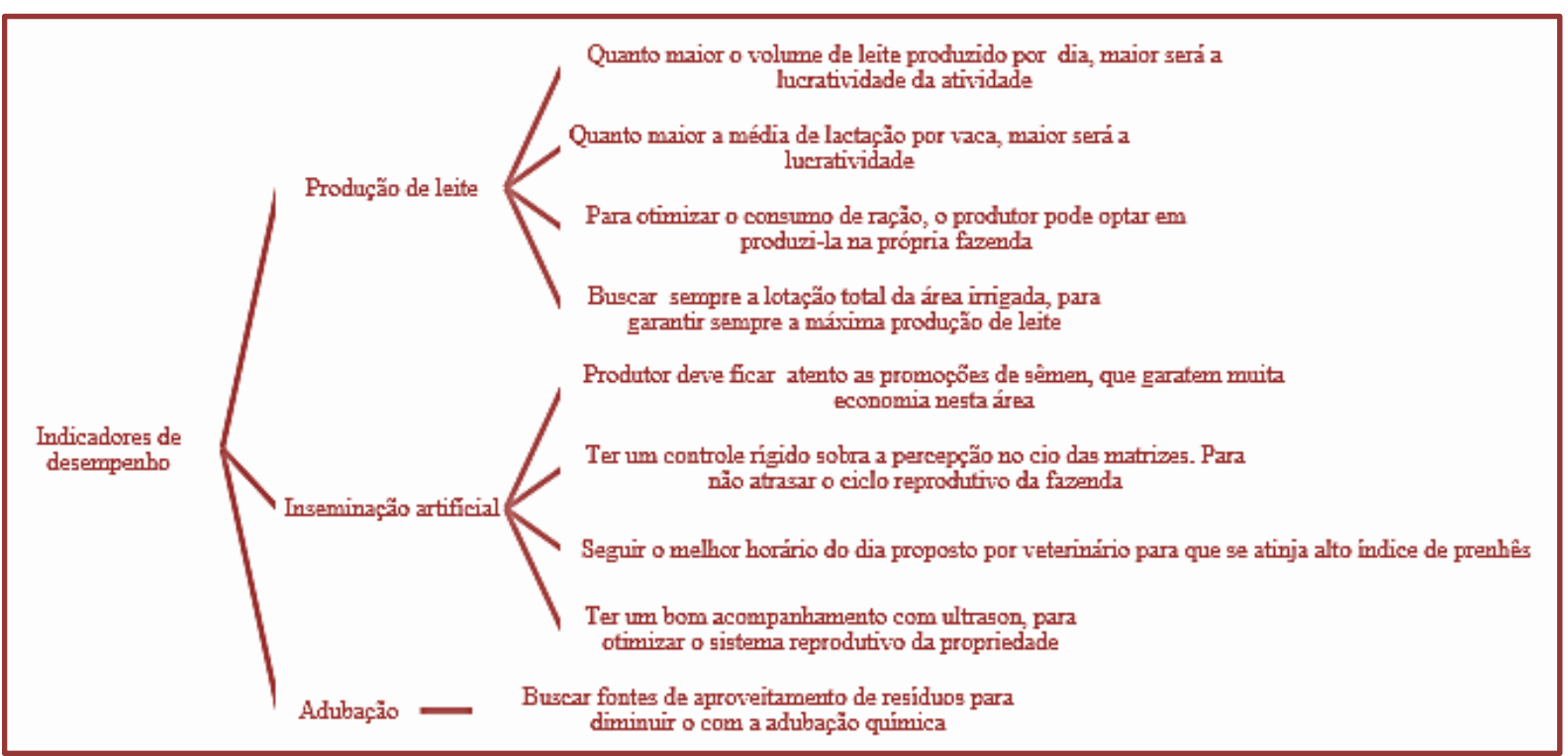




\subsection{ANÁLISE DE VIABILIDADE}

A verificação da viabilidade do projeto foi efetuada pelo VPL, usando uma taxa de $13 \%$ extraída do CDI (certificado de depósito interbancário). O Valor Presente Líquido foi de R\$ 84.819,35.

Para saber em que ano o projeto se paga, foi realizado o cálculo do Payback Descontado, trazendo a valor presente com a mesma taxa de $13 \%$ extraída do CDI. 0 projeto se paga no sétimo ano (2023), quando o saldo do investimento é positivo no valor de R $\$ 5466,18$. Assim o produtor recupera o capital no sétimo ano de produção e ainda obtém lucratividade total nos 4 últimos anos do projeto, em 2026 . 0 cálculo do Payback descontado pode ser observado na Figura 15

Figura 15 - Cálculo do Payback Descontado

\begin{tabular}{|l|rr|r|r|r|r|r|r|r|}
\hline PAYBACK DESCONTAD0 & 2016 & 2017 & 2018 & 2019 & 2020 & 2021 & 2022 & 2023 \\
\hline ANO & 0 & 1 & 2 & 3 & & 4 & 5 & 6 & 7 \\
\hline INVESTIMENTO & $-\mathrm{R} \$$ & $180.349,64$ & & & & & & & \\
\hline LUCRO NOMINAL & & $-\mathrm{R} \$ 15.637,04$ & $\mathrm{R} \$ 45.991,14$ & $\mathrm{R} \$$ & $50.239,03$ & $\mathrm{R} \$ 54.601,98$ & $\mathrm{R} \$ 58.734,81$ & $\mathrm{R} \$ 62.982,70$ & $\mathrm{R} \$ 78.103,78$ \\
\hline VALOR PRESENTE & & & $-\mathrm{R} \$ 13.838,09$ & $\mathrm{R} \$ 36.017,81$ & $\mathrm{R} \$ 34.818,17$ & $\mathrm{R} \$ 33.488,42$ & $\mathrm{R} \$ 31.878,90$ & $\mathrm{R} \$ 30.251,76$ & $\mathrm{R} \$ 33.198,84$ \\
\hline SALDO DO INVESTIMENTO & $-\mathrm{R} \$$ & $180.349,64$ & $-\mathrm{R} \$ 194.187,73$ & $-\mathrm{R} \$ 158.169,91$ & $-\mathrm{R} \$ 123.351,74$ & $-\mathrm{R} \$ 89.863,33$ & $-\mathrm{R} \$ 57.984,42$ & $-\mathrm{R} \$ 27.732,67$ & $\mathrm{R} \$ 5.466,18$ \\
\hline
\end{tabular}

Fonte: Autoria Própria (2017)

\section{CONSIDERAÇÕES FINAIS}

Com o presente trabalho foi avaliado o investimento do sistema de pastejo rotacionado irrigado e silvipastoril em uma propriedade rural da região de Ituiutaba- MG.

Pela proposição espera-se de acordo com os estudos realizados o aumento na concentração de vacas em lactação por hectare, passando de 1 para 7,6, levando ao incremento da produção por área, espera-se também a melhora na qualidade da alimentação dos animais, o que refletirá na elevação da produção de leite e fim do uso de silagem para vacas lactantes. Com o incremento do sistema silvipastoril espera-se um maior ganho com venda de madeira e uma melhoria do bem-estar animal, tendo como consequência um ganho de produtividade do leite, pelo auxílio do controle de temperatura e sombreamento aos animais. Outro aspecto importante levantando pelos estudos é a necessidade de investimento em genética de sêmen sexado, aumentando o número de fêmeas no rebanho, para garantir a evolução genética, elevar a produção dos animais e alavancar a venda de gado de qualidade no mercado.

Em termos quantitativos pode-se observar pelos levantamentos de custo e receita que a venda do leite é responsável pelo pagamento dos custos de operação do sistema, enquanto a venda de gado e a venda de madeira representam os lucros do empreendimento. Foi possível determinar alguns indicadores de desempenho dentro do sistema, e com esses indicadores foi possível enxergar os gargalos e pontos críticos de uma produção leiteira. Esses indicadores auxiliam a tomada de decisão do produtor.

Segundo Peres, (2006), a ferramenta VPL pode ser aplicada no campo. A aplicação do VPL no estudo de caso confirmou a viabilidade da proposta, pois o Valor Presente Líquido (VPL) foi de R \$ 84.819,35, com o retorno sobre o investimento a partir do sétimo ano. Indicando assim que a associação do sistema de pastejo rotacionado irrigado e silvipastoril pode ser um caminho para melhorar os ganhos nas propriedades rurais produtoras de leite. 


\section{REFERÊNCIAS}

[1] BROM, L. G.; BALIAN, J. E. A. Análise de Investimentos e Capital de Giro. São Paulo: Saraiva, 2007.

[2] CASTRO, C. R. T. D; PACIULLO, D. S. C. Boas práticas para a implantação de sistemas silvipastoris. Embrapa Gado de Leite, Comunicado Técnico, 50., Juiz de Fora, ago., 2006. Disponível em: <http://www.infoteca.cnptia.embrapa.br/bitstream/doc/595889/1/COT50.pdf>. Acesso em: 17 out. 2016.

[3] CEPEA - Centro de Estudos Avançados em Economia Aplicada. PIB Agro CEPEA-USP/CNA, jan/dez 2016. Disponível em: http://www.cepea.esalq.usp.br/pib/. Acesso em: 13 jan. 2017.

[4] DE ANDRADE, C. D. L. T. D; BRITO, R. A. Métodos de irrigação e quimigação. Embrapa Milho e Sorgo, Circular Técnica, Sete Lagoas, dez., 2006. Disponível em: <http://www.cnpms.embrapa.br/publicacoes/publica /2006/circular/Circ_86.pdf>. Acesso em: 10 set. 2016.

[5] DRUMOND, L. C. D. Irrigação de pastagem. Universidade Federal de Viçosa- Campus de Rio Paranaíba, ago. ,2013. Disponível em:<http://www.pecnordestefaec.org.br/2013/wp-content/uploads/2013/08/Luis-C\%C3\% A9sar-Dias-Drumond-Irriga\%C3\%A7\%C3\%A3o-de-Pastagem.pdf>. Acesso em: 3 jun. 2016.

[6] EPAGRI. Epagri - 40 anos de Pesquisa Agropecuária em Santa Catarina. Florianópolis, 2015. Disponível em: <http://docweb.epagri.sc.gov.br/website_epagri/EPAGRI_40-anos-de-pesquisa-agropecuaria.pdf>. Acesso em: 13 jun. 2016.

[7] MARTINS, C. E. et al. Inseminação Artificial. Embrapa Gado de Leite. Juiz de Fora, nov., 2011. Disponível em: <http://www.cnpgl.embrapa.br/sistemaproducao/49831-vantagens-da-utiliza\%C3\%A7\%C3\%A3o-da-ia >. Acesso em: 15 dez. 2016.

[8] MIGUEL, P. A. C. et al. Estudo de caso na engenharia de produção: estruturação e recomendações para sua condução. Revista Produção, v. 17, n. 1, p. 216-229, 2007. Disponível em: <http://www.scielo.br/scielo. php?script=sci_arttext\&pid=S0103-65132007000100015>. Acesso em: 19 jun. 2016.

[9] NICODEMO, M. L. F. Sistemas silvipastoris: árvores e pastagens, uma combinação possível. Zootec-Produção Animal e responsabilidade, Campo $\quad$ Grande, $2005 . \quad$ Disponível em:<http://saf.cnpgc.embrapa.br/publicacoes/arvoresepastagens.pdf>. Acesso em: 7 jun. 2016.

[10] PERES, A. A. C. Viabilidade técnica e econômica de sistemas de produção a pasto para vacas em lactação sob manejo rotacionado. Campos dos Goytacazes, RJ, v. 181, nov., 2006 . Disponível em: <http://www.uenf.br/Uenf/Downloads/PGANIMAL_3896_1214250997.pdf>. Acesso em: 6 set. 2016.

[11] SANTOS, P. M.; CORRÊA, L. A. Manejo de pastagens tropicais. Embrapa Pecuária Sudeste, 2009. Disponível em: <http://www.cppse.embrapa.br/sites/default/files/principal/publicacao/Documentos46.pdf>. Acesso em: 21 out. 2016.

[12] SCALOPPI, E. J. Irrigação de baixo custo em sistemas de pastejo rotacionado. Coleção PROEX Digital (UNESP), 2014. Disponível em: <http://200.145.6.238/handle/11449/126253>. Acesso em: 10 ago. 2016.

[13] TAKASHINA, Newton Tadachi; FLORES, Mario Cesar Xavier. Indicadores da Qualidade e do Desempenho: como estabelecer metas e medir resultados. (1996). 


\section{Capítulo 10}

\section{A elasticidade - Renda da demanda do Setor Privado do Ensino Superior Presencial no Brasil}

\section{Alexandre Barreto de Oliveira}

Cristiane Heleodoro Cardoso

Daiane Rodrigues dos Santos

Ludmila Santana de Azevedo Matos

Waldemar Antônio das Chagas Bezerra

Resumo: 0 presente artigo analisou a elasticidade-renda da demanda com base nos dados do Censo do Ensino Superior e do Rendimento Médio da população Brasileira, com o intuito de demonstrar como a renda familiar influencia substancialmente no número de alunos matriculados do ensino superior Privado do País, nesse sentido, segundo Vasconcelos (2011), é de grande contribuição essa análise, pois, mediante aos resultados obtidos será possível a elaboração do planejamento empresarial do setor, ou seja, projetar as matrículas futuras, com base no crescimento da renda do País.

O Ensino superior Brasileiro registrou um notório crescimento a partir dos anos 90, explicado pelas mudanças ocorridas na Lei de Diretrizes e Bases da Educação (LDB) de 1996, mudanças essas que possibilitaram a ampliação do setor privado, em mais de $500 \%$, desde a década 80 até o ano de 2018. Com o designo de garantir a sustentabilidade econômica dessa expansão, via setor privado, o Governo criou o Fundo de Financiamentos Estudantil (FIES) e o Programa Universidade para Todos (Prouni), programas esses que facilitaram a entrada das famílias de baixa renda no ensino Superior Privado.

Palavras-Chave: Ensino Superior, Ensino Presencial, Renda, Universidade Privada. 


\section{INTRODUÇÃO}

O Ensino como forma de melhoria na distribuição de renda e da qualidade de vida tem sido alvo de diversas pesquisas ao longo da história Brasileira, estudos como os desenvolvidos por Barros et. al (2002) e Langoni (2005) afirmam que, a desigualdade instalada no Brasil é um reflexo direto da lenta expansão do sistema educacional, portanto, um maior investimento em educação contribuirá para a diminuição gradual da desigualdade e consequentemente para crescimento econômico.

A desigualdade na distribuição de renda é real e por mais que a renda média tenha apresentado uma sensível melhora dentro do período analisado, os recursos financeiros, assim como os demais, são finitos e escassos, fazendo com que ingressar no ensino superior seja uma importante decisão e que envolve inúmeros trade-offs.

Mesmo diante deste paradigma, o estudo o publicado pelo o Fórum Nacional das instituições de Ensino Superior Católicas (2018), que considerou os dados obtidos de algumas das principais Instituições do Brasil, aponta uma projeção de crescimento da base de alunos até 2020 sendo impulsionados principalmente pelo Ensino à Distância (EAD), tanto pelo seu baixo custo, como por sua facilidade de adequação a rotina do estudante.

Portanto, o objetivo central deste artigo é estimar e analisar o impacto da elasticidade-renda da demanda do setor privado e presencial. A primeira parte consiste na contextualização do ensino superior. A segunda analisa o comportamento das matrículas e da renda média da população no período de 1984-2018. Já a terceira parte expõe os modelos utilizados e discorre sobre os resultados obtidos. Além desta Introdução e de um capítulo dedicado as conclusões finais.

\section{CONTEXTUALIZAÇÃO DO SETOR PRIVADO E PRESENCIAL DO ENSINO SUPERIOR BRASILEIRO}

\subsection{UM BREVE HISTÓRICO DO ENSINO SUPERIOR PRIVADO NO BRASIL}

Ao dissertar o ensino superior é necessário abordar seu histórico no Brasil, para obter-se uma visão holística de todo o processo desde a sua concepção passada aos dias atuais.

Saviani (2010), menciona o início precursor, mas, ainda, insipiente de que os jesuítas, no período colonial, deram os primeiros passos para a contribuição do ensino superior no Brasil, com os cursos de filosofia e teologia, porém não se pode confirmar.

De acordo com Sampaio (2000), os cursos superiores no Brasil, conforme registros, surgiram a partir de 1808 , ano de chegada da família real em nossa terra, tendo em vista a necessidade em atender aos jovens da elite da época.

Mesmo com cursos de nível superior no Brasil, o direito de conhecimento era considerado elitistas, pois somente tinham acesso, os filhos da aristocracia colonial que tiveram por Napoleão, o direito de estudar na Europa cerceado. Esta parte da sociedade retinham o conhecimento, enquanto a maioria do povo era escravizada, ou subjugada por seus colonizadores.

Em 1920, surge a primeira Universidade no Brasil - A Universidade do Rio de Janeiro - criada pelo decreto de número 14.343 de sete de setembro de 1920 que reuniam a Escola Politécnica do Rio de Janeiro, a Faculdade de Medicina do Rio de Janeiro e a Faculdade de Direito do Rio de Janeiro, o qual foi um marco no Brasil.

De acordo com Sampaio (1991), a autonomia da Universidade era, enfim, discutida e deveria ser organizada da seguinte forma:

"a) de maneira que se integrem num sistema único, mas sob direção autônoma, as faculdades profissionais (medicina, engenharia, direito), institutos técnicos especializados (farmácia, odontologia), e instituições de altos estudos (faculdades de filosofia e letras, de ciências matemáticas, físicas naturais, de ciências econômicas e sociais, de educação, etc.);

b) e de maneira que, sem perder o seu caráter de universalidade, se possa desenvolver, como uma instituição orgânica e viva, posta pelo seu espírito científico, pelo nível dos estudos, pela natureza e eficácia de sua ação, a serviço da formação e desenvolvimento da cultura nacional." (NAGLE, 1974), 
Já o Ensino Superior Privado teve seu início no período republicano. Com a constituição da República em 1891, que possibilitou a abertura do ensino superior ao setor privado, porém caminhando a passos vagarosos até 1920 .

Martins (2002) ressalta que no período Compreendido entre 1930 e 1945 houve uma intensa disputa entre a elite laica e a católica pelo controle da educação, principalmente do setor privado. Em 1931, durante a era Vargas, foi promovida uma reforma na educação que entre outras coisas, caminhava ao encontro da Constituição da República, mantendo o sistema de ensino superior aberto à iniciativa privada.

No período seguinte até 1968, a luta era com os professores e movimentos estudantis, que reivindicavam a absorção do setor privado pelas Instituição públicas, porém com a publicação da primeira LDB em 1961, caracterizou-se a vitória do setor privado (HERNÁNDEZ HUERTA, 2017).

Em 1964, com a ditadura, os movimentos estudantis forma reprimidos e as universidades públicas forma mantidas sobre forte vigilância. 0 controle feito pelo Estado faz deslocar a demanda ao setor privado que passou a atender cerca de 75\% dos 1.400 .000 alunos matriculados em 1980.

Após o Regime militar (1985 até 1995) o número de matrículas esteve relativamente estável e foi registrado um decréscimo da participação das instituições privadas no setor. De 1995 em diante é notório o crescimento das instituições privadas caracterizado fundamentalmente pela nova LDB de 1996.

O ensino superior no Brasil constituiu um acontecimento tardio:

[...] as primeiras universidades na América Latina foram criadas nos séculos XVI e XVII, quando já existiam várias universidades na Europa. Ao contrário da colonização espanhola, na América Latina os portugueses mostravam-se hostis à criação de escolas superiores e de universidades em sua colônia brasileira. As primeiras instituições de ensino superior (IES) no Brasil foram criadas somente no início do século XIX, com a transferência da corte portuguesa, em 1808, para a colônia. Elas tinham por objetivo apenas fornecer quadros profissionais para desempenhar diferentes funções ocupacionais na corte. (NEVES E MARTINS, P.96, 2014).

\subsection{PROGRAMAS DE ACESSO AO ENSINO SUPERIOR PRIVADO}

Em 1999 foi criado o Fundo de financiamento do Ensino superior (FIES). Um programa destinado a financiar total ou parcialmente alunos regularmente matriculados em cursos superiores e não gratuitos. Apesar de ter iniciado em 1999, ele foi estruturado somente em 2001, através da Lei ํ 10.260. Desde sua criação o programa passou por diversas modificações normativas.

Em 2004 foi criado o Prouni - Programa Universidade para Todos, com o objetivo conceder bolsas de estudo integrais e parciais em cursos de graduação e sequenciais de formação específica, em instituições privadas de ensino superior registrou no primeiro ano 112.275 bolsas, sendo 71.950 integrais e 40.370 parciais, fechando o ano de 2018 com aproximadamente 417.276 bolsas concedidas, dessas 182.474 integrais e 234.629 parciais. O programa, desde sua criação até o ano de 2018, já atendeu cerca de 2,47 milhões de estudantes, com 69\% de bolsas integrais.

Após a criação do Prouni o governo se esforçou no sentido de criar uma aproximação entre os dois programas. Com a Portaria Normativa no 30, de 2007 o bolsista parcial do Prouni poderia financiar até 50\% do montante não coberto, o GRÁFICO 1 mostra a evolução dos dois programas e o resultado dessa aproximação. Então, em 2010, o percentual passível de financiamento alcançaria a totalidade, essa modificação normativa tornou os programas complementares, favorecendo a permanência do estudante no ensino superior e em 2015 sofreu medidas de ajustes para frear o crescente ritmo de expansão do programa. 
Gráfico 1 - Matrículas na rede privada, por tipo de Financiamento/bolsa (2009-2017)

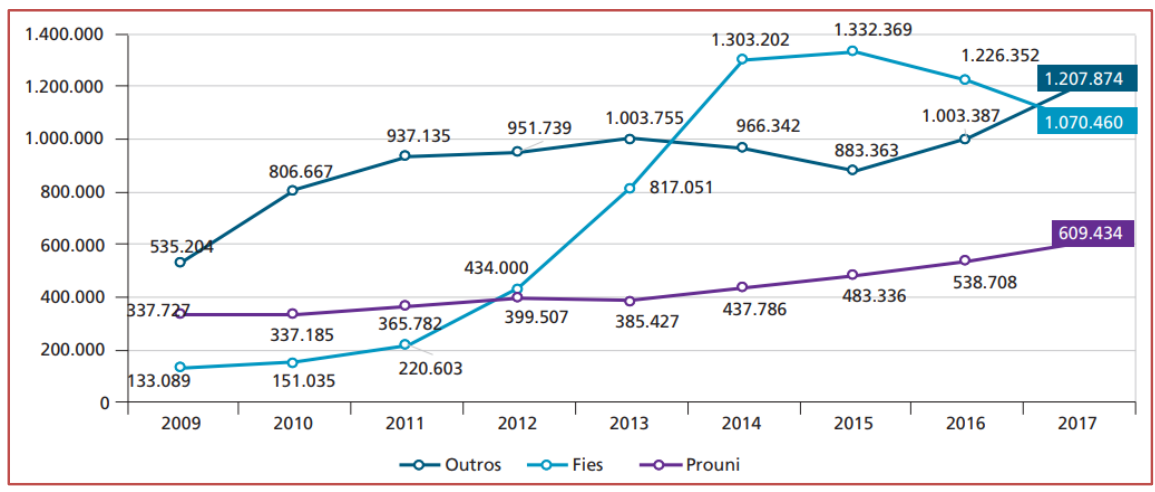

Fonte:Inep/MEC.

Segundo o Ministério da Educação - MEC, o "Novo Fies instituído pela Lei 13.530/2017, adotou novos parâmetros para o ingresso de estudantes possibilitando juros zero a quem mais precisa e uma escala de financiamentos que varia conforme a renda familiar do candidato. O novo FIES traz melhorias na gestão do fundo, dando sustentabilidade financeira ao programa a fim de garantir a sustentabilidade do programa e viabilizar um acesso mais amplo ao ensino superior". Com isso, haverá o limite superior correspondente a 2 salários mínimos e meio de renda familiar per capita, passou a priorizada também a oferta em cursos das regiões Norte, Nordeste e Centro-Oeste, visando corrigir desigualdades regionais existentes no país. Para comparação, atualmente $60 \%$ dos contratos de financiamento se encontram nas regiões Sul e Sudeste e no Distrito Federal, entre outras alterações.

Baseado na reportagem divulgada pela Associação Brasileira de Mantenedoras de Ensino Superior (ABMES), o GRÁFICO 2 mostra que o Fies fechou o ano de 2018 com menos de 85 mil contratos, sendo o pior desempenho desde o ano de 2010.

Gráfico 2 - Evolução dos contratos do FIES (2009-2018)

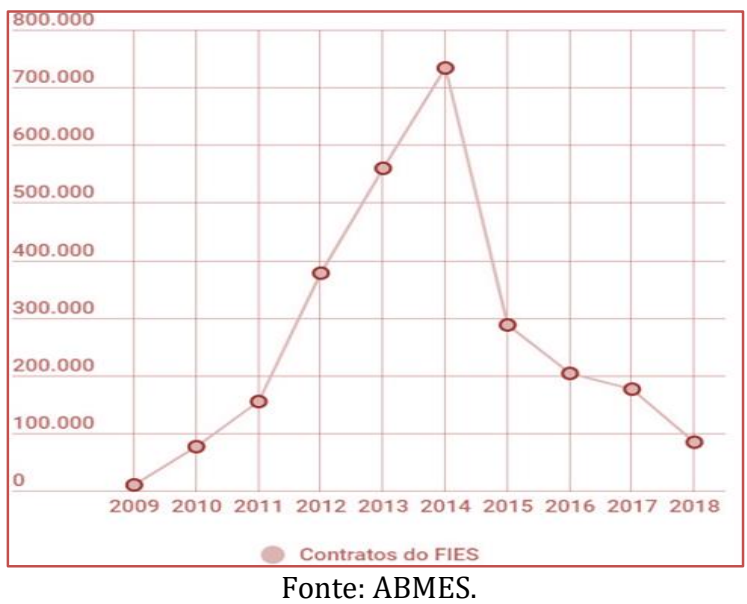

Contudo, a criação do FIES pode ser justificada pela própria história do país. De acordo com Jardim (2018):

"No Brasil, o acesso à Universidade de estudantes oriundos das camadas populares, afrodescendentes, entre outros que historicamente estiveram à margem do Ensino Superior, é fato relativamente recente. A implementação de políticas de inclusão social - via ações afirmativas - vem se materializando preponderantemente no campo da educação superior e no mercado de trabalho. Trata-se de matéria polêmica, que desperta o interesse da sociedade em geral e, no senso comum, o debate polariza-se entre os que pregam que as denominadas políticas de ação afirmativa - ao contrário de trazerem benefícios estigmatizam ainda mais tais segmentos sociais alijados" (JARDIM, 2018). 


\section{COMPORTAMENTO DAS MATRÍCULAS E DA RENDA MÉDIA DA POPULAÇÃO}

\subsection{EVOLUÇÃO DAS MATRÍCULAS DO ENSINO SUPERIOR}

O ensino superior privado passou por profundas mudanças no Brasil. Para Tachibana et al. (2015), a expansão do ensino superior no Brasil nas últimas duas décadas foi conduzida, majoritariamente, pelo setor privado. De acordo com os autores: Durham (1998) e Souza (2003) a participação do setor público nas matrículas da graduação presencial era maior que a do setor privado até o final da década de 1960. A partir de 1970, contudo, a situação começa a se inverter, e, na década seguinte, o setor privado assume papel majoritário no número de matrículas. Essa participação, de 64,3\% em 1980, se eleva para 67,1\% em 2000, e alcança um nível ainda mais elevado nos anos posteriores, atingindo 71,1\% em 2013. (Tachibana et al. p. 7, 2015). como exposto no GRÁFICO 3, a partir da tabulação e análise dos dados é possível afirmar que o sistema caminha para uma inversão de elitizado para um sistema de massificação, sobretudo durante o período em que o partido dos trabalhados esteve governando o Brasil.

Gráfico 3 - Matrículas no ensino superior presencial - Brasil (1984-2018)

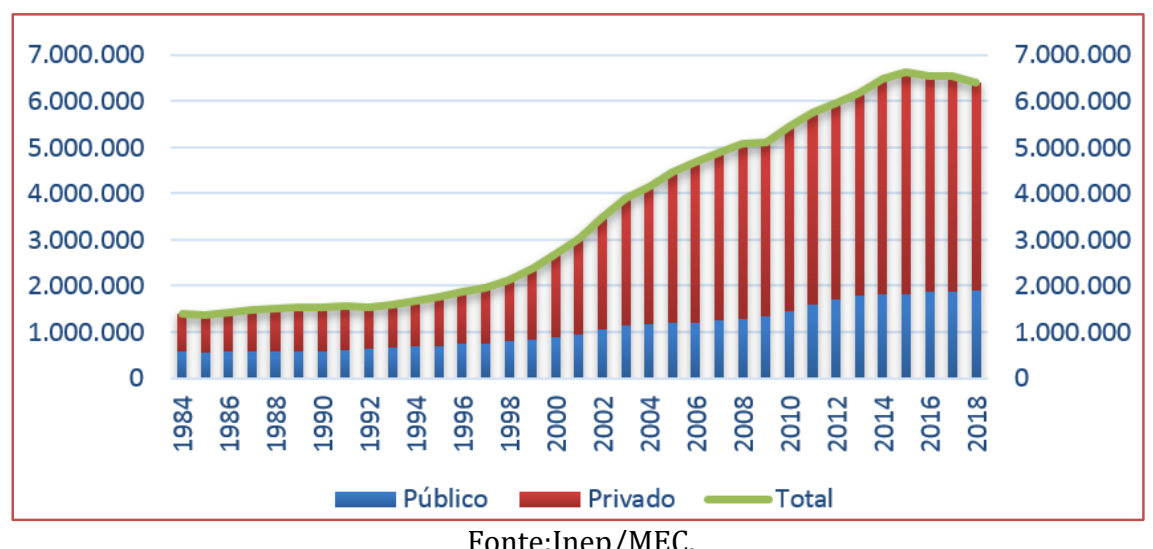

Na TABELA 1 é possível verificar que essa massificação se deu principalmente através do setor privado, que somente no período analisado teve um crescimento médio superior a $500 \%$, enquanto o público apresentou aproximadamente 333\%. Aumentar o número de vagas, facilitar o acesso e melhorar a educação são necessidades para uma mão de obra melhor qualificada e ainda ajuda a criar saltos tecnológicos que beneficiam toda a cadeia de produção de um país.

Tabela 1- Evolução das Matrículas na Educação superior Presencial - Brasil (1984-2018)

\begin{tabular}{|c|c|c|c|c|c|}
\hline \multicolumn{6}{|c|}{ Evolução das Matrículas na Educação superior Presencial - Brasil (1984-2018) } \\
\hline Ano & Público & Privado & Total & \% público & \%privado \\
\hline 1984 & 571.879 & 827.660 & 1.399 .539 & 40,86 & 59,14 \\
\hline 1994 & 690.450 & 970.584 & 1.661 .034 & 41,57 & 58,43 \\
\hline 2004 & 1.178 .328 & 2.985 .405 & 4.163 .733 & 28,30 & 71,70 \\
\hline 2014 & 1.821 .629 & 4.675 .696 & 6.497 .325 & 28,04 & 71,96 \\
\hline 2018 & 1.904 .554 & 4.489 .690 & 6.394 .244 & 29,79 & 70,21 \\
\hline $\begin{array}{c}\% \text { de Crescimento } \\
\text { Médio }\end{array}$ & 333,03 & 542,46 & 456,88 & $* * *$ & $* * *$ \\
\hline
\end{tabular}

Fonte: Elaboração Própria. 
Para o presente trabalho foi utilizado o Rendimento médio real de todas as fontes que é medido pelo instituto Brasileiro de geografia e estatísticas (IBGE), através da Pesquisa Nacional por amostra de domícilios Contínua Mensal (PNAD) e reúne as informações de rendimentos provenientes do trabalho, assim como os provenientes de outras fontes, como por exemplo: aluguéis, pensões, aposentadorias e outros rendimentos. Pois entende-se que a mensalidade do ensino superior pode advir de quaisquer fontes de renda disponíveis ao alunado.

O GRÁFICO 4, abaixo exposto, foi produzido com base na harmonização das informações do arcevo histórco do IBGE e foi deflácionado pelo Indíce Nacional de Preços ao Consumidor (INPC) de setembro de 2018. Tal indíce é usado para ajustar a valor presente o poder de compra do salário da população assalariada e com rendimentos mais baixos (1 até 5 salários Mínimos).

Gráfico 4 - Rendimento médio real anual de todas as fontes - Brasil (1984-2018)

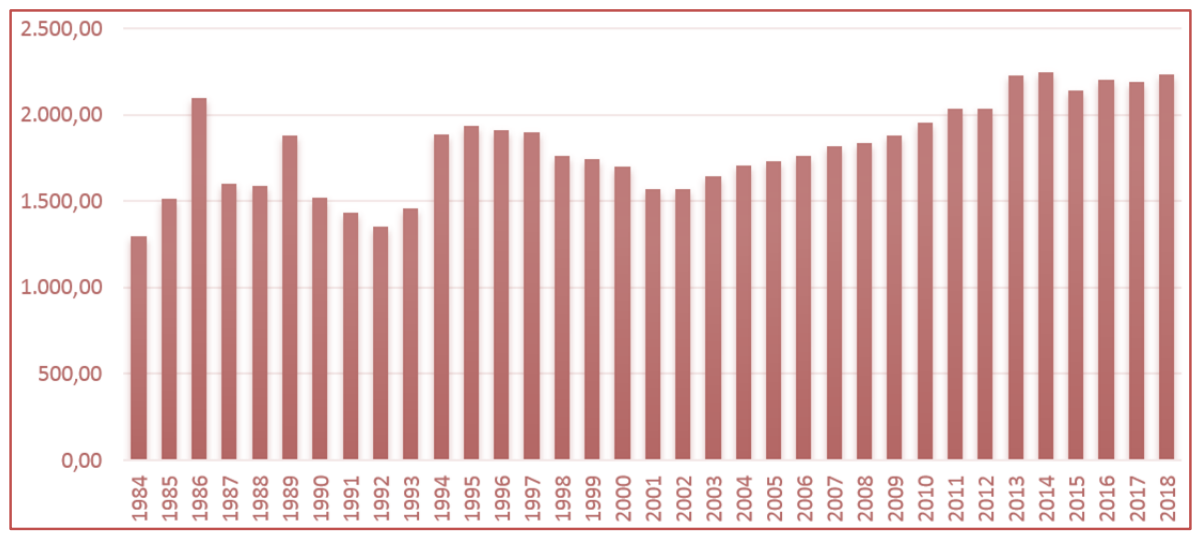

Fonte:IBGE/ Elaboração própria.

Em relação aos rendimentos de todas as fontes, de acordo com os resultados, é possível notar que refletem a realidade das mudanças econômicas, sociais e políticas vividas pelo Brasil em cada período. De 2004 a 2014 o Brasil caminhou para redução da desigualdade social e o aumento do rendimento médio, porém em 2015 houve um retrocesso quando este rendimento chegou a ser de $\mathrm{R} \$ 2.137,13$ com uma redução de aproximadamente 5\% se comparado ao Período anterior (2014). Entre 1984 e 2018 o indicador apresentou um crescimento de $42 \%$.

\section{MODELOS UTILIZADOS E RESULTADOS OBTIDOS}

\subsection{REGRESSÃO LINEAR}

A regressão linear simples consiste no fato de estabelecer uma função matemática linear que relacione duas variáveis e sua análise permite mensurar em valores o quanto uma variável influência no comportamento da outra. Da mesma forma como a média é usada para resumir uma variável aleatória, a reta de regressão é usada para resumir a estimativa linear entre duas variáveis aleatórias, cuja relação se pressupõe causa e efeito, de explanação do comportamento entre as variáveis LAPPONI (1997).

Nos casos em que a variável dependente e a variável independente são transformadas em log variáveis, a interpretação é uma combinação dos casos linear-log e log-linear (Benoit et al. 2011). Em outras palavras, a interpretação é dada como uma mudança percentual esperada em Y quando X aumenta em alguns percentagem. Tais relacionamentos, onde Y e X são transformados em log, são comumente referidos como elasticidade na econometria.

A regressão estuda a correlação das variáveis, que é uma medida de do grau de relação existente entre as variáveis analisadas, para saber se existe ou não correlação entre X e Y é necessário efetuar o cálculo do valor de R e interpretar seu resultado. Segundo a classificação sugerida por Santos (2007), exposta no QUADRO 1, o nível de correlação das variáveis pode ser definido como: 
Quadro 1 - Classificação da correlação.

\begin{tabular}{|c|c|}
\hline $\begin{array}{c}\text { Coeficiente de } \\
\text { correlação }\end{array}$ & Correlação \\
\hline$R_{x y}=1$ & Perfeita positiva \\
\hline $0,8 \leq R_{x y}<1$ & Forte positiva \\
\hline $0,5 \leq R_{x y}<0,8$ & Moderada positiva \\
\hline $0,1 \leq R_{x y}<0,5$ & Fraca positiva \\
\hline $0 \leq R_{x y}<0,1$ & Ínfima positiva \\
\hline 0 & Nula \\
\hline$-0,1 \leq R_{x y}<0$ & Ínfima negativa \\
\hline$-0,5 \leq R_{x y}<-0,1$ & Fraca negativa \\
\hline$-0,8 \leq R_{x y}<-0,5$ & Moderada negativa \\
\hline$-1 \leq R_{x y}<-0,8$ & Forte negativa \\
\hline$R_{x y}=-1$ & Perfeita negativa \\
\hline \multicolumn{2}{|c|}{ Fonte: Santos (2007). } \\
\hline
\end{tabular}

\subsection{ELASTICIDADE-RENDA DA DEMANDA}

Um dos fatores que influencia o consumo é a renda. Segundo Vasconcellos (2011), a elasticidade-renda da demanda mensura a variação percentual da demanda dada uma variação na renda do consumidor, ou seja, o cálculo da elasticidade-renda da demanda indica o quanto a mais o consumidor está disposto a consumir, ou deixar de consumir se sua renda variar, positiva ou negativamente. Ela é calculada através da fórmula 1:

$$
\text { Elasticidade }- \text { Renda da Demanda }=\frac{\text { Variação Percentual da Quantidade Demandada }}{\text { Variação Percentual da Renda }}=\frac{\Delta \% Q_{D}}{\Delta \% R}
$$

E de acordo com Lacombe (2004) o resultado obtivo pode ser classificada entre:

$$
\begin{aligned}
& \text { Bens necessários: } 0<\varepsilon_{R}<1 \\
& \text { Bens de luxo: } \varepsilon_{R}>1
\end{aligned}
$$

Ou seja, um bem será considerado de luxo sempre que o aumento da quantidade demandada for superior ao aumento da renda. Portanto, quando a renda aumentar, seu consumo aumentará de forma superior e quando a renda for reduzida, a demanda por esse bem tenderá a cair drasticamente, já que é o primeiro item a ser cortado da cesta de consumo caso haja uma retração da renda do consumidor. Os bens necessários são aqueles que quando a renda aumenta, o seu consumo aumenta de forma não mais que proporcional.

Como o presente estudo utilizou-se da regressão linear como modelo econométrico para mensurar os resultados, neste caso, para Gujarati (2008) o modelo log-linear é o indicado para medir a elasticidade e seus resultados são obtidos através da fórmula 2.

$$
\log Y_{i}=\alpha+\beta X_{i}+\varepsilon_{i}
$$


Ainda conforme Gujarati (2008), um aspecto atraente do modelo log-linear, que o tornou muito difundido nos trabalhos aplicados, é que o coeficiente angular beta 2 mede a elasticidade de do bem y em relação a variável x (preço do bem (y), preço do bem relacionado (z) ou renda, por exemplo), isto é, a variação percentual de $\mathrm{Y}$ correspondente a uma dada variação percentual (pequena) do bem X.

\subsection{RESULTADOS OBTIDOS}

Este estudo utilizou como base de mensuração de resultados o cálculo da regressão linear demanda do ensino superior privado e presencial no brasil, o recorte temporal analisado compreende os anos de 1984 até 2018.

A regressão linear pretende estimar a variação das matrículas (variável dependente), a partir da variação da média dos rendimentos da população (variável independente). Para obter tal resultado, o cálculo foi efetuado utilizando a ferramenta de análise de dados do excell e apresentou o seguinte resultado.

Tabela 2- Resultados da regressão linear

\begin{tabular}{|lr|}
\hline \multicolumn{2}{|c|}{ Estatística de regressão } \\
\hline R múltiplo & 0,7 \\
R-Quadrado & 0,6 \\
R-quadrado ajustado & 0,5 \\
\hline
\end{tabular}

Fonte: Elaboração própria.

$O R^{2}$ é o coeficiente de determinação ou coeficiente de explicação e mede o percentual de variação de $Y$ que é explicado pela variável $X$, ou seja, a análise desse resultado sugere que $60 \%$ da variação das matrículas é explicado pela variação da renda média, sendo os outros $40 \%$ explicados por outros fatores tais como os desejos e necessidades do indivíduo, assim como sua perspectiva de vida entre outros.

Já o cálculo da elasticidade-renda da demanda é medido pela regressão linear como exposto na Fórmula 2, sendo uma função que relaciona a variável independente, a renda ( $\mathrm{x}$ ) com a variável dependente, o $\mathrm{n}^{\circ} \mathrm{de}$ Matrículas (y). Ou seja, ele mede o acréscimo que o número de matrículas sofrerá caso haja um acréscimo na renda do estudante, ou do patrocinador do mesmo. 0 cálculo apontou uma elasticidade de aproximadamente 2,96, ou seja, para cada unidade acrescida na renda, a demanda pelo ensino superior será acrescida de aproximadamente 2,96 unidades.

Vale ressaltar que, os coeficientes de relação do modelo demonstraram resultados positivos e que o modelo está bem ajustado, apresentando resultados de Teste $\mathrm{F}$ e P-valor menores que o nível se significância, neste caso 5\%, indicando que de fato há uma correlação linear entre X e Y, ou seja, quanto maior a renda maior será o número de matrículas.

0 que significa dizer que, a entrada no ensino superior presencial pode ser considerada como um bem elástico, classificado como um bem superior (de luxo) e que sua variação depende principalmente da renda do indivíduo, mas também é influenciada por outros fatores, como por exemplo, a entrada no ensino superior a distância que apresenta um custo menor ou a escolha de ingressar em um curso técnico ou profissional, ou ainda, o grau de ambição ou a perspectiva de futuro do indivíduo.

\section{CONSIDERAÇÕES FINAIS}

0 ensino superior Brasileiro é formado em sua maioria por instituições privadas que, em sua maioria visam ao lucro, até mesmo em detrimento da qualidade do ensino, enquanto o foco principal deveria ser na formação e promoção técnico-cientifica, economia e cultural dos discentes (NUNES, 2012).

Portanto, com base nos resultados obtidos é possível concluir que a renda é o principal fator que impacta o acesso de Estudantes de baixa renda ao Ensino superior. Mesmo com os programas de financiamentos 
estudantis existentes no País, é importante que o Governo Brasileiro se atente a cada vez mais ampliar e aprimorar essas formas de acesso do alunado, pois somente através da educação e qualificação da população será possível melhorar a distribuição da renda e reduzir a desigualdade social.

\section{REFERÊNCIAS}

[1] A Lei de Diretrizes e Bases da Educação Brasileira (LDB 9394/96). Disponível em: <http://www.planalto.gov.br/ccivil_03/leis/19394.htm >Acesso em: 20 de outubro de 2019.

[2] Agência IBGE Notícias. Rendimento Médio de todos os trabalhos (2016-2017).Disponível em: <https://agenciadenoticias.ibge.gov.br/agencia-sala-de-imprensa/2013-agencia-de-noticias/releases/20843-pnadcontinua-10-da-populacao-concentravam-quase-metade-da-massa-de-rendimentos-do-pais-em-2017 >Acesso em: 07 de novembro de 2019.

[3] Agência IBGE Notícias. Rendimento Médio de todos os trabalhos (2018). Disponível em: < https://agenciadenoticias.ibge.gov.br/agencia-sala-de-imprensa/2013-agencia-de-noticias/releases/25700-pnadcontinua-2018-10-da-populacao-concentram-43-1-da-massa-de-rendimentos-do-pais >Acesso em: 07 de novembro de 2019.

[4] Associação Brasileira de Mantenedoras de Ensino Superior (ABMES). Fies Termina Ano Com O Menor Número De Novos Contratos Desde 2010. Disponível em: <http://www.abmes.org.br/noticias/detalhe/3110/fiestermina-ano-com-o-menor-numero-de-novos-contratos-desde-2010> Acesso em: 30 de setembro de 2019.

[5] BARROS, Ricardo Paes de; FRANCO, Samuel; MENDONÇA, Rosane. A recente queda da desigualdade e o acelerado progresso educacional brasileiro da última década. Rio de Janeiro, IPEA, Texto para Discussão, $\mathrm{n}^{\circ} 1304$, setembro/2007 Disponível em:< http://repositorio.ipea.gov.br/bitstream/11058/1439/1/TD_1304.pdf> Acesso em: 29 de setembro de 2019.

[6] BENOIT, Kenneth. Linear Regression Models with Logarithmic Transformations. Methodology Institute,London School of Economics. March,2011. Disponível em:

<https://kenbenoit.net/assets/courses/ME104/logmodels2.pdf> Acesso em: 30 de setembro de 2019.

[7] Cálculo deflácionario pelo Indíce Nacional de Preços ao Consumidor (INPC). Disponível em: < https://calculoexato.com.br/parprima.aspx?codMenu=FinanAtualizaIndice >. Acesso em: 07 de novembro de 2019.

[8] DURHAM, E. R. Uma política para o ensino superior brasileiro: diagnóstico e proposta. São Paulo: Universidade de São Paulo; Nupes, 1998. 66p. (Documento de Trabalho Nupes n. 1/98).

[9] Fundo de Financiamento Estudantil (FIES). Disponível em: < http://fies.mec.gov.br/> Acesso em: 07 de outubro de 2019.

[10] GUJARATI, D. N.; PORTER, D. C. Econometria básica. 5. ed. Porto Alegre: AMGH, 2011. 924 p.

[11] HERNÁNDEZ HUERTA, José Luis. La rivolta studentesca brasiliana del '68. Considerazioni a partire dalla stampa quotidiana. In: TODARO, Letterio. Pedagogia, istanze di emancipazione trasformazioni dell'immaginario educativo tra gli anni '60 e '70 del Novecento. Roma, 2017.

[12] IBGE Brasil em síntese: rendimento de todos os trabalhos (2007-2015). disponível em:<https://brasilemsintese.ibge.gov.br/trabalho/rendimento-de-todos-os-trabalhos.html> Acesso em: 07 de novembro de 2019.

[13] IBGE | Séries Estatísticas \& Séries Históricas : Rendimento médio mensal de todos os trabalhos (1981-2007). Disponível em: <https://seriesestatisticas.ibge.gov.br/series.aspx?no=7\&op=0\&vcodigo=FDT800\&t=rendimentomedio-mensal-todos-trabalhos-pessoas> Acesso em: 07 de novembro de 2019.

[14] JARDIM, Tânia. Destinos (im)prováveis: a formação em serviço social transformando trajetórias. 1 ed.-Rio de Janeiro, 2018.

[15] LANGONI, C. Distribuição de renda e desenvolvimento econômico no Brasil. 3a ed. Rio de Janeiro: FGV, 2005.

[16] LAPPONI, J. C. Estatística usando Excel 5 e 7. São Paulo: Lapponi, 1997

[17] MARTINS, 2002 Antonio Carlos Pereira Martins. Ensino superior no Brasil: da descoberta aos dias atuais em Acta Cirúrgica Brasileira, 17 (3) (2002), pp. 04-06, São Paulo

[18] NAGLE, A., 1974 - Educação e Sociedade na Primeira República. S.P. EPU - Editora Pedagógica Universitária Ltda. e Editora da Universidade de São Paulo.

[19] NEVES, Clarissa; MARTINS, Carlos; 2014. Disponível em: <http://repositorio.ipea.gov.br/bitstream/11058/9061/1/Ensino\%20superior\%20no\%20Brasil.pdf > Acesso em: 25 de outubro 2019.

[20] NORONHA, João. Fórum Nacional das IES Católicas. Setor de Educação no Brasil. Disponível em: < 
http://anec.org.br/wp-content/uploads/2018/08/Financiamento-Santander-1.pdf> Acesso em: 25 outubro 2019.

[21] NUNES, Edson de Oliveira. Educação Superior no Brasil: estudos, debates, controvérsias, Rio de Janeiro: Garamond, 2012. História UFRJ. Disponível em: < https://ufrj.br/historia>. Acesso em: 25 outubro 2019.

[22] Programa Universidade para todos - Prouni. Disponível em: < http://prouniportal.mec.gov.br/o-programa> Acesso em: 07 de outubro de 2019.

[23] SAMPAIO, HELENA. Documento de Trabalho 8/91: Evolução do ensino superior Brasileiro 1808-1990. Núcleo de Pesquisas sobre o ensino Superior da Universidade de São Paulo.1991

[24] SAMPAIO, HELENA. Ensino superior no Brasil: O setor privado. São Paulo. FAPESP, 2000.

[25] SAMPAIO, HELENA. O setor privado de ensino superior no Brasil: continuidades e transformações. Ensino Superior: Campinas: Unicamp, 2011.

[26] SANTOS, C. M. A.; Estatística Descritiva - Manual de auto-aprendizagem; Edições Sílabo; 2007.

[27] SAVIANI, Dermeval. A expansão do ensino superior no Brasil: Mudanças e continuidades. Poíesis pedagógica, v. 8, n.2, p. 4-17, 2010.

[28] Sinopses Estatísticas da Educação Superior - Graduação. Disponível em:

<http://portal.inep.gov.br/web/guest/sinopses-estatisticas-da-educacao-superior>. Acesso em: 07 outubros de 2019.

[29] SOUSA, J. V. O ensino superior privado no Distrito Federal: uma análise de sua recente expansão (19952001). 2003. 279f. Tese (Doutorado) - Universidade de Brasília, Brasília, 2003.

[30] TACHIBANA, Thiago Yudi et al. Policy Paper, n. 14, dez .2015. Disponível em: <https://www.insper.edu.br/wp-content/uploads/2018/09/Ensino-superior-no-Brasil.pdf>. Acesso em: 28 outubro 2019.

[31] VASCONCELlOS, Marco Antonio Sandoval de. Economia: Micro e Macro: Teoria e exercícios, glossário com 300 principais conceitos econômicos. -5. Ed.- São Paulo: Atlas, 2011. 


\section{Capítulo 11}

Impactos da terceirização na contratação de mão de obra sob a ótica da saúde e segurança do trabalho

Anderson Alves de Alcântara

Emerson Nóbrega de Medeiros

Letícia Dantas Muniz Alves

Eduardo Braga Costa Santos

Denise Dantas Muniz

Resumo: A terceirização acarreta diversas modificações nas atividades e contextos de trabalho e impacta também a saúde do trabalhador. 0 presente artigo tem como objetivo realizar uma revisão bibliográfica acerca dos efeitos da terceirização na saúde e segurança dos trabalhadores. Os resultados evidenciaram impactos negativos na saúde dos trabalhadores, pois foi identificado na literatura que a precarização observada das condições de trabalho em seus respectivos ambientes são associadas à terceirização, caracterizada por diferenças salariais e de benefícios, redução e/ou perda dos direitos trabalhistas, excesso da jornada de trabalho e falta de treinamento. Também foi identificada, nos estudos analisados, a relação da terceirização com fatores desencadeadores de estresse, doenças relacionadas ao trabalho, riscos de acidentes, falta de suporte à saúde e à segurança, adoecimento psíquico e insegurança. Conclui-se que os trabalhadores terceirizados estão expostos a condições desfavoráveis de trabalho, entendidas pela literatura como "precarização" do trabalho. Porém, a adoção de medidas entre as empresas (tomadoras/terceirizadas) no que se refere à saúde e segurança do trabalho pode contribuir para modificar esse contexto, melhorando as condições de trabalho para os trabalhadores terceirizados.

Palavras-chaves: Terceirização; Precarização; Saúde e Segurança do Trabalho. 


\section{INTRODUÇÃO}

As transformações ocorridas no processo produtivo desde as últimas três décadas do século XX impactaram profundamente o mundo do trabalho. Após o longo período de crescimento da economia de mercado, iniciado no pós-guerra, os anos 1970 seriam marcados pela estagnação e pela crise, estampadas de forma mais visível na crise através da acumulação do princípio taylorista e fordista, mas que encontravam suas determinações mais profundas, caracterizadas por uma crise estrutural do sistema capital (MÉSZÁROS, 2002; ANTUNES, 2010).

Com isso, a nova forma de contratação através da terceirização da atividade-fim criou uma relação triangular, o que gerou grandes mudanças neste setor (VIANA, 2016), onde uma empresa denominada prestadora de serviços contrata empregados, constituindo entre eles o vinculo empregatício e fornece o serviço desses trabalhadores para outra empresa denominada de tomadora. Sintetizando, o trabalhador desenvolve sua atividade laboral na empresa tomadora, mas não é com ela que constitui seu vinculo empregatício e sim com a empresa prestadora, sendo esta encarregada de pagar seu salário, bem como todos os demais encargos trabalhistas.

No entanto, o tema da terceirização trabalhista tem sido bastante discutido atualmente no Brasil acerca dos seus efeitos sobre a saúde e segurança do trabalhador e, especialmente em virtude da aprovação da Lei 13.429/2017 que dispõe sobre as relações de trabalho na empresa de prestação de serviços a terceiros. Segundo Filgueiras e Cavalcante (2015), os efeitos deteriorantes da terceirização são facilmente perceptíveis, seja nos tipos de contratos, seja na remuneração, ou ainda nas piores condições de trabalho e falta de representatividade sindical, suscitando a criação de trabalhadores de "primeira" e "segunda" classe, o que motiva a discriminação e casos de bullying contra os terceirizados.

Dados comprovaram que "o mecanismo de terceirização é altamente pernicioso para os trabalhadores brasileiros e fere gravemente os princípios constitucionais e o direito do trabalho" (DIEESE, 2014, p. 07). Neste ponto, 26,8\% da força de trabalho formal no Brasil é terceirizada. Todavia, é impossível estimar o número real de terceirizados, pois existe um grande número que está na informalidade e não possui o devido registro junto aos órgãos competentes.

\section{REFERENCIAL TEÓRICO}

\subsection{ASPECTOS GERAIS DA TERCEIRIZAÇÃO}

Conforme explica Leite (2017), o termo "terceirização" constitui neologismo originado da palavra "terceiro", no sinônimo de intermediário, interveniente, interposto, medianeiro. É necessário enfatizar que é uma realidade das relações de emprego, haja vista a globalização do trabalho, a flexibilização das normas e das relações de trabalho, cada vez mais presentes e ativas no mundo capitalista e no campo empresarial.

A expressão terceirização surgiu no âmbito de administração de empresas, "objetivando dar ênfase à descentralização empresarial de atividades para outrem, um terceiro à empresa" (FERRAZ, 2006. p. 239). A terceirização, portanto, "constitui a realização, por um terceiro, de atividade-fim ou atividade-meio da empresa contratante" (MORAES, 2003, p. 876). Todavia, é importe ressaltar que existem outras terminologias que denominam a contratação terceirizada, tais como: subcontratação, terciarização, filialização, reconcentração, desverticalização, exteriorização do emprego, focalização, parceria, ou ainda, horizontalização, externalização de atividades, contrato de fornecimento, entre outros. (MARTINS, 2009, p. 06).

De naturezas iguais, são nomenclaturas utilizadas para especificar a terceirização pela administração empresarial. É importante não confundir a terceirização com a "intermediação de mão de obra", a qual, em regra, é proibida pelo sistema jurídico brasileiro, uma vez que o trabalho não pode ser referido como mercadoria, o que seria antagônico ao seu valor social e à dignidade humana (GARCIA, 2017).

A terceirização, para o Direito do Trabalho, é o instituto pelo qual uma empresa - a tomadora de serviços contrata uma terceira empresa - prestadora de serviços - para oferecer mão de obra, quase sempre em busca de diminuir custos e aumentar a produtividade e, por conseguinte, o lucro. Nesta perspectiva, a tomadora de serviços rechaça os laços de contrato de emprego com os empregados, de sorte que estes mantêm vínculo empregatício apenas com a empresa interposta. Deste modo, surge uma relação trilateral:

[...] o obreiro, prestador de serviços, que realiza suas atividades materiais e intelectuais junto à empresa tomadora de serviços; a empresa terceirizante, que contrata este obreiro, firmando com ele os vínculos 
jurídicos trabalhistas pertinentes; a empresa tomadora de serviços, que recebe a prestação de labor, mas não assume a posição clássica de empregadora desse trabalhador envolvido. (DELGADO, 2017, p.503)

Sendo assim, surge uma relação em contraste àquela já usualmente realizada, a relação bilateral: empregado e empregador. Para averiguar como a terceirização atua dentro do modelo de relação de trabalho entre as partes envolvidas, esta também é definida como:

[...] a estratégia empresarial que consiste em uma empresa transferir para outra, e sob o risco desta, a atribuição, parcial ou integral, da produção de uma mercadoria ou a realização de um serviço, objetivando - isoladamente ou em conjunto - a especialização, a diminuição de custos, a descentralização da produção ou a substituição temporária de trabalhadores (SANTOS, 2010, p. 19).

A terceirização, na ótica do poder econômico, se caracteriza como uma tática da empresa tomadora dos serviços em concentrar em sua atividade-fim, deixando-as mais competitivas e ágeis e com isso proporcionando um atendimento mais rápido e eficiente às transformações determinadas pelo mercado (SANTOS, 2010). Em resumo, a terceirização é um acordo entre duas empresas, em que a prestadora de serviços se compromete pelas obrigações decorrentes da relação trabalhista, fornecendo mão de obra à tomadora de serviços, para que essa possa diminuir seus custos, aumentar a especialidade dos seus serviços e sua competitividade no mercado.

\subsection{PROCESSO DE TRABALHO E SAÚDE}

Atualmente, na concepção técnico-científica e diante de uma área de conhecimento e de ação, existem pelo menos duas maneiras de compreender a saúde no trabalho: a primeira, mais restrita e que se limita essencialmente ao fato preventivo dos danos causados à saúde pelo trabalho, isto é, a proteção contra riscos de doenças ocupacionais e acidentes de trabalho; e a segunda, mais ampla e que envolve o conjunto dos problemas que abrangem a saúde dos trabalhadores, incluindo seus aspectos curativos e preventivos (MIRANDA, 2006, p. 05).

Silva, Goulart Junior e Camargo (2019) apontaram a terceirização como elemento significativamente responsável pela ampliação dos riscos de redução dos níveis de qualidade de vida no trabalho, reiterando a desatenção aos fatores psicossociais integrantes da relação trabalhador-organização-trabalho, provocando um processo cíclico que se retroalimenta e que culmina com a ampliação do risco de adoecimento físico e mental do trabalhador. Destacaram também que a organização, quando opta por uma política de redução de custos com mão de obra via terceirização, reduz os investimentos nos processos que fomentam uma gestão mais saudável dos fatores psicossociais de risco à saúde física e mental do trabalhador.

Para Passos e Nogueira (2018), a forma aplicada pelas empresas no tocante à terceirização tem por função a redução de custos através da flexibilização do trabalho, transferindo a outrem os riscos e as responsabilidades trabalhistas, intensificando a precarização da força de trabalho, independente do âmbito do negócio - privado ou público.

Outro trabalho que merece ser destacado é o de Dejours (2006), no qual buscou relações na própria organização do trabalho, por um lado, e o sofrimento psíquico do trabalhador, de outro. 0 mesmo autor retratou a correlação trabalho-saúde mental, empregando o método de pesquisa do campo da psicopatologia do trabalho, com a finalidade de entender como as mais variadas formas de organização do empreendimento atuam sobre o pensar e o sentir dos trabalhadores, provocando angústias, medos, sofrimentos e infelicidades. Para Dejours (2006) "o trabalho se revela essencialmente ambivalente. Pode causar infelicidade, alienação e doença mental, mas pode também ser mediador da auto-realização, da sublimação e da saúde" (p.98).

Fischer et al (1995) evidenciam que os trabalhadores estão sujeitos a um número elevado de fatores chamados de "psicossociais", além dos riscos ambientais existentes no local de trabalho. Esses fatores psicossociais, ainda que não evidenciem a especificidade dos riscos ambientais alegados em lei, trazem desconforto, limitam a participação dos trabalhadores nas atividades familiares e sociais, são intensificadores de doenças, minoram a qualidade de vida. 
Entre os aspectos psicossociais, é possível citar a velocidade de produção controlada, etapas de trabalho repetitivas, diminuição da utilização dos conhecimentos dos trabalhadores, interrupção do trabalho para descanso insuficiente, equipamentos e locais de trabalho não compatíveis com as necessidades de concentração, entre outros. Face ao exposto, o processo saúde/doença do trabalhador é a consequência do conjunto de circunstâncias em que os trabalhadores vivem e trabalham, dependendo do setor de atividade, do ramo e do porte da empresa. Conforme sublinham Abramides e Cabral (2003, p.07), "a força de trabalho, considerada mercadoria básica no processo de produção capitalista, é requerida pelo mercado, mas lhe é exigido ter a saúde necessária para executar um processo de trabalho", sendo consumida até o seu desgaste, ou seja, o consequente processo de adoecimento.

Dessa forma, o estudo do processo trabalho/doença ocupacional não pode deixar de investigar pelo menos os seus condicionantes básicos: processo de trabalho, as relações de trabalho e as condições gerais de vida. No entanto, as condições gerais de vida devem ser mensuradas levando em consideração as condições fornecidas pelo padrão e volume dos bens de consumo coletivo propiciados pelo Estado, e as condições que recaem sobre o consumo individual obtido pelo salário (MIRANDA, 2006, p. 07).

\subsection{TERCEIRIZAÇÃO: RISCOS E BENEFÍCIOS}

São inúmeras as vantagens ao se terceirizar e isso tem atraído inúmeras empresas, dentre as principais é que a tomadora de serviços consegue focar seus esforços nos resultados da empresa, deixando a cargo da prestadora de serviços todas as responsabilidades, como seleção, admissão, treinamentos e acompanhamentos - ações essenciais para a contratação de profissionais capacitados e competentes (MIRAGLIA, 2008).

Para Martins (2001), a principal vantagem sob o aspecto administrativo seria a de se ter alternativas para melhorar a qualidade do produto ou serviço vendido e também a produtividade. Seria uma forma também de se obter um controle de qualidade total dentro da empresa, sendo que um dos objetivos básico dos administradores é a diminuição dos encargos trabalhistas e previdenciários, além da redução do preço final do produto. Por meio dos repasses das atividades-meio para que terceiros as executem, as empresas conseguem dedicar-se com empenho e concentração ao desenvolvimento de suas atividades-fim.

Com a aprovação e sanção da Lei 13.429/2017, aconteceram mudanças circunstanciais no fenômeno da terceirização. Anteriormente a esta Lei, o conceito de terceirização girava em torno da realização de atividades acessórias de uma determinada empresa, desta maneira, a vantagem primordial apontada pelos especialistas era que, não necessitando se preocupar com as atividades-meio, as empresas poderiam concentrar suas atenções ao desenvolvimento, aprimoramento e especialização das suas atividades principais, buscando assim, melhorar a qualidade de seus produtos e serviços.

Segundo Franco et al (1994), os diagnósticos concretos, em diversas áreas econômicas em diversas regiões do país, tem evidenciado uma proporção real das consequências da terceirização, ou seja, uma crescente precarização, no emprego/trabalho e na condição de saúde dos trabalhadores. E, diante do problema de ordem técnica e metodológica, vários estudos tem levantado um diagnóstico comparativo das estatísticas sobre acidentes de trabalho e doenças profissionais para constatar os efeitos negativos da terceirização.

Um problema inicial é que, no Brasil, a informação à Previdência Social sobre uma ocorrência de um acidente de trabalho ou doença profissional depende, sobretudo, da empresa, sendo efetuada através da emissão da Comunicação de Acidente de Trabalho - CAT. Contudo, essas mesmas empresas se negam em emitir a CAT e sua emissão somente ocorre, geralmente, quando os danos à saúde já são irremediáveis e o trabalhador classificado como incapaz para o trabalho e de reabilitação para o exercício de sua atividade (MIRANDA, 2006, p. 08).

Os valores-fetiche da produção transpassam a barreira dos muros das organizações e perpassam todos os espaços de sociabilidade e, neste caminhar, todo o corpo de empregados submetidos à lógica da manipulação acaba sofrendo prejuízos físicos que, de forma ainda mais devastadora, atingem a ordem psíquica e espiritual, manifestando-se em sintomas psicossomáticos. Nesse contexto, o trabalho, como expressão da alienação, deixa de ser fonte de realização do homem e passa a gerar sérios prejuízos à saúde do trabalhador (ALVES, 2013). 


\title{
2.4 TERCEIRIZAÇÃO E PRECARIZAÇÃO DO TRABALHO
}

A Tabela 1 revela a dimensão dos vínculos de emprego nas atividades tipicamente terceirizadas e nas tipicamente contratantes para as regiões do Brasil, bem como por sua faixa de remuneração. A tabela nos mostra que as diferenças por região refletem nas desigualdades de remuneração entre os dois segmentos de atividades.

Tabela 1: Participação dos segmentos terceirizados no total de vínculos formais de emprego segundo quartos da distribuição da remuneração Brasil, Grandes Regiões, 2014 (em \%).

\begin{tabular}{|c|c|c|c|c|c|c|}
\hline Faixa de remuneração & Norte & Nordeste & Sudeste & Sul & $\begin{array}{c}\text { Centro- } \\
\text { Oeste }\end{array}$ Brasil \\
\hline $25 \%$ menores remunerações & 20,6 & 26,0 & 31,4 & 30,6 & 25,0 & 28,3 \\
\hline $2^{\circ}$ quarto & 22,8 & 29,6 & 29,7 & 26,8 & 25,7 & 28,4 \\
\hline $3^{\circ}$ quarto & 24,5 & 23,9 & 31,4 & 27,4 & 25,6 & 28,8 \\
\hline $25 \%$ maiores remunerações & 12,2 & 12,6 & 21,2 & 16,7 & 11,3 & 17,9 \\
\hline Total & 19,9 & 24,0 & 28,1 & 25,1 & 21,2 & 25,8 \\
\hline
\end{tabular}

Fonte: MTb. Rais Elaboração: DIEESE (2014). Subseção CUT Nacional. Obs.: Remuneração em dezembro.

Verifica-se, em todas as regiões, que há uma queda no percentual de vínculos nas atividades tipicamente terceirizadas, conforme segue em direção às remunerações mais elevadas. A desvalorização é mais acentuada no Nordeste, onde apenas $12,6 \%$ dos vínculos de emprego nas atividades terceirizadas se encaixam numa faixa maior de remuneração. Na região Sudeste do Brasil, este percentual alcança 21,2\%.

Com relação aos acidentes de trabalho, os trabalhadores terceirizados também são os que mais sentem, pois são mais constantes no meio dessas empresas. De acordo com o DIEESE (2014), no setor elétrico em 2011, dos 79 óbitos que aconteceram, 61 ocorreram em empresas terceirizadas. Várias dessas empresas são de pequeno porte e não tem suporte e nem disponibilizam os EPI's essenciais para que os trabalhos sejam executados com segurança, justificando esses dados tão preocupantes.

São inúmeros os malefícios causados pela terceirização aos trabalhadores, como os já considerados, remuneração menor, maior carga horária de trabalho, maior rotatividade e maior probabilidade de sofrer acidentes o trabalho. Ademais, o trabalhador terceirizado também sofre com a discriminação e o preconceito, visto que o terceirizado, no final das contas, recebe um salário menor em uma jornada de trabalho maior que o contratado direto para a mesma função, além disso, na maioria das empresas eles são obrigados a utilizar uma farda diferente que o restante da empresa, não podem utilizar do mesmo refeitório, entre outras áreas da empresa. Além disso, Severo (2015) afirma:

\begin{abstract}
A terceirização cria uma classe de indivíduos invisíveis, para que os quais não são negados apenas direitos, mas também o próprio reconhecimento da condição de trabalho. Nas atividades de limpeza e conservação, por exemplo, seres humanos trabalham sem que os empregados da "tomadora dos serviços" saibam seus nomes ou mesmo os cumprimentem. Na ânsia de evitar a configuração de vínculos, o ambiente de trabalho torna-se verdadeiramente inóspito, pela condição de invisibilidade que lhes é relegada (SEVERO, 2015, p. 18).
\end{abstract}

A diferenciação acontece pela desigualdade criada nos locais de trabalho entre trabalhadores diretamente contratados e os terceirizados, seja porque o modelo de trabalho executado pelo terceirizado é visto como menos significativo, seja pelas diferenças de remuneração, jornada, qualificação e nas próprias condições de trabalho. Os trabalhadores terceirizados mostram a dificuldade de usufruir os vestiários, refeitórios e uniformes distintos dos utilizados pelos trabalhadores diretamente contratados. 


\subsection{NORMAS DE SEGURANÇA E SAÚDE DO TRABALHO E A TERCEIRIZAÇÃO}

No tocante ao processo de terceirização, a NR-5 (BRASIL, 2011), em seu item 5.48, estabelece que a empresa contratante e as contratadas, que atuem num mesmo estabelecimento, deverão implementar, de forma integrada, medidas de prevenção de acidentes e doenças do trabalho, de forma a garantir o mesmo nível de proteção em matéria de segurança e saúde a todos os trabalhadores do estabelecimento. A empresa contratante deverá adotar medidas necessárias para que as empresas contratadas, suas CIPAs, os designados e os demais trabalhadores lotados naquele estabelecimento recebam as informações sobre os riscos presentes nos ambientes de trabalho, bem como sobre as medidas de proteção adequadas. Além do mais, a contratante deverá, ainda, adotar medidas necessárias para acompanhar o cumprimento das medidas de segurança e saúde no trabalho pelas empresas contratadas que atuam no seu estabelecimento.

Um problema importante é o enquadramento das empresas prestadoras de serviços para fins de dimensionamento da CIPA. A maioria dessas empresas são enquadradas como código CNAE: 74.99-3 (outras atividades de serviços prestados principalmente às empresas), classificadas como integrantes do Grupo C-35. Com essa classificação, as empresas prestadoras de serviço somente estão obrigadas a constituir a CIPA quando possuírem mais de 50 empregados no estabelecimento. As empresas com menos de 50 empregados estão obrigadas a apenas designar um responsável pelas questões relacionadas com a prevenção de acidentes e doenças decorrentes do trabalho.

A NR-4 (BRASIL, 2016), em seu item 4.5, estabelece que a empresa que contratar outra(s) para prestar serviços deverá incluir aos empregados da contratada o auxílio de seu SESMT, no caso da empresa contratada não ter o seu próprio serviço de saúde. Na realidade, porém, a maioria das empresas contratadas não mantém seu próprio serviço médico e, em geral, as contratantes também não incluem a assistência de seu SESMT para os empregados das contratadas. As empresas contratadas geralmente usufruem os serviços do Sistema Único de Saúde (SUS) ou contratam outras empresas particulares que prestam serviços de saúde para realizar os exames médicos ocupacionais de seus empregados.

Em relação à terceirização, a NR-9 (BRASIL, 2014), em seu item 9.6.1, determina que sempre que vários empregadores realizem, simultaneamente, atividade no mesmo local de trabalho, terão o dever de realizar ações integradas para aplicar as medidas previstas no PPRA, visando à proteção de todos os trabalhadores expostos aos riscos ambientais gerados. No caso das empresas terceirizadas, outro aspecto essencial é o desconhecimento de quase todos os riscos ambientais presentes nos mais diversos setores de trabalho da contratante e, com isso, a falta de medidas que poderiam mitigar ou solucionar as questões relativas a esses riscos. A decorrência disso, em geral, tem sido uma crescente piora das condições de segurança e saúde no trabalho, principalmente para os trabalhadores terceirizados.

\section{METODOLOGIA}

A pesquisa aplicada é a bibliográfica, desenvolvido a partir de livros e artigos disponibilizados em revistas científicas online, com o desígnio de esclarecer as questões pertinentes à temática apresentada. Em relação aos critérios de seleção de conteúdo, levou-se em conta pesquisas eletrônicas auxiliadas por buscadores acadêmicos, são estes: Scielo, Google Acadêmico, DIEESE, Secretaria do Trabalho do Ministério da Economia e o Anuário Estatístico da Previdência Social. A busca nos bancos de dados foi realizada utilizando terminologias em português. Entre as palavras-chaves utilizadas: terceirização, precarização, saúde e segurança do trabalho. Os trabalhos científicos que se enquadravam com as terminologias acima citada foram selecionados e separados de acordo com o conteúdo abordado. A identificação das Normas Regulamentadoras também seguiu esse mesmo método de pesquisa.

\section{RESULTADOS}

Constatou-se que a terceirização é uma alternativa que as empresas possuem de reduzir seu quadro funcional, buscando se concentrar nas suas atividades principais, desta forma as empresas não precisam ficar desperdiçando tempo e recursos em atividades não rentáveis a empresa. Entretanto, através dos estudos das mais diversas literaturas, bem como através de dados obtidos na Relação Anual de Informações Sociais - RAIS (2015) - nos mostraram que, de uma forma geral, nas atividades terceirizadas, os trabalhadores tem uma jornada de trabalho maior, suas remunerações são inferiores e as condições de trabalho são bem abaixo do que nas atividades contratantes.

Em resumo, as informações obtidas para o ano de 2014 nos mostraram que: 
- As remunerações nas atividades contratantes eram, em média, 23,4\% maior do que nas atividades terceirizantes, cifra de $\mathrm{R} \$ 2.639,00$ contra $\mathrm{R} \$ 2.011,00$;

- $85,9 \%$ dos relacionamentos nas atividades terceirizantes possuíam uma carga horária de trabalho entre 41 e 44 horas semanais. No entanto no setor contratante, a dimensão era de 61,6\%;

- $\quad 0$ alto índice de rotatividade é duas vezes maior no setor terceirizado $(57,7 \%$, contra $28,8 \%$ no setor contratante);

- No setor terceirizado, 44,1\% dos relacionamentos de trabalho foram firmados no mesmo ano, enquanto que no setor contratante, o percentual foi de $29,3 \%$;

- As remunerações pagas aos terceirizados, exceto da região Sudeste eram inferiores, o que demonstra as diferenças regionais;

- A probabilidade de ocorrência de acidentes fatais com trabalhadores terceirizados é de cerca de 5 a 5,6 vezes maior quando comparados com os índices de acidentes dos empregados que realizam serviços diretamente ao seu empregador.

Fica claro que existe uma diferença entre os direitos dos trabalhadores terceirizados com os direitos dos trabalhadores temporários. Afirmando isso, abordaram-se, no presente trabalho, uma revisão bibliográfica entre os trabalhadores efetivos de uma empresa, a dos trabalhadores terceirizados, chegando a conclusão que a terceirização traz consequências negativas à saúde do trabalhador. Com relação às NRs, o quadro 1 mostra os itens associados à terceirização.

Quadro 1 - Normas Regulamentadoras associadas à terceirização

\begin{tabular}{|c|c|}
\hline NR & Item relacionado à terceirização \\
\hline NR-4 & 4.5 (incluir o auxílio do SESMT) \\
\hline NR-5 & 5.48 (implementar de forma integrada as medidas de prevenção) \\
\hline NR-7 & 7.1.3 (comunicar a empresa contratada acerca dos riscos existentes) \\
\hline NR-9 & 9.6.1 (realizar ações integradas previstas no PPRA) \\
\hline NR-10 & 10.13.2 (responsabilidade dos contratantes em informar os riscos que estão expostos) \\
\hline NR-22 & 22.3.5 (medidas relativas a segurança e saúde dos trabalhadores da contratada) \\
\hline NR-24 & 24.6.1.1 (ampliar aos trabalhadores da contratada as mesmas condições de higiene e conforto) \\
\hline NR-31 & $\begin{array}{l}31.23 .8 \text { (garantir aos trabalhadores das empresas contratadas para a prestação de serviços as } \\
\text { mesmas condições de higiene, conforto e alimentação) }\end{array}$ \\
\hline NR-32 & Mesmas especificações da NR-10 \\
\hline NR-33 & Mesmas especificações da NR-10 \\
\hline
\end{tabular}

A terceirização no âmbito da Administração Pública, além de burlar o princípio constitucional do concurso público, a terceirização integral na seara pública pode provocar uma queda na qualificação do funcionário e também estimular a prática do nepotismo, da corrupção e da "pejotização", além de que os trabalhadores terceirizados são despreparados em sua maioria.

\section{CONSIDERAÇÕES FINAIS}

Conclui-se que os estudos tem mostrado a proporção real dos efeitos da terceirização, isto é, somente constatam a precariedade nas condições de trabalho, segurança e saúde dos trabalhadores nas empresas terceirizadas. Sobre a segurança e saúde dos trabalhadores, os efeitos prejudiciais da terceirização têm sido apontados e, na maior parte da literatura, foi possível observar um aumento significativo da ocorrência destes eventos entre os trabalhadores terceirizados, pois estes possuem jornadas de trabalho superiores aos trabalhadores efetivos de uma empresa, sua remuneração é mais baixa e, além disso, a maior exposição ao risco iminente de vida gerado pelos distúrbios psicossociais inerentes do modelo de relação terceirizada de trabalho. 
Finalizando, é imprescindível que se faça uma reflexão com relação a terceirização em uma perspectiva mais humana, que leve em consideração suas consequências em todas as suas dimensões, dando prioridade à dignidade humana, direito previsto a todos pela Constituição e a defesa do ambiente hígido, saudável e seguro pertence ao Estado, à sociedade, ao trabalhador e ao empreendedor, cabendo a esses agentes sociais a busca por mecanismos que reduzam os riscos inerentes ao trabalho, ou seja, a busca da implementação dos mecanismos de segurança no trabalho que perpassam pelas fases de antecipação, identificação, avaliação e controle dos riscos ocupacionais.

\section{REFERÊNCIAS BIBLIOGRÁFICAS}

[1] ABRAMIDES, M. B. C.; CABRAL, M. S. R. Regime de Acumulação Flexível e Saúde do Trabalhador. São Paulo, 2003.

[2] ALVES, G. Marxismo, a alienação e o tempo histórico da barbárie social do capital. Revista Katálysis, Florianópolis, v. 16, n. 1, p. 57-62, jan./jun. 2013.

[3] ANTUNES, R. Adeus ao trabalho? Ensaio sobre as metamorfoses e a centralidade do mundo do trabalho. (Edição especial de 20 anos.) São Paulo: Cortez, 2015.

[4] BRASIL. Ministério do Trabalho. Portaria MTPS n.o 510, de 29 de abril de 2016. NR 4 - serviços especializados em engenharia de segurança e em medicina do trabalho. Brasília: Ministério do Trabalho 2016. Disponível em: http://www.trabalho.gov.br/ Acesso em: 08 dez 2018.

[5] __. Ministério do Trabalho. Portaria SIT n.o 247, de 12 de julho de 2011. NR 5 - comissão interna de prevenção de acidentes. Brasília: Ministério do Trabalho 2011. Disponível em: http://www.trabalho.gov.br/ Acesso em: 08 dez 2018.

[6] __. Ministério do Trabalho. Portaria MTE n. 1.471, de 24 de setembro de 2014. NR 9 - programa de prevenção de riscos ambientais. Ministério do Trabalho 2014. Disponível em: http://www.trabalho.gov.br/ Acesso em: 08 dez 2018.

[7] _. Ministério do Trabalho. Manual de orientação da RAIS. Ano-base: 2015. Brasília: Cget/DES/ SPPE/MTB.

[8] DEJOURS, C. A banalização da injustiça social. 7. ed. Rio de Janeiro: FGV, 2006.

[9] DELGADO, M. G. Curso de Direito do Trabalho. 16. ed. São Paulo: LTr, p.503, 2017.

[10] DIEESE - DEPARTAMENTO INTERSINDICAL DE ESTATÍSTICA E ESTUDOS SOCIOECONÔMICOS. Rotatividade e políticas públicas para o mercado de trabalho. São Paulo: Dieese, 2014.

[11] FERRAZ, F. B. Terceirização e demais formas de flexibilização do trabalho. São Paulo: Ed. LTr, Junho, 2006.

[12] FILGUEIRAS, V. A. Terceirização e os limites da relação de emprego: trabalhadores mais próximos da escravidão e morte. 2014. Disponível em: https://indicadoresdeemprego.files.wordpress.com/ Acesso em: 11 jan. 2018.

[13] FISCHER, F. M.; LIEBER, R. R.; BROWN, F. M. Trabalho em Turnos e as Relações com a Saúde-Doença. In: MENDES, R. (Org.) - Patologia do Trabalho. Rio de Janeiro: Editora Atheneu, p. 545-572. 1995.

[14] FRANCO, T. M. et al. Mudanças de gestão, precarização do trabalho e riscos industriais. Cadernos CRH, Salvador, n.21, jul-dez. p. 68-89. 1994.

[15] GARCIA, G. F. B. Curso de direito do trabalho. 11. ed. Rio de Janeiro: Forense, 2017.

[16] LEITE, C. H. B. Curso de direito do trabalho. 8. ed. São Paulo: Saraiva, 2017.

[17] MARTINS, S. P. A terceirização e o direito do trabalho. 5.ed.São Paulo: Atlas, 2001.

[18] MÉSZÁROS, I. Para além do capital. São Paulo: Boitempo, 2002.

[19] MIRAGLIA, L. M. M. A terceirização trabalhista no Brasil. 5ํㅡ ed. São Paulo: Ed. Quartier Latin, 2008.

[20] MIRANDA, C. R. Ataque ao mundo do trabalho: terceirização e seus reflexos na segurança e saúde do trabalhador. 2006. Portal Saúde e Trabalho Online. Disponível em http://www.saudeetrabalho.com.br/ Acesso em 06 mai 2018.

[21] MORAES, L. F. N. As cooperativas de trabalho ante a terceirização e as novas diretivas previdenciárias. Revista de Direito do Trabalho. Curitiba: Genesis, Junho p. 876-7, 2003.

[22] PASSOS, R. G.; NOGUEIRA, C. M. O fenômeno da terceirização e a divisão sociossexual e racial do trabalho. Revista Katálysis, Florianópolis, v. 21, n. 3, p. 484-503, set./dez. 2018. DOI: http://dx.doi.org/10.1590/198202592018v21n3p484 
[23] SANTOS, D. P. F. S. Terceirização de serviços pela administração pública: estudo de responsabilidade subsidiária. São Paulo: Saraiva, 2010.

[24] SEVERO, V. S. Terceirização: o perverso discurso do mal o menor. 2015. Disponivel em: http://www.femargs.com.br/ Acesso em: 19 dez. 2017.

[25] SILVA, L. A. T.; GOULART JÚNIOR, E.; CAMARGO, M. L. Terceirização é prejudicial a saúde: um estudo bibliográfico nacional sobre a precarização do trabalho. Revista Labor, Fortaleza/CE, v. 1, n. 21, p. 76-97, jan./jun. 2019.

[26] VIANA, R. K. Terceirização: apontamentos sobre a responsabilidade civil do tomador de serviços em caso de acidente de trabalho. In: MARTINS FILHO, I. G. S.; NAHAS, T. C. Revista de Direito do Trabalho. RDT. São Paulo, v. 170, n. 42, p. 57-78. Jul./Ago. 2016. 


\section{Capítulo 12}

Identificação de riscos na estruturação do sistema de trabalho em uma metalúrgica através da análise ergonômica do trabalho: Um estudo de caso

Ana Maria Moura Gouveia

Juliana Machion Gonçalves

Resumo: 0 estudo do trabalho vem trazendo novos valores para a investigação e aperfeiçoamento do trabalho. Ao conciliar técnicas e métodos de análise, é possível identificar os fatores de risco para melhorar a eficiência do trabalho e otimizar o ambiente produtivo, de acordo com as necessidades de cada empresa ou instituição. Este estudo busca entender, analisar e apresentar soluções visando melhoria de processos, conforto e segurança dos operadores de uma organização do setor metalúrgico localizada na província de Buenos Aires - Argentina. Para isso, foi desenvolvida uma pesquisa qualitativa baseada em um estudo de caso com pressupostos da análise ergonômica do trabalho. Foram feitas análises utilizando como base de estudo as ferramentas EWA, RULA e o método QFD para priorizar as soluções encontradas. Dentre os problemas encontrados, estão a falta de organização no ambiente produtivo, espaço de trabalho inadequado e posturas inadequadas. As propostas de solução foram desenvolvidas juntamente com o trabalhador, trazendo suas perspectivas e sugestões, tais como: destinação de resíduos, ajustes nas bancadas de trabalho e reorganização do layout do sistema produtivo. Assim, buscando alternativas de baixo custo e eficientes, foi possível apresentar soluções para manter o equilíbrio, saúde e procutividade.

Palavras-chave: Ergonomia; Riscos; Metalurgia; Trabalho. 


\section{INTRODUÇÃO}

Investigar e aperfeiçoar as condições de trabalho tem sido feito desde que o esforço humano se organizou para inovar e empreender nas empresas (KANAWATY, 1996). De acordo com Camarotto (2007), o estudo de trabalho é o uso de técnicas, métodos e medições, para examinar em todos os seus aspectos, investigando fatores que influem na eficiência e desempenho, com finalidade de melhorar o conforto e segurança do trabalho, aumentando a produtividade. Esse tema é utilizado neste artigo com o intuito principal de aumentar o rendimento de uma metalúrgica mediante a reorganização do ambiente produtivo.

Neste contexto, esse artigo foi feito com base em uma experiência de intercâmbio cultural em uma Organização Não Governamental (ONG) na Argentina. A importância do estudo se dá pela adequação dos postos de trabalho para a minimização de riscos ocupacionais, uma vez que exige posturas estáticas e repetitivas que possam agredir seu desenvolvimento biomecânico (SHINNAR, ALTINAR, INDELICATO, 2004). Bem como a produtividade e eficiência, é importante ressaltar a ergonomia e segurança do trabalho que influenciam nos aspectos produtivos, aperfeiçoando diversas etapas dos processos (CAMAROTTO, 2007).

Conforme a Organização Internacional do Trabalho (OIT, 2020), em um período de três anos (2015-2018) foram registrados um total de 601.752 casos de acidentes e doenças do trabalho não fatais, além de 471 casos de acidentes e doenças do trabalho fatais, nas indústrias de manufatura na América do Sul. Assim, nesses dados há pesquisas que mostram a Argentina como quinto país, em âmbito mundial, a registrar maior número de acidentes e doenças do trabalho não fatais nas indústrias de manufatura, e o sétimo com maior número de acidentes fatais (167 fatalidades). Ainda, o Brasil foi identificado como segundo país a registrar o maior número de acidentes e doenças não fatais nessas indústrias no mundo, e o primeiro com o maior número de acidentes fatais (650 fatalidades).

Nesse contexto, este artigo evidencia uma pesquisa feita em uma metalúrgica, através do estudo detalhado com o intuito de identificar possíveis falhas na estruturação do sistema de trabalho. Como objetivo, pretende-se analisar o ambiente de trabalho e layout industrial. Os objetivos específicos incluem minimizar o custo de produção, aproximação dos departamentos produtivos, flexibilizar o arranjo e operações, racionalizar o espaço, cuidar da segurança do trabalho e tratar questões ergonômicas.

\section{APORTE TEÓRICO}

Para Buarque e Iida (2016), o ser humano interage com diversos componentes do sistema de trabalho de forma sistêmica, e cabe a Ergonomia buscar adequar essas interações para o desempenho confortável, eficiente e seguro. Através da análise ergonômica, buscamos soluções adequadas, tendo como referência a análise da tarefa e atividade (GUERIN et al, 2001), a própria empresa e a realidade de trabalho, para alcançar melhores condições e otimizar os processos.

A ergonomia tem como finalidade o estudo do trabalho, constituindo-se de três unidades básicas: condições de trabalho, resultado do trabalho ou atividade de trabalho (GUÉRIN et al., 2001). Esta é uma disciplina que contempla a análise de situações de trabalho e o projeto com implementação de melhorias, adaptando as condições de trabalho às características psicofisiológicas dos trabalhadores (BRASIL, 2002). Permite minimizar os riscos ergonômicos, equilibrando a relação saúde-produtividade.

0 projeto no posto de trabalho analisa o relacionamento das pessoas envolvidas com local de trabalho, compreendendo como interferem no desempenho, desgaste e fadiga, e possíveis danos físicos causados (SLACK, CHAMBERS, JOHNSTON, 2009). Quando não há adequação do posto de trabalho, poderão surgir consequências futuras para o trabalhador, sendo primordial a busca por adaptabilidade (BALLARDIN et. al, 2005).

0 dimensionamento dos postos de trabalho sob o aspecto ergonômico baseia-se tanto nas medidas antropométricas dos trabalhadores, como no comportamento e exigências requeridas para o desenvolvimento do trabalho (FALZON, 2007). Há também que considerar fatores como qualidade, inspeção, controle, armazenagem, movimentação e manutenção de materiais e equipamentos utilizados durante a produção, que influenciam sobre a segurança, produtividade e eficiência dos processos. 


\section{METODOLOGIA}

0 estudo foi desenvolvido com uma pesquisa qualitativa, que segundo Yin (2015), analisa condições contextuais em que as pessoas vivem, representando opiniões e perspectivas de um certo tema. Foram realizadas observações semiestruturadas em campo, e entrevistas com as partes interessadas. Para compreender e analisar a situação de trabalho, foram feitas entrevistas, restringindo-se a um estudo de caso, ou seja, uma análise prática de situações reais, utilizando resultados de materiais teóricos para a coleta e análise de dados (YIN, 2015).

O procedimento básico do estudo do trabalho, segundo Camarotto (2007) se aplica a todos os estudos em qualquer ramo industrial. Neste trabalho, cobrimos as etapas de seleção do trabalho ou processo estudado; registro e coleta de dados; análise crítica dos dados e propostas de outros métodos.

Determinamos os processos a serem estudados e logo, foram feitas observações e registros. Para auxiliar a análise da atividade foi utilizada Ergonomics Workplace Analysis (EWA) que se baseia nos possíveis fatores de risco dentro do ambiente do trabalho e inclui 14 itens de análise (SHARAN, 2012). É uma ferramenta participativa para que os trabalhadores possam expor sua opinião e o analista dá uma nota de 1 a 5. Também foi utilizada a ferramenta RULA (Rapid Upper Limb Assessment), que foi desenvolvida para investigar a exposição de trabalhadores à fatores de risco associados a posturas (MCATAMNEY; CORLETT, 1993).

A utilização da ferramenta EWA, juntamente com entrevistas informais, propõe entender melhor a tarefa e atividade da perspectiva do trabalhador, os desconfortos e a razão do modo operatório com que a tarefa é realizada, trazendo o trabalhador como parte da análise e da solução. Através da ferramenta RULA, buscamos analisar fatores de risco posturais, como quantidade de movimentos e posturas determinadas por máquinas e equipamentos.

A partir dos dados coletados e de suas análises, com o objetivo da implantação de melhorias no processo, foi utilizado o método da matriz QFD (Quality Function Deployment), que, de acordo com Cheng e Melo Filho (2007, apud GONÇALVES, 2014), para identificar e priorizar problemas e soluções. Finalmente, pensadas de acordo com a realidade da empresa, e de seus trabalhadores, foi descrita propostas de soluções, e que o propósito dessas intervenções são a melhoria das condições do trabalho e o conforto dos trabalhadores.

\section{RESULTADOS}

\subsection{CARACTERIZAÇÃO DA EMPRESA}

Trata-se de uma associação civil reconhecida pelo Estado, localizada em González Catán - La Matanza, provincia de Buenos Aires - Argentina. A indústria encontra-se em fase inicial de desenvolvimento de seus processos produtivos e é subdividida em três setores principais: Marcenaria de madeira, marcenaria de alumínio e metalúrgica. Neste trabalho, analisamos o setor da metalúrgica, que atualmente produz grades de ferro para janelas, portas e portões; para a comercialização local. 0 sistema de produção é semiautomatizado, mantendo a intervenção direta do homem com as máquinas (GOLDMAN, 2000). Não há cargos, ou tarefas bem definidas. 0 processo produtivo é intermitente: produto processado em pequenos lotes sem regularidade de período; dependente de encomendas; produtos padronizados, sofrendo pequenas variações de acordo com o pedido (CAMAROTTO; MENEGON, 1997).

\subsection{ANÁLISE ERGONÔMICA}

Ao observar o trabalho, a priori, percebemos a falta de adesão aos Equipamentos de Segurança necessários, que são indispensáveis, especialmente tendo em vista a natureza do trabalho e das máquinas manuseadas.

O ambiente de trabalho se encontra desorganizado; não há distinção entre materiais a serem utilizados, novos, e desperdícios, afetando a qualidade da produção. Encontramos máquinas paradas e inutilizadas, e não há estoque físico para armazenamento de peças, materiais e equipamentos. Há alguns suportes para a matéria prima, mas em sua maioria, encontram-se dispostas no chão do ambiente de trabalho.

Foram selecionados dois postos de trabalho predominantes na produção, demonstrados na figura 1, para serem estudados. As tarefas são: corte do material (esquerda), montagem e soldagem das peças (direita). Foi realizada a análise das atividades, estudo dos movimentos corporais e posturas adotados pelos 
trabalhadores dentro dos postos, com o objetivo de reduzir os riscos aos quais os trabalhadores estão expostos, gerar maior conforto e otimizar o trabalho.

Figura 1: Postos de trabalho para análise: Posto 1 (corte) e Posto 2 (montagem)
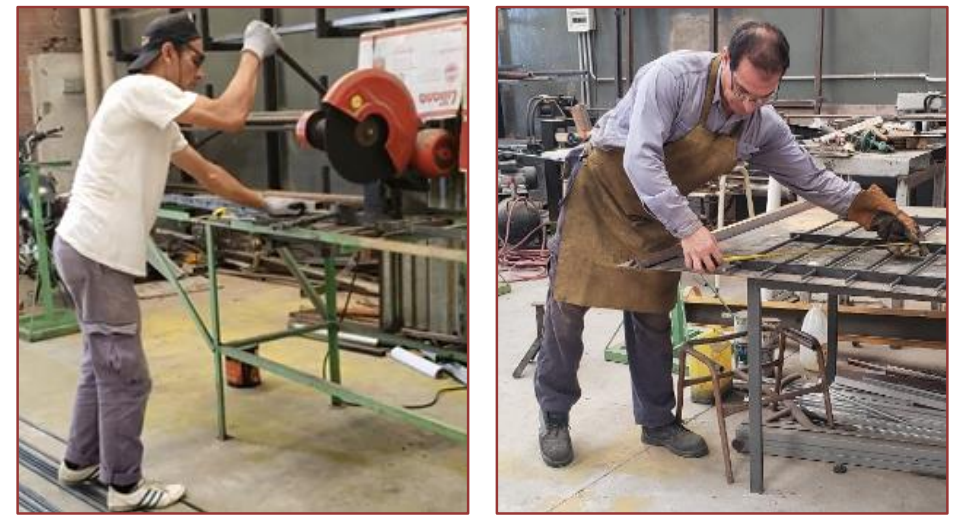

Delimitamos o posto de trabalho através de um esboço (Figura 2): compõe-se por 4 mesas utilizadas para realização das tarefas; uma onde se localiza a máquina de corte, outra onde é realizada a montagem e soldagem e mais duas mesas de apoio. Por trás das mesas de trabalho a matéria prima utilizada está distribuída em suportes na parede e há material espalhado pelo chão e sob as bancadas.

Figura 2: Esboço do ambiente de trabalho analisado

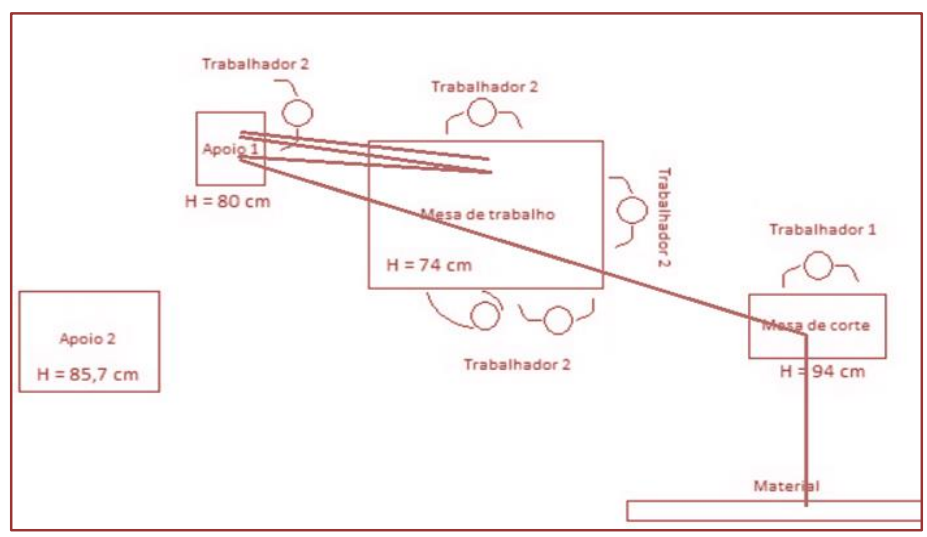

Na Figura 2 se vê o fluxo da produção, iniciando desde o material, passando pela mesa de corte, mesa de apoio (lixamento das rebarbas) e terminando na mesa de trabalho onde são feitos os processos de montagem e soldagem, podendo apresentar variações, devido à flexibilidade da divisão e ordem de tarefas. Identifica-se a falta de um fluxo contínuo.

Em seguida com ajuda dos operadores, descrevemos as tarefas do processo produtivo, buscando maior precisão e semelhança ao trabalho real executado. São elas: 1) Receber as medidas das grades a serem produzidas; 2) Colocar os materiais a serem utilizados próximo, no piso ou nos suportes da parede; 3 ) Medir o material de acordo com pedido, dispor na máquina de corte e ajustar para o material específico; 4) Realizar o corte, lixar rebarbas e encaixar as peças para soldar. 


\subsection{ERGONOMICS WORKPLACE ANALYSIS (EWA) E RAPID UPPER LIMBS ASSESSMENT (RULA)}

0 primeiro posto analisado se resume à fase de corte do material (ferro redondo e barras chatas de ferro), que é feito de acordo com o tamanho da grade, dependendo do pedido. Foi subdividida em 6 fases para maior precisão do estudo. A tarefa consiste no recebimento das medidas, marcação e corte da matéria prima a ser transformada (ferro redondo e barras chatas de ferro), e o acabamento (lixamento) - que também pode ser feito pelo segundo trabalhador ao receber o material. Cada fase da atividade foi analisada individualmente na ferramenta RULA. Os resultados mostram que em $83 \%$ das posturas que o trabalhador adota para realizar a atividade estudada são prejudiciais à postura das costas e pescoço pois o trabalhador precisa curvar o pescoço para ter uma boa visão da atividade.

Adaptando a ferramenta EWA para este estudo, escolhemos as variáveis aplicáveis a serem analisadas: espaço de trabalho, posturas de trabalho e movimentos, risco de acidente e atenção. A análise foi feita juntamente com os trabalhadores, conforme a tabela 1.

TABELA 1: Análise de trabalho no posto 1 através do EWA

\begin{tabular}{|l|c|c|c|c|}
\hline \multicolumn{1}{|c}{ Fator } & $\begin{array}{c}\text { Espaço de } \\
\text { trabalho }\end{array}$ & $\begin{array}{c}\text { Posturas e } \\
\text { movimentos }\end{array}$ & Risco de acidente & Atenção \\
\hline Posição 1 (Corte) & 3 & 4 & 5 & 4 \\
\hline
\end{tabular}

Analisando os resultados do EWA, percebe-se problemas relacionados ao espaço de trabalho, sobretudo a altura da bancada $(0,94 \mathrm{~m})$ que é inadequada para as tarefas realizadas, resultando em movimentos e postura de trabalho inadequadas. A situação de trabalho requer muita atenção, por demandar precisão no corte, além de lidar com risco de acidentes consideravelmente alto durante suas atividades e manuseio de máquinas

0 segundo posto analisado, trata-se da maior parte do processo: montagem e soldagem. Se refere a todo o processo de montagem da grade: marcação, encaixe e soldagem das peças. Apresenta variações no que diz respeito ao processo de rebarbas dos materiais, podendo ser feito previamente, e à perfuração das chapas de ferro, dependendo do pedido.

Também foi analisada cada fase da atividade individualmente na ferramenta RULA, que apresentou resultados críticos, evidenciando posturas danosas à saúde do trabalhador. A análise mostra que mais de 85\% das posturas adotadas encontram-se muito prejudiciais, exigindo mudança imediata.

As análises feitas pelo EWA, conforme tabela 2, confirmam os problemas encontrados na área de trabalho - questões de organização e logística, além de apresentar uma mesa de trabalho muito baixa, condicionando o trabalhador a adotar posições muito curvadas para realizar o trabalho. A mesa de trabalho apresenta 1,97x1,37 m de área e 0,74m de altura, sendo a mais baixa, e consequentemente, a que exige que o trabalhador adote as piores posturas estudadas, especialmente sabendo que em processos de soldagem, a bancada de trabalho deve ser mais alta que nas demais tarefas realizadas para oferecer conforto ao trabalhador, prevenindo posturas danosas. É agravado por ser o posto de trabalho que toma a maior parte do tempo de produção. Além dessas, há duas mesas de apoio, onde normalmente são feitos os processos de rebarba: a mesa de apoio 1 com 0,8m de altura e a mesa de apoio 2 com 0,85m de altura.

Tabela 2: Análise de trabalho no posto 2 através do EWA

\begin{tabular}{|c|c|c|c|c|}
\hline Fator & \multicolumn{1}{c}{$\begin{array}{c}\text { Espaço de } \\
\text { trabalho }\end{array}$} & $\begin{array}{c}\text { Posturas e } \\
\text { movimentos }\end{array}$ & Risco de acidente & Atenção \\
\hline Posição 2 (Montagem e soldagem) & 4 & 5 & 4 & 3 \\
\hline
\end{tabular}

A área de trabalho também envolve problemas de mobilidade, especialmente nesse posto de trabalho, onde há materiais inutilizados dispostos no chão e sob a mesa, tornando a mobilidade do trabalhador extremamente difícil e inadequada, agravando riscos de acidente, tendo que não há apoio, tampouco espaço, para os pés. 
Durante a soldagem o trabalhador está sujeito a riscos de acidente, que podem ter sua gravidade minimizada pelos EPI's, porém não completamente evitados. Por se tratar dos processos de montagem e soldagem do produto, o trabalhador necessita de um grande nível de atenção para evitar erros projetados no produto final.

\subsection{PROPOSTAS}

Por fim, através do QFD, fizemos a relação dos problemas com ideias para soluções, com intuito de 116uantifica-las por importância, resolução e dificuldade organizacional, sendo analisadas as ações em propostas, listadas a seguir, em ordem de importância relativa:

a) Destinação de resíduos: 0 ambiente apresenta um problema de organização, sendo assim, o passo inicial é destinar o que é dispensável, gerando um ambiente limpo e livre, o que é relevante para questões de segurança, organização do espaço de trabalho e layout.

b) Ajuste das bancadas de trabalho: Deve ser feita em conjunto com o trabalhador, através de testes simulando alturas até atingir o conforto, e de manter-se regulável.

c) Utilização de EPI's: sugerimos um estudo para verificar o melhor EPI adequado às atividades, levando em consideração o conforto e uso durante toda sua jornada de trabalho.

d) Reorganização do layout e construção de um estoque físico: sabendo que a empresa apresenta uma baixa variedade de produtos, deve apresentar um layout onde os equipamentos estejam posicionados acordando com a linha de produção, arranjados segundo a sequência das operações para a execução do produto, pressupondo-se a uniformidade. (CAMAROTTO; MENEGON, 1997).

e) Construção de um estoque físico para ter um local de trabalho livre e ordenado. É de extrema importância para a organização dos materiais, que ficam espalhados na área de trabalho.

Após estudo dos problemas, foi desenvolvido um esboço (Figura 3); com os postos de trabalho rearranjados de acordo com as características e necessidades da empresa, levando em conta fatores de produtividade e organização, bem como fluxo produtivo e otimização do sistema.

Figura 3: Esboço do layout proposto

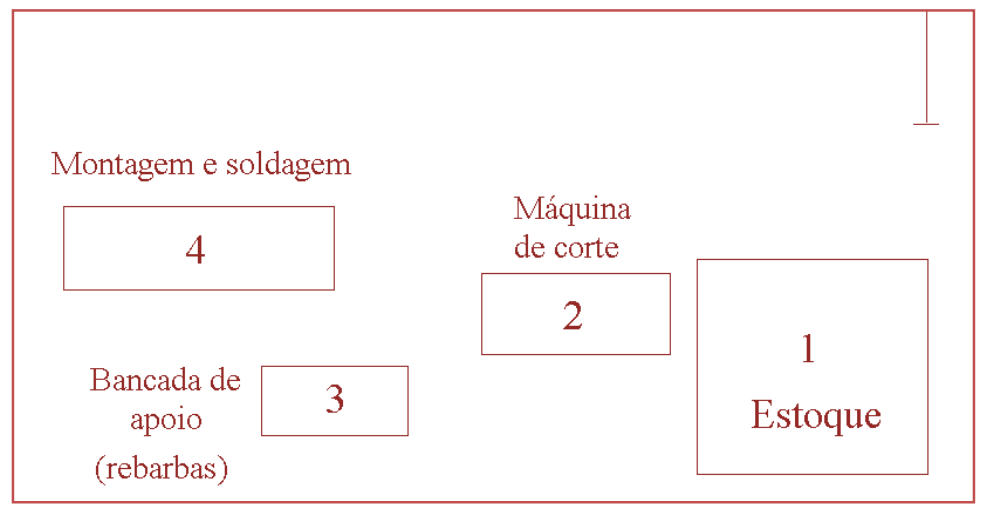

e) Divisão e definição de tarefas: definir suas tarefas e atividades individuais, seguindo o fluxo de produção.

f) Restauração e manutenção das máquinas de produção: Deve-se realizar plano de manutenção preventiva de forma a incluir substituição e restauração de máquinas, buscando estar sempre ciente do problema em prol da melhoria constante da situação de trabalho.

\section{CONCLUSÕES}

O aumento na demanda das empresas gera mudanças significativas nas condições do trabalho exigidas, gerando impactos na saúde e bem-estar dos trabalhadores. Esses aspectos são de vital importância para o desenvolvimento das empresas. Ao pensar em saúde e trabalho, é relevante que se destaque o equilíbrio 
entre saúde e produtividade, de forma a adequar os postos de trabalho, objetivando minimizar os riscos ocupacionais existentes.

Inicialmente foram evidenciados problemas de produtividade na metalúrgica, instituídos levantamentos e observações sistemáticas acerca dos problemas constatados. As atividades realizadas exigem dos trabalhadores mais do que as condições existentes oferecem, quando relacionado ao espaço e divisão do trabalho. Com os resultados atingidos foi possível observar os riscos ergonômicos inerentes do posto que, além do trabalho repetitivo, compreendem posturas inadequadas, dimensionamento e arranjo inapropriado do posto de trabalho.

Foi realizado um projeto do posto de trabalho, o qual envolveu o layout e o mobiliário, possibilitando melhoria das condições de trabalho. As propostas foram expostas e serão ainda validadas pelas pessoas envolvidas (operadores/proprietários), porém todas as soluções foram colocadas em um cronograma, já que a implementação de algumas propostas, será realizada até final de 2020. A adaptação do trabalho ao homem nem sempre tem uma solução simples, que possa ser resolvido na primeira tentativa. Assim, se faz necessário o aprofundamento da análise global e real de forma situada, das condições de trabalho para estudos futuros, levando em considerações o setor metalúrgico de diferentes portes, de forma a proporcionar melhores condições de trabalho a esse setor.

\section{REFERÊNCIAS}

[1] BUARQUE, L. IIDA, I Ergonomia Projeto E Produção. - 3 ed. - São Paulo: Edgard Blücher, 2016.

[2] BALlARDIN, L.; FONTOURA, C.; FELLIPA, C.S.; VOGT, MS. Análise Ergoômica dos postos de trabalho de operadores de caixa de supermercado. Produção Vol. 5/Num. 3. Florianópolis - SC, 2005.

[3] BRASIL. Manual de aplicação da Norma Regulamentadora no 17. - 2 ed. - Brasília: MTE, SIT, 2002.

[4] CAMARotTo, J.A. PROJETO DO TRABALHO: Métodos, tempos, modelos, posto de trabalho. São Carlos: UFSCar, 2007. Notas de aula.

[5] CAMARotTO, J.A.; MENEGON, N.L. Projeto de instalações industriais. São Carlos, UFSCar, 1997. Apostila de curso de especialização em gestão da produção.

[6] CHENG LC, MELO, LDR Fo. QFD-Desdobramento da Função Qualidade na gestão de Desenvolvimento de Produtos. São Paulo: Blucher; 2007

[7] FALZON, P. (Ed.). Ergonomia. - 2 ed. - São Paulo: Edgard Blücher, 2018.

[8] GOLDMAN, C.F. Análise de acidentes de trabalho ocorridos na atividade da indústria metalúrgica e metalmecânica no estado do Rio Grande do Sul em 1996 e 1997: Breve interligação sobre o trabalho do soldador [Dissertação]. Porto Alegre: Universidade Federal do Rio Grande do Sul; 2000.

[9] GONÇALVES, J. M. Ação Ergonômica e Estratégias de Operações: Proposta de Integração na Prática. 2014. 238 f. Dissertação (Doutorado em Engenharia de Produção) - Universidade Federal de São Carlos, São Carlos. 2014.

[10] GUÉRIN, F.; LAVILLE, A.; DANIELLOU, F.; DURAFFOURG, J.; KERGUELEN, A. Compreender o Trabalho para Transformá-lo. São Paulo: Edgard Blücher, 2001.

[11] OIT. Organização Internacional do Trabalho. "Cases of fatal occupational injury by economic activity - anual ILO Modelled Estimates," 2020. Disponível em < https://ilostat.ilo.org/data> Acesso em: 11 mai 2020

[12] OIT. Organização Internacional do Trabalho. "Cases of non-fatal occupational injury by economic activity anual - ILO Modelled Estimates,” 2020. Disponível em < https://ilostat.ilo.org/data> Acesso em: 11 mai 2020

[13] KANAWATY, G.I. Introducción al estudio del trabajo. OIT, 1996.

[14] MÁSCULO, F.; MATTOS, U.M. Higiene e Segurança do Trabalho para Engenharia de Produção. 2011.

[15] MCATAMNEYM L.; CORLETT, E. N. RULA: A survey Method for the investigation of work - related upper limb disorders. Applied Ergonomics, N. 24(2), 1993.

[16] SHARAN, D. Ergonomic Workplace Analysis (EWA). RECOUP Neuromusculoskeletal Rehabilitation Centre, Bangalore, India, 2012. Disponível em: <https://content.iospress.com/articles/work/wor0821>

[17] SHINNAR, A. ALTINAR, M; INDELICATO, J. Survey of ergonomic features of supermarket cash registers. J. Industrial Ergonomics; V. 34, p. 535-542, 2004.

[18] SLACK, N.; CHAMBERS, S.; JOHNSTON, R. Administração da produção. 3aㅡ edição. São Paulo, ATLAS, 2009.

[19] YIN, R. LK. Estudo de caso: Planejamento e método. Porto Alegre. BOOKMAN, 2015. 


\section{Capítulo 13}

Desenvolvimento de equipamentos para automação de um processo de fabricação de corantes

\section{Carolina de Padua Fernandes \\ José Tomadon Júnior \\ Thiago Pereira Paiva}

Resumo: Para elevar a presença de uma empresa no mercado de trabalho, atualmente, muitas delas estão procurando pela evolução de seus processos, e uma das principais maneiras é através da automação de seus processos, com estudo de maquinários, sistemas e mapeamento do fluxo de valor com a medição do tempo do processo. Uma indústria química da cidade de Franca-SP conta com um processo de fabricação totalmente manual e com a competividade do mercado aumentando, almeja automatizar etapas de sua linha de produção para que ocorra melhora no seu tempo de processamento, aumento na produtividade e na visibilidade dentro do mercado.

Palavras chave: Automação, Tempo, Processamento, Produtividade, Mapeamento. 


\section{INTRODUÇÃO}

O processo evolutivo das indústrias brasileiras começou a se desenvolver junto ao fim da crise de 1929, porém só se efetivou com o início da industrialização no final da Segunda Guerra Mundial e perdura pela sociedade até o presente momento, onde os estudiosos consideram a era da automação industrial ou Terceira Revolução Industrial (DESCOMPLICA, 2017), que une processos mecânicos/manuais à tecnologia da informação.

Devido ao grande crescimento dessa revolução, diversas empresas - de todos os setores - estão, cada vez mais, buscando profissionais que os auxiliem na automação de seus processos, para que seus serviços não percam visibilidade e espaço no mercado.

Segundo Moraes; e Castrucci (2010, p. 12):

Entende-se por automação qualquer sistema, apoiado em computadores, que substitua o trabalho humano em favor da segurança das pessoas, da qualidade dos produtos, da rapidez da produção ou da redução de custos, assim aperfeiçoando os complexos objetivos das indústrias e dos serviços. Exemplos: automação da mineração, da manufatura metálica, dos grandes processos químicos contínuos.

0 presente trabalho apresenta o desenvolvimento de um projeto de automação para uma indústria de pequeno porte, onde todos os processos são realizados de forma artesanal, suficientes para produzir uma quantidade reduzida de produtos, que satisfazem o fluxo do mercado atual da empresa, mas que não o serão caso o proprietário resolva expandir suas vendas. Em todos seus sub processos são encontrados riscos a segurança do funcionário e alto tempo para finalização dos processos, pela organização do ambiente de trabalho e do maquinário utilizado.

O objetivo é estudar as etapas do processo da empresa, levantar os requisitos necessários para realização da automação em etapas cruciais e por fim, disponibilizar ao proprietário um projeto contendo todas as mudanças e benefícios (produtividade, segurança) à sua Indústria.

\section{REFERENCIAL TEÓRICO}

\subsection{PRODUÇÃo}

Com o passar dos anos, estudos surgiram sobre o tema produção e produtividade, novas formas de organização e gerenciamento da produção apareceram. Em conjunto, começaram a surgir ideias e conceitos sobre como a automação está ligada a essa produção. 0 quanto se valoriza as melhorias para satisfazer o cliente, sejam através de tecnologias, ou um melhor mapeamento do local de trabalho.

Relacionado diretamente a produção, o termo produtividade "é a procura incessante por melhores métodos de trabalho e processos de produção, com o objetivo de se obter melhoria da produtividade com o menor custo possível" (MARTINS e LAUGENI - 2005, p.2). Hoje em dia, essa é uma definição em alta, as empresas buscam, cada vez mais, trazer qualidade aos seus produtos para satisfazerem seus clientes e conquistarem ainda mais mercado.

\subsubsection{LEAD TIME}

Com a aplicação da automação em processos muito se fala sobre a redução do tempo gasto durante a produção, ou melhoria contínua, que leva à otimização da linha fabril, para produzir mais em um menor espaço de tempo. Esse tempo é conhecido por lead time, "uma medida do tempo gasto pelo sistema produtivo para transformar matérias-primas em produtos acabados" (TUBINO, 2000).

\subsubsection{MAPEAMENTO DO FLUXO DE VALOR}

Uma das melhores maneiras de se obter o lead time é utilizando o Mapeamento do Fluxo de Valor (MFV), uma vez que esse promove a visualização de todo o processo produtivo, demonstrando o fluxo de 
materiais e informações (ABDULMALEK; RAJPGOPAL, 2007). Ou seja, o MFV é "o simples processo de observação direta do fluxo de informação e de materiais conforme eles ocorrem, resumindo-os visualmente e vislumbrando um estado futuro com melhor desempenho" (JONES; WOMACK, 2004).

Figura 1 - Ícones Básicos MFV

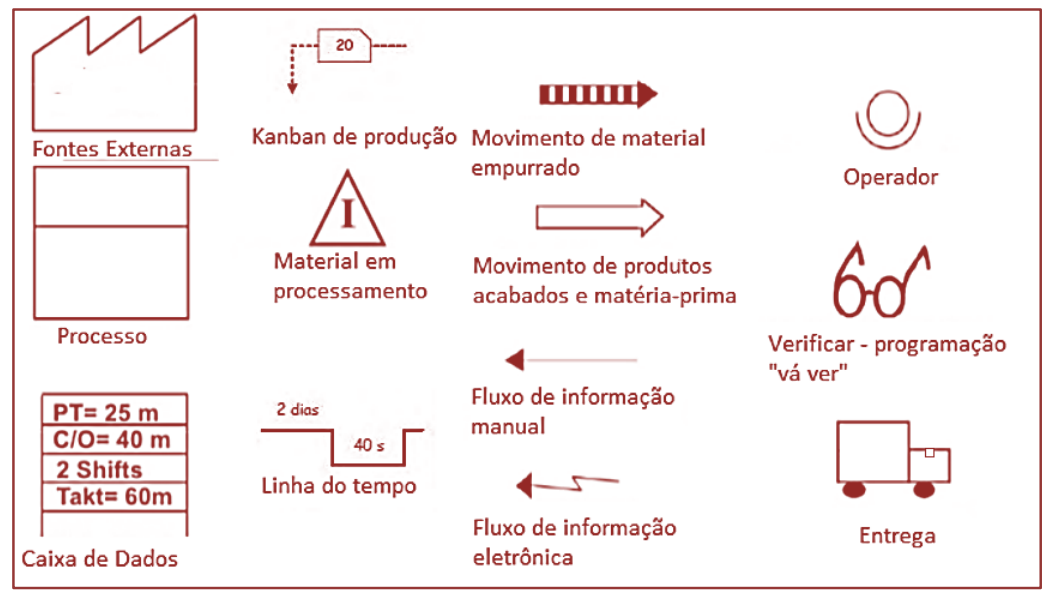

Fonte: Adaptado de Jones; Womack (2004)

Assim é possível analisar onde há desperdício na linha de produção, e comparar como o maior uso de tecnologias em troca da mão de obra humana pode melhorar a entrega de resultados.

\subsubsection{CLASSIFICAÇÃO DOS SISTEMAS PRODUTIVOS}

Toda linha de produção possui uma organização sistêmica, que visa auxiliar no entendimento das peculiaridades que cada sistema e suas atividades possuem. Os principais tipos de sistemas produtivos são quatro: contínuos; discretos - em massa, em lotes e sob encomenda. (TUBINO, 2017)

Destaca-se o sistema de produção em lotes, que é caracterizado pela fabricação de determinado produto em lotes, em que cada lote segue uma série de operações dependentes entre si (TUBINO, 2017).

\subsection{AUTOMAÇÃO}

A automação apareceu na humanidade a muito tempo, sem a definição propriamente dita do conceito, mas com a sua execução prática. Um exemplo clássico é a invenção da roda, que ocorreu por volta de 3500 a.C. (antes de Cristo) (BBC News, 2017) e é possível inferir conceitos de automação, já que através dela o meio de transporte dos povos foi melhorado, tornando-se mais rápido e menos desgastante ao homem. Outros grandes exemplos são encontrados até chegar-se a automação nos dias de hoje, que visa melhorar os processos de uma indústria, um investimento, um sistema.

A automação visa de um modo geral, fazer com que os diferentes níveis de uma empresa sejam modificados para favorecer, ao mesmo tempo, o trabalhador - com a otimização de atividades repetitivas e a produtividade da empresa. Independente de seu porte - micro, pequeno, médio ou grande - é um processo importante para todos e em todas as áreas, pois traz competitividade e vitalidade às empresas (MORAES e CASTRUCCI, 2010).

\section{METODOLOGIA}

O presente trabalho foi conduzido com características de uma pesquisa descritiva, uma vez que se analisou o ambiente de trabalho da Indústria, e observaram-se seus problemas; e pesquisa explicativa, já que além da análise, houve uma identificação das causas raízes dos problemas. 
A estratégia para obtenção do estudo completo da automação na empresa Courotec está demonstrada na Figura 2.

Figura 2 - Etapas do trabalho

\begin{tabular}{|c|c|}
\hline $\begin{array}{l}\text { Passo 1: } \\
\text { >studo da } \\
\text { empresa } \\
\text { > Aplicação de } \\
\text { questionário }\end{array}$ & $\begin{array}{l}\text { Resultado esperado: } \\
\text { Diagnóstico dos } \\
\text { problemas enfrentados }\end{array}$ \\
\hline $\begin{array}{l}\text { Passo 2: } \\
\text { Analisar e interpretar } \\
\text { vertentes dos problemas } \\
\text { diagnosticados } \\
\text { Estudo de materiais } \\
\text { técnicos relacionados } \\
\text { aos problemas }\end{array}$ & $\begin{array}{l}\text { Resultado esperado: } \\
\text { Diagnóstico das principais } \\
\text { vertentes (exemplo: } \\
\text { segurança, produção, etc.) } \\
\text { Definição dos principais } \\
\text { materiais técnicos } \\
\text { encontrados }\end{array}$ \\
\hline $\begin{array}{l}\text { Passo } 3 \text { : } \\
\text { Desempenhar } \\
\text { quadro } \\
\text { comparativo }\end{array}$ & $\begin{array}{l}\text { Resultado esperado: } \\
\text { Seleção da(s) } \\
\text { melhor(es) técnicas }\end{array}$ \\
\hline $\begin{array}{l}\text { Passo 4: } \\
\text { Desenvolvimento } \\
\text { da proposta de } \\
\quad \text { solução }\end{array}$ & $\begin{array}{l}\text { Resultado esperado: } \\
\text { Relatório com a } \\
\text { proposta e seus } \\
\text { beneficios }\end{array}$ \\
\hline
\end{tabular}

Fonte: Autoria própria

\section{SOBRE A EMPRESA}

A empresa Courotec, sediada na cidade de Franca, interior de São Paulo trabalha na preparação de corantes para importação, com a matéria prima - ácidos azóicos - importados da Índia, e o sal - $\mathrm{NaCl}$ micronizado - comprado em território nacional. A fabricação dos corantes tem como base principal o corante azóico, ou como são conhecidos na indústria química, azocorantes, definidos como "compostos coloridos insolúveis em água, que são realmente sintetizados sobre a fibra durante o processo de tingimento" (FORGIARINI, 2006).

A partir da matéria prima, é possível fabricar dois diferentes tipos de corantes: líquidos e pó. Esse sistema produtivo segue a classificação em lote, já que para iniciar a mistura é preciso que todos os materiais estejam peneirados/aquecidos, e pesados (caso contrário, o processo fica parado); e após o início da mistura é preciso esperar para que se inicie outra ordem, uma vez que os processos possuem peculiaridades e precisam ser inspecionados de tempo em tempo, ou se realize testes de qualidade.

\section{RESULTADOS}

\subsection{ESTUDO APROFUNDADO}

A partir da avaliação dos processos, percebeu-se que os principais problemas ocorrem quanto:

a) À ergonomia, em que o funcionário precisa segurar uma elevada carga até a balança e depois retirá-la. E, além do peso elevado, acaba estacionando em posições curvadas, prejudiciais a sua coluna;

b) A imprecisão humana, pois são os funcionários que controlam o momento no qual a balança atinge o valor desejado. E, foi possível observar que ao manusear as embalagens, mesmo depois de pesadas, os funcionários não tinham cuidado com o conteúdo, e uma quantidade não aferida de material acabava desperdiçada, e não descontada no final das medições;

c) Também foi notado que quanto maior a quantidade de corante a ser fabricado, maior será a quantidade de sal peneirada e maior o tempo que o funcionário levará para executar a ação; acarretando em aumento no tempo final de fabricação. Fato esse que pode fazer com que a fabricação dure uma manhã toda, ou uma tarde toda, e assim, prejudique um ritmo de produção acelerado e aumento de lucros.

Usualmente, infere-se que a origem principal para o encontro desses problemas se dá devido ao fato da empresa ser de pequeno porte, e ter o pensamento centralizado na ideia de que com o nível atual de produção consegue atender seus principais clientes; mas, se houver expansão de mercado, a produção não 
terá capacidade. Além, da cultura dos próprios funcionários, que relataram estarem acostumados com a dificuldade e a quantidade de movimentos repetitivos que precisa executar.

\subsubsection{MAPEAMENTO CENÁRIO ATUAL}

Durante a realização das visitas e observação de como o processo de produção dos corantes ocorre, houve a medição do tempo gasto para realizar a produção de um pedido padrão, $300 \mathrm{~kg}$ de corante. Com essa informação e a análise do fluxo de informação foi possível desenhar o mapa de fluxo de valor do cenário atual da indústria, apresentado na Figura 3.

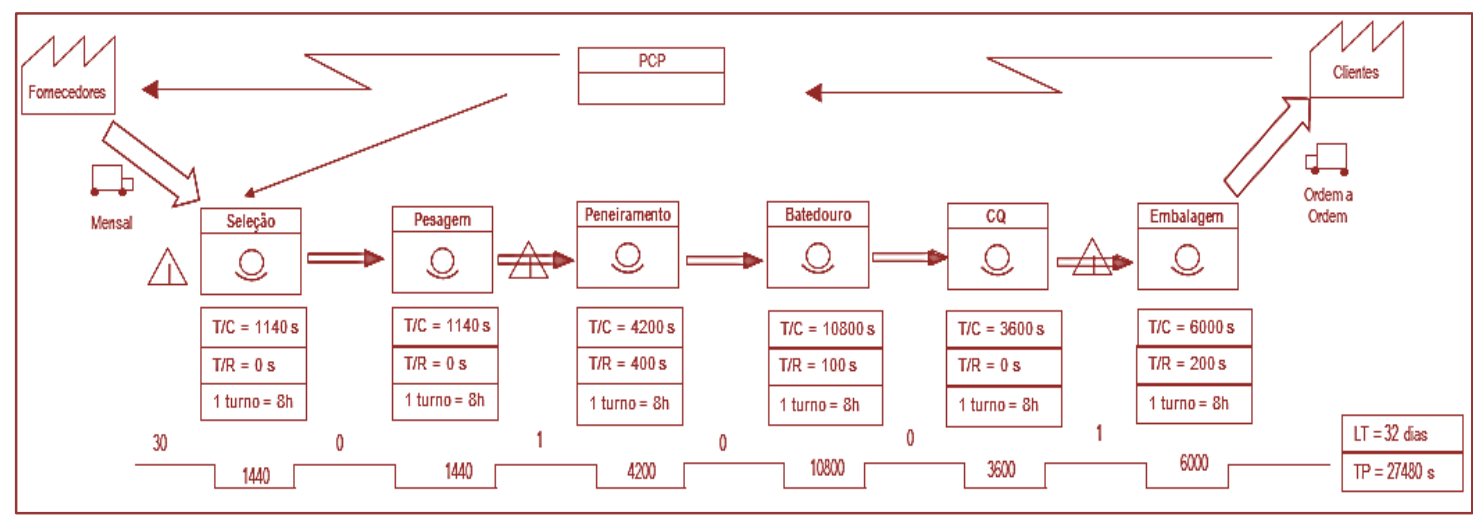

Figura 3 - Mapeamento do cenário atual fabricação corante pó

Fonte: Autoria própria

Obteve-se um tempo de ciclo (TP) da fabricação do corante em pó de 27480 segundos, aproximadamente, 7 horas e meia. Com tempo de setup, para ajuste do processo de 11 minutos.

Já o cenário (Figura 4) obtido para a fabricação do corante líquido foi:

Figura 4 - Mapeamento cenário atual fabricação corante líquido

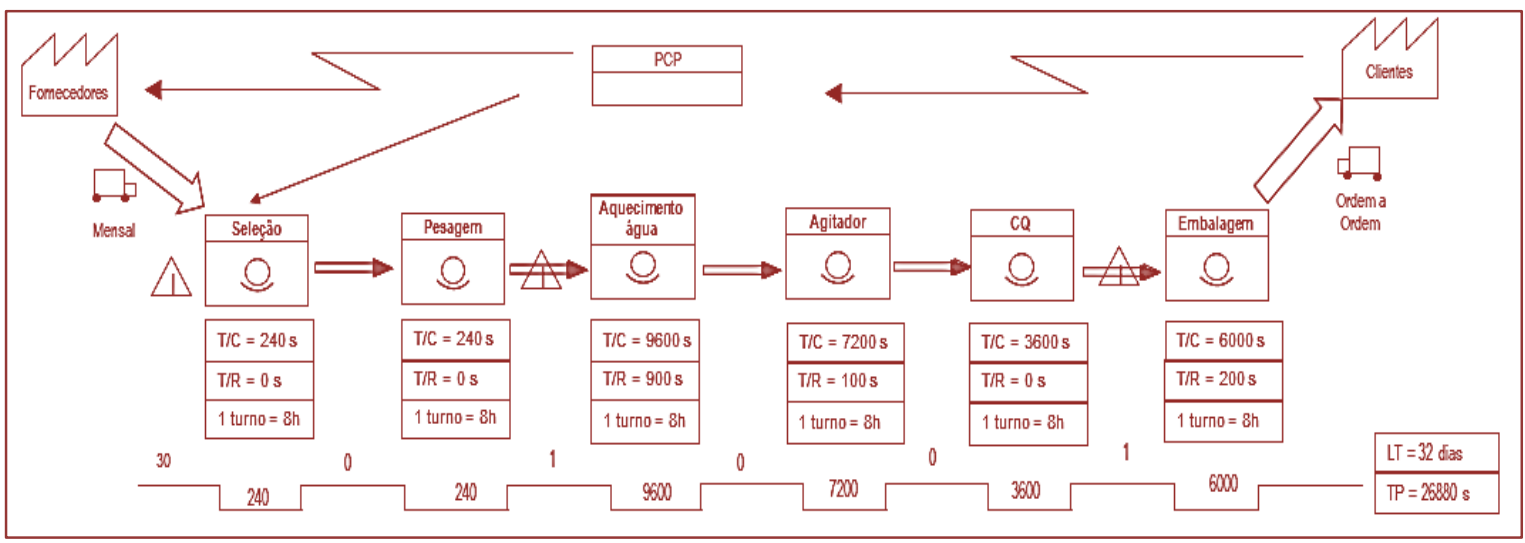

Fonte: Autoria própria

Em que o tempo de ciclo é 26880 segundos, aproximadamente, 7 horas e 20 minutos. Com tempo de setup, para ajuste do processo de 20 minutos.

É possível perceber que os principais pontos de estoque são de matéria prima e produto acabado, devido a produção ser em lote (como citado no Tópico 4) e uma etapa depender da outra, seguindo contínuas pelas 
características de cada ordem solicitada. 0 prazo para entrega do fornecedor é alto, pois, algumas matérias são importadas e isso causa insegurança nos prazos, gerando excesso ou falta do material.

\subsubsection{TÉCNICAS E MAQUINÁRIOS}

Através do estudo dos melhores equipamentos, sistemas/circuitos que pudessem otimizar o tempo das etapas: aquecimento de água e peneiramento do sal, obteve-se os seguintes resultados:

\subsubsection{OTIMIZAÇÃO DA ETAPA DE AQUECIMENTO DE ÁGUA}

Para realizar a otimização do processo de aquecimento de água durante a fabricação do corante líquido surgiu a necessidade de encontrar um equipamento ou desenvolver um sistema que aquecesse a água sem que o operador precisasse permanecer por tempo prolongado em contato com o calor e de um modo que o tempo de espera pela água aquecida diminuísse pelo menos $30 \%$.

A primeira opção encontrada foi a utilização de aquecedores já fabricados, como o modelo H200L Luxo Cobre da Thermas, um equipamento robusto, de uso industrial. Outro modelo listado foi o Aquecedor a Gás 3700DE GN da marca Lorenzetti, equipamento não direcionado ao uso industrial, mas que se adequaria ao processo devido a baixa complexidade. A terceira opção consiste no uso de uma resistência elétrica tipo sobreborda da F.A RESISTÊNCIAS (Figura 5) que possui $5 \mathrm{~kW}$ de potência, 60 centímetros de altura e, como maior diferencial, contém junto a si um termostato que disponibiliza a opção de seleção da temperatura almejada, onde então, é possível que o operador selecione-a temperatura e ligue o sistema à energia.

Figura 5 - Resistência Elétrica tipo Sobreborda

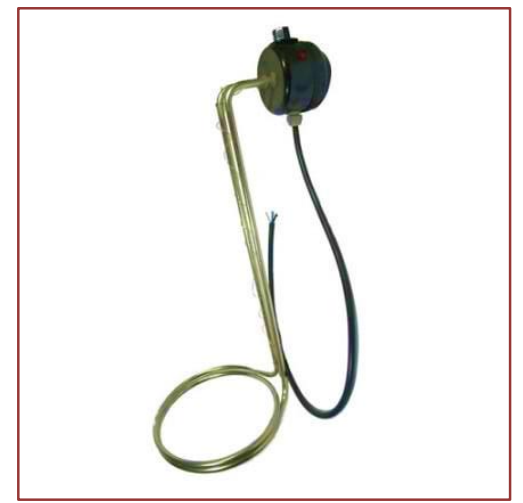

Fonte: Shopping GadStore

Para analisar se a resistência suportaria a demanda do processo calculou-se a potência que o mesmo necessitaria nas condições de produção, com base na seguinte fórmula:

$$
P=m \cdot C_{p} \cdot \Delta T
$$

Sabendo que m é a massa do material a ser aquecido, $C_{p}$ seu calor específico (encontrado em literatura) e $\Delta \mathrm{T}$ a diferença da temperatura ambiente do material com a que desejo chegar. Coletou-se o calor específico da água em $1 \mathrm{cal} / \mathrm{g}$. ${ }^{\circ} \mathrm{C}$ e sabendo que o volume médio a ser aquecido é 200 litros o valor utilizado para a massa foi então de $200 \mathrm{~kg}$, uma vez que: 


$$
1 \mathrm{~kg}=1 \text { litro }
$$

A diferença de temperatura será:

$$
\begin{aligned}
& \Delta T=T f-T a \\
& \Delta T=50-25=25^{\circ} \mathrm{C}
\end{aligned}
$$

Portanto, a potência máxima necessária para o aquecimento da água durante o processo é:

$$
P=200.1 .50=5000 W
$$

Assim comprova-se que o modelo da resistência é usual para o presente sistema. 0 controle de ligação será do tipo on/off, de modo que quando for necessário produzir corante líquido, o operador ligará o cabo da resistência na tomada.

\subsubsection{OTIMIZAÇÃO DA ETAPA DE AQUECIMENTO DE ÁGUA: NÍVEL}

Para que se saiba também o momento que se atingiu a quantidade de água necessária, far-se-á o uso de um circuito eletrônico simples com bateria 9V para alimentação, um CI (circuito integrado) tipo ULN 2003AN, resistores de $1 \mathrm{k} \Omega$ e $10 \mathrm{k} \Omega$ e leds nas cores azul, vermelho, amarelo e verde (utilizadas para diferenciar os pontos do nível da água), que indicarão a evolução do enchimento do tanque. A Figura 6 exemplifica como será a gestão visual do nível do reservatório através do acendimento dos leds.

Figura 6 - Exemplo tanque com indicação de níveis

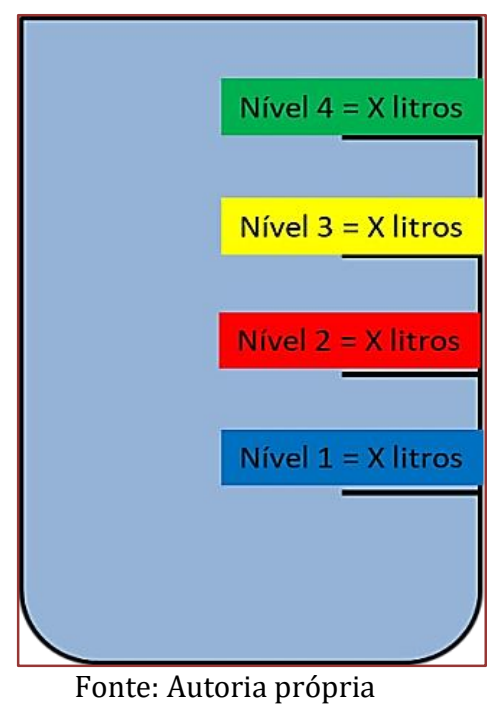

Seu esquema elétrico é apresentado na Figura 7. Essa representação será utilizada no momento de desenvolver o circuito impresso e soldar todos os componentes em suas corretas ligações. 
Figura 7 - Desenho esquemático sistema controle nível

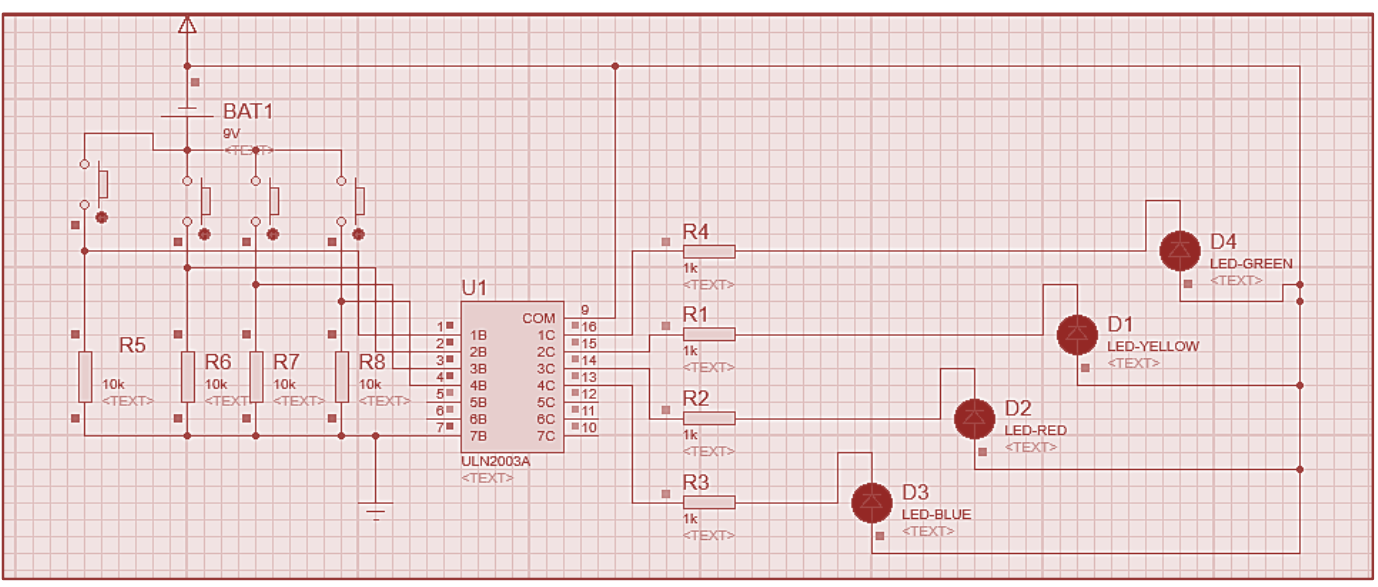

Fonte: Autoria própria

\subsubsection{OTIMIZAÇÃO DA ETAPA DE PENEIRAMENTO DO SAL}

Através das pesquisas metodológicas foram identificadas diversas possibilidades para o sistema de otimização do peneiramento, porém, existiram dois que melhor se encaixaram na Courotec.

o primeiro sistema seria adquirido já pronto: uma peneira, nomeada Peneira Elétrica Fácil, desenvolvida pela Verde Equipamentos, capaz de trazer mobilidade e simplicidade ao processo.

A segunda opção identificada contém um sistema projetado (Figura 8) pela presente pesquisadora que conterá:

- $\quad$ Suporte de metal com altura de $1,40 \mathrm{~m}$, para a tela de peneiramento;

- $\quad$ Tela de peneiramento com dimensão $0,9 \mathrm{~m}$ x 0,45m e abertura de $1 \mathrm{~mm}$;

- $\quad$ Suporte de metal para a peneira $1 \mathrm{~m} \times 0,5 \mathrm{~m}$;

- 4 roldanas para portão de correr em "V";

- 2 dobradiças planas externas 40 x 40 com abertura até $180^{\circ}$;

- Placa para escoamento do material já peneirado com comprimento de $1,25 \mathrm{~m}$ e $0,5 \mathrm{~m}$ de largura;

- $\quad$ Puxador tipo alça (para elevação da peneira);

- $\quad$ Parafusos e arruelas;

- Motor elétrico de baixa indução com no mínimo 1695,4 rpm.

Figura 8 - Esboço suporte de peneiramento

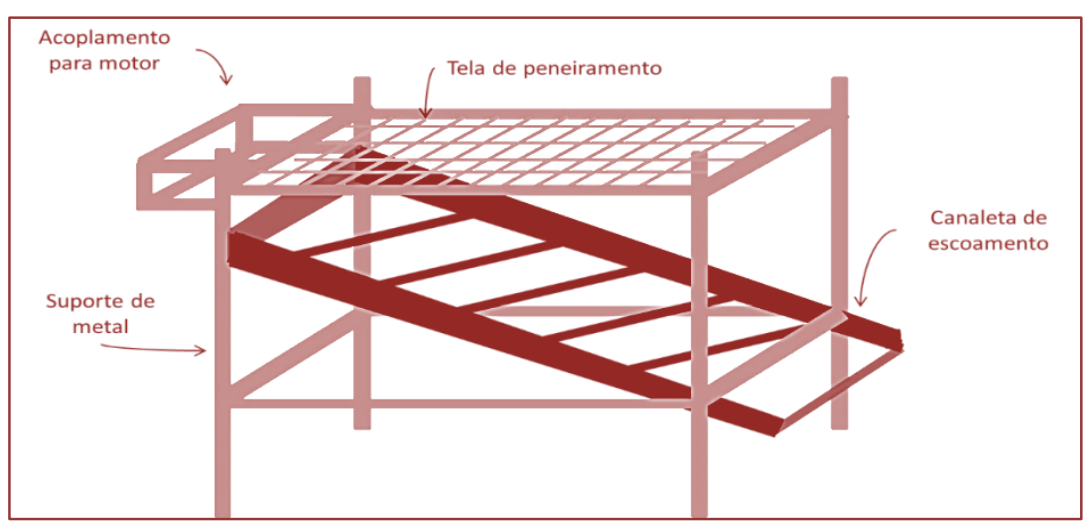

Fonte: Autoria própria 
A placa de escoamento será soldada no suporte a uma altura de $1,2 \mathrm{~m}$, com um ângulo de $30^{\circ}$ e estará a 0,70m do chão, de uma forma que será possível alocar uma caixa para receber o sal já peneirado.

A peneira terá um suporte acoplado ao restante do sistema, o mesmo contará com quatro roldanas posicionadas duas na frente e duas atrás (Figura 9), de modo que quando o motor começar a vibrar, ela tenha liberdade de movimento e peneire o sal corretamente.

Figura 9 - Posicionamento roldanas

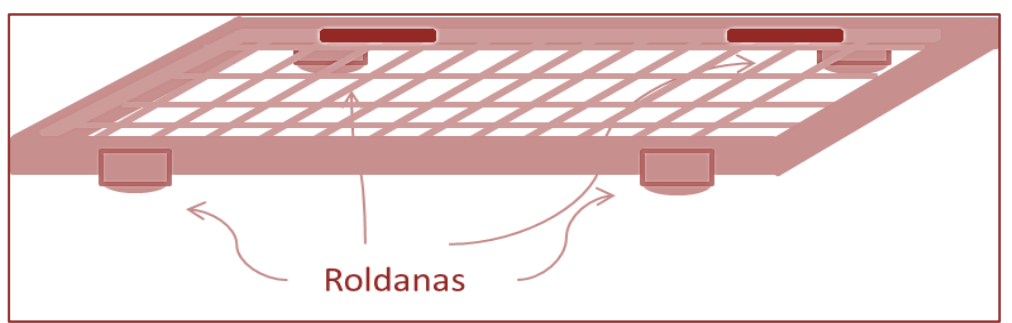

Fonte: Autoria própria

Para que seja prática a retirada dos resíduos que forem gerados sobre a peneira, haverá a instalação de duas dobradiças no encontro da peneira com seu suporte (Figura 10), de modo que o operador possa fazer o movimento de subida (para que o material caia) e descida para retornar a peneira até sua posição inicial.

Figura 10 - Posicionamento das dobradiças

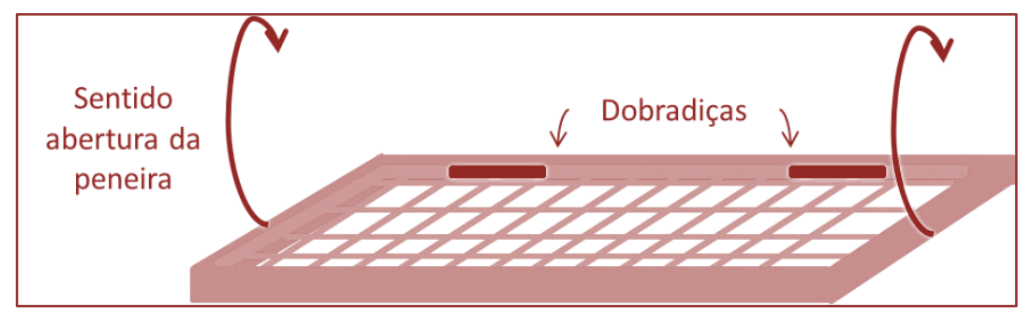

Fonte: Autoria própria

Para encontrar qual o motor ideal para peneirar o sal sem sobrecarga ou subcarga foi preciso seguir a fórmula:

$$
\omega=1695,4 \cdot a^{-0,1651}
$$

Onde CHAVES; PERES (1999) dizem que a velocidade angular, $\omega$, depende da abertura da tela de peneiramento, a.

Devido a espessura do sal $\mathrm{NaCl}$, a espessura da tela foi estabelecida em a=1 mm, portanto:

$$
\begin{aligned}
& \omega=1695,4 \cdot 1^{-0,1651} \\
& \omega=1695,4 \mathrm{rpm}
\end{aligned}
$$


Ou seja, o motor precisará ter, no mínimo, 1695,4 rpm.

Diversos modelos que atendessem essa capacidade foram encontrados, foram selecionados então dois principais, para uma análise mais profunda:

- Motor Weg 11385077 1/2 Cv 4 Pólos Trifásico lp55, que possui velocidade de rotação angular de até $1800 \mathrm{rpm}$ e uma potência de 0,5CV.

- Motor Elétrico $2 \mathrm{hp}$ trifásico aberto 4 pólos, também possui velocidade de rotação angular de até $1800 \mathrm{rpm}$.

O sistema desenvolvido foi pensado para ser usual e funcionar para uma necessidade básica, porém algumas questões como a granulometria do material, da peneira, o cisalhamento, torque do sistema, não foram consideradas, mas no momento de se aumentar a demanda e alterar o material a ser peneirado merecem detalhamento e exigirão o acompanhamento de um Engenheiro Mecânico especializado em tipos de peneiras e movimentos vibracionais.

\subsection{PROPOSTA DE AUTOMAÇÃO}

\subsubsection{AUTOMAÇÃO AQUECIMENTO DA ÁGUA}

Ficou decidido que para a automação do aquecimento de água será utilizada a resistência elétrica tipo sobre borda em conjunto com o sistema de controle de nível. Pela necessidade do processo de aquecer apenas o fluído água, foi detectado que o uso de uma resistência já melhora o tempo da etapa e beneficia o operador, sem necessidade de instalação de equipamentos mais robustos que possam trazer um aumento significativo (sem necessidade) no gasto de energia da fábrica.

Assim, o novo processo de aquecimento de água contará com: instalação de um tanque dimensões $1 \mathrm{~m} x$ $0,5 \mathrm{~m} \times 0,5 \mathrm{~m}$, mangueira de borracha enfaixada (para que a água aquecida seja depositada diretamente no misturador), torneira, resistência elétrica tipo sobre borda e o sistema visual de controle de nível. Com um custo total de $\mathrm{R} \$ 2463,98$.

\subsubsection{AUTOMAÇÃO PENEIRAMENTO}

Já a otimização do sistema de peneiramento será realizada com a compra e instalação da Peneira Elétrica Fácil da Verde Equipamentos. A escolha se realizou devido à praticidade que o material traz com sua fácil locomoção para diferentes ambientes, além da rapidez que trará ao processo de peneiramento do sal, e maior qualidade de vida ao operador. Assim, o custo total da automação da etapa de peneiramento será $\mathrm{R} \$ 2800,00$.

\subsubsection{TEMPO DE PROCESSO}

Para encontrar a melhoria no tempo do processo devido à automação na etapa de aquecimento de água foi preciso calcular qual seria o novo tempo de aquecimento para cada litro de água.

Uma vez que o novo processo usará uma resistência, a troca de calor se dará pelo mecanismo de transferência de calor, condução (HALLIDAY, 2009), onde pode-se encontrar o tempo que essa transferência levará através da fórmula:

$$
Q=P . t
$$


Sabe-se que P é a energia transferida por unidade de tempo (potência), t o tempo gasto e Q a quantidade de calor. Nota-se que temos duas incógnitas na Equação 9, o tempo e a quantidade calor. Entretanto, de acordo com HALLIDAY (2009), a quantidade de calor é definida como:

$$
Q=c \cdot m \cdot \Delta T
$$

Onde c é o calor específico ( $\left.\mathrm{cal} / \mathrm{g}^{\circ} \mathrm{C}\right), \mathrm{m}$ a massa da quantidade a ser aquecida, em gramas, e $\Delta \mathrm{T}$ a variação de temperatura. Sabe-se que para a situação do processo de produção:

$$
\begin{aligned}
& c=1 \mathrm{cal} / \mathrm{g}^{\circ} \mathrm{C} \\
& m=2,3 \times 10^{6} \mathrm{~g} \\
& \Delta T=50-25=25^{\circ} \mathrm{C}
\end{aligned}
$$

Portanto:

$$
Q=5,75 \times 10^{6} \mathrm{cal}=24,07 \times 10^{6} \mathrm{~J}
$$

De (10), se tem:

$$
t=\frac{Q}{P}
$$

Onde de (5), $P=5000 \mathrm{~W}$.

Assim, o novo tempo gasto para aquecer a água será:

$$
t=\frac{24,07 \times 10^{6}}{5000}=4813,9 \text { segundos }=80 \text { minutos }(16)
$$

Sabendo que para o enchimento do tanque o tempo médio será de 23 minutos, contando que a vazão média da mangueira seja 10l/min. 0 tempo total da etapa de captura/aquecimento de água será 103 minutos, melhorando o tempo da etapa em um total de 57 minutos, $35 \%$.

Já o ganho no processo devido à automação da etapa de peneiramento pode ser mensurado através das notações contidas no manual da Peneira Elétrica Fácil, onde se informa que é possível peneirar até $3 m^{3}$ de material por hora. Considerando que a média de material peneirado por ordem é $m=300 \mathrm{~kg}$, e que (HALLIDAY, 2009): 


$$
\rho=m / V
$$

Onde $\rho$ é a massa específica, $\frac{\mathrm{kg}}{\mathrm{m}^{3}}, \mathrm{~m}$ a massa, $\mathrm{kg}$ e $\mathrm{V}$ o volume, $\mathrm{m}^{3}$ (valor que se quer encontrar).

Pela literatura (HALLIDAY, 2009) a densidade do sal $(\mathrm{NaCl})$, principal material a ser peneirado é:

$$
\rho=998 \mathrm{~kg} / \mathrm{m}^{3}
$$

Portanto:

$$
V=\frac{300}{2160}=0,139 m^{3}
$$

Ou seja,

$$
\begin{gathered}
3 m^{3}=1 \text { hora }=60 \text { minutos } \\
0,139 m^{3}=0,046 \text { hora }=3 \text { minutos }
\end{gathered}
$$

Tendo em vista que o tempo de peneiramento era 70 minutos, espera-se que o tempo de processo após a automação reduza em 66 minutos, 94\%. Sabe-se que esse valor, de 3 minutos, é o ótimo, e que devido a diferentes fatores como a qualidade do sal, a abertura da peneira e a quantidade de material que a peneira comporta de uma vez só ele pode aumentar, mas percebe-se pelo gap que existe entre o tempo do processo anterior que mesmo que esse valor de 3 minutos suba em 500\%, ainda haverá uma redução no tempo de peneiramento de $78 \%$.

A partir de todas as mudanças sugeridas, o novo cenário do fluxo de produção para a fabricação do corante em pó será:

Figura 11 - Cenário fluxo do processo do corante pó com as melhorias

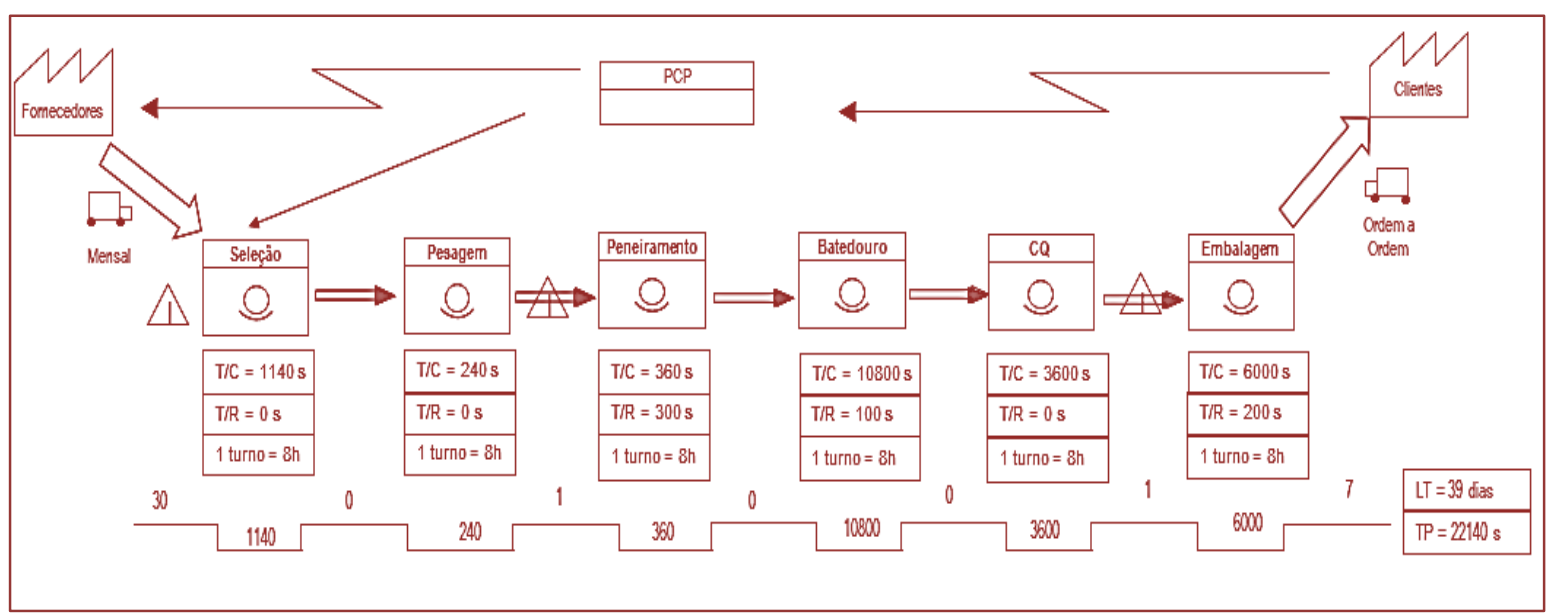

Fonte: Autoria própria 
Nota-se pela Figura 11 que o tempo de processamento caiu significativamente em 1 hora e meia, já que o tempo de processamento do peneiramento foi reduzido com a automação.

O cenário do corante líquido se torna o apresentado na Figura 12, com as mudanças sugeridas.

Figura 12 - Cenário fluxo do processo do corante líquido com as melhorias

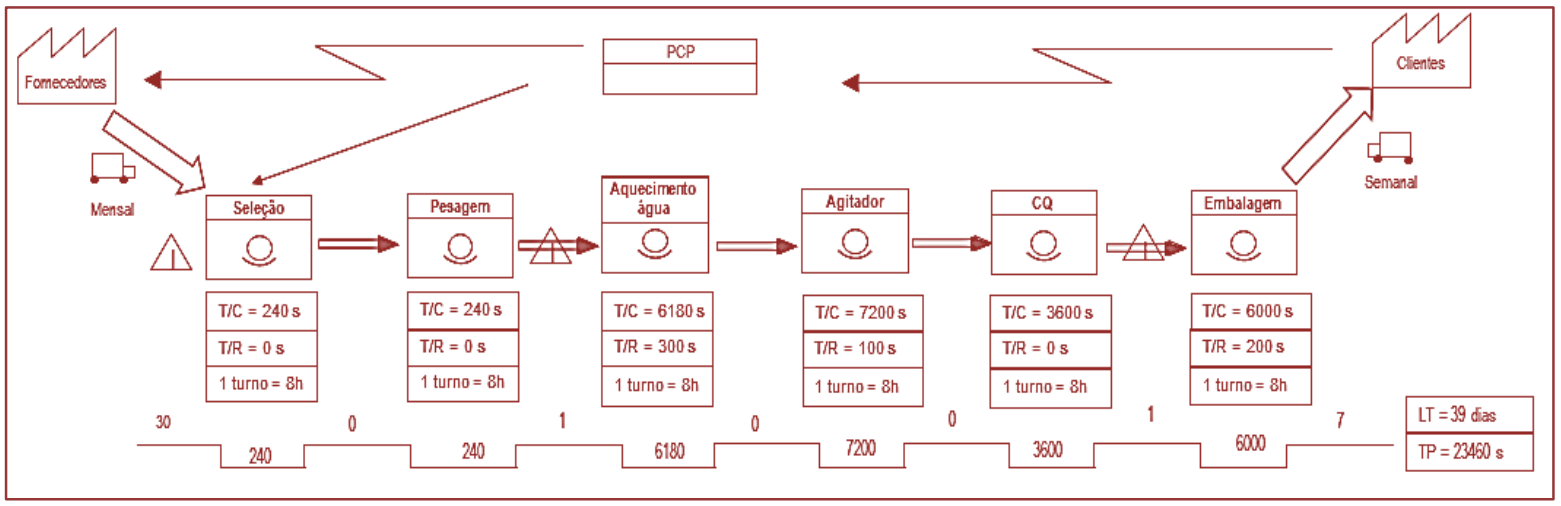

Fonte: Autoria própria

Houve uma significativa melhora no tempo de processamento aqui também, devido a automação do aquecimento de água, reduzindo o tempo total de fabricação para 6 horas e meia. Bem como uma melhora de $50 \%$ no tempo de setup, uma vez que a preparação que era realizada para o aquecimento da água (separação de madeiras, acendimento da chama) não precisará mais ocorrer.

Apesar de todas as melhorias no tempo de processamento e no setup, ainda não foi possível melhorar significativamente o lead time, uma vez que os principais fornecedores são indianos e entregas mais rápidas se tornam de difícil viabilidade pela distância e alto custo. Quanto ao estoque de produto acabado será possível melhorar a rapidez da sua entrega conforme a automação for entrando na cultura da produção e a empresa adquirir mais clientes.

\section{CONCLUSÃO}

Através do desenvolvimento do presente trabalho, que tinha como finalidade a entrega de um projeto da automação de etapas de um processo de fabricação de corantes, foi possível um contato direto com a indústria e com os problemas que ela enfrenta.

Apresentou-se uma proposta ao proprietário da indústria onde houve relato de todos os problemas levantados e as soluções para os principais deles (aquecimento de água e peneiramento do sal). Sabe-se que o projeto beneficiará em mais de uma hora o tempo de processamento de todos os dois processos desenvolvidos na Courotec (líquido e pó), bem como decairá o setup do processo líquido em 50\%. Números que são extremamente significativos e possibilitarão um aumento na quantidade de corante fabricado por dia, além de trazerem robustez para uma empresa que objetiva melhorar sua presença no mercado, sobressaindo seus concorrentes e conquistando novos clientes. 


\section{REFERÊNCIAS}

[1] ABDULMALEK, F. A; RAJGOPAL, J. Analyzing the benefits of Lean manufacturing and VSM via simulation: a process sector case study. International Journal of Production Economics, v.107, n.1, p. 223-236,2007.

[2] ANSCHAU, C. T. et al. Benefícios do investimento em automação no processo de empacotamento de farinha de trigo. Chapecó, 2018. ANAIS - Engenharia de Produção, UCEFF.

[3] CASTRUCCI, P.L; MORAES, C.C.M. Engenharia de automação industrial. 2ª edição. Rio de Janeiro: LTC, 2010.

[4] CHIAVENATO, Idalberto. Gestão da produção: uma abordagem introdutória. 3aㅡ ed. Barueri: Manole, 2014.

[5] FORGIARINI, Eliane. Degradação de Corantes e Efluentes Têxteis pela Enzima Horseradish Peroxidase (HRP). Dissertação (Mestrado em Engenharia Química) - Programa de Pós-Graduação em Engenharia Química do Centro Tecnológico, da Universidade Federal de Santa Catarina. Florianópolis, p. 31. 2006.

[6] HALLIDAY, D; RESNICK, R; WALKER, J. Fundamentos de Física. 8ª edição. Rio de Janeiro: LTC, 2009. Vol. 2.

[7] LAUGENI, F.P; MARTINS, P.G. Administração da produção. São Paulo: Saraiva, 2005.

[8] TOCCI, Q. J; WIDMER, N.S. Sistemas digitais: princípios e aplicações. Tradução: José Franco Machado do Amaral e Jorge Luís Machado do Amaral. Rio de Janeiro: LTC, 2000.

[9] TUBINO, D. F. Manual de planejamento e controle da produção. São Paulo: Atlas, 2000.

[10] TUBINO, D. F. Planejamento de controle da produção: teoria e prática. São Paulo: Atlas, 2017.

[11] VIEIRA, A.C.S, et al. Aplicação do Mapeamento do Fluxo de Valor (MFV) em uma indústria moveleira. XXXVII ENCONTRO NACIONAL DE ENGENHARIA DE PRODUCAO, 2017. 


\section{Capitulo 14}

Soldas do aço inoxidável lean duplex grau 2101: Avaliação do grau de passivação e resistência à corrosão por polarização potenciodinâmica on-site $e$ SKPFM

\section{Luís Henrique Guilherme}

José Guilherme Cossetti

Fernando Santos da Silva

Cecilio Sadao Fugivara

Dirk Engelberg

Assis Vicente Benedetti

Resumo: Este trabalho avaliou a resistência à corrosão de juntas de aço inoxidável duplex Lean 2101 (UNS S32101) soldadas pela técnica TIG (Tungsten Inert Gas) em duas condições: $2,4 \mathrm{~kJ} / \mathrm{mm}$ e $1,5 \mathrm{~kJ} / \mathrm{mm}$. A caracterização microestrutural foi realizada por microscopia ótica e eletrônica de varredura e o desempenho quanto à resistência à corrosão foi avaliado por ensaios eletroquímicos usando uma minicélula eletroquímica portátil. Mapas de potencial de superfície foram obtidos por microscopia de força atômica no modo Kelvin Probe. Os resultados indicaram que o aporte térmico de 1,5 $\mathrm{kJ} / \mathrm{mm}$ obteve soldas com maior resistência à corrosão, uma vez que a microestrutura mostrou melhor balanço entre fases austenita e ferrita, e reduzida ocorrência de precipitação de nitretos de cromo. Os resultados eletroquímicos, mapas de potencial Volta, a morfologia e a microestrutura demostraram-se correlacionados.

Palavras-Chave: aço inoxidável lean duplex 2101, soldagem TIG, filme passivo, resistência à corrosão, polarização potenciodinâmica, SKPFM. 


\section{INTRODUÇÃO}

Os aços inoxidáveis duplex são de grande importância tecnológica devido à combinação de elevada resistência mecânica e de corrosão, fácil trabalhabilidade, soldabilidade e operação em temperaturas elevadas e criogênicas. Recentemente um elevado número de aços inoxidáveis foram inseridos no mercado como opção ao aço inoxidável duplex 2205. Esses aços são classificados em função do Pitting Resistance Equivalent Number (PREN), que quantifica a resistência à corrosão por pite com base na composição química da liga. 0 aço lean duplex grau 2101 é uma opção econômica na classe dos duplex. Estes aços são considerados de estrutura complexa para a soldagem e inúmeros fatores devem ser considerados para que suas propriedades não sejam degradadas devido à soldagem inadequada. ${ }^{1-5}$

Tanques de processo e estocagem com requisitos de resistência à corrosão e assepsia têm substituído as ligas dos aços inoxidáveis austeníticos 304L e 316L pelo lean duplex 2101, com ganho na redução da espessura das partes do tanque. Isso porque a liga 2101 é mais resistente mecanicamente e pela perspectiva de maior disponibilidade do equipamento ao reduzir paradas de manutenção devido à degradação causada por corrosão, tipicamente registradas para as ligas 304L e 316L quando aplicadas em tanques assépticos.

No entanto, as referências sobre a soldagem da liga 2101 ainda são limitadas na literatura, e recomendações para a soldagem dos aços inoxidáveis duplex permitem uma ampla faixa para o aporte térmico, na ordem de 0,5-2,5 kJ/mm. . $^{6-9}$

Este estudo focou a avaliação do grau de passivação e resistência à corrosão de microrregiões de juntas soldadas do aço inoxidável lean duplex grau 2101 soldados por dois procedimentos de soldagem qualificados de acordo com o código ASME seção IX. Para tanto, um corpo de prova soldado para cada procedimento de soldagem qualificado ASME foi preparado e a caracterização microestrutural foi realizada por microscopia ótica (MO) e microscopia eletrônica de varredura (MEV). As propriedades de passivação de distintas microrregiões das juntas soldadas foram caracterizadas por ensaios eletroquímicos usando uma minicélula eletroquímica portátil e a quantificação do parâmetro PotencialVolta por microscopia de potencial de superfície (SKPFM - Scanning Kelvin Probe Force Microscopy).

\section{MATERIAIS E MÉTODOS}

Como metal base foi utilizado o aço inoxidável UNS S32101 da Outokumpu com espessura de 6,0 milímetros e como metal de adição uma vareta AWS ER 2209 com diâmetro de 2,4 mm. A Tabela 1 apresenta a composição química de ambos.

Tabela 1. Composição química do metal base e de adição.

\begin{tabular}{|c|c|c|c|c|c|c|c|c|c|c|}
\hline \multirow{10}{*}{ Amostra } & \multicolumn{10}{c|}{ Concentração dos elementos em massa (\%) } \\
& C & Cr & Ni & Mo & Mn & P & S & Si & N & Cu \\
\hline LDX 2101 & 0,019 & 21,32 & 1,15 & 0,19 & 4,87 & 0,024 & 0,001 & 0,73 & 0,22 & 0,53 \\
\hline ER 2209 & 0,020 & 22,90 & 8,6 & 3,20 & 1,6 & 0,017 & 0,001 & 0,40 & 0,16 & 0,10 \\
\hline
\end{tabular}

A soldagem foi realizada pelo processo TIG manual usando a máquina EWM Tetrix 351 Confort FW na posição plana e em uma junta em $\mathrm{V}$ com backing gás no passe de raiz, sendo, portanto, desnecessário a contra-solda na face da raiz (soldagem por um único lado). A Figura 1 esquematiza a junta soldada e os parâmetros de soldagem de cada procedimento são apresentados nas Tabela 2 e 3. Destaca-se que ambos os procedimentos foram qualificados sob critérios do código ASME IX ${ }^{10}$ para a construção de tanques expostos a meio corrosivo e com propriedades assépticas. A comparação entre os procedimentos está relacionada ao aporte térmico aplicado: (i) o procedimento 1 (EPS 1) com aporte térmico médio de 1,1 $\mathrm{kJ} / \mathrm{mm}$, e (ii) o procedimento 2 (EPS 2) com aporte térmico médio de $2,5 \mathrm{~kJ} / \mathrm{mm}$. Além do aporte térmico, destaca-se a diferença entre o pico de temperatura relacionado à máxima densidade de corrente e a velocidade de deslocamento. Todas essas condições geram diferentes histórias térmicas para a junta soldada (ciclo térmico e repartição térmica), que implicam no modo de solidificação do metal de solda. Isto significa que a velocidade de resfriamento e solidificação, crescimento de fases e equalização entre a 
fração de austenita e ferrita, a precipitação de fases intermetálicas/deletérias entre outros aspectos serão distintas entre os procedimentos de soldagem.

Figura 1. (a) esquema da preparação do chanfro para soldagem, (b) passes de soldagem da EPS 1 e (c) passes de soldagem da EPS 2. É mostrado também em 1.a e 1.b a posição do microcapilar da mini-célula para ensaios eletroquímicos de corrosão em microrregiões específicas da junta soldada.

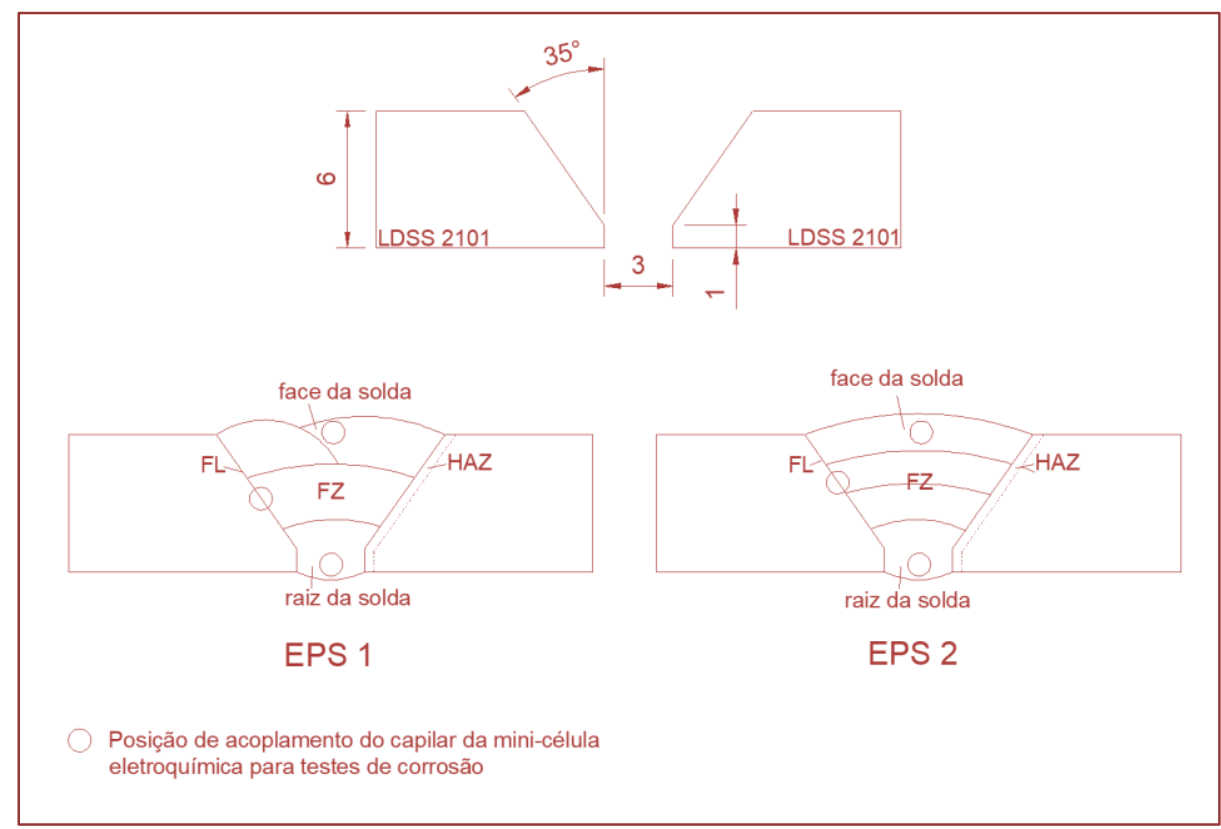

Tabela 2. Parâmetros de soldagem da EPS 1.

\begin{tabular}{|c|c|c|c|c|}
\hline Passe de solda & Corrente (A) & Tensão (V) & $\begin{array}{c}\text { Velocidade de } \\
\text { soldagem } \\
(\mathrm{mm} / \mathrm{s})\end{array}$ & $\begin{array}{c}\text { Aporte térmico } \\
\qquad\left(\mathrm{kJ} \mathrm{mm} \mathrm{mm}^{-1}\right)\end{array}$ \\
\hline 1 & $120 \pm 1$ & $15,9 \pm 0,1$ & $1,2 \pm 0,2$ & $1,6 \pm 0,2$ \\
\hline 2 & $140 \pm 1$ & $14,8 \pm 0,1$ & $0,8 \pm 0,1$ & $2,7 \pm 0,1$ \\
\hline 3 & $142 \pm 1$ & $15,3 \pm 0,1$ & $1,2 \pm 0,2$ & $1,8 \pm 0,1$ \\
\hline 4 & $142 \pm 1$ & $15,8 \pm 0,1$ & $1,1 \pm 0,1$ & $2,0 \pm 0,1$ \\
\hline
\end{tabular}

Tabela 3. Parâmetros de soldagem da EPS 2.

\begin{tabular}{|c|c|c|c|c|}
\hline \multirow{2}{*}{ Passe de solda } & Corrente (A) & Tensão (V) & $\begin{array}{c}\text { Velocidade de } \\
\text { soldagem } \\
(\mathrm{mm} / \mathrm{s})\end{array}$ & $\begin{array}{c}\text { Aporte térmico } \\
(\mathrm{kJ} \mathrm{mm}-1)\end{array}$ \\
\hline 1 & $185 \pm 1$ & $16,0 \pm 0,1$ & $2,5 \pm 0,1$ & $1,2 \pm 0.2$ \\
\hline 2 & $250 \pm 1$ & $17,1 \pm 0,1$ & $3,7 \pm 0,2$ & $1,2 \pm 0.1$ \\
\hline 3 & $275 \pm 1$ & $20,5 \pm 0,2$ & $4,8 \pm 0,2$ & $1,2 \pm 0.2$ \\
\hline 4 & $276 \pm 1$ & $19,7 \pm 0,1$ & $5,6 \pm 0,2$ & $1,0 \pm 0.1$ \\
\hline
\end{tabular}

*Distância bico de contato-peça (DBCP): $\pm 10 \mathrm{~mm}$.

*Gás de proteção / Vazão / Polaridade: 100\% Ar / 15 L min-1 / DCEN (-). 
A caracterização das juntas soldadas foi realizada pelas técnicas de MO e MEV observando-se a secção transversal. Para obter as imagens em secção transversal, as amostras de juntas soldadas foram cortadas em uma cortadora Struers Labotom com disco de diamante e a secção transversal embutida em resina acrílica. Em seguida as amostras foram desbastadas com lixas de Carbeto de Silício (SiC) de granulometria 240, 600, 1200 e 4000; e polidas com pastas de diamante com partículas de 6 e $1 \mu \mathrm{m}$.

A secção transversal das amostras foi analisada em um microscópio eletrônico de varredura acoplado a um sistema de microanálise (EDS- espectroscopia de dispersão de energia de raios X) modelo JEOL 7500F. Também foram feitas imagens de microscopia ótica em um microscópio ótico KOZO modelo DCMC310. Para a revelação da microestrutura foi realizado um ataque químico utilizando solução de Beraha modificada, cuja composição química é de $80 \mathrm{~mL}$ de água destilada e deionizada, $20 \mathrm{~mL}$ de ácido clorídrico e $1 \mathrm{~g}$ de metabissulfito de potássio. A amostra foi imersa por cerca de 2 min na solução, sendo em seguida lavada com água e seca com jato de ar. A caracterização das fases na microestrutura das amostras foi realizada por difração de raios X utilizando o equipamento SIEMENS D500 com energia $\mathrm{Cu} \mathrm{K} \alpha \mathrm{de} 45 \mathrm{kV}$ e uma corrente de $40 \mathrm{~mA}$. A variação de $2 \theta$ foi de 4 até $100^{\circ}$ com passo de 0,017을 e medidas de 50 segundos por passo.

Adicionalmente, o teor de ferrita foi mensurado para as diferentes microrregiões de cada junta soldada, conforme indicado na Figura 1, utilizando-se de um ferritosópio Fisher MP30, de modo a obter uma estimativa da fração volumétrica da fase ferrita para cada microrregião específica.

Para os ensaios eletroquímicos foi utilizada uma minicélula descrita em publicações anteriores ${ }^{11}$, e conforme ilustra a Figura 2, com diâmetro de 1,0 milímetro no capilar. Utilizou-se como eletrodo de referência $\mathrm{Ag}|\mathrm{AgCl}| \mathrm{KCl} 3 \mathrm{~mol} / \mathrm{L}$, fio de platina como eletrodo auxiliar e as amostras soldadas e metal base como eletrodo de trabalho. As microrregiões de interesse analisadas são apresentadas na Figura 1, sendo: metal base (MB), face da solda (FC), linha de fusão (LF) e a raiz da solda (RS).

Figura 2. Microcélula eletroquímica com diâmetro de 1,0 milímetro.

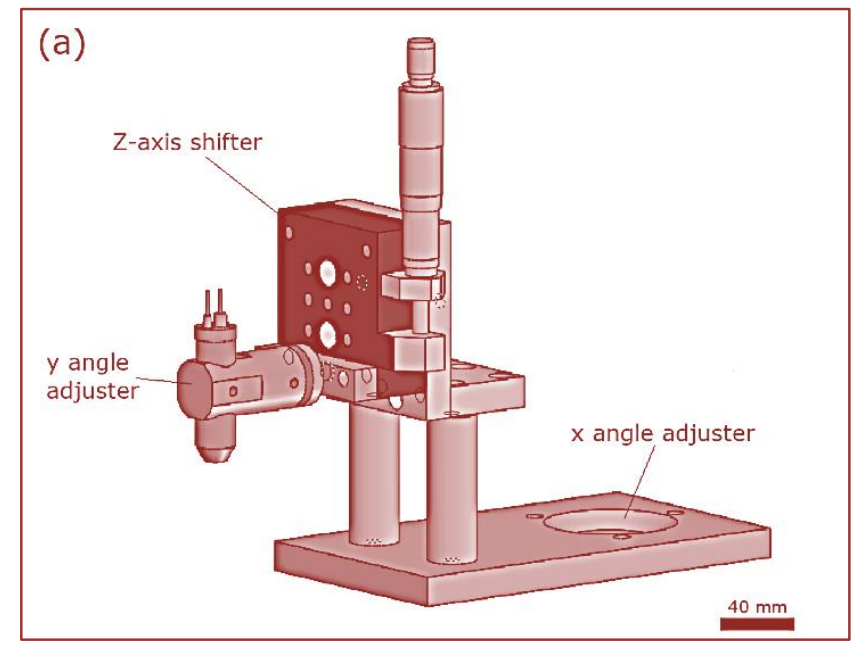

A resistência à corrosão das amostras foi avaliada por: (i) polarização potenciodinâmica e (ii) reativação potenciocinética de duplo ciclo (DL-EPR). As curvas de polarização potenciodinâmica foram obtidas em $3,5 \% \mathrm{NaCl}$ a $25{ }^{\circ} \mathrm{C}$. As medidas foram realizadas a partir de $-50 \mathrm{mV}$ vs. $E_{\mathrm{CA}}$ (potencial em circuito aberto) até $+1000 \mathrm{mV}$ ou até obter o potencial de pite $\left(E_{\text {pit }}\right)$, com velocidade de varredura de $1 \mathrm{mV} / \mathrm{s}$. Os valores de potencial de pite $\left(E_{\text {pit }}\right)$ e corrente de corrosão $\left(i_{\text {corr }}\right)$ foram obtidos a partir da extrapolação das curvas. Foram realizados testes de DL-EPR em solução 0,5 mol/ $\mathrm{L} \mathrm{H}_{2} \mathrm{SO}_{4}+0,01 \mathrm{~mol} / \mathrm{L} \mathrm{KSCN}$ a $25{ }^{\circ} \mathrm{C}$ para obter o grau de sintetização dos materiais (DOS - degree of sensitization). Os testes foram realizados varrendo a faixa de potencial de $-0,5 \mathrm{~V}$ até $+0,3 \mathrm{~V} / E_{\mathrm{CA}}$, revertendo o sentido da varredura de potencial e finalizando a curva em -0,5 V ( $\left.E_{\text {final }}\right)$ com velocidade de varredura de 1,67 mV/s. Após as medidas foi feita a inspeção da superfície das amostras por MO. 
A microscopia de potencial de superfície foi conduzida para as mesmas microrregiões citadas para os ensaios eletroquímicos na Figura 1, obtendo-se um mapa de superfície de $80 \mu \mathrm{m}$ x $80 \mu \mathrm{m}$. As medidas foram realizadas com o microscópio de força atômica (AFM) Dimension D3100 usando ponteiras revestias em platina com raio na ponta de $25 \mathrm{~nm}$. 0 parâmetro potencial Volta $(\Delta \Psi)$ foi mensurado em temperatura ambiente. 0 software de apoio à aquisição de imagens Nanoscope Analysis V1.5 foi usado para gerar os mapas de superfície.

\section{RESULTADOS E DISCUSSÃO}

A caracterização microestrutural mostrou uma microestrutura balanceada entre as fases ferrita e austenita (43:57) para o metal de base. A soldagem acarretou na formação de uma estrutura bruta de solidificação com o aumento da fração volumétrica da fase ferrita, principalmente para a EPS 2, em função do maior aporte térmico utilizado no processo de soldagem, e menor velocidade de solidificação do metal de solda. Observa-se na Figura 3.e morfologia com presença de precipitados de nitreto de cromo enquanto a Figura 3.f mostra contornos de grãos sensitizados devido à presença destes precipitados. Na Figura 3 tem-se a caracterização microestrutural das amostras soldadas.

Figura 3. Microscopia ótica (a) do metal de base, (b) da face da solda (EPS 1); (c/d) da linha de fusão do corpo de prova da EPS 2 com a presença de precipitados de nitreto de cromo, (e/f) imagens obtidas por MEV da solda da EPS 1.

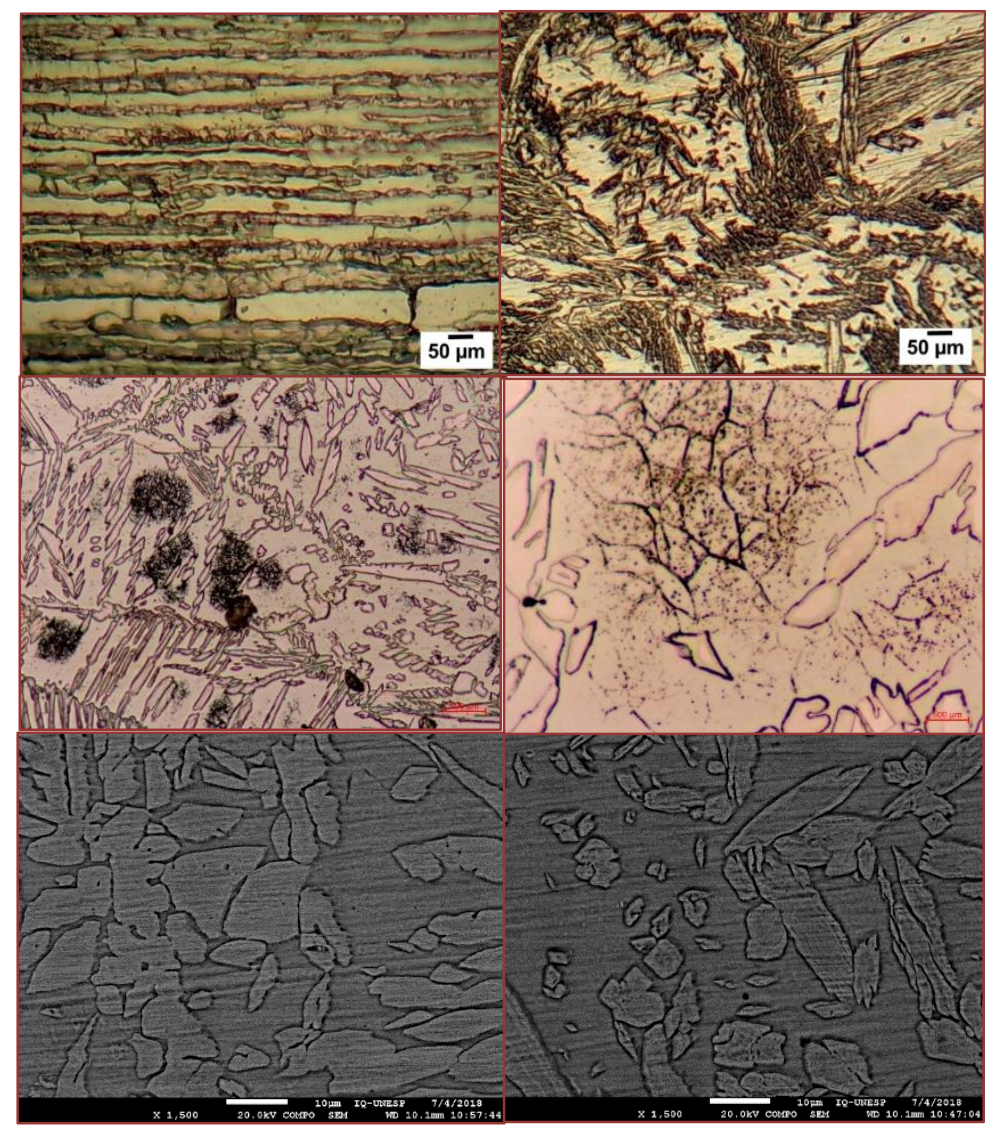

A determinação do teor de ferrita foi realizado para as microrregiões da solda: face, raiz e linha de fusão. A EPS 2 demonstrou, de um modo geral, um maior teo: de ferrita. A maior velocidade de soldagem gerou mais rápida solidificação do metal de solda, limitando a formação da fase secundária, a austenita, acarretando assim em um maior teor de ferrita. Regiões da solda exposta a ciclos térmicos multipasse também obtiveram aumento no teor de ferrita decorrente da precipitação de fases intermetálicas, que são 
magnéticas. Na linha de fusão o aumento do teor de ferrita ocorreu devido à elevada precipitação de nitretos de cromo na região. A Figura 4 mostra o teor de ferrita para cada microrregião da solda.

Figura 4. Fração volumétrica da fase ferrita medido por ferritoscópio.

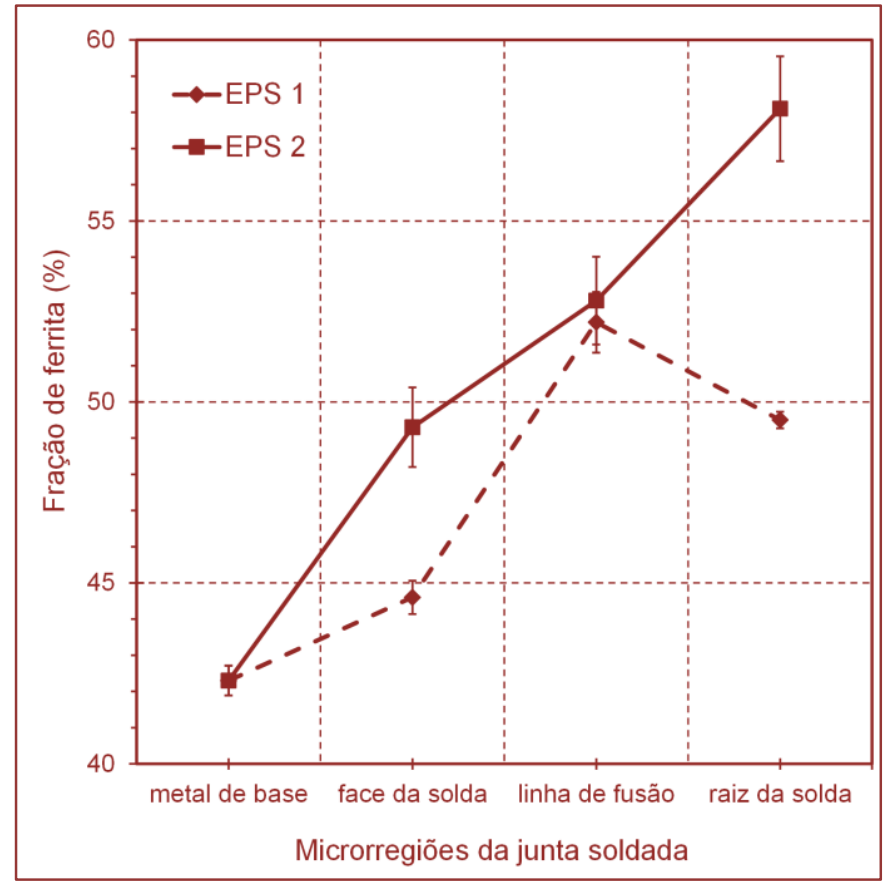

A difração de raios $\mathrm{X}$ realizada no centro do cordão de solda foi capaz de determinar uma estrutura bifásica composta pelos microconstituintes ferrita e austenita. A técnica não foi capaz de identificar os precipitados intermetálicos observados na análise por microscopia ótica. A Figura 5 mostra os espectros de difração de raios X para cada EPS.

Figura 5. Difração de raios X das juntas soldadas da (a) EPS 1 e (b) EPS 2. A difração de raios X concentrou o feixe no centro do cordão de solda.
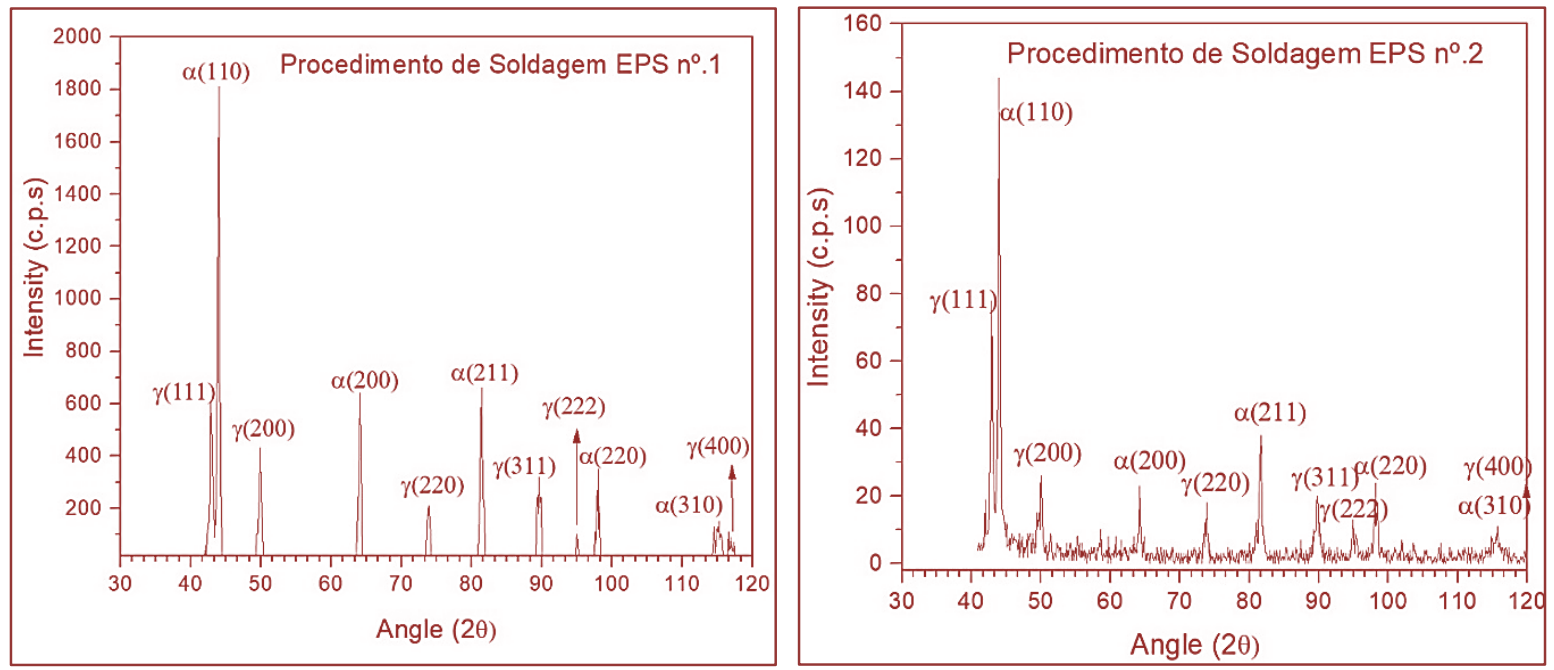
Os ensaios eletroquímicos DL-EPR foram realizados com o objetivo de determinar o valor DOS em cada microrregião de interesse das juntas soldadas. Observou-se que a EPS 1 obteve resultados superiores para a face e raiz da solda quando comparado com a EPS 2, contudo, um alto grau de sensitização na linha de fusão foi observado para a EPS 1. A Figura 6 mostra curvas DL-EPR para a linha de fusão da EPS 1 e EPS 2, enquanto a Figura 7 apresenta os valores do DOS para as microrregiões de ambos os procedimentos de soldagem.

Figura 6. Curvas DL-EPR obtidas para as microrregiões da (a) EPS 1 e (b) EPS 2.

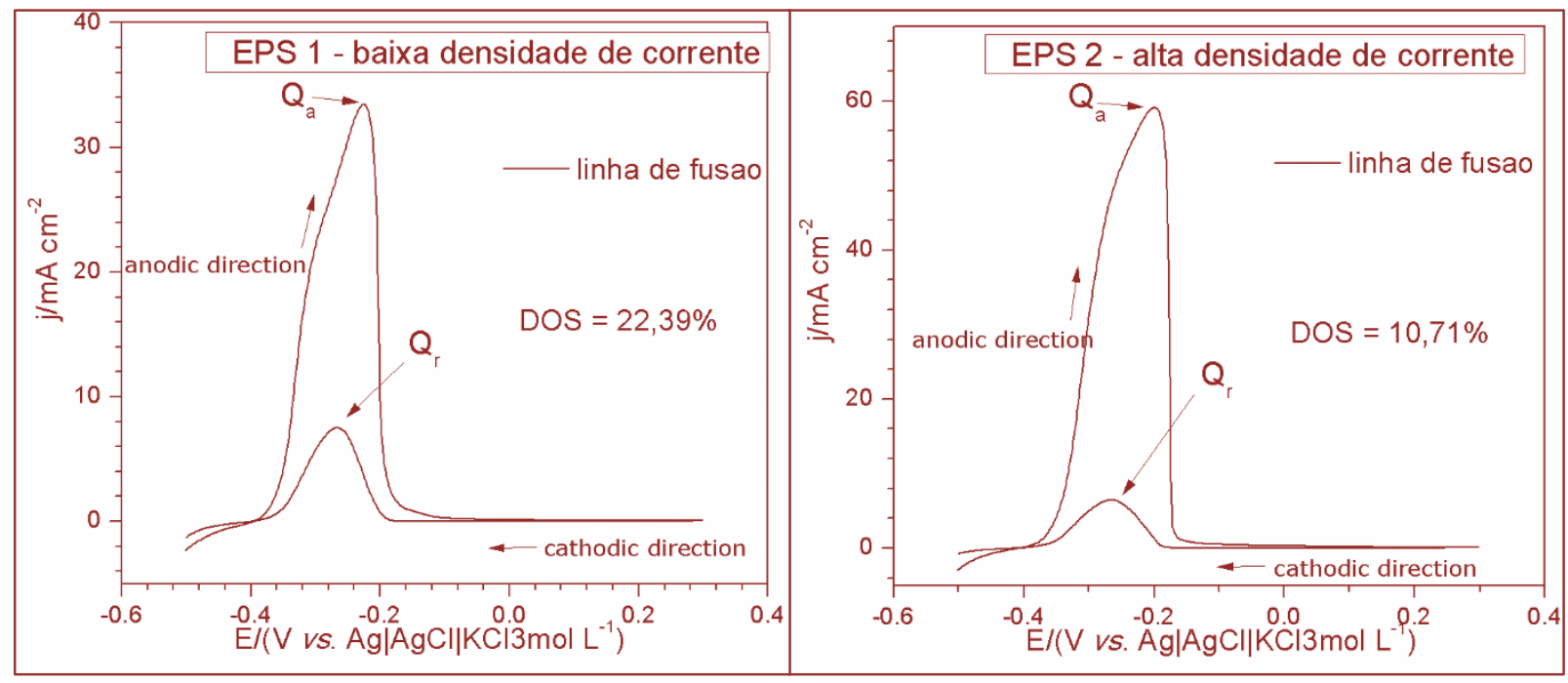

Figura 7. Determinação do grau de sensitização para cada microrregião das juntas soldadas pela EPS 1 e 2.

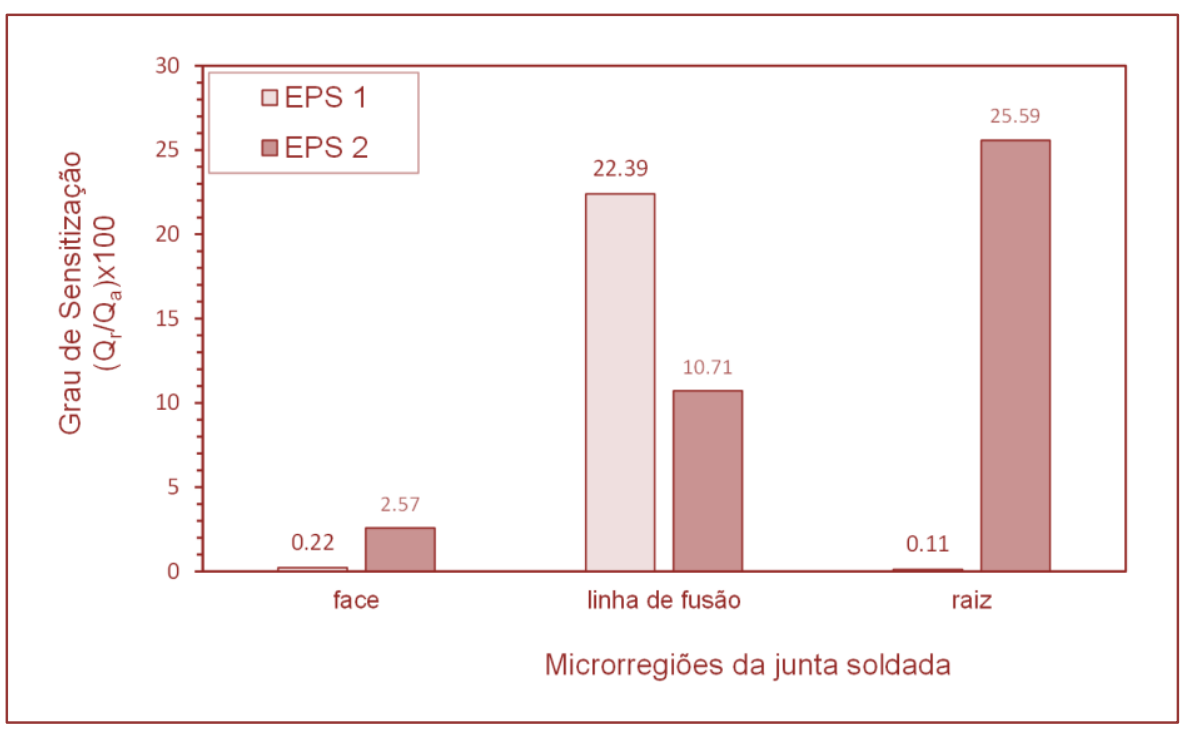


Ensaios eletroquímicos de polarização potenciodinâmica foram conduzidos em solução $\mathrm{H}_{2} \mathrm{SO}_{4} 2 \mathrm{~mol} / \mathrm{L}+$ $0,5 \mathrm{NaCl} \mathrm{mol} / \mathrm{L} \mathrm{com}$ a finalidade de determinar a resistência à corrosão das regiões da solda em meio contendo cloreto. A Figura 8 apresenta as curvas de polarização para cada EPS e a Tabela 4 quantifica o potencial de corrosão e a corrente de corrosão. Com base nos parâmetros eletroquímicos é evidente que o potencial de passivação das regiões de solda é relativamente semelhante, contudo, vale ressaltar que a corrente de corrosão é expressivamente superior para a EPS 2, indicando maior taxa de corrosão. Isto se deve ao maior grau de sensitização da microestrutura, o que acarreta corrosão localizada na região de formação de nitreto de cromo.

Figura 8. Curvas de polarização potenciodinâmica das microrregiões de solda em solução $\mathrm{H}_{2} \mathrm{SO}_{4} 2 \mathrm{~mol} / \mathrm{L}+$ $0,5 \mathrm{NaCl} \mathrm{mol} / \mathrm{L}$ da (a) EPS 1 e (b) EPS 2.

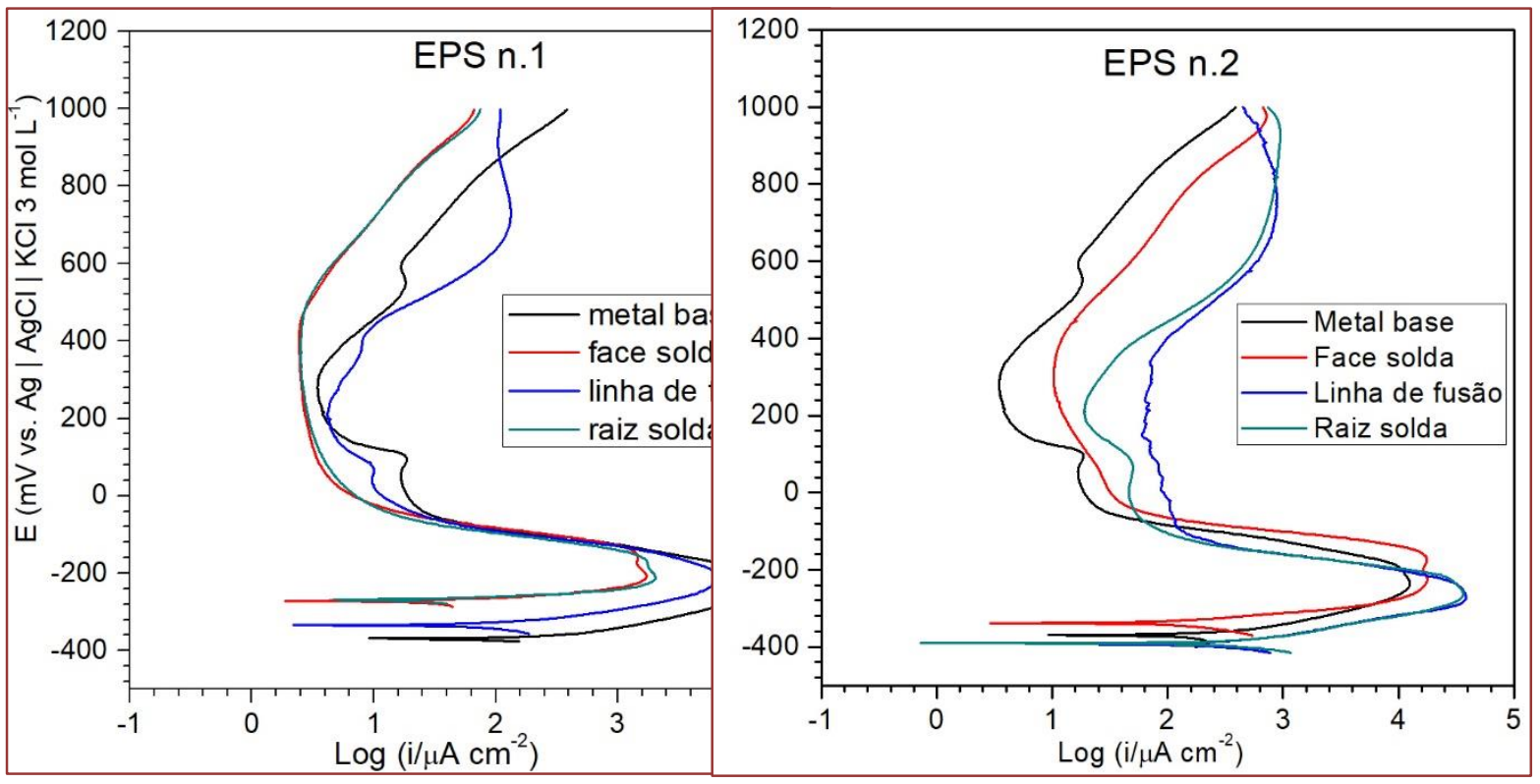

Tabela 4. Valores de $E_{\text {corr }}$ e $i_{\text {corr }}$ obtidos a partir da extrapolação das curvas de Tafel.

\begin{tabular}{|c|c|c|c|c|c|cc|c|c|}
\hline \multirow{2}{*}{$\begin{array}{c}\text { Parâmetros de } \\
\text { Desempenho }\end{array}$} & $\begin{array}{c}\text { Metal } \\
\text { base }\end{array}$ & $\begin{array}{c}\text { Face } \\
\text { solda }\end{array}$ & $\begin{array}{c}\text { Linha de } \\
\text { fusão }\end{array}$ & $\begin{array}{c}\text { Raiz } \\
\text { solda }\end{array}$ & $\begin{array}{c}\text { Metal } \\
\text { base }\end{array}$ & \multicolumn{2}{c|}{$\begin{array}{c}\text { Face } \\
\text { solda }\end{array}$} & $\begin{array}{c}\text { Linha de } \\
\text { fusão }\end{array}$ & $\begin{array}{c}\text { Raiz } \\
\text { solda }\end{array}$ \\
\hline $\mathrm{E}_{\text {corr }}(\mathrm{mV})$ & -440 & -340 & -415 & -390 & -430 & -380 & -410 & -418 \\
\hline $\mathrm{i}_{\text {corr }}\left(\mathrm{mA} / \mathrm{cm}^{-2}\right)$ & 10 & 1,5 & 25 & 15 & 17 & 45 & 80 & 142 \\
\hline
\end{tabular}

Os mapas obtidos pela microscopia de potencial de superfície SKPFM demostraram que regiões da solda com solidificação controlada resultam em um parâmetro de potencial Volta semelhante ao metal base (na ordem de 20-30 mV), um indicativo de que é reduzida a susceptibilidade à corrosão localizada nessa microrregião. Contudo, regiões empobrecidas em $\mathrm{Cr}$ e Mo, tipicamente localizadas em regiões da solda com elevado teor da fase ferrita, austenita secundária e precipitados de nitreto de cromo apresentaram um elevado valor de potencial Volta (na ordem de 45-60 mV), indicando susceptibilidade à formação de um par galvânico localizado entre as fases, o que aumenta a fragilidade à corrosão localizada. A Figura 9 mostra os mapas de superfície do SKPFM. 
Figura 9. Mapa de potencial de superfície obtida por microscopia SKPFM e respectivos potencial Volta para (a) metal de base, (b) face da solda e (c) raiz da solda em região empobrecida em Cr e Mo.

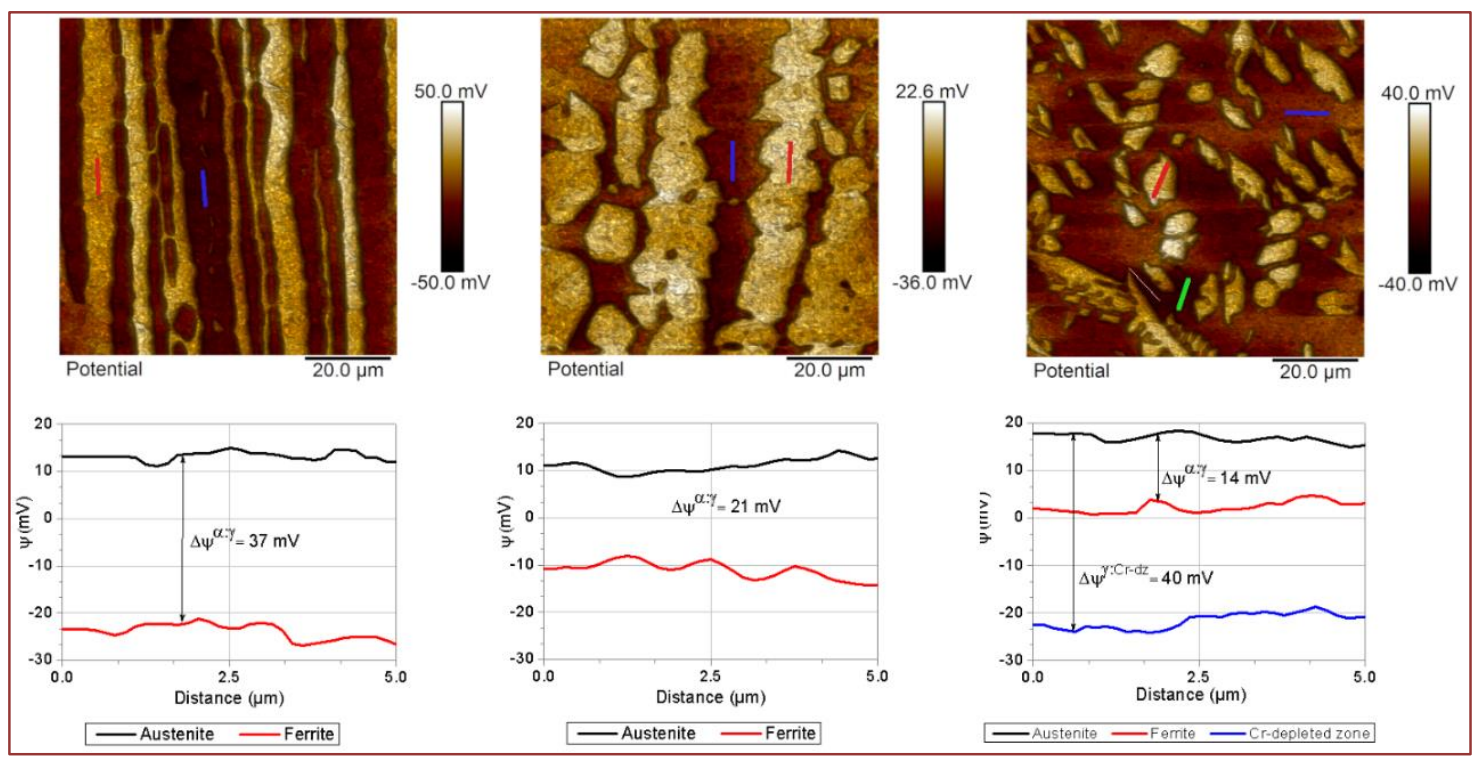

A caracterização microestrutural e eletroquímica demonstraram forte correlação entre os parâmetros de soldagem e a resistência à corrosão da junta soldada. Destaca-se que o procedimento de soldagem com elevado aporte térmico, alta densidade de corrente e alta velocidade de deslocamento favoreceu uma estrutura com maior teor da fase ferrita e precipitados de nitretos de cromo, principalmente em regiões expostas a ciclos térmicos de soldagem multipasse.

\section{CONCLUSÃO}

Com base nos resultados pode-se concluir que:

- 0 procedimento de soldagem EPS 1 resultou em maior resistência à corrosão em função dos parâmetros de soldagem com menor aporte térmico e menor velocidade de deslocamento.

- As técnicas eletroquímicas de corrosão usando minicélula associada ao uso da microscopia de potencial de superfície SKPFM mostraram-se eficazes no estudo da resistência à corrosão de juntas soldadas, corroborando os resultados de cada técnica.

- A região da linha de fusão da solda obteve a menor resistência à corrosão localizada, uma vez que a transição microestrutural característica da região (metal de solda para o metal base) favoreceu a precipitação de nitretos de cromo.

- A face da solda configurou a região de maior resistência à corrosão devido à exposição a um único ciclo térmico de soldagem e à diluição de metal de solda com metal de solda previamente depositado, resultando em composição química mais nobre para essa região.

\section{REFERÊNCIAS}

[1] 1. Guilherme, L.H.; Reccagni, P.;Benedetti, A.V.; Fugivara, C.S.; Engelberg, D.L., Corrosion 75 (2019): pp. 1216-1229.

[2] 2. A Hosseini, V., K. Hurtig, D. Eyzop, A. Östberg, P. Janiak, and L. Karlsson, Weld. World 63 (2019): pp. 551-563, http://link.springer.com/10.1007/s40194-018-00681-1.

[3] 3. A Hosseini, V., L. Karlsson, D. Engelberg, and S. Wessman, Weld. World 62 (2018): pp. 517-533.

[4] 4. Engelberg, D.L., F. Léonard, S.A. McDonald, P.J. Withers, A. Prajapati, and C. Örnek, Npj Mater. Degrad. 2 (2018): pp. 1-15, http://dx.doi.org/10.1038/s41529-018-0030-9.

[5] 5. Magnabosco, R., and N. Alonso-Falleiros, Corrosion 61 (2005): pp. 130-136. 
[6] 6. Sicupira, D.C., R.C. Junior, A.Q. Bracarense, G.S. Frankel, and V. de F. Cunha Lins, Mater. Res. J. Mater. 20 (2017): pp. 161-167.

[7] 7. Silva, R., L.F.S. Baroni, M.B.R. Silva, C.R.M. Afonso, S.E. Kuri, and C.A.D. Rovere, Mater. Charact. 114 (2016): pp. 211-217, http://dx.doi.org/10.1016/j.matchar.2016.03.002.

[8] 8. Örnek, C., and D.L. Engelberg, Corros. Sci. 99 (2015): pp. 164-171, http://dx.doi.org/10.1016/j.corsci.2015.06.035.

[9] 9. Reccagni, P.; Guilherme, L.H.; Lu, Q.; Gittos, M.; Engelberg, D.L., Corros. Sci. (2019): p. (accepted).

[10] 10. ASME IX, "Qualification Standard for Welding, Brazing and Fusing Procedures," in ASME Boil. Press. Vessel Code (2015).

[11] 11. Guilherme, L.H., A. Benedetti, and C. Fugivara, Corrosion 75 (2018): pp. 340-348, http://corrosionjournal.org/doi/10.5006/3004. 


\section{Capítulo 15}

\section{Modelo de regressão múltipla para previsão da série temporal de um piezômetro usando regressão múltipla}

\section{Emerson Lazzarotto}

Resumo: Neste artigo investiga-se a influência da variável temperatura ambiente sobre as medidas da série temporal de um instrumento de monitoramento de barragem, denominado piezômetro, por meio de um modelo de regressão linear múltipla. 0 objetivo é aplicar ferramentas de controle estatístico da qualidade como uma ferramenta adicional à análise de risco de barragens. Este estudo de caso foi realizado com dados de um piezômetro e termômetros instalados na barragem da Usina Hidrelétrica de Itaipu. Considerando a autocorrelação existente em séries temporais de instrumentos de monitoramento, este estudo comparou a precisão do ajustamento de modelos de regressão linear múltipla pelo método de mínimos quadrados e do método de ajustamento otimizado de Cochrane-Orcutt. Os resultados indicam que a temperatura ambiente pode colaborar a na modelagem do comportamento do instrumento e, consequentemente, da variável que ela avalia, além de prever, com boa precisão, seu futuro comportamento. 0 ajuste otimizado de Cochrane-Orcutt mostrou desempenho de previsão superior ao método de mínimos quadrados.

Palavras-chave: Regressão linear múltipla; Controle estatístico da qualidade; monitoramento de barragem; Previsão de séries temporais. 


\section{INTRODUÇ̃̃OO}

As barragens de usinas geradoras de hidroeletricidade oferecem benefícios que contribuem para a melhoria da qualidade de vida da população. Em geral, deseja-se assegurar que as barragens sejam seguras, econômicas e ambientalmente sustentáveis. É desejável prolongar o período operacional da barragem e retardar seu envelhecimento através do contínuo investimento em ações para este fim. (CIGBICOLD, 2008).

A manutenção das condições de segurança podem evitar obras de reparação caras e quase sempre conflitantes com a produção de energia. 0 aprimoramento das barragens assegura não somente a operação e o desempenho seguro, mas também melhoria na sua eficiência (XXIII ICOLD QUESTION 88, 2009), (XXIII ICOLD QUESTION 90, 2009).

Além de inspeções visuais, a forma mais importante de avaliar o comportamento de uma barragem se dá pela instalação e acompanhamento de instrumentos de monitoramento. Estes instrumentos fornecem medidas quantitativas do comportamento de importantes características de engenharia que estejam sendo monitoradas (SILVEIRA, 2003).

A análise dos dados da instrumentação ajuda na gestão da segurança e da qualidade da barragem. Uma hipótese aventada pelos engenheiros de segurança é que, mesmo em barragens que operam 'normalmente', a variação da temperatura ao longo do ano é um importante fator de variação de séries temporais de instrumento de monitoramento.

Desta forma, neste artigo, realiza-se a investigação da influência da temperatura ambiente sobre um instrumento de monitoramento de uma barragem por meio de um modelo de regressão linear múltipla. 0 objetivo é encontrar um modelo de regressão linear múltipla que seja o mais ajustado possível aos dados de monitoramento que se possui, que responda a questão da influência da temperatura e seja capaz de prever com a melhor precisão possível o futuro comportamento da série temporal que monitora um instrumento e, consequentemente, a característica de engenharia que aquele instrumento monitora.

Para tanto, desenvolve-se, sequencialmente, alguns aspectos básicos da teoria de regressão múltipla, o material e os métodos utilizados, os resultados obtidos e algumas considerações finais.

\section{ANÁLISE DE REGRESSÃo}

A análise de regressão é uma das técnicas mais amplamente utilizadas para análise de dados multivariados. Sua ampla utilidade resulta do processo conceitualmente lógico de usar uma equação para expressar a relação entre uma variável de interesse (a resposta) e um conjunto de variáveis de regressão relacionadas. A análise de regressão também é interessante teoricamente por causa da elegante matemática subjacente e de uma teoria estatística bem desenvolvida. (MONTGOMERY, PECK e VINNING, 2012).

Um modelo para descrever a relação entre uma variável dependente y e $\mathrm{k}$ variáveis regressoras $\mathrm{x} 1, \mathrm{x} 2, \ldots$, xk é dado pela equação

$$
y=\beta_{0}+\beta_{1} x_{1}+\beta_{2} x_{2}+\ldots+\beta_{k} x_{k}+\varepsilon
$$

em que os parâmetros $\beta \mathrm{k}$ do modelo são denominados de coeficientes de regressão e o termo $\varepsilon$ é chamado de termo do erro/termo estocástico. Ressalta-se que não só funções lineares dos dados observáveis como na equação acima pode ser considerados modelos de regressão linear múltipla. 0 que caracteriza tais tipos de modelo de regressão linear é que são lineares nos parâmetros.

Os pressupostos do modelo clássico de regressão linear múltipla sobre o termo do erro $\varepsilon$ são que ele tem média (esperança matemática) nula, variância constante e são não autocorrelacionadas, na terminologia estatística, representa-se isto por 


$$
\varepsilon \sim \operatorname{NID}\left(0, \sigma^{2}\right)
$$

Em geral, a análise de regressão objetiva estimar os parâmetros desconhecidos no modelo de regressão e, em seguida, realiza uma de verificação de adequação do modelo e a qualidade do ajuste é verificada. Através de tais análises, a utilidade do modelo de regressão pode ser determinada. 0 resultado da verificação de adequação pode indicar que o modelo é razoável ou que o ajuste original deve ser modificado. Assim, a análise de regressão é um procedimento iterativo, no qual os dados levam a um modelo e é produzido um ajuste do modelo aos dados. A qualidade do ajuste é então investigada, levando à modificação do modelo ou do ajuste ou à adoção do modelo. (MONTGOMERY, PECK e VINNING, 2012)

Um modelo de regressão não implica uma relação de causa e efeito entre as variáveis. Embora possa existir uma forte relação empírica entre duas ou mais variáveis, isso não pode ser considerado evidência de que as variáveis regressivas e a resposta estão relacionadas de maneira causa e efeito. Para estabelecer a causalidade, o relacionamento entre as variáveis de regressão e a variável resposta deve ter uma base fora dos dados da amostra - por exemplo, o relacionamento pode ser sugerido por considerações teóricas. A análise de regressão pode ajudar na confirmação de um relacionamento de causa e efeito, mas não pode ser a única base de tal alegação. (MONTGOMERY, PECK e VINNING, 2012)

Em especial, engenheiros de segurança relatam a forte dependência das leituras de instrumentos de monitoramento da temperatura ambiente. (ITAIPU BINACIONAL, 2002) Deste modo, neste artigo, a análise de regressão é usada com o propósito de estimar parâmetros e realizar previsões.

Há diversas formas de estimar os parâmetros do modelo de regressão linear múltipla, dentre eles, destacase o método de mínimo quadrados ordinários. Quando lida-se com séries temporais, em geral, observações sucessivas costumam apresentar intercorrelações. Neste caso, sugere-se o método de ajuste otimizado de Cochrane-Orcutt Este ajuste é indicado quando o termo do erro possui autocorrelação no tempo. (GUJARATI e PORTER, 2011)

A estratégia é modelar os resíduos. Sugere-se a utilização do modelo

$$
\varepsilon_{\mathrm{t}}=\rho \varepsilon_{\mathrm{t}-1}+\mathrm{e}_{\mathrm{t}}
$$

onde $|\rho|<1$ e os novos termos de erro et são um ruído branco, ou seja, normalmente e independentemente distrbuídos com média 0 e variância constante. Desta forma, o ajuste de CochraneOrcutt transforma o modelo de regressão múltipla, por meio de um processo de diferenças, em um modelo cuja termo do erro é um ruído branco em que a inferência estatística de mínimos quadrados é aplicável e os parâmetros $\beta \mathrm{k}$ podem ser estimados condicionados a autocorrelação $\rho$. Uma vez que $\rho$, em geral, não é conhecida, também é estimado por um processo iterativo. (COCHRANE e ORCUTT, 1949)

Diversos testes de hipóteses são aplicados sobre os parâmetros de um modelo de regressão linear múltipla para ajudar a medir sua utilidade. Estes testes requerem os pressupostos sobre o termo do erro, já citados. (MONTGOMERY, 2013) Alguns destes testes são:

1) Teste de significância da regressão: testa se pelo menos das variáveis de regressão contribui significativamente para o modelo. Envolve uma análise de variância que decompõe a soma de quadrados total de variação na variável dependente em uma parcela de soma de quadrados decorrente do modelo de regressão e uma soma de quadrados decorrente dos resíduos ou do erros. Resumidamente: $S_{T}=S Q_{R}+$ SQE. 
2) A estatística $R^{2}$, chamada de coeficiente de determinação, definida por

$$
\mathrm{R}^{2}=\mathrm{SQ}_{\mathrm{R}} / \mathrm{SQ}_{\mathrm{T}}=1-\left(\mathrm{SQ}_{\mathrm{E}} / \mathrm{SQ}_{\mathrm{T}}\right)
$$

Como $\mathrm{SQ}_{\mathrm{T}}$ é uma medida da variabilidade na variável dependente sem considerar o efeito das variáveis de regressão e $S Q_{R}$ é uma medida da variabilidade remanescente após as variáveis de regressão terem sido consideradas, $\mathrm{R}^{2}$ é frequentemente chamado de proporção da variação explicada pelas variáveis de regressão. Como $0 \leq \mathrm{SQ}_{\mathrm{R}} \leq \mathrm{SQ} \mathrm{Q}_{\mathrm{T}}$, segue-se que $0 \leq \mathrm{R}^{2} \leq 1$. Valores de $\mathrm{R}^{2}$ próximos de 1 implicam que a maior parte da variabilidade é explicada pelo modelo de regressão.

3) Teste de coeficientes individuais de regressão: importantes para determinar a utilidade de cada variável de regressão no modelo.

Após a escolha de um modelo de regressão linear múltipla e da estimativa dos parâmetros do modelo, uma etapa fundamental da análise dos dados é realizar um diagnóstico do modelo de regressão. Gráficos de resíduos devem ser examinados em um modelo de regressão. É necessário o exame do modelo ajustado para se garantir que ele fornece uma aproximação adequada para o verdadeiro sistema e a verificação de que nenhuma das hipóteses de regressão foi violada. (MONTGOMERY, 2013)

Para a análise de resíduos e seus gráficos costuma-se levar em consideração os denominados resíduos padronizados, que são escalonadas e, desta forma, transmitem mais informação do que os resíduos ordinários uma vez que são padronizados com média 0 e variância 1, a 'maioria' dos resíduos padronizados fica no intervalo entre -3 e 3 assim, eles são úteis na busca de valores atípicos (outliers).

Por sua vez, quando existirem pontos classificados como outliers, eles devem ser estudados - podem representar erro no registro de dados ou região no espaço das variáveis de regressão em que o modelo ajustado não é uma boa aproximação da variável dependente (regredida). A sugestão é que sejam investigados e, eventualmente, excluídos da análise. (MONTGOMERY, 2013)

\section{MATERIAL E MÉTODOS}

Este estudo, segundo Brasileiro (2013), refere-se a uma pesquisa cujo principal método de procedimento é o estatístico, em que métodos e técnicas estatísticas são usadas para quantificar fatos e fenômenos naturais e sociais. Quanto aos fins é uma pesquisa aplicada e quanto aos meios é um estudo de caso.

O material disponível para a realização deste estudo consiste de cinco séries temporais de leituras de monitoramento de um instrumento denominado piezômetro, responsável por medir a subpressão no contato concreto-rocha e em níveis mais permeáveis do maciço basáltico da fundação (ITAIPU BINACIONAL, 1984), além de quatro termômetros localizados próximos a este piezômetro, responsáveis por medir a temperatura ambiente em diferentes pontos dos blocos de concreto da barragem. Doravante, a leitura do piezômetro num instante t será simbolicamente representada por $\mathrm{P}(\mathrm{t})$ e os termômetros serão representados por T_1, T_2, T_3 e T_4(t).

Estes instrumentos estão instalados na barragem da usina hidrelétrica de Itaipu Binacional, localizada entre o Brasil e o Paraguai. Itaipu é líder mundial em produção de energia limpa e renovável. Possui 20 unidades geradoras e 14.000 MW de potência instalada, fornecendo (em média) 11,3\% da energia consumida no Brasil e 88,1\% no Paraguai (ITAIPU, 2020).

Os dados disponíveis destas series temporais referem-se (inicialmente) às médias mensais das leituras realizadas no período de janeiro de 1984 a maio de 2016, ou sejam, totalizando 389 dados mensais de cada série de leituras. Separou-se os últimos 12 dados mensais para validar o modelo. Deste modo, a TABELA 1 ilustra a separação da amostra usada para estimar e prever os modelos utilizados. 
Tabela 1 - Separação da amostra

\begin{tabular}{|l|c|c|}
\hline Etapa ou período & Intervalo de tempo & Quantidade de dados \\
\hline Estimativa & $01 / 1984$ a $05 / 2015$ & 377 \\
\hline Validação & $06 / 2015$ a $05 / 2016$ & 12 \\
\hline
\end{tabular}

Conforme já mencionado, com o objetivo de investigar a influência das medidas da temperatura ambiente para o piezômetro segundo um modelo de regressão linear múltipla, não somente no instante de tempo atual, $t$, mas também da possível influência da temperatura de até três períodos de tempo anteriores na medida do piezômetro, buscou-se inicialmente trabalhar com um modelo de regressão linear múltipla com até 17 variáveis, sendo uma constante no modelo e 16 variáveis que representariam cada um dos 4 termômetros disponíveis em 4 instantes de tempo: t, t_-(-1), t_(-2) e t(-3), ou seja, tempo atual e mais 3 instantes de tempo defasados. A TABELA 2 apresenta a lista das variáveis levadas em consideração nos modelos estatísticos de regressão múltipla. Desta forma, $T_{-} \mathrm{i}(-\mathrm{j})$ representa medidas do termômetro i no instante -j de tempo em relação ao instante atual. As medidas do piezômetro são na unidade padrão do instrumento: MSNM (metros sobre o nível do mar) e dos termômetros em graus.

Tabela 2 - Variáveis do modelo

\begin{tabular}{|c|c|c|c|c|}
\hline \multicolumn{5}{|c|}{ Iependente } \\
\hline \multirow{4}{*}{ P } & T_1 & T_1(-1) & T_1(-2) & T_1(-3) \\
\cline { 2 - 5 } (Piezômetro) & T_2 & T_2(-1) & T_2(-2) & T_2(-3) \\
\cline { 2 - 5 } & T_3 & T_3(-1) & T_3(-2) & T_3(-3) \\
\cline { 2 - 5 } & T_4 & T_4(-1) & T_4(-2) & T_4(-3) \\
\cline { 2 - 5 } & C (constante) & \\
&
\end{tabular}

Para o ajuste de um modelo de regressão linear múltipla adotou-se dois métodos: o método de mínimos quadrados ordinários (MQO) e o ajuste otimizado de Cochrane-Orcutt (CO). Como premissas para a análise de adequação de um modelo de regressão linear múltipla considerou-se que:

- Todas as variáveis presentes no modelo devem possuir coeficiente estatisticamente significativo;

- A medida da estatística $\mathrm{R}^{2}$ ajustada deve ser o máximo possível;

- Os resíduos do modelo devem ser normais e independentemente distribuídos com média 0 e desvio padrão 1. A independência significa a ausência de autocorrelação. Em especial, $\rho$ representa a autocorrelação de retardo ou $\operatorname{lag} 1$ e deve estar próxima de 0 .

- 0 erro absoluto médio (MAE) de previsão no período de estimativa e validação deve ser o mínimo possível;

- O modelo deve, preferencialmente, não possuir resíduos padronizados não usuais (RNU) (maiores, em módulo, do que 3).

\section{RESULTADOS}

Na primeira etapa do procedimento metodológico, testou-se (em software) dentre as dezessete variáveis inicialmente estabelecidas qual a quantidade e qual a combinação de variáveis produzia o modelo com melhor grau de ajustamento. Assim, foram testados quase 65000 modelos de mínimos quadrados nesta etapa. 0 melhor modelo encontrado foi chamado de 'modelo 0 '.

0 'modelo 0' não satisfez diversas premissas estabelecidas para classificá-lo como um modelo estatisticamente adequado. Conforme se observa na TABELA 3. A seguir, considerando somente as variáveis cujo coeficiente mostrava-se estatisticamente significativo, foi determinado outro modelo, denominado 'modelo 1 '. 
0 'modelo 1' melhorou alguns aspectos de diagnóstico, entretanto, ainda mostrou-se inadequado segundo as premissas dos modelos de regressão. Então, a partir do seu conjunto de variáveis que foram consideradas estaticamente significativas, considerando a alta autocorrelação residual de lag ou retardo 1 nos resíduos simbolizada por $\rho$ (veja TABELA 3), formulou-se um modelo de regressão com ajuste otimizada de Cochrane-Orcutt (CO), denominado 'modelo 2'.

0 'modelo 2' partiu inicialmente de 5 variáveis estatisticamente significativas já evidenciadas pelos modelos anteriores e seu diagnóstico revelou ser teoricamente adequado aos propósitos da regressão (TABELA 3). Contudo, apresentou 4 observações classificadas como resíduos padronizados não usuais (RNU), conforme

Tabela 4.

Tabela 3 - Modelos construídos e suas características

\begin{tabular}{|c|c|c|c|c|c|c|}
\hline Modelo & Número de Variáveis & Variáveis Significativas & Tipo de Ajuste & R2 (\%) & $\rho$ & Adequado \\
\hline 0 & 17 & 2 & MQO & 66,48 & 0,87 & Não \\
\hline 1 & 6 & 6 & MQO & 66,75 & 0,86 & Não \\
\hline 2 & 5 & 5 & $\mathrm{CO}$ & 70,93 & 0,02 & Sim \\
\hline 3 & 5 & 5 & $\mathrm{CO}$ & 74,52 & 0,05 & Sim \\
\hline Referência & -- & Todas & -- & 100 & & \\
\hline
\end{tabular}

Finalmente, a partir do modelo de ajuste de Cochrane-Orcutt e das variáveis selecionadas no 'modelo 2', resolveu-se excluir do modelo as observações classificadas como resíduos não usuais. A retirada sucessiva destes pontos levou a outros modelos com pontos classificados desta forma até que, após a retirada de 13 pontos (dados), chegou-se a um modelo, chamado de 'modelo 3' que não apresentou nenhum resíduo não usual, conforme TABELA 4, última coluna.

Considerando a progressiva melhoria do grau de ajustamento $\left(\mathrm{R}^{2}\right)$ e do erro absoluto médio (MAE) exibidos na TABELA 4, o 'modelo 3', que é a representação de um conjunto de modelos buscados, foi o escolhido para a etapa de previsão ou validação. Na TABELA 3 e TABELA 4 foram colocados, na última linha, os valores de referência para a característica avaliada, quando existirem. Espera-se que o MAE seja o mais próximo possível de 0 .

Tabela 4 - Erro absoluto médio (MAE) e outras características dos modelos

\begin{tabular}{|c|c|c|c|c|}
\hline Modelo & MAE Estimativa & MAE Validação & $\mathrm{RNU}>3$ & Observações Excluídas \\
\hline 0 & 1,53 & 2,77 & 1 & 0 \\
\hline 1 & 1,57 & 2,53 & 1 & 0 \\
\hline 2 & 0,68 & 1,70 & 4 & 0 \\
\hline 3 & 0,60 & 1,39 & 0 & 13 \\
\hline Referência & 0 & 0 & 0 & -- \\
\hline
\end{tabular}

A equação (1) é a equação do modelo 3 que representa a dependência da variável dependente $\mathrm{P}$ em função de 5 variáveis independentes estatisticamente significativas

$$
\mathrm{P}=188,84-0,2576 \mathrm{~T} \_3-0,6214 \mathrm{~T} \_2(-1)-0,2365 \mathrm{~T} \_3(-1)-0,1220 \mathrm{~T} \_3(-3) \text {. }
$$


A FIGURA 1 exibe uma comparação dos erros absolutos dos modelos 1 a 3. A unidade de medida do eixo y é metros sobre o nível do mar.

FIGURA 1 - Comparação do erro absoluto dos modelos 1, 2 e 3 no período de estimativa

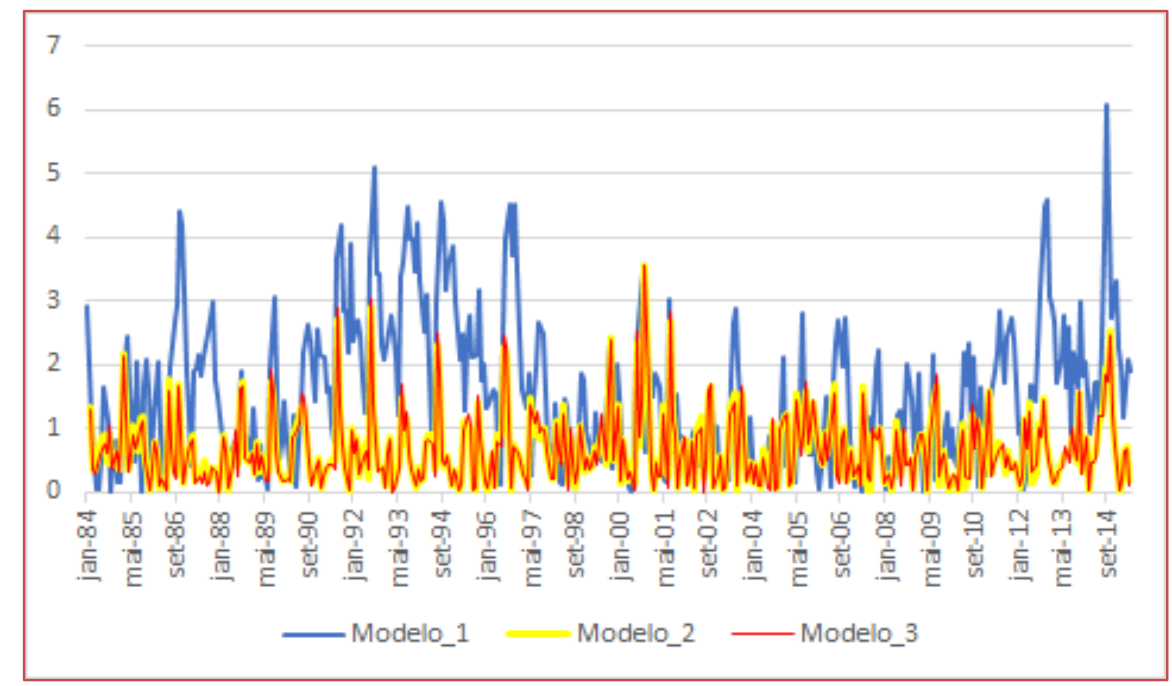

Na FIGURA 2 exibem-se os erros absolutos no período de validação dos 4 modelos, ou seja, a diferença (em módulo) do previsto pelo modelo e pelo observado pelo piezômetro. Na FIGURA 3 apresenta-se o erro absoluto percentual do modelo 3 , no período de validação.

FIGURA 2 - Comparação do MAE dos 4 modelos no período de validação

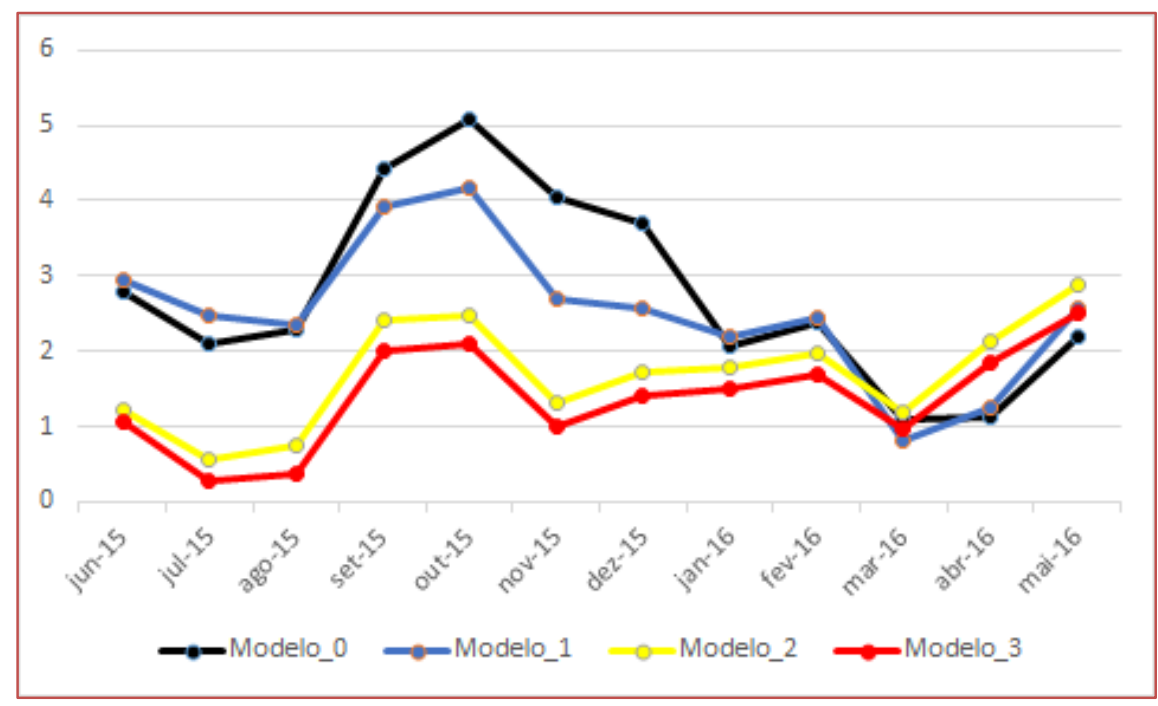


FIGURA 3 - Erro absoluto percentual do modelo 3 (melhor) no período de validação

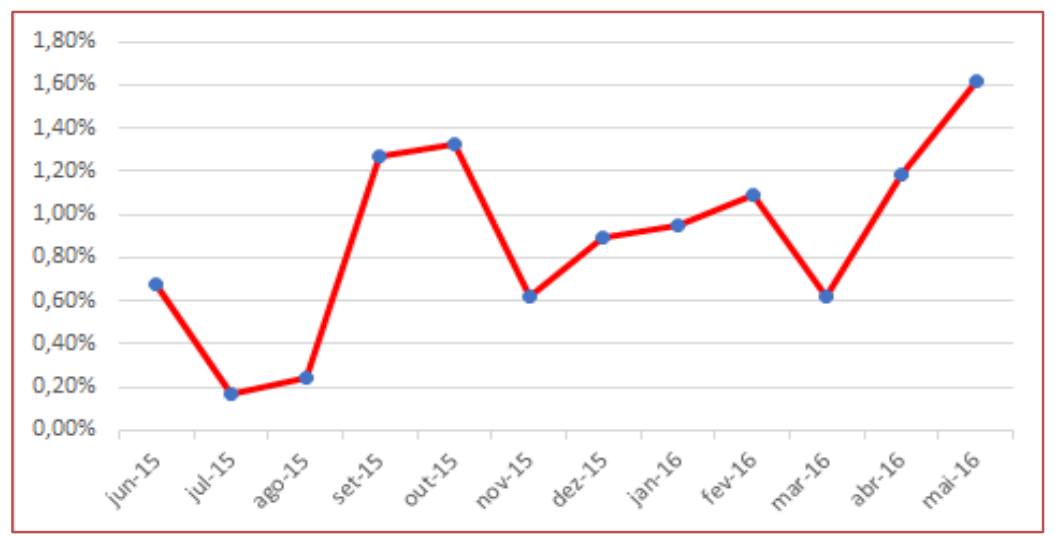

A FIGURA 4 exibe um comparativo entre os valores previstos pelo modelo 3 e os valores observados da variável dependente (piezômetro). Um modelo 'perfeito' implicaria que todos os pontos estariam sobre a reta do gráfico. Além disso, exibe (em vermelho) os pontos excluídos do modelo destacados na TABELA 4.

FIGURA 4 - Visualização dos valores observados (piezômetro) e previstos (modelo 3)

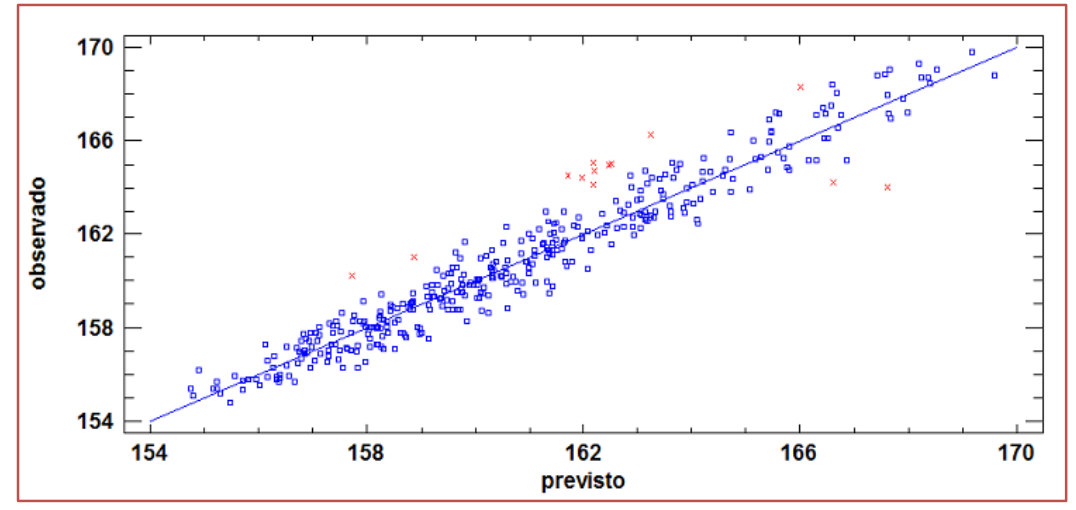

, apresentam-se os dados das previsões dos 4 modelos e do piezômetro no período de validação em que se observa graficamente o melhor desempenho do modelo 3.

FIGURA 5 - Comparação das medidas do piezômetro e dos modelos ajustados no período de validação

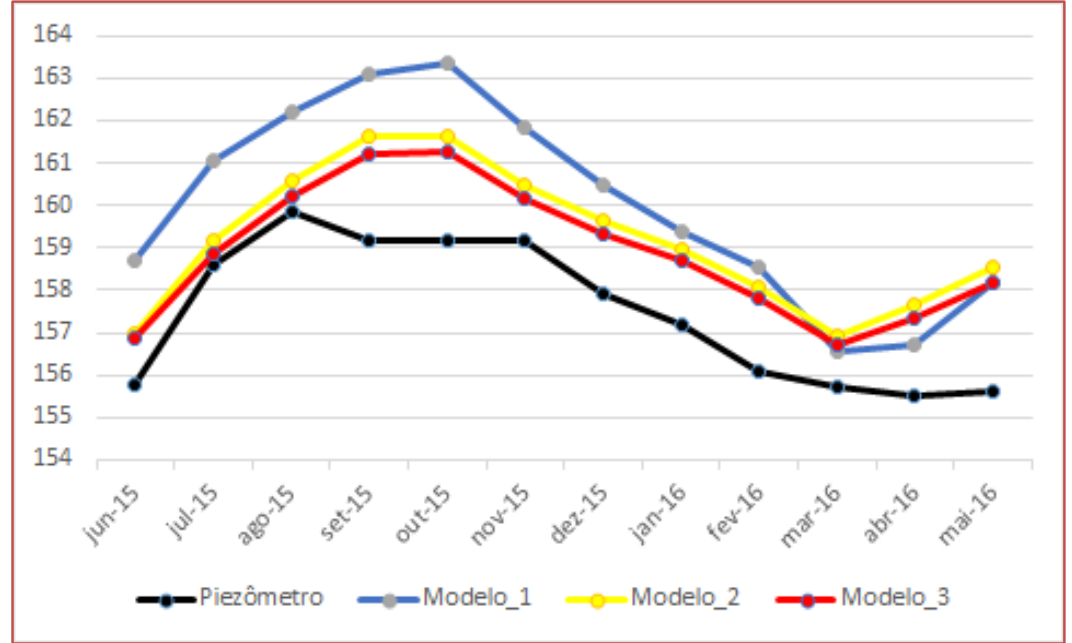




\section{CONSIDERAÇÕES FINAIS}

Este estudo buscava investigar a influência da temperatura ambiente sobre as medidas da leitura de um instrumento de monitoramento de barragem por meio de um modelo de regressão linear múltipla. 0 conhecimento empírico de equipes de engenheiros de segurança de barragem e a análise gráfica das séries temporais que monitoram a temperatura e determinados instrumentos embasam esta suposição.

É importante comprovar esta hipótese e, caso afirmativa, usar modelos de regressão múltipla usando dados da temperatura ambiente para fins de controle e previsão do comportamento da característica de engenharia monitorada por um certo instrumento.

Os resultados desta aplicação específica com dados de um piezômetro que monitora a barragem da usina hidrelétrica de Itaipu mostram que modelos de regressão linear múltipla podem colaborar na confirmação de que a temperatura ambiente é um fator fundamental para a avaliação da subpressão.

Em especial, dos 4 termômetros investigados, conforme a equação (1), observa-se que somente T_2 e T_3 são variáveis que influenciam o piezômetro e que a medida da temperatura em T_3 tem influência em diversos instantes de tempo para o piezômetro.

Além disso, pode ajudar a realizar previsões com elevado grau de precisão, com base na disponibilidade de novos dados de temperatura, do comportamento estatístico esperado da variável monitorada pelo instrumento. Estas previsões ajudam a controlar o comportamento daquela variável e podem indicar alguma anormalidade que deve ser investigada.

Outro aspecto destacável dos resultados é sobre as observações qualificadas como resíduos não usuais no modelo 3. Uma análise destes dados indicou que elas estavam relacionadas com medidas atípicas da temperatura. Em especial uma característica atípica da temperatura que acabava provocando previsões com maior de grau de erro era a ocorrência de maior frio em meses como maio ou agosto, ao invés de junho ou julho, o mais comum, analogamente para meses do verão. Este fato justifica a retirada destes dados no modelo 3 e a melhoria geral da qualidade de previsão observada neste modelo em relação aos demais.

Por fim, acredita-se que tais técnicas e resultados podem ser estendidos a outros instrumentos e outras barragens que sejam monitoradas. Servindo, portanto, como ferramenta adicional a análise de risco da barragem.

\section{REFERÊNCIAS}

[1] BRASILEIRO, A. M. M. Manual de produção de textos acadêmicos e científicos. São Paulo: Atlas, 2013.

[2] CIGB-ICOLD. 80 Years - Dams for human sustainable development. Paris: International Comission on Large Dams , 2008.

[3] COCHRANE, D.; ORCUTT, G. H. Application of Least Squares Regression to Relationships Containing AutoCorrelated Error Terms. Journal of the American Statistical Association., 44, n. 245, 1949. 32-61.

[4] GUJARATI, D. N.; PORTER, D. C. Econometria Básica. 5a. ed. Porto Alegre : AMGH, 2011.

[5] ITAIPU. Itaipu Binacional, 2020. Disponivel em: <https://www.itaipu.gov.br/energia/geracao>. Acesso em: 16 julho 2020.

[6] ITAIPU BINACIONAL. Síntese das Principais Informações de Projeto para o Controle da Instrumentação da Barragem Principal - Trechos E, F e I. Foz do Iguaçu. 1984.

[7] MONTGOMERY, D. C. Introdução ao controle estatístico de qualidade. 5ạ. ed. Rio de Janeiro: LTC, 2013.

[8] MONTGOMERY, D. C.; PECK, E. A.; VINNING, G. Introduction to linear regression analysis. 5 th. ed. Hoboken: John Wiley \& Sons, 2012.

[9] SILVEIRA, J. F. A. Instrumentação e comportamento de fundações de barragens de concreto. São Paulo: Oficina de Textos, 2003.

[10] XXIII ICOLD QUESTION 88. Hydropower current developments. Dams and Hydropower. Brasília: ICOLD International Comitee of Large Dams. 2009.

[11] XXIII ICOLD QUESTION 90. Upgrading of existing dam. Dams and Hydropower. Brasília: ICOLD - International Comitee of Large Dams. 2009. 


\section{Capítulo 16}

\section{Verificação da precisão nas medições realizadas por um medidor de distância a laser}

\section{Lucas Carvalho Martins}

Lucas Pereira Silveira

Hamma Carolina de Lima Nogueira

Bárbara Carolina Martins Teodoro

Resumo: A metrologia tem evoluído consideravelmente nos últimos anos e os instrumentos de medição estão cada vez mais ágeis e precisos. Um instrumento bastante utilizado é a trena a laser, que permite medições instantâneas das dimensões desejadas. Sendo assim, o presente estudo tem como objetivo verificar a precisão das medições realizadas pela trena a laser comparando-as com um padrão, a trena de fita de aço. Para efeito comparativo, realizou-se medições de 4 dimensões aproximadas sendo feitas 10 medições com a trena a laser e 10 medições com a trena convencional, para cada dimensão. Posteriormente, foi realizado o balanço de incerteza para as 8 médias encontradas e obteve-se resultados que extrapolaram o intervalo de medição do padrão escolhido, tornando as medições feitas pela trena a laser como não confiáveis. Sugere-se evitar a situação 2 que foi a fonte de incerteza que mais contribuiu percentualmente para a incerteza global do sistema de medição.

Palavras-chave: metrologia; trena a laser; precisão da medição; trena convencional; balanço de incertezas. 


\section{INTRODUÇÃO}

A medição, passou por muitas transformações e melhorias. Desde os primórdios, a necessidade de estimar quantidades levou a sociedade a adotar critérios para que o comércio interno pudesse fluir. Nesse cenário, os números foram as primeiras medições existentes e posteriormente surgiram as medições baseadas na anatomia humana (milha, cúbito, pé, passo, entre outros). Consequentemente, o desenvolvimento da tecnologia e comércio obrigou o processo de medição a ir além e com isso a metrologia começou a ser aprimorada.

O estudo da metrologia trouxe mudanças importantes para o mundo globalizado, como a padronização das unidades de medidas que foi fundamental para a implementação das transações comerciais regionais, nacionais e internacionais. A importância da metrologia vem crescendo exponencialmente nos últimos anos por trazer padronização, confiabilidade, credibilidade e qualidade às medidas e a consequência disso é um investimento dos países industrializados de $4 \%$ a $6 \%$ do PIB (Produto Interno Bruto) nos processos de medição (SILVA NETO, 2012).

Mas o que envolve a palavra metrologia? Segundo o VIM 2008 (Vocabulário Internacional de Metrologia), a metrologia é a ciência da medição e suas aplicações, estando presente tanto nos aspectos teóricos quanto práticos da medição e evidenciando a dispersão dos valores envolvidos (incerteza de medição).

Todo processo de medição envolve critérios a serem seguidos para que os erros possam ser minimizados e obter-se um resultado mais confiável. A seleção de um sistema de medição adequado a tarefa de medição é um desses critérios e a grande diversidade de sistemas de medição no panorama tecnológico atual, torna essa escolha uma tarefa não muito simples. A escolha de um sistema de medição inadequado pode gerar resultados com incerteza de medição que não atendam as necessidades exigidas (ALBERTAZZI, 2008).

Um instrumento de medição muito conhecido e utilizado atualmente é a trena. Ela possui escala em milímetros e polegada, pode ser feita de aço, tecido ou fibra e de diversos tamanhos (geralmente de $3 \mathrm{~m}$ a $50 \mathrm{~m}$ ), sendo montada em um estojo que a fita enrola e desenrola à medida que sua extremidade é puxada. Segundo Silva Neto (2012), a trena é utilizada em situações que não exigem muita exatidão, sejam peças pequenas ou grandes. Nos dias atuais, já existem trenas a laser que podem medir distâncias assim como a trena convencional, apenas apontando o laser para o ponto de referência.

Baseado neste contexto, o presente estudo apresenta como objetivo geral verificar a precisão das medições realizadas pela trena a laser comparando-as com um padrão, a trena de fita de aço. Como objetivos específicos, o experimento buscou realizar medições com o medidor de distância a laser em 4 dimensões diferentes, fazer o balanço de incertezas para as medidas encontradas e analisar a precisão da trena a laser comparando-a com um padrão.

\section{METROLOGIA INDUSTRIAL}

A metrologia pode ser conceituada como o domínio da ciência e da tecnologia que determina o processo de medição e suas respectivas incertezas, bem como todos os aspectos que podem influenciá-la, como sistema de medição, o operador, o ambiente, entre outros (GUEDES, 2011).

0 ato de medir é cotidiano do ser humano e é empregado para diferentes necessidades, desde as mais simples até as mais complexas. A metrologia é uma atividade que se ocupa de quantificar um fenômeno de forma segura. E medir, pode ser entendido, como os atos técnicos que buscam identificar valores para as grandezas físicas de determinado objeto de medição, chamado de mensurando, especificado em um padrão que seja válido internacionalmente (ALBERTAZZI, 2008; SILVA NETO, 2012; SANTANA, 2012).

\subsection{MEDIÇÕES DIRETAS E INDIRETAS}

Albertazzi classifica as medições em 2 tipos: medições diretas, que são aquelas que apenas um sistema de medição está envolvido e ele indica diretamente o valor do mensurando, por exemplo a medição da espessura de uma lâmina com o micrômetro ou a medição do diâmetro de uma peça com o paquímetro; já as medições indiretas, definem o valor do mensurando utilizando uma equação que relaciona duas ou mais medidas associadas a diferentes grandezas, por exemplo a determinação da área de um terreno retangular (multiplicando o comprimento pela largura) ou velocidade média de um carro (dividindo a distância pelo tempo) (ALBERTAZZI, 2008). 


\subsection{BALANÇO DE INCERTEZAS}

Para ser calculado o resultado de uma medição com várias fontes incertezas que contribuem de forma considerável no processo de medição, pode ser considerado o seguinte caminho (ALBERTAZZI, 2008):

a) Análise do processo de medição: compreender o processo de medição, os fenômenos envolvidos e fatores que podem influenciar cada elemento que afeta o resultado da medição - definição do mensurando, procedimento de medição, condições ambientais, operador e sistema de medição.

b) Identificação das fontes de incerteza: identificar as fontes de incerteza relevantes, atribuindo um símbolo e uma descrição de cada fonte. Na dúvida se a fonte de incerteza deve ou não ser incluída, é melhor incluí-la.

c) Quantificação dos efeitos sistemáticos: analisar a contribuição de cada fonte de incerteza para os efeitos sistemáticos - componente do erro de medição que permanece constante ou varia de maneira previsível - e aplicar a correção na unidade de medida do mensurando.

d) Quantificação dos efeitos aleatórios: analisar o procedimento de cada fonte de incerteza (tipo A ou tipo B), estimar a incerteza-padrão e os respectivos graus de liberdade. Caso a fonte de incerteza seja do tipo A, ou seja, um procedimento estatístico, a incerteza padrão pode ser estimada a partir do desvio-padrão ou quando a média de "m" medições é efetuada, utiliza-se a Equação (1). 0 número de graus de liberdade é sempre o número de medições para calcular o desvio padrão menos 1.

$$
u\left(I_{\text {média }}\right)=\frac{u(I)}{\sqrt{m}}
$$

onde, $u$ ( $\left.I_{m e ́ d i a}\right)$ é a incerteza-padrão média de “ $m$ " indicações, u (I) é a incerteza-padrão das indicações e $m$ é o número de medições repetidas usadas para calcular a média.

Quando não há dados suficientes e outras informações devem ser utilizadas para estimar os limites da distribuição de probabilidade, tem-se um procedimento não estatístico, ou seja, uma fonte de incerteza do tipo B. Neste caso, a distribuição pode ser normal, retangular, triangular ou do tipo "U” - conforme pode ser visto na Figura 1 - e a incerteza padrão deve ser calculada. Lembre-se, quando a distribuição é retangular, triangular ou do tipo "U”, o número de graus de liberdade é infinito.

Figura 1 - Distribuições de probabilidade e respectivas incertezas-padrão: (A) uniforme ou retangular, (B) triangular, (C) normal e (D) em "U"

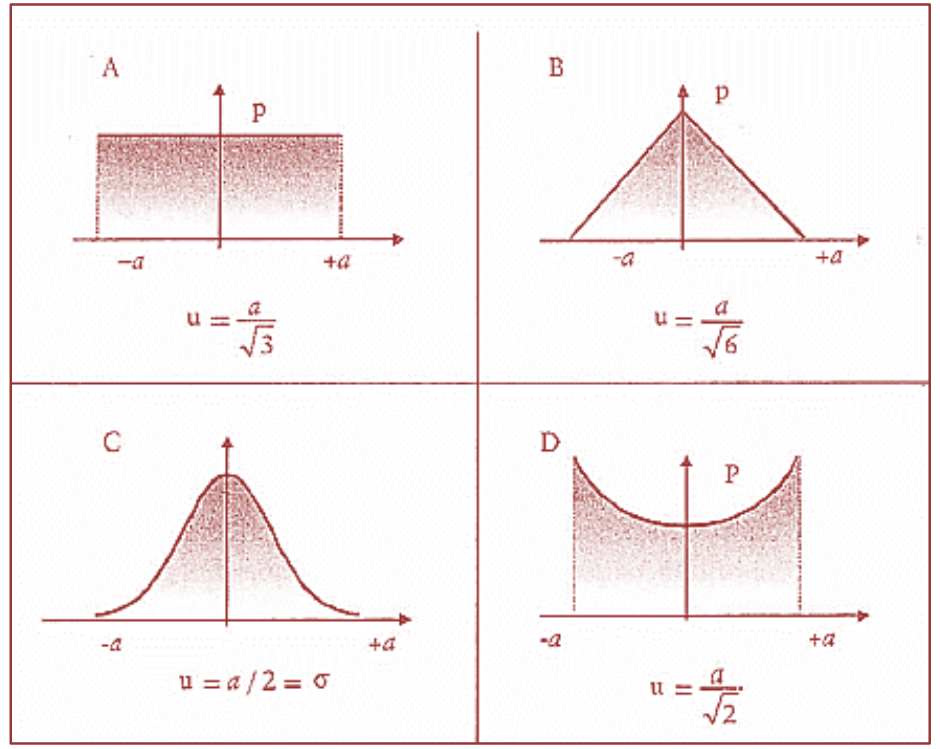


e) Cálculo da correção combinada: deve ser calculada a partir da soma algébrica das correções individuais de cada fonte de incerteza, conforme Equação (2):

$$
C_{C}=C_{1}+C_{2}+C_{3}+\cdots+C_{i}
$$

sendo $C_{C}$ a correção combinada e $C_{i}$ a correção da i-ésima fonte de incerteza.

f) Cálculo da incerteza combinada e do número de graus de liberdade efetivos: a incerteza combinada é calculada a partir da Equação (3) e os graus de liberdade efetivos pela Equação (4)

$$
u_{C}{ }^{2}=u_{1}{ }^{2}+u_{2}{ }^{2}+u_{3}{ }^{2}+\cdots+u_{i}{ }^{2}
$$

onde, $u_{C}$ é a incerteza combinada e $u_{i}$ é a incerteza-padrão da i-ésima fonte de incerteza.

Para calcular os graus de liberdade efetivo, utiliza-se os números de grau de liberdade e a incertezapadrão de cada fonte de incerteza pela equação de Welch-Satterthwaite.

$$
\frac{u_{C}^{4}}{v_{e f}}=\frac{u_{1}^{4}}{v_{1}}+\frac{u_{2}^{4}}{v_{2}}+\cdots+\frac{u_{i}^{4}}{v_{i}}
$$

onde, $u_{C}$ é a incerteza combinada, $v_{e f}$ é o número de graus de liberdade efetivo, $u_{i}$ é a incerteza-padrão da i-ésima fonte de incerteza e $v_{i}$ é o número de graus de liberdade da i-ésima fonte de incerteza.

g) Cálculo da incerteza expandida: a incerteza expandida é calculada pela Equação (5).

$$
U=t \cdot u_{c}
$$

onde, $U$ é a incerteza expandida do processo de medição, $t$ é o coeficiente de Student para 95,45\% de abrangência e a quantidade de graus de liberdade efetivos e $u_{C}$ é a incerteza combinada.

h) Expressão do resultado da medição: o resultado de medição é expresso pela Equação (6).

$$
R M=I_{\text {média }}+C_{C} \pm U
$$

sendo, $R M$ o resultado medido, $I_{\text {média }}$ é a media das indicações, $C_{C}$ é a correção combinada e $U$ é a

\begin{tabular}{|c|c|c|c|c|c|c|}
\hline \multicolumn{2}{|c|}{ Fontes de incertezas } & \multirow{2}{*}{$\begin{array}{c}\text { Efeitos sistemáticos } \\
\text { Correção }\end{array}$} & \multicolumn{4}{|c|}{ Efeitos aleatórios } \\
\hline Símbolo & Descrição & & $A$ & Distribuição & $\mathrm{u}$ & $\mathrm{N}$ \\
\hline $\mathrm{C}_{\mathrm{c}}$ & correção combinada & & & & & \\
\hline $\mathrm{u}_{\mathrm{c}}$ & incerteza combinada & & & Normal & & \\
\hline $\mathrm{U}$ & incerteza expandida & & & Normal & & \\
\hline
\end{tabular}
incerteza expandida.

As informações e cálculos realizados no balanço de incertezas são colocadas na Tabela 1 .

Tabela 1 - Tabela para organizar o balanço de incertezas

\begin{tabular}{|l|l|l|l|}
\hline \multicolumn{2}{|c|}{ Balanço de Incertezas } \\
\hline Processo de medição & & unidade: & $\mathrm{Mm}$ \\
\hline
\end{tabular}

Fonte: Albertazzi (2008) 


\section{MATERIAIS E MÉTODOS}

Como visto na Figura 2, foi usado para a coleta de dados uMa trena convencional marca Starret $t$ modelo KTS1-10ME-S, com as seguintes especificações técnicas:

- Graduação em milímetro e polegadas;

- $\quad$ Fita de aço de largura 25 mm e extensão 10 metros;

- $\quad$ Resolução de 0,001 m ou 1 mm;

- $\quad$ Erro máximo admissível, de acordo com a NBR 10123:1987 para trena de fita de aço com classe de exatidão II, é $\pm(0,3+0,2$ x valor do comprimento considerado). 0 valor do comprimento considerado é arredondado para cima para o próximo número inteiro em metros.

Figura 2 - Trena Starrett modelo KTS1-10ME-S, utilizada na medição

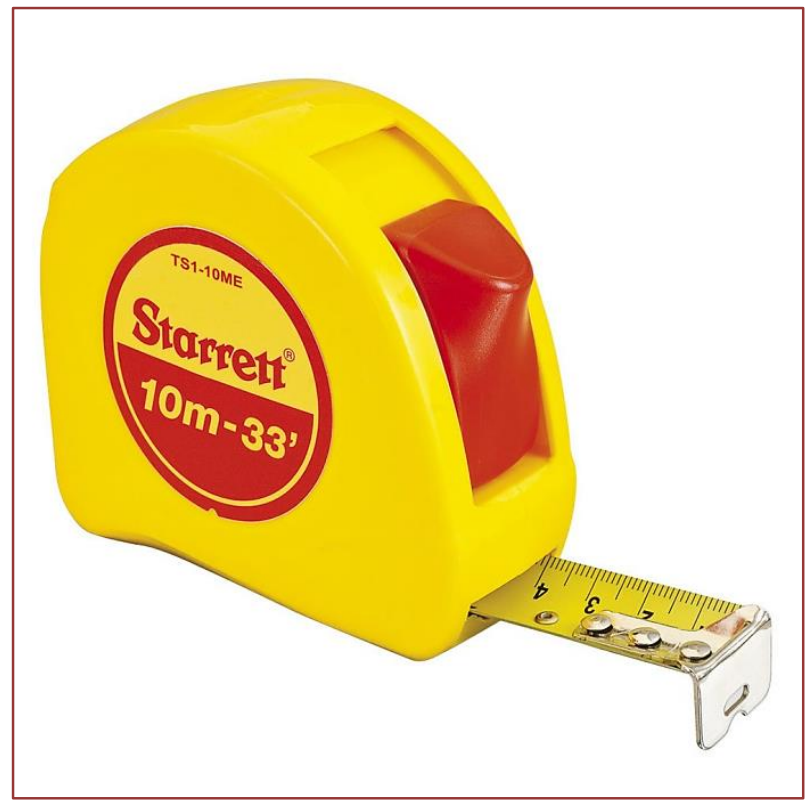

Fonte: LF Máquinas e Ferramentas (2019)

Outro instrumento utilizado foi um medidor de distância a laser da marca Bosch modelo GLM 30 professional e no 3601 K72 500, como visto na Figura 3. Algumas especificações técnicas são mostradas a seguir:

- $\quad$ Faixa de medição de 0,15 a 30 m;

- $\quad$ Resolução de 0,001 m ou $1 \mathrm{~mm}$;

- $\quad$ Precisão de medição de $\pm 2,00$ mm;

- $\quad$ Temperatura de funcionamento de $(-10 \mathrm{a}+45){ }^{\circ} \mathrm{C}$;

Situação 1: em caso de medição a partir do rebordo traseiro do instrumento de medição, válido para uma elevada capacidade de reflexão do destino (por exemplo, uma parede pintada de branco), fraca iluminação de fundo e temperatura de funcionamento de $25^{\circ} \mathrm{C}$. Ha ainda que contar com uma influência de $\pm 0,05$ $\mathrm{mm} / \mathrm{m}$.

Situação 2: Em caso de medição a partir do rebordo traseiro do instrumento de medição, válido para uma capacidade de reflexão do destino reduzida (por exemplo um cartão preto), forte iluminação de fundo e temperatura de funcionamento $-10^{\circ} \mathrm{C} \mathrm{a}+45^{\circ} \mathrm{C}$. Ha ainda que contar com uma influência de $\pm 0,15 \mathrm{~mm} / \mathrm{m}$. 
Figura 3 - Medidor de distância a laser Bosch modelo GLM 30 professional, utilizada na medição

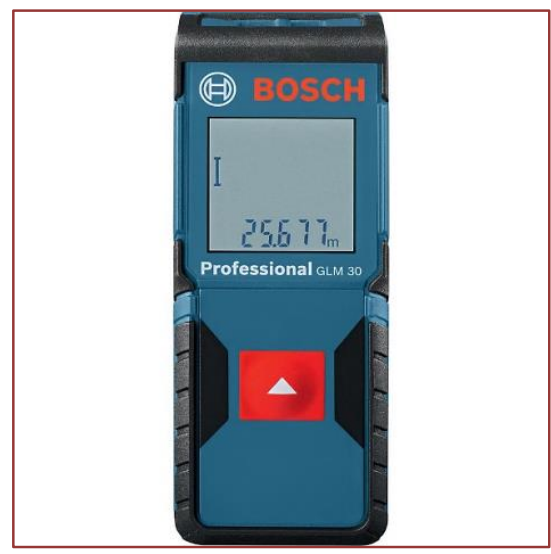

Fonte: Lojas Americanas (2019)

A coleta de dados foi realizada na Universidade Federal de Goiás (UFG) - Regional Catalão no período vespertino (mais precisamente entre as 15:30 e 17:30 horas). 0 procedimento foi feito por duas pessoas, no Laboratório de Automação da Engenharia de Produção, e enquanto uma realizava as medições a outra anotava os dados e vice-versa. Cada pessoa realizou 5 medições para cada instrumento de medição para as 4 dimensões escolhidas da sala do laboratório (D1, D2, D3 e D4), essa decisão foi tomada para minimizar o erro relacionado ao operador.

Alguns cuidados foram tomados para minimizar os erros: as dimensões D1, D2, D3 e D4 foram medidas com a trena no chão para minimizar o erro por interferência da catenária (barriga); o medidor de distância a laser foi apoiada em uma base para que o ângulo vertical ficasse perpendicular ao solo e também evitasse o erro relacionado a linearidade do instrumento de medição e o feixe de luz; o medidor de distância a laser apoiado na base elimina o erro relacionado à movimentação da pessoa.

\section{DESENVOLVIMENTO}

Nesta seção, serão desenvolvidos, os cálculos e análises do experimento de medição.

\subsection{COLETA DE DADOS}

Na Tabela 2 é apresentada os dados coletados pelo medidor de distância a laser para as 4 dimensões escolhidas com as suas respectivas médias e desvios-padrão e na Tabela 3 os dados coletados pela trena somente com as médias de cada dimensão.

Tabela 2 - 10 medições das dimensões D1, D2, D3 e D4 com a medidor de distância a laser e suas respectivas médias e desvios-padrão

\begin{tabular}{|c|c|c|c|c|}
\hline Medidor a laser & D1 $(\mathrm{mm})$ & D2 $(\mathrm{mm})$ & 14693 & 15601 \\
\hline Medida 1 & 4475 & 9163 & 14691 & 15599 \\
\hline Medida 2 & 4475 & 9164 & 14690 & 15599 \\
\hline Medida 3 & 4474 & 9162 & 14691 & 15600 \\
\hline Medida 4 & 4473 & 9161 & 14691 & 15599 \\
\hline Medida 5 & 4475 & 9165 & 14692 & 15601 \\
\hline Medida 6 & 4474 & 9158 & 14691 & 15601 \\
\hline Medida 7 & 4474 & 9158 & 14695 & 15601 \\
\hline Medida 8 & 4475 & 9158 & 14693 & 15602 \\
\hline Medida 9 & 4476 & 9157 & 14691 & 15601 \\
\hline Medida 10 & 4475 & 9159 & 14692,75000 & 15600,12500 \\
\hline Média & 4474,37500 & 9161,12500 & 1,47573 & 1,07497 \\
\hline Desvio-padrão & 0,84327 & 2,87711 & & \\
\hline
\end{tabular}


Tabela 3 - 10 medições das dimensões D1, D2, D3 e D4 com a trena e suas respectivas médias

\begin{tabular}{|c|c|c|c|c|}
\hline Trena & D1 (mm) & D2 (mm) & D3 (mm) & D4 (mm) \\
\hline Medida 1 & 4474 & 9158 & 14691 & 15600 \\
\hline Medida 2 & 4474 & 9160 & 14690 & 15600 \\
\hline Medida 3 & 4475 & 9159 & 14691 & 15599 \\
\hline Medida 4 & 4474 & 9159 & 14692 & 15600 \\
\hline Medida 5 & 4474 & 9158 & 14691 & 15600 \\
\hline Medida 6 & 4473 & 9157 & 14690 & 15600 \\
\hline Medida 7 & 4474 & 9158 & 14691 & 15600 \\
\hline Medida 8 & 4474 & 9158 & 14690 & 15599 \\
\hline Medida 9 & 4474 & 9157 & 14691 & 15600 \\
\hline Medida 10 & 4474 & 9158 & 14690 & 15600 \\
\hline Média & 4474,00000 & 9158,37500 & 14690,75000 & 15599,75000 \\
\hline
\end{tabular}

Fonte: Autoria própria (2019)

\subsection{BALANÇO DE INCERTEZAS PARA O MEDIDOR DE DISTÂNCIA A LASER}

Para realizar os cálculos do balanço de incertezas e chegar ao resultado da medição com o medidor de distância, foi utilizado o caminho mostrado no tópico 2.2 .

\subsubsection{ANÁLISE DO PROCESSO DE MEDIÇÃO}

Para o processo de medição, foram medidas as dimensões D1, D2, D3 e D4 com o medidor de distância a laser. A escolha das 4 dimensões foi feita buscando abranger grande parte da faixa de medição de instrumento e analisar o comportamento do erro conforme aumenta ou diminui a distância. Como já foi dito, realizou-se 10 medições com medidor de distância a laser e antes de começar, o instrumento foi colocado sob uma base de apoio. As medições foram realizadas no laboratório de automação da Universidade Federal de Goiás - Regional Catalão, com uma temperatura ambiente de $(27,5 \pm 1,0) \stackrel{\mathrm{o}}{\mathrm{C}}$ medido com um termo higrômetro digital de resolução $1,0 \stackrel{\circ}{ } \mathrm{C}$.

\subsubsection{IDENTIFICAÇÃO DAS FONTES DE INCERTEZA}

Para mostrar as fontes de incerteza identificadas durante o processo de medição, foi feito um diagrama de Ishikawa que está ilustrado na Figura 4.

Figura 4 - Diagrama de Ishikawa para as medições com o medidor de distância a laser

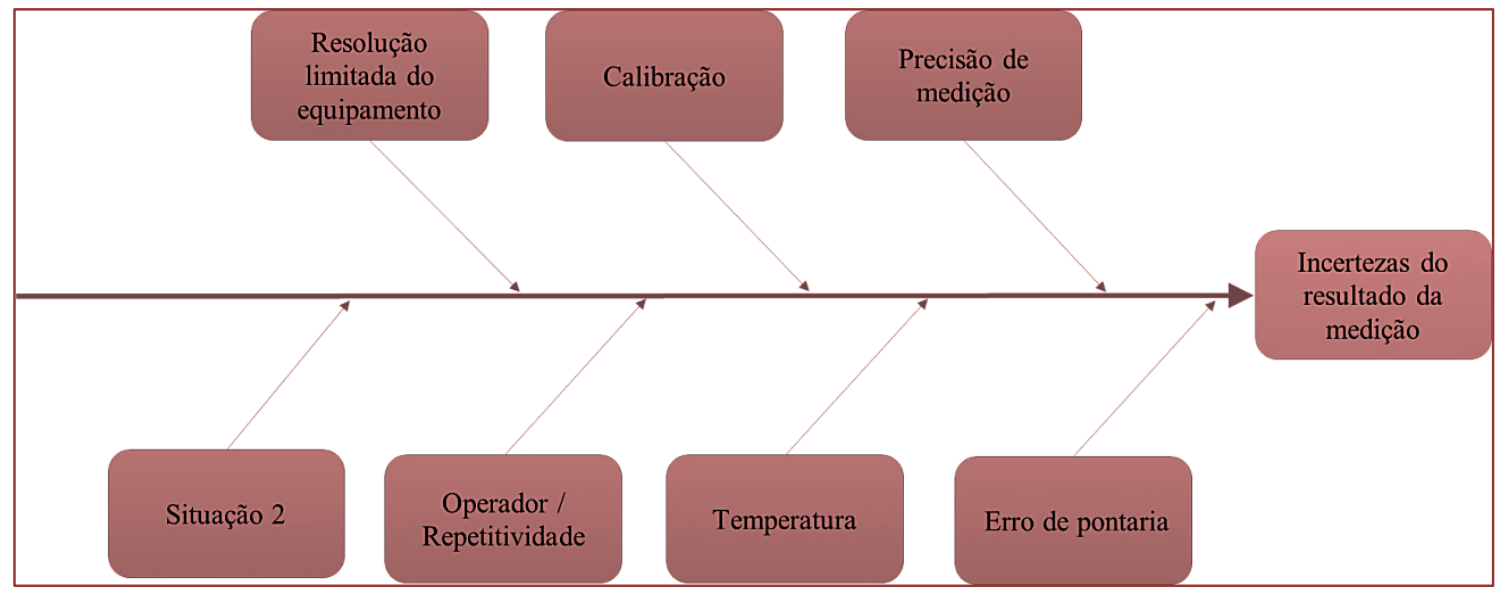

Fonte: Autoria própria (2019) 
Posteriormente, as incertezas associadas ao resultado da medição foram numeradas e associadas a um símbolo de identificação.

a) Erro de pontaria (E): ao realizar medições com o medidor de distância a laser, deve-se considerar o erro associado a precisão do operador em apontar o feixe luminoso na mesma direção que o instrumento de medição está posicionado. Como o medidor a laser foi colocado sob um apoio, diminui-se em grande escala o erro associado a pontaria e por isso essa fonte de incerteza não será considerada nos cálculos.

b) Operador/Repetitividade (Re): essa incerteza reflete nas indicações de medições repetidas não apresentarem sempre o mesmo valor. Quando é citado medições repetidas, implicitamente as influências do operador estão se manifestando, ou seja, considera-se que a influência do operador está embutida na própria repetitividade, podendo assim tratá-las juntas.

c) Temperatura (T): neste caso, como a especificação do instrumento de medição prevê uma temperatura de funcionamento de $(-10 \text { a }+45)^{\circ} \mathrm{C}$ e a temperatura no dia do procedimento está dentro dessa faixa, será desconsiderado a influência dessa fonte de incerteza.

d) Resolução limitada da trena a laser (R): a limitação da resolução de alguns equipamentos dificulta a medição do mensurando e reflete diretamente na incerteza da medição. As indicações poderiam conter mais casas decimais evitando o arredondamento para o número mais próximo, como não é possível saber se este arredondamento está sendo feito para cima ou para baixo, considera-se uma contribuição aleatório.

e) Calibração do equipamento de medição (C): de acordo com o certificado de calibração do equipamento é possível obter as correções da calibração (parcela sistemática) e a incerteza das calibrações (parcela aleatória).

f) Precisão da medição (P): o próprio instrumento de medição possui uma precisão relacionada a medição, porém como está sendo feito diversas medidas, a precisão utilizada será aquela relacionada a fonte de incerteza Re que considera todas as medições realizadas.

g) Situação 2 (S): em caso de medição a partir do rebordo traseiro do instrumento de medição, a capacidade de reflexão do destino é reduzida (neste caso, o destino possui coloração cinza dificultando a reflexão), forte iluminação de fundo e temperatura de funcionamento $-10{ }^{\circ} \mathrm{C}$ a +45 ${ }^{\circ} \mathrm{C}$, é considerada uma influência proporcional à distância medida. Como a influência pode ser positiva ou negativo, considera-se uma contribuição aleatória.

\subsubsection{QUANTIFICAÇÃO DOS EFEITOS SISTEMÁTICOS}

Apenas uma das fontes de incerteza citadas no tópico anterior possui componente sistemática: a calibração do equipamento de medição (C).

Para a fonte de incerteza C, foi obtida a correção de acordo com a faixa de medição pelo certificado de calibração. Foi exposto na Tabela 4 a faixa de medição e o valor da correção correspondente:

Tabela 4 - Valores da correção do certificado de calibração para as respectivas faixas de medição

\begin{tabular}{|c|c|}
\hline Faixa de medição & Valor da correção \\
\hline 0 a 2000 & $+0,1 \mathrm{~mm}$ \\
\hline 2000 a 5000 & $+0,15 \mathrm{~mm}$ \\
\hline 5000 a 10000 & $+0,18 \mathrm{~mm}$ \\
\hline 10000 a 20000 & $+0,2 \mathrm{~mm}$ \\
\hline 20000 a 30000 & $+0,5 \mathrm{~mm}$ \\
\hline
\end{tabular}

Fonte: Autoria própria (2019) 
Portanto, temos a correção para cada dimensão que foi medida exposta na Tabela 5.

Tabela 5 - Valores da correção do certificado de calibração para cada dimensão

\begin{tabular}{|c|c|}
\hline Dimensão & Correção C (mm) \\
\hline D1 & $+0,15$ \\
\hline D2 & $+0,18$ \\
\hline D3 & $+0,2$ \\
\hline D4 & $+0,2$ \\
\hline
\end{tabular}

Fonte: Fonte: Autoria própria (2019)

\subsubsection{QUANTIFICAÇÃO DOS EFEITOS ALEATÓRIOS}

As fontes de incerteza que possuem componente aleatória, são: Re, R, C, I e S.

A incerteza-padrão de Re para o medidor a laser pode ser estimada a partir da equação (1). Como já foi calculado o valor do desvio-padrão de cada dimensão e a informação do número de medições é conhecida, o resultado das incertezas-padrão de D1, D2, D3 e D4 são expostas na Tabela 6.

Tabela 6 - Valores das incertezas-padrão de Re das dimensões D1, D2, D3 e D4

\begin{tabular}{|c|c|}
\hline Dimensão & Incerteza-padrão Re (mm) \\
\hline D1 & $\pm 0,26667$ \\
\hline D2 & $\pm 0,90982$ \\
\hline D3 & $\pm 0,46667$ \\
\hline D4 & $\pm 0,33993$ \\
\hline
\end{tabular}

Fonte: Autoria própria (2019)

O número de graus de liberdade é igual ao número de medições menos um, portanto, $v_{r e}=9$ para todas as dimensões.

Para calcular a incerteza-padrão de R, ou seja, o erro devido ao arredondamento provocado pela resolução do equipamento, utiliza-se a propriedade de distribuição de probabilidades retangular devido a simetria da distribuição. A fórmula utilizada para calcular a incerteza-padrão, nesse caso, é dada pela figura 1 (A). Sabendo que $a=\frac{R}{2}$, onde $\mathrm{R}$ é a resolução do equipamento utilizado na medição, foi obtido o valor de $u_{R}=0,28868 \mathrm{~mm}$ para todas as dimensões. 0 número de graus de liberdade efetivo para todos é infinito. A Tabela 7 resume os dados apresentados anteriormente.

Tabela 7 - Valores das incertezas-padrão de R das dimensões D1, D2, D3 e D4

\begin{tabular}{|c|c|}
\hline \multicolumn{1}{|c|}{ Dimensão } & Incerteza-padrão R (mm) \\
\hline D1 & $\pm 0,28868$ \\
\hline D2 & $\pm 0,28868$ \\
\hline D3 & $\pm 0,28868$ \\
\hline D4 & $\pm 0,28868$ \\
\hline
\end{tabular}


A incerteza-padrão de C é obtida pelo certificado de calibração e varia de acordo com a faixa de medição do instrumento, conforme é mostrado na Tabela 8.

Tabela 8 - Valores da incerteza-padrão do certificado de calibração para as respectivas faixas de medição

\begin{tabular}{|c|c|}
\hline Faixa de medição & Valor da incerteza \\
\hline 0 a 2000 & $\pm 0,01 \mathrm{~mm}$ \\
\hline 2000 a 5000 & $\pm 0,015 \mathrm{~mm}$ \\
\hline 5000 a 10000 & $\pm 0,015 \mathrm{~mm}$ \\
\hline 10000 a 20000 & $\pm 0,02 \mathrm{~mm}$ \\
\hline 20000 a 30000 & $\pm 0,025 \mathrm{~mm}$ \\
\hline
\end{tabular}

Fonte: Fonte: Autoria própria (2019)

Portanto, a incerteza-padrão de C para cada dimensão que foi medida é apresentada na Tabela 9.

Tabela 9 - Valores da incerteza-padrão do certificado de calibração de cada dimensão

\begin{tabular}{|c|c|}
\hline Dimensão & Incerteza-padrão C (mm) \\
\hline D1 & $\pm 0,015$ \\
\hline D2 & $\pm 0,015$ \\
\hline D3 & $\pm 0,02$ \\
\hline D4 & $\pm 0,02$ \\
\hline
\end{tabular}

Fonte: Fonte: Autoria própria (2019)

A incerteza-padrão de S é de $\pm 0,15 \mathrm{~mm}$ por metro medido e como temos esta informação pelos dados de cada dimensão, foi feito o cálculo arredondado o número de metros sempre para cima por conveniência. 0 resultado dos cálculos foi exposto na Tabela 10.

Tabela 10 - Valores da incerteza-padrão I de cada dimensão

\begin{tabular}{|c|c|}
\hline Dimensão & Incerteza-padrão S (mm) \\
\hline D1 & $\pm 0,75$ \\
\hline D2 & $\pm 1,50$ \\
\hline D3 & $\pm 2,25$ \\
\hline D4 & $\pm 2,4$ \\
\hline
\end{tabular}

Fonte: Fonte: Autoria própria (2019)

\subsubsection{CÁlCULO DA CORREÇÃO COMBINADA}

A correção combinada é calculada a partir da Equação (2). Como cada dimensão possui apenas a correção do certificado de calibração, a correção combinada é o mesmo valor da correção C, ou seja, os mesmos dados expostos na Tabela 5 .

\subsubsection{CÁLCULO DA INCERTEZA COMBINADA E DO NÚMERO DE GRAUS DE LIBERDADE EFETIVOS}

A incerteza combinada que é o desvio-padrão da ação combinada das componentes aleatórias de todas as fontes de incerteza que afetam o processo, é calculada a partir da equação (3). Já para calcular o número de graus de liberdade efetivos, foi utilizada a equação (4). Na Tabela 11, estão expostos os valores das incertezas combinadas e dos números de graus de liberdade efetivos para cada dimensão. 
Tabela 11 - Incerteza combinada e graus de liberdade efetivos para cada dimensão

\begin{tabular}{|c|c|c|}
\hline Dimensão & Incerteza combinada & Graus de liberdade efetivos \\
\hline D1 & 0,84686 & 915 \\
\hline D2 & 1,77801 & 131 \\
\hline D3 & 2,31603 & 5459 \\
\hline D4 & 2,44117 & 23937 \\
\hline
\end{tabular}

Fonte: Autoria própria (2019)

\subsubsection{CÁLCULO DA INCERTEZA EXPANDIDA}

Para o cálculo da incerteza expandida foi utilizada a Equação (5) e considerado o arredondamento para 2 algarismos significativos. Os resultados foram expostos na Tabela 12.

Tabela 12 - Incerteza expandida e incerteza expandida arredondada com 2 algarismos significativos para as dimensões D1, D2, D3 e D4

\begin{tabular}{|c|c|c|}
\hline Dimensão & Incerteza expandida & Incerteza expandida arredondada \\
\hline D1 & $\pm 1,69716$ & $\pm 1,7$ \\
\hline D2 & $\pm 3,59166$ & $\pm 3,6$ \\
\hline D3 & $\pm 4,63557$ & $\pm 4,6$ \\
\hline D4 & $\pm 4,88233$ & $\pm 4,9$ \\
\hline
\end{tabular}

Fonte: Autoria própria (2019)

\subsubsection{EXPRESSÃO DOS RESULTADOS}

O passo a passo foi realizado para a determinação da medida das dimensões D1, D2, D3 e D4 com o medidor de distância a laser de resolução $1 \mathrm{~mm}$. Neste tópico, apresenta-se um resumo de tudo o que foi feito nos tópicos 4.2.1 a 4.2.7 por meio do balanço das incertezas (Tabela 13,14, 15 e 16).

Tabela 13 - Balanço de incertezas para a medição da distância D1 com uma trena a laser de resolução 1 $\mathrm{mm}$

\begin{tabular}{|c|c|c|c|}
\hline \multicolumn{2}{|c|}{ Balanço de Incertezas } \\
\hline $\begin{array}{c}\text { Processo de } \\
\text { medição }\end{array}$ & Medição da distância D1 com uma trena a laser de resolução $1 \mathrm{~mm}$. & unidade: & mm \\
\hline
\end{tabular}

\begin{tabular}{|c|c|c|c|c|c|c|}
\hline \multicolumn{2}{|c|}{ Fontes de incertezas } & \multirow{2}{*}{$\begin{array}{c}\text { Efeitos sistemáticos } \\
\text { Correção }\end{array}$} & \multicolumn{4}{|c|}{ Efeitos aleatórios } \\
\hline Símbolo & Descrição & & $A$ & Distribuição & $\mathrm{U}$ & $\mathrm{N}$ \\
\hline E & Erro de pontaria & - & & & & \\
\hline $\operatorname{Re}$ & Operador/Repetitividade & - & & Normal & 0,26667 & 9 \\
\hline $\mathrm{T}$ & Temperatura & - & & & & \\
\hline RL & $\begin{array}{l}\text { Resolução limitada da } \\
\text { trena a laser }\end{array}$ & - & 0,5 & Retangular & 0,28868 & $\infty$ \\
\hline $\mathrm{C}$ & $\begin{array}{l}\text { Calibração do } \\
\text { equipamento de medição }\end{array}$ & 0,15 & 0,03 & Normal & 0,015 & $\infty$ \\
\hline$P$ & Precisão de medição & - & & & & \\
\hline$S$ & Situação 2 & - & 0,15 & Retangular & 0,75 & $\infty$ \\
\hline $\mathbf{C}_{\mathrm{c}}$ & correção combinada & 0,15 & & & & \\
\hline $\mathbf{u}_{\mathbf{c}}$ & incerteza combinada & & & Normal & 0,84686 & 10 \\
\hline $\mathbf{U}$ & incerteza expandida & & & Normal & 1,69716 & \\
\hline
\end{tabular}

Fonte: Fonte: Autoria própria (2019) 
0 resultado da medição da distância D1 com a trena a laser de resolução $1 \mathrm{~mm}$ foi obtido a partir da Equação (6):

$$
\begin{gathered}
R M=I_{\text {média }}+C_{c} \pm U \\
R M=(4474,8 \pm 1,7) \mathrm{mm}
\end{gathered}
$$

Tabela 14 - Balanço de incertezas para a medição da distância D2 com uma trena a laser de resolução 1 $\mathrm{mm}$

\begin{tabular}{|c|c|c|c|c|c|c|}
\hline \multicolumn{2}{|r|}{ Fontes de incertezas } & \multirow{2}{*}{$\begin{array}{c}\text { Efeitos } \\
\text { sistemáticos } \\
\text { Correção }\end{array}$} & \multicolumn{4}{|c|}{ Efeitos aleatórios } \\
\hline Símbolo & Descrição & & $A$ & Distribuição & $\mathrm{U}$ & N \\
\hline $\mathrm{E}$ & Erro de pontaria & - & & & & \\
\hline $\operatorname{Re}$ & Operador/Repetitividade & - & & Normal & 0,90982 & 9 \\
\hline $\mathrm{T}$ & Temperatura & - & & & & \\
\hline RL & $\begin{array}{l}\text { Resolução limitada da } \\
\text { trena a laser }\end{array}$ & - & 0,5 & Retangular & 0,28868 & $\infty$ \\
\hline $\mathrm{C}$ & $\begin{array}{l}\text { Calibração do } \\
\text { equipamento de medição }\end{array}$ & 0,18 & 0,03 & Normal & 0,015 & $\infty$ \\
\hline$P$ & Precisão de medição & - & & & & \\
\hline $\mathrm{S}$ & Situação 2 & - & 0,15 & Retangular & 1,50 & $\infty$ \\
\hline $\mathbf{C}_{\mathbf{c}}$ & correção combinada & 0,18 & & & & \\
\hline $\mathbf{u}_{\mathbf{c}}$ & incerteza combinada & & & Normal & 1,77801 & 10 \\
\hline $\mathbf{U}$ & incerteza expandida & & & Normal & 3,59166 & \\
\hline
\end{tabular}

\begin{tabular}{|l|l|l|l|}
\multicolumn{5}{c|}{ Balanço de Incertezas } \\
\hline $\begin{array}{l}\text { Processo } \\
\text { medição }\end{array}$ & $\begin{array}{l}\text { Medição da distância D2 com uma trena a laser de } \\
\text { resolução } 1 \mathrm{~mm} .\end{array}$ & unidade: & mm \\
\hline
\end{tabular}

Fonte: os autores. 
O resultado da medição da distância D2 com a trena a laser de resolução $1 \mathrm{~mm}$ foi obtido a partir da Equação (6):

$$
\begin{gathered}
R M=I_{\text {média }}+C_{c} \pm U \\
R M=(9161,3 \pm 3,6) \mathrm{mm}
\end{gathered}
$$

Tabela 15 - Balanço de incertezas para a medição da distância D3 com uma trena a laser de resolução 1 $\mathrm{mm}$

\begin{tabular}{|c|c|c|c|c|c|c|}
\hline \multicolumn{2}{|c|}{ Fontes de incertezas } & \multirow{2}{*}{$\begin{array}{c}\text { Efeitos } \\
\text { sistemático } \\
\text { Correção }\end{array}$} & \multirow[b]{2}{*}{$A$} & \multicolumn{2}{|c|}{ Efeitos aleatórios } & \multirow[b]{2}{*}{$v$} \\
\hline Símbolo & Descrição & & & Distribuição & $\mathrm{U}$ & \\
\hline $\mathrm{E}$ & Erro de pontaria & - & & & & \\
\hline $\operatorname{Re}$ & Operador/Repetitividade & - & & Normal & 0,46667 & 9 \\
\hline $\mathrm{T}$ & Temperatura & - & & & & \\
\hline RL & $\begin{array}{l}\text { Resolução limitada da } \\
\text { trena a laser }\end{array}$ & - & 0,5 & Retangular & 0,28868 & $\infty$ \\
\hline C & $\begin{array}{l}\text { Calibração do } \\
\text { equipamento de medição }\end{array}$ & 0,20 & 0,04 & Normal & 0,02 & $\infty$ \\
\hline $\mathrm{P}$ & Precisão de medição & - & & & & \\
\hline $\mathrm{S}$ & Situação 2 & - & 0,15 & Retangular & 2,25 & $\infty$ \\
\hline $\mathbf{C}_{\mathbf{c}}$ & correção combinada & 0,20 & & & & \\
\hline $\mathbf{u}_{\mathbf{c}}$ & incerteza combinada & & & Normal & 2,31603 & 10 \\
\hline $\mathbf{U}$ & incerteza expandida & & & Normal & 4,63557 & \\
\hline
\end{tabular}

\begin{tabular}{|c|c|c|c|}
\multicolumn{2}{|c|}{ Balanço de Incertezas } \\
\hline $\begin{array}{c}\text { Processo de } \\
\text { medição }\end{array}$ & Medição da distância D3 com uma trena a laser de & unidade: & mm \\
\hline
\end{tabular}

0 resultado da medição da distância D3 com a trena a laser de resolução $1 \mathrm{~mm}$ foi obtido a partir da Equação (6):

$$
\begin{gathered}
R M=I_{\text {média }}+C_{c} \pm U \\
R M=(14692,0 \pm 4,6) \mathrm{mm}
\end{gathered}
$$


Tabela 16 - Balanço de incertezas para a medição da distância D4 com uma trena a laser de resolução 1 $\mathrm{mm}$

\begin{tabular}{|l|l|l|l|}
\hline \multicolumn{2}{|c|}{ Balanço de Incertezas } & & \\
\hline Processo de medição & Medição da distância D4 com uma trena a laser de resolução 1 mm. & unidade: & mm \\
\hline
\end{tabular}

\begin{tabular}{|c|c|c|c|c|c|c|}
\hline \multicolumn{2}{|r|}{ Fontes de incertezas } & \multirow{2}{*}{$\begin{array}{c}\text { Efeitos sistemáticos } \\
\text { Correção }\end{array}$} & \multicolumn{4}{|c|}{ Efeitos aleatórios } \\
\hline Símbolo & Descrição & & $A$ & Distribuição & $\mathrm{u}$ & $\mathrm{N}$ \\
\hline E & Erro de pontaria & - & & & & \\
\hline $\operatorname{Re}$ & Operador/Repetitividade & - & & Normal & 0,33993 & 9 \\
\hline $\mathrm{T}$ & Temperatura & - & & & & \\
\hline RL & Resolução limitada da trena a laser & - & 0,5 & Retangular & 0,28868 & $\infty$ \\
\hline $\mathrm{C}$ & Calibração do equipamento de medição & 0,20 & 0,04 & Normal & 0,02 & $\infty$ \\
\hline $\mathrm{P}$ & Precisão de medição & - & & & & \\
\hline S & Situação 2 & - & 0,15 & Retangular & 2,40 & $\infty$ \\
\hline $\mathbf{C}_{\mathrm{c}}$ & correção combinada & 0,20 & & & & \\
\hline $\mathbf{u}_{\mathbf{c}}$ & incerteza combinada & & & Normal & 2,44117 & 10 \\
\hline $\mathbf{U}$ & incerteza expandida & & & Normal & 4,88233 & \\
\hline
\end{tabular}

Fonte: Fonte: Autoria própria (2019)

O resultado da medição da distância D4 com a trena a laser de resolução $1 \mathrm{~mm}$ foi obtido a partir da Equação (6):

$$
\begin{gathered}
R M=I_{\text {média }}+C_{c} \pm U \\
R M=(15600,6 \pm 4,9) \mathrm{mm}
\end{gathered}
$$

\subsubsection{CONTRIBUIÇÃO PERCENTUAL DAS INCERTEZAS-PADRÃO}

A seguir, são apresentadas 4 tabelas (Tabela 17, 18, 19 e 20) que mostram a contribuição percentual de cada incerteza-padrão na incerteza global de cada dimensão medida.

Tabela 17 - Contribuição percentual das incertezas na medição da dimensão D1.

\begin{tabular}{|c|c|}
\hline Incertezas de D1 & \% de contribuição \\
\hline Incerteza Re & 9,92 \\
\hline Incerteza R & 11,62 \\
\hline Incerteza C & 0,03 \\
\hline Incerteza S & 78,43 \\
\hline
\end{tabular}

Fonte: Autoria própria (2019) 
Tabela 18 - Contribuição percentual das incertezas na medição da dimensão D2

\begin{tabular}{|c|c|}
\hline Incerteza de D2 & \% de contribuição \\
\hline Incerteza Re & 26,18 \\
\hline Incerteza R & 2,64 \\
\hline Incerteza C & 0,01 \\
\hline Incerteza S & 71,17 \\
\hline
\end{tabular}

Fonte: Autoria própria (2019)

Tabela 19 - Contribuição percentual das incertezas na medição da dimensão D3

\begin{tabular}{|c|c|}
\hline Incerteza de D3 & \% de contribuição \\
\hline Incerteza Re & 4,06 \\
\hline Incerteza R & 1,55 \\
\hline Incerteza C & 0,01 \\
\hline Incerteza S & 94,38 \\
\hline
\end{tabular}

Fonte: Autoria própria (2019)

Tabela 20 - Contribuição percentual das incertezas na medição da dimensão D4

\begin{tabular}{|c|c|}
\hline Incerteza de D4 & \% de contribuição \\
\hline Incerteza Re & 1,94 \\
\hline Incerteza R & 1,40 \\
\hline Incerteza C & 0,01 \\
\hline Incerteza S & 96,66 \\
\hline
\end{tabular}

Fonte: Autoria própria (2019)

\subsubsection{MEDIÇÃO COM A TRENA DE FITA DE AÇO}

Como obtive-se os resultados da medição com a trena a laser, agora é necessário estipular o intervalo de medição do instrumento padrão que será comparado, neste caso a trena de fita de aço da marca Starrett.

Segundo a ABNT NBR 10123:1987 o erro admissível para trena de fita de aço com classe de exatidão II é calculado pela Equação (7):

$$
\text { Erro admissível }= \pm(0,3+0,2 \times \mathrm{L}) \mathrm{mm}
$$

Onde, $L$ é o valor do comprimento considerado, que é arredondado para cima para o próximo número inteiro em metros.

Portanto, como o valor em metros pode ser obtido pela Tabela 3, os valores para os erros admissíveis de D1, D2, D3 e D4 foram expostos na Tabela 21. 
Tabela 21 - Erro admissível para D1, D2, D3 e D4 na medição com trena de fita de aço.

\begin{tabular}{|c|c|c|}
\hline Dimensão & Valor do comprimento - L (m) & Erro admissível (mm) \\
\hline D1 & 5 & 1,3 \\
\hline D2 & 10 & 2,3 \\
\hline D3 & 15 & 3,3 \\
\hline D4 & 16 & 3,5 \\
\hline \multicolumn{2}{|c|}{ Fonte: Autoria própria (2019) } \\
\hline
\end{tabular}

Após o cálculo do erro admissível da trena de fita de aço, foi encontrado o intervalo de medição que compreende cada distância e os dados são mostrados na Tabela 22.

Tabela 22 - Intervalo de medição para D1, D2, D3 e D4 na medição com trena de fita de aço

\begin{tabular}{|c|c|c|c|c|}
\hline Dimensão & Média (mm) & Erro admissível (mm) & Limite inferior (mm) & Limite Superior (mm) \\
\hline D1 & 4474,00000 & 1,3 & 4472,70000 & 4475,30000 \\
\hline D2 & 9158,37500 & 2,3 & 9156,07500 & 9160,67500 \\
\hline D3 & 14690,75000 & 3,3 & 14687,45000 & 14694,05000 \\
\hline D4 & 15599,75000 & 3,5 & 15596,25000 & 15603,25000 \\
\hline
\end{tabular}

Fonte: Autoria própria (2019)

\section{COMPARAÇÃO DOS RESULTADOS}

Depois de feito os balanços de incerteza para a trena a laser e calculado o intervalo de medição para a trena de fita de aço, é o momento de comparar os dois e verificar a precisão das medidas encontradas. Na Tabela 23 é apresentado o intervalo de medição para os resultados encontrados para a trena a laser.

Tabela 23 - Intervalo de medição para D1, D2, D3 e D4 na medição com trena a laser

\begin{tabular}{|c|c|c|c|}
\hline Dimensão & Resultado medido (mm) & Limite inferior (mm) & Limite Superior (mm) \\
\hline D1 & $4474,8 \pm 1,7$ & 4473,10000 & 4476,50000 \\
\hline D2 & $9161,3 \pm 3,6$ & 9157,70000 & 9164,90000 \\
\hline D3 & $14692,0 \pm 4,6$ & 14687,40000 & 14696,60000 \\
\hline D4 & $15600,6 \pm 4,9$ & 15595,70000 & 15605,50000 \\
\hline
\end{tabular}

Fonte: Autoria própria (2019)

Quando comparado a tabela 18 com a Tabela 19 (padrão), percebe-se que o limite superior de D1 pode ser extrapolado, o limite superior de D2 pode ser extrapolado, o limite inferior e superior de D3 pode ser extrapolado e o limite inferior e superior de D4 pode ser extrapolado.

Ao confrontar os dados coletados pela trena a laser (Tabela 2) com o intervalo padrão (Tabela 22), os valores com preenchimento de fundo destacados na tabela 24 mostraram-se fora do intervalo padrão. 
Tabela 24 - Valores da medição com a trena a laser destacando as medidas fora do intervalo padrão

\begin{tabular}{|c|c|c|c|c|}
\hline Medidor a laser & D1 (mm) & D2 (mm) & D3 (mm) & $\mathrm{D} 4(\mathrm{~mm})$ \\
\hline Medida 1 & 4475 & 9163 & 14693 & 15601 \\
\hline Medida 2 & 4475 & 9164 & 14691 & 15599 \\
\hline Medida 3 & 4474 & 9162 & 14690 & 15599 \\
\hline Medida 4 & 4473 & 9161 & 14691 & 15600 \\
\hline Medida 5 & 4475 & 9165 & 14691 & 15599 \\
\hline Medida 6 & 4474 & 9158 & 14692 & 15601 \\
\hline Medida 7 & 4474 & 9158 & 14691 & 15601 \\
\hline Medida 8 & 4475 & 9158 & 14695 & 15601 \\
\hline Medida 9 & 4476 & 9157 & 14693 & 15602 \\
\hline Medida 10 & 4475 & 9159 & 14691 & 15601 \\
\hline
\end{tabular}

Fonte: Autoria própria (2019)

\section{CONCLUSÃO}

Neste trabalho, observa-se que o objetivo geral e os objetivos específicos foram atingidos e obteve-se um aprendizado maior com relação aos instrumentos de medição citados.

Percebe-se que os resultados obtidos com a trena a laser através do balanço de incertezas, extrapolaram o intervalo de medição da trena de fita de aço que foi denominada como padrão. Portanto, vê se que a trena a laser ainda não apresenta medições confiáveis.

Para que haja uma melhora nas medições realizadas pela trena a laser, sugere-se evitar a situação 2 (mostrada no tópico 3) já que a sua incerteza foi a que mais contribuiu percentualmente para a incerteza global do sistema de medição das dimensões D1, D2, D3 e D4.

\section{REFERÊNCIA}

[1]. Albertazzi, Armando. Sousa, André R. de. Fundamentos de metrologia e industrial. Barueri, SP: Manole, 2008.

[2]. ASSOCIAÇÃO BRASILEIRA DE NORMAS TÉCNICAS. NBR 10123:1987 Trena de fita de aço. Rio de Janeiro, 2004.

[3]. GUEDES, P. Metrologia Industrial. - Portugal: Etep: 2011

[4]. INMETRO. Vocabulário Internacional de Metrologia: Conceitos fundamentais e gerais e termos associados (VIM 2008). Rio de Janeiro: INMETRO, 2009.

[5]. Medidor de Distância a Laser. Lojas Americanas, 2019. Disponível em: < https://www.americanas.com.br/produto/45154005/trena-20m-laser-glm20-bosch>. Acesso em: junho, 2019.

[6]. NETO, João Cirilo da Silva. Metrologia e controle dimensional: conceitos, normas e aplicações. Rio de Janeiro: Campus/Elsiever, 2012.

[7]. Trena Manual. LF Máquinas e Ferramentas, 2019. Disponível em: <https://www.lfmaquinaseferramentas.com.br/trena-starret-10-

metros/p?idsku=43171\&gclid=CjwKCAjwtuLrBRAlEiwAPVcZBm3gD5tVWeb8LfHzeAWk_szN12nvTN2pIxlTGS5_Zdce F2kX751apBoCJgUQAvD_BwE>. Acesso em: junho, 2019. 


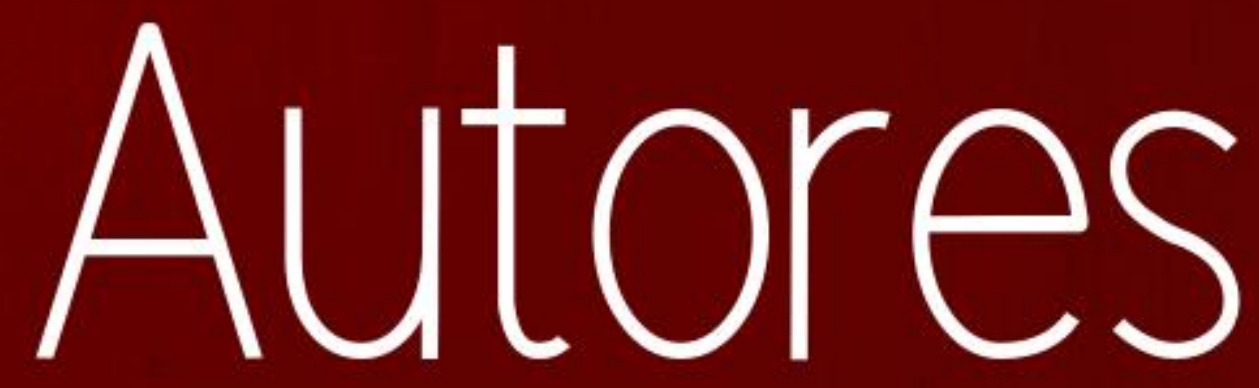




\section{RAFAEL ALVES PEDROSA (ORGANIZADOR)}

Consultor de Gestão com enfoque em Logística Portuária e de Transportes, com graduação em Administração, Comércio Exterior, Logística e Transporte Multimodal e Gestão Portuária; Pós Graduação em Gestão de Comércio Exterior e Logística; Gestão Empresarial; Gestão, Docência e Tecnologias do Ensino Superior; MBA em Docência do Ensino Superior pela Fundação Getúlio Vargas - FGV; Mestre em Sustentabilidade de Sistemas Costeiros com dissertação voltada a Dragagem de Aprofundamento do Porto de Santos/SP; Doutorado em Planejamento e Gestão pela Universidade Federal do $\mathrm{ABC}$ (UFABC) com tese voltada ao impactos da expansão portuária do Porto de Santos na integração porto/cidade. Autor e organizador de livros e capítulos de livros relacionados a sua área de atuação. Coordenador de projetos de pesquisa e revisor de periódicos ligados as áreas de Logística e Comércio Exterior e planejamento territorial e urbano. Professor conteudista de cursos superiores em EaD. Possui cursos de atualização nas áreas de Administração, Logística e Comércio Exterior, fez intercâmbio na Argentina adquirindo fluência no idioma Espanhol, além de participar constantemente de fóruns destinados a estas áreas. Coordenador do curso de pós graduação em Gestão Portuária e Operações Internacionais. Com experiências na coordenação de Logística e transportes em empresas multinacionais sendo responsável pelo planejamento de distribuição e Logística das regiões Sul e Sudeste do país. Tendo sido contemplado com o prêmio de Melhor ideia inovadora 2010 . Atuou ainda no papel de Coordenador de Operações Portuárias. Já na docência foi contemplado com o prêmio Mérito Docente por atuação acadêmica destacada e foi contemplado com o prêmio Dr. Milton Teixeira pela orientação do melhor trabalho de iniciação cientifica.

\section{ADRIANO DINOMAR BARP}

Possui graduação em Ciências Contábeis pela Universidade do Vale do Itajaí - UNIVALI (2009), Pós-graduação em gestão do Terceiro Setor pela Faculdade Anita Garibaldi (2010). Mestrado em Ciências Contábeis na Universidade Regional de Blumenau - FURB (2012). Atualmente é Coordenador dos cursos de MBA em Contabilidade Financeira e Gerencial; Gestão Tributária e Perícia Contábil e Trabalhista na Universidade do Vale do Itajaí Campus KOBRASOL; Coordenador do Curso MBA em Administração Financeira e Controladoria na Universidade do Vale do Itajaí Campus Tijucas; professor da Universidade do Vale do Itajai - UNIVALI - Campus Biguaçu, ministrando as disciplinas de Laboratório Contábil para o 7ํ e 8o períodos (TCC) e Sistemas de Informações Gerenciais no curso de Ciências Contábeis; professor da Universidade do Vale do Itajai - UNIVALI campus Kobrasol curso de pós graduação em Gestão e Planejamento Tributário ministrando a disciplina de Contabilidade Societária; professor da Universidade do Vale do Itajai UNIVALI campus Tijucas curso de MBA em Administração Financeira e Controladoria ministrando a disciplina de Análise das Demonstrações Financeiras.

\section{ALEXANDRE BARRETO DE OLIVEIRA}

Mestrando em Economia e Gestão Empresarial pela Universidade Cândido Mendes/RJ (2018). Pósgraduação em Administração Escolar pela AVM Faculdade Integrada (2016) e Pós-graduação em Orientação Educacional na AVM Faculdade Integrada (2016). Pós-Graduaç̧ão em Gestão de Pessoas pela Academia ABN-AMRO (2008). Possui MBA/Pós-Graduação em Gestão Empresarial pela Fundação Getúlio Vargas (2004). Possui MBA/Pós Graduação em Controladoria e Finanças pela Universidade Federal Fluminense (2002). Possui graduação em Administração pela SOCIEDADE UNIFICADA DE ENSINO SUPERIOR E CULTURA LTDA (1999). Atualmente Supervisor Administrativo do Colégio La Salle Abel, pertencente a Rede La Salle Brasil-Chile-Moçambique, presente em mais de 80 países. Experiência na área de Gestão Educacional, Empresarial, Controladoria e Finanças. Ministra cursos na área financeira e administração financeira pessoal.

\section{ANA MARIA MOURA GOUVEIA}

Engenheira de produção em formação, e apaixonada pela linha de desenvolvimento e melhoria contínua. Acredito que a criatividade, pensamento crítico, interação e integração nos forçam a entender o papel de cada um no ambiente em que nos encontramos, o que é essencial para o crescimento, melhoria e sucesso, seja ele pessoal ou profissional. Yellow Belt na linha Lean Six 
Sigma, e em busca da formação do Green Belt. Já teve experiências com logística e em melhoria da linha de produção, sendo essa, tema de um artigo publicado.

\section{ANDERSON ALVES DE ALCÂNTARA}

Graduado em Engenharia Ambiental pela Universidade Federal da Paraíba (UFPB) e Especialista em Engenharia de Segurança do Trabalho pelo Centro Universitário de João Pessoa. Atualmente é gestor da Unidade de Conservação Área de Relevante Interesse Ecológico de Goiamunduba/PB.

\section{ANDRÉ CRISTIANO SILVA MELO}

Professor Titular da área de Suprimentos e Coordenador dos Programas de Pós-Graduação Stricto Sensu do CCNT/UEPA. Engenheiro Mecânico pela UFPA, Mestre e Doutor em Engenharia de Produção pela COPPE/UFRJ. Atualmente professor de disciplinas da área de logística em cursos de graduação e pós-graduação da UEPA. Atuou, em Belém, como Coordenador do curso de graduação em Engenharia de Produção da Unama e como Coordenador na Secretaria de Estado de Ciência, Tecnologia e Inovação (SECTI) e, no Rio de Janeiro, como Consultor pela Fundação COPPETEC em projetos junto às empresas Bunge Alimentos - Divisão Santista e Furnas Centrais Elétricas S. A. Como Professor de Logística, atuou na Unama (PA), UERJ (RJ), UGF/RJ e UFRJ. Atuou como instrutor de cursos de Logística no PIEBT/UFPA, no E-MBSIG/UFRJ e em empresas, como Petrobrás e Schlumberger e prestou consultoria em Furnas Centrais Elétricas S. A.

\section{ANDRÉ DE MENDONÇA SANTOS}

Professor Assistente na Universidade Federal do Recôncavo da Bahia. Engenheiro de Produção formado pela Universidade Estadual de Santa Cruz (UESC). Mestrado em Ciências, Inovação e Modelagem em Materiais pela UESC. Doutorando em Engenharia Industrial - UFBA. Possui experiência na área de Engenharia de Produção, atuando principalmente nos seguintes temas: simulação e otimização de processos, Lean Manufacturing, Empreendedorismo e Gestão de Serviços.

\section{ASSIS VICENTE BENEDETTI}

Possui graduação em Farmácia e Bioquímica pela Universidade Federal de Alfenas (1973, diploma Registrado na Universidade Federal de Juiz de Fora, 1980), graduação em Licenciatura em Química pela Universidade José do Rosário Vellano (1975), mestrado em Química (Físico-Química) pela Universidade de São Paulo (1977) e doutorado em Química (Físico-Química) pela Universidade de São Paulo (1980). Professor do Instituto de Química UNESP como professor titular da ativa da Universidade Estadual Paulista Júlio de Mesquita Filho até 2011. Atualmente Prof. do Programa de Pós-graduação de Química do Instituto de Química - UNESP - Campus de Araraquara e do Campus de SJRP. No Instituto de Química desempenhou várias funções de coordenação: graduação e pósgraduação e foi presidente de várias comissões. Foi Vice-presidente da divisão de Eletroquímica da SBQ. Estagiou em diversas Universidades no exterior. É revisor de 69 periódicos científicos. Tem experiência na área de Química, termodinâmica de misturas de solventes, eletroquímica fundamental, eletroquímica de compostos inorgânicos em solução, compostos de coordenação, eletroquímica em solventes não aquosos, eletroquímica de metais e ligas metálicas, fragilização por hidrogênio em aços, corrosão em aços, aços inoxidáveis, ligas de alumínio, técnicas de spray térmico e microeletroquímica. Ultimamente vem atuando em estudos de regiões de solda em diferentes tipos de aços, incluindo aços inoxidáveis utilizados nas indústrias de alimentos e farmacêutica, aços duplex e superduplex, eletroquímica de minerais e revestimentos para proteção de materiais metálicos contra a corrosão. É professor aposentado com vínculo de Prof. Voluntário junto ao Instituto de Química da UNESP e desde maio/2017 é Editor-Chefe da Eclética Química Journal.

\section{BÁRBARA CAROLINA MARTINS TEODORO}

Engenheira de Produção Especialista em Gestão de Projetos 


\section{BRUNA SOARES SILVA DE CARVALHO}

Graduanda em Engenharia de Produção Técnica em Química Industrial Auditora SG1 Empreendedora Pesquisadora do MIT GeneSys

\section{BRUNO MATOS PORTO}

Doutorando em Engenharia de Produção pela Universidade Federal do Rio Grande do Sul (UFRGS), sob orientação do prof. Dr. Flávio Sanson Fogliatto. Mestrando em Administração pelo Programa de Pós Graduação em Administração (PPGAD) da UFMS. Bacharel em Administração na UFMS (2018), cursa ciências contábeis na UFMS, Integrante do Grupo de Pesquisa em Cooperação Tecnológica e Inovação Sustentável (GPCTIS) Áreas de interesse de pesquisa: Previsão de preços de commodities agrícolas; Previsão de séries temporais.

\section{CAROLINA DE PADUA FERNANDES}

Possui graduação em Engenharia de Controle e Automação pela Universidade Tecnológica Federal do Paraná (2020). Atualmente atua como Business Partner de TI na empresa multinacional Honda Brasil.

\section{CECÍLIO SADAO FUGIVARA}

Graduação em Bacharelado em Química pela Universidade Estadual Paulista (1982), mestrado em Química (Físico-Química) pela Universidade de São Paulo (1989) e doutorado em Química (FísicoQuímica) pela Universidade de São Paulo (1997). Atualmente é professor assistente doutor da Universidade Estadual Paulista Júlio de Mesquita Filho. Tem experiência na área de Química, com ênfase em Eletroquímica, atuando principalmente nos seguintes temas: microcélula eletroquímica e microeletroquímica, inibidores voláteis de corrosão, revestimentos metálicos e permeação do hidrogênio em aços.

\section{CRISTIANE HELEODORO CARDOSO}

Mestranda em Economia e Gestão Empresarial; Pós-Graduada em Finanças Corporativas: Avaliação de projetos e Empresas; Extensão em Controladoria e Graduada em Administração de empresas. Experiência na área previdenciária, controladoria, finanças, custos e planejamento. Responsável por ministrar palestras e cursos ligadas à área de atuação. 0 trabalho de conclusão do curso de graduação concorreu ao prêmio ETHOS DE RESPONSABILIDADE SOCIAL. 6ª edição. Tema: "A IMPORTÂNCIA ESTRATÉGICA DA RESPONSABILIDADE SOCIAL UTILIZADA NOS NEGÓCIOS”

\section{DAIANE RODRIGUES DOS SANTOS}

Economista, professora no departamente de economia na UERJ, professora do Mestrado em Economia e Gestão Empresarial da Universidade Candido Mendes e professora da graduação em Engenharia de Produção da UVA. Possui Doutorado em Engenharia Elétrica na área de concentração Métodos de apoio à decisão, na PUC Rio - Pontifícia Universidade Católica do Rio de Janeiro, Mestrado em Economia na UFES - Universidade Federal do Espírito Santo e graduação em Economia pela UERJ - Universidade do Estado do Rio de Janeiro.

\section{DANIELA ALTHOFF PHILIPPI}

Doutora em Administração pela Universidade Nove de Julho com estágio doutoral na North Carolina State University, Mestre e Bacharel em Administração pela Universidade Federal de Santa Catarina. Professora Adjunta da Universidade Federal de Mato Grosso do Sul, na área de Administração da Produção e Operações. Dedica-se especialmente às áreas de Administração da Produção e Operações e Inovação. Os temas de pesquisa abrangem a transferência de tecnologia entre universidade e empresas; inovação sustentável; cooperação tecnológica; Planejamento e Controle da Produção (PCP); modelos de previsão na produção e operações; gestão da qualidade; 
logística reversa e gestão socioambiental. Docente do Curso de Graduação em Administração (UFMS/CPAQ). Coordenadora do Grupo de Pesquisa em Cooperação Tecnológica e Inovação Sustentável (GPCTIS/UFMS/CNPq)

\section{DENILSON RICARDO DE LUCENA NUNES}

Possui graduação em Engenharia Civil pela Universidade da Amazônia (1999) e mestrado em Engenharia Civil pela Pontifícia Universidade Católica do Rio de Janeiro (2002) e doutorado em Engenharia de Produção (2014) pela Pontifícia Universidade Católica do Rio de Janeiro. É professor adjunto I da Universidade do Estado do Pará (UEPA) no curso de Engenharia de Produção. Tem experiência na área de Engenharia Civil, com ênfase em Estruturas de Concreto e metálica. Na Engenharia de Produção atua principalmente nas seguintes áreas: planejamento e modelagem de estoques, logística e modelagem matemática.

\section{DENISE DANTAS MUNIZ}

Bacharel em Administração de Empresas pelo Centro Universitário de João Pessoa, Mestre em Engenharia de Produção e Doutora em Ciência e Engenharia de Materiais pela Universidade Federal da Paraíba. Atualmente é pesquisadora-chefe do Laboratório de Pesquisa com Cactáceas LAPEC - em parceria com a FAPESQ e a FINEP através do Programa Centelha.

\section{DIRK ENGELBERG}

Atualmente é Diretor Adjunto do Centro de Performance de Materiais (MPC) e do Centro de Proteção e Corrosão (CPC) da Universidade de Manchester (Inglaterra). Engenheiro de materiais (2000) pela Aalen University (HTW Aalen, Germany), concluiu seu mestrado (2002) e doutorado (2005) no programa de Engenharia de Corrosão no departamento Corrosion and Protection Centre (UMIST) da Universidade de Manchester.

\section{DJOILLE DENNER DAMM}

Doutor em Engenharia e Ciência de Materiais pela Universidade Federal de São Paulo (UNIFESP, 2019). Possui mestrado em Ciência, Inovação e Modelagem em Materiais pela Universidade Estadual de Santa Cruz (UESC, 2016) e graduação em Engenharia de Produção e Sistemas pela Universidade Estadual de Santa Cruz (UESC, 2012). Detém experiência profissional na área de Engenharia de Produção, atuando como supervisor de produção na produção de clorato de sódio da multinacional Akzonobel PPC BA, empresa especializada em fabricação, armazenamento e distribuição de químicos para o branqueamento de celulose. Dispõe de competência quanto a processos químicos de fabricação com ênfase em Planejamento, Projeto e Controle de Sistemas de Produção, atuando principalmente nos seguintes temas: desenvolvimento e aprimoramento de processos produtivos, manufatura enxuta, gestão por processos, liderança situacional e gestão de recursos, custos e pessoas.

\section{EDUARDO BRAGA COSTA SANTOS}

Graduado em Engenharia de Produção e Mestre em Ciência, Inovação e Modelagem em Materiais pela Universidade Estadual de Santa Cruz (UESC) e Doutor em Ciência e Engenharia de Materiais pela Universidade Federal da Paraíba (UFPB). Atualmente é professor efetivo pela Faculdade de Engenharia Industrial da Universidade Federal do Pará (UFPA).

\section{EMERSON LAZZAROTTO}

Possui graduação em Matemática pela Universidade Estadual do Oeste do Paraná (1998), Mestrado em Matemática pela Universidade Estadual de Maringá (2001) e Doutorado no Programa de Pós-Graduação em Métodos Numéricos em Engenharia da Universidade Federal do Paraná. É professor adjunto da Universidade Estadual do Oeste do Paraná - Campus de Foz do Iguaçu, desde 
2001. Tem atuado, a partir de 2016, em projeto de pesquisa relacionada ao controle estatístico da qualidade aplicada em séries temporais de dados de monitoramento de barragem.

\section{EMERSON NÓBREGA DE MEDEIROS}

Bacharel em Direito pela Universidade Estadual da Paraíba - UEPB, Especialista em Direito Público pela Escola Nacional de Administração Pública - ENAP. Advogado há 22 anos, atua como Analista Técnico da Fiotec/Fiocruz-RJ, consultor da UNESCO, assessor jurídico do Gabinete Jurídico de Políticas Públicas - GAJUC - e do Serviço Nacional de Aprendizagem Rural na Paraíba - SENARAR/PB.

\section{FABYANE DIAS DA SILVA}

Graduanda do $8^{\circ}$ período do Bacharelado Interdisciplinar em Energia e Sustentabilidade com terminalidade em Engenharia de Produção pela Universidade Federal do Recôncavo da Bahia/Centro de Ciência e Tecnologia em Energia e Sustentabilidade (UFRB/CETENS). Voluntária em projeto de iniciação científica na área de Pesquisa Operacional.

\section{FERNANDO SANTOS DA SILVA}

Pós-doutorado em Química pelo Instituto de Química da UNESP Araraquara. Doutor em Química pelo Instituto de Química da UNESP Araraquara, área de concentração Físico-Química, com período de doutorado sanduíche no Thermal Spray Center Universidade de Barcelona. Atua nos seguintes temas: Eletroquímica, Espectroscopia de Impedância Eletroquímica, Corrosão, Cold Gas Spray (Aspersão Fria), Aspersão térmica, superfícies com atividade antibacteriana, materiais odontológicos, análise de solos, água, tecido vegetal e análise físico-química de biomassas. Atualmente é bolsista de desenvolvimento tecnológico do Instituto Senai de Inovação Biomassa. Atuando em projetos EMBRAPII de inovação na área de energia, biomassa e aproveitamento de resíduos sólidos para produção de combustíveis.

\section{GLEYZER MARTINS}

Engenheiro Mecânico Doutor em Engenharia mecânica

\section{GRAYCE FONTÃO}

Possui graduação em Ciências Contábeis pela Universidade do Vale do Itajaí - UNIVALI (2018). CRC 43667 SC. Atualmente é Coordenadora Comercial na empresa Liderança Serviços, que atua na prestação de serviços combinados de asseio, apoio administrativo, operacional e de vigilância patrimonial.

\section{HAMMA CAROLINA DE LIMA NOGUEIRA}

Administradora. Mestranda em Engenharia de Produção

\section{JOSÉ GUILHERME COSSETTI}

Possui graduação em Engenharia de Produção pela Universidade de Araraquara(2018). Tem experiência na área de Engenharia de Produção.

\section{JOSÉ TOMADON JÚNIOR}

Possui graduação em Engenharia de Produção Agroindustrial pela Faculdade Estadual de Ciências e Letras de Campo Mourão(2007), mestrado em Engenharia Química pela Universidade Estadual de Maringá(2011) e doutorado em Engenharia Química pela Universidade Estadual de Maringá(2015). Atualmente é Professor Assistente da Universidade Tecnológica Federal do Paraná. 


\section{JULIANA RIBEIRO RANIERI}

Servidora pública exercendo o cargo de Assistente em Administração, desde 2014, na Universidade Federal do Pará (UFPA). Atualmente, é chefe da seção de Gestão de Pessoal do ILC/UFPA. Graduada em Engenharia de Produção pela Universidade do Estado do Pará (UEPA), com interesse nas áreas de gestão de projetos, finanças e logística. Especialista em Gestão Financeira Empresarial (UFPA), com projeto pessoal de tecnologia para o setor da construção civil.

\section{KALIL FIGUEIREDO ALMEIDA}

Mestre em Ciência, Inovação e Modelagem em Materiais (2016) e Engenheiro de Produção (2012) pela Universidade Estadual de Santa Cruz (UESC). Atualmente é Professor Assistente do Curso de Engenharia de Produção pela Universidade Federal do Recôncavo da Bahia/Centro de Ciência e Tecnologia em Energia e Sustentabilidade (UFRB/CETENS). Tem experiência na área de Engenharia de Produção, com ênfase em Engenharia de Processos, com foco em: modelagem, simulação, otimização de processos, trabalho padronizado e mapeamento de processos.

\section{LETÍCIA DANTAS MUNIZ ALVES}

Atualmente é estudante do ensino médio integrado ao curso técnico em Controle Ambiental pelo Instituto Federal de Educação, Ciência e Tecnologia da Paraíba - IFPB - Campus João Pessoa.

\section{LUCAS CARVALHO MARTINS}

Engenheiro de Produção. Mestre em Engenharia de Produção

\section{LUCAS PEREIRA SILVEIRA}

Engenheiro de Produção

\section{LUCIANO DA SILVA FERREIRA}

Professor universitário e profissional de Logística e Administração de Empresas. Mestre em Gestão e Tecnologia em Sistemas Produtivos, na unidade de pós-graduação, extensão e pesquisa do Centro Estadual de Educação Tecnológica Paula Souza. Pós-graduado em Logística Empresarial pela Universidade Presbiteriana Mackenzie. Formado em Administração de Empresas pela Universidade Guarulhos. Tem experiência de mais de 20 anos em Logística, tanto no serviço público como em empresas privadas e leciona a mais de 10 anos em cursos técnicos e tecnológicos nas áreas de Logística e Administração de empresas. Experiência em instituições de ensino como FATEC, UNIP, UniSantaRita, Centro Universitário ENIAC e em empresas privadas como Companhia Brasileira de Alumínio e Fibria, ambas do Grupo Votorantim, e também na Suzano Papel e Celulose e SKY Brasil Serviços. No serviço Público é Oficial da Reserva do Exército Brasileiro, no posto de $1^{\circ}$ Tenente de Intendência, tendo exercido o cargo de comandante da Companhia Logística de Suprimentos no $22^{\circ}$ Batalhão de Logística leve.

\section{LUDMILA SANTANA DE AZEVEDO MATOS}

Mestranda em Economia e Gestão Empresarial pela Universidade Cândido Mendes/RJ (2018). Possui MBA em Administração financeira e Banking pela Universidade Paulista (2020); Licenciatura em Administração de Empresas pelo Instituto A Vez do Mestre (2018) e Graduação em Administração de Empresas pela Universidade Candido Mendes (2017). Sua principal linha de pesquisa é voltada para a área de finanças pessoais e comportamentais. Atualmente é Tutora da Universidade Paulista e ministra palestras com temas ligados ao seu campo de pesquisa. 


\section{LUIS HENRIQUE GUILHERME}

Possui graduação em Engenharia de Produção pela Universidade de Araraquara (2008), mestrado (2011) e doutorado (2017) em Ciências e Engenharia de Materiais pela Escola de Engenharia de São Carlos da Universidade de São Paulo (EESC-USP), e pós-doutorado em Físico-Química pelo Instituto de Química da Universidade Estadual Paulista - UNESP (2017-2018) com período de estágio técnico no departamento Corrosion \& Protection Centre - University of Manchester (UK). Atua há 15 anos no setor metal-mecânico no segmento de construções soldadas tais como tanques, trocadores de calor, vasos de pressão, tubulações industriais e estruturas metálicas. Ocupou cargos nos departamentos de engenharia de projeto, controle de qualidade e supervisão de fabricação / montagem. Possui amplo conhecimento sobre normas e códigos de projeto como ASME VIII div. I, ASME IX, ASME V, ASME B31.1, ASME B31.3, ASME BPE, AWS D1.1, API 650, NBR 7821. Em 2012 fundou a Soudap soldagem e inspeção, empresa especializada em inspeção de solda e montagem mecânica de equipamentos industriais. Em 01/2016, na qualidade de spin-off, fundou a empresa Soudap solda sanitária para a prestação de serviços especializados com base no código ASME BPE dedicados a processos assépticos ou corrosivos. Criou em 08/2016 o Soudap-lab, laboratório para pesquisa aplicada na área de soldagem e corrosão, sendo o departamento responsável pelo suporte técnico dos projetos executivos da empresa. Atualmente exerce o cargo de diretor técnico da Soudap solda sanitária e a função de pesquisador responsável do projeto de pesquisa inovativa em pequenas empresas (Projeto PIPE) financiado pela Fundação de Amparo à Pesquisa do Estado de São Paulo (FAPESP), fazendo da Soudap a primeira empresa brasileira a aplicar uma microcélula eletroquímica portátil no controle de qualidade de soldas em uma unidade industrial. Gerenciou projetos de prestação de serviços com faturamento acumulado superior a $\mathrm{R} \$ 8$ milhões (2012 ? 2018)

\section{LYDIA CHEIBUB DE MATOS}

Engenheira de Produção

\section{MARCOS ANTONIO PACIFICO DA SILVA}

Possui Mestrado Profissional em Sistemas de Gestão, pela Universidade Federal Fluminense (UFF) / Laboratório de Tecnologia, Gestão de Negócios e Meio Ambiente (LATEC), da Escola de Engenharia. Atualmente é Professor do Centro Federal de Educação Tecnológica Celso Suckow da Fonseca / RJ (CEFET-CSF) e pertence aos colegiados dos Cursos Técnicos de Eletrotécnica e Mecânica. Com 30 anos de experiência em docência, participou da construção do Projeto Pedagógico do Curso Técnico de Eletrotécnica; é supervisor de monitoria no CEFET-CSF; orientador de projetos para a semana de ensino, pesquisa e extensão; avaliador da Comissão Específica de Avaliação dos Projetos de Extensão; membro de bancas de concursos públicos para o setor elétrico; ministrou aulas no Programa de Mobilização da Indústria Nacional de Petróleo e Gás Natural (PROMINP); e atua como consultor para programas de trainees em empresas do setor de energia elétrica. Tem publicações nos Simpósios de Engenharia de Produção: VIII SIMEP e XXVIII SIMPEP.

\section{MAYLANE NERES COSTA SANTOS}

Graduanda do $4^{\circ}$ período do Bacharelado Interdisciplinar em Energia e Sustentabilidade com terminalidade em Engenharia de Produção pela Universidade Federal do Recôncavo da Bahia/Centro de Ciência e Tecnologia em Energia e Sustentabilidade (UFRB/CETENS). Voluntária em projeto de iniciação científica na área de Pesquisa Operacional.

\section{PROF. DR. JADIR PERPÉTUO DOS SANTOS}

Pós Doc em Engenharia de Produção e Inovação e Pesquisador do CNPQ, Doutor em Engenharia Mecânica. Mestrado em Administração. Especialização em docência de nível superior. Pósgraduação em Engenharia de Produção, Engenharia de Qualidade e em Administração da Produção. Graduação em Administração. Professor-Tutor de EAD e conteudista. Revisor de 
revistas científicas. Parecerista em congressos. Autor de livro. Professional Coach of life. Participante de commitees.

\section{PROF. DR. ROBERTO KANAANE}

Pedagogo, Psicólogo, Mestre e Doutor em Ciências pela USP, Sócio Diretor da Roka Consultoria. Membro da Academia Paulista de Psicologia, ocupando a cadeira 21. Atuação nos Programas de Mestrados Profissionais no Centro Tecnológico Paula Souza. Autor de livros na área de Gestão de Pessoas, Comportamento Humano e Gestão Pública.

\section{PROF. M.SC. MARCELO PARANZINI}

Mestre em Tecnologia e Sistemas Produtivos - Ênfase em Relações Humanas. Master in Business Administration (MBA) em Gestão Empresarial com Coaching e em Gestão de Pessoas com Coaching. Pós-graduado nas especialidades de Qualidade e Produtividade Empresarial. Graduado em Direito e em Engenharia Metalúrgica. Master Coach. Mentor. Professor. Gestor de empresas. Empreendedor e Empresário nos setores do Comércio, Serviços e Indústria.

\section{ROBERTO KANAANE}

Pedagogo, Psicólogo, Mestre e Doutor em Ciências pela USP, Sócio Diretor da Roka Consultoria. Membro da Academia Paulista de Psicologia, ocupando a cadeira 21. Atuação nos Programas de Mestrados Profissionais no Centro Tecnológico Paula Souza. Autor de livros na área de Gestão de Pessoas, Comportamento Humano e Gestão Pública.

\section{RODRIGO RANGEL RIBEIRO BEZERRA}

Professor Assistente do curso de Engenharia de Produção e Coordenador do Laboratório de Engenharia de Produção do CCNT/UEPA/Campus VIII - Marabá. Engenheiro de Produção pela UEPA, Mestre em Engenharia de Produção pela PUC-RIO. Atuou, em Belém, como professor do curso de graduação da Unama, UNIFESSPA e UFRA. Na indústria, tive atuação na Fábrica de Bebidas Duelo Ltda., na Tramontina Belém S.A. e na Endicon Engenharia.

\section{ROSELI DA CONCEIÇ̃̃O SILVA DE FREITAS SANTA ANA}

Profissional com formação em Gestão Ambiental Superior, graduanda em Engenharia de Produção pela Universidade Estácio de Sá e Pos - Graduada em Engenharia Ambiental e Indicadores de Qualidade no Instituto Brasileiro de Formação, MBA Segurança do trabalho e Gestão Ambiental . Atuando como consultora em Gestão Ambiental pela Total Quality Consultoria. Expertise em Gerenciamento e desenvolvimento de Sistemas de Gestão de Segurança do Trabalho e Meio Ambiente, baseados nas normas NBR ISO 14001:2004, OHSAS 18001:2007; Gestão de implantação de Ferramentas ligadas ao SGI, criando um ambiente favorável no que tange a elaboração da Política de SMS e seus procedimentos; Apoio integral na implementação dos documentos e sistema de Gestão Ambiental incluindo o apoio operacional ao de SGI, de acordo com os requisitos da qualidade definidos pela NBR ISO 9001:2008/2015.

\section{STELLA REGINA REIS DA COSTA}

Possui graduação em Engenharia Química pela Universidade Federal do Rio de Janeiro (1979), mestrado em Engenharia Química pela Universidade Federal do Rio de Janeiro (1981) e doutorado em Engenharia Química pela Universidade Federal do Rio de Janeiro (1991). Atualmente é professora aposentada Titular da Universidade Federal Rural do Rio de Janeiro. Docente/ orientadora no mestrado em Sistemas de Gestão e do Doutorado em Sistemas de Gestão Sustentáveis da Universidade Federal Fluminense . Foi coordenadora do Programa Qualidade Rio do Governo do Estado do Rio de Janeiro. Foi Diretora técnica da FLUTEC da secretaria de Estado de Ciência e Tecnologia. Foi Assessora das Secretarias de Estado de Ciência e Tecnologia e a de Energia, Indústria Naval e Petróleo. Foi vice-presidente do Conselho Empresarial de Gestão 
Estratégica para Competitividade da FIRJAN. Foi Chefe de Tecnologia do SENAI Alimentos e Bebidas de Vassouras. Tem experiência nas áreas de Engenharia de Produção e de Engenharia de Alimentos com ênfase em Gestão Pela Excelência, atuando principalmente nos seguintes temas: qualidade, segurança alimentar, excelência, PNQ, gestão, certificação de laboratórios e BSC. Foi coordenadora de Projetos da Incubadora de Empresas da UFRRJ-INEAGRO. Foi coordenadora do Programa de Pós-Graduação em Ciência e Tecnologia de Alimentos. Foi Assessora especial da Reitoria da UFRRJ para consolidação do Parque Tecnológico.

\section{VÍVIAN TEREZA DE SOUZA FERREIRA}

Graduação em Engenharia de Produção Universidade do Estado do Pará, Belém - 12/2017 Pós-graduação em Gestão de Negócios com Foco em Competências Comportamentais Business Behavior Institute, Chicago- Illinois - Início 11/2019 (em conclusão) Analista de Logística da SCLOG Consultoria Analista de Logística Sênior da Distribuidora American Farma Consultora Empresarial da NZ EPI's Consultora Júnior da Rlima Consultoria

\section{WALDEMAR ANTONIO DAS CHAGAS BEZERRA}

Mestrando em Economia e Gestão empresarial na Universidade Candido Mendes, com pósgraduação Gerenciamento de Projetos(2012), Pós-graduação em Direito e Processo do Trabalho(2011) e Pós-graduação em Processo Civil(2011), todas em pós-graduações realizadas na AVM - Cândido Mendes. Possui 2(duas) graduações em Direito e Análise de Sistemas pelo Centro Universitário da Cidade nos anos de 2001 e 2008. Atualmente advoga nas áreas Trabalhistas, Cível e Previdenciária, atuando ainda como Delegado de Prerrogativas da OAB-RJ Seccional Rio de Janeiro junto. 
